\title{
LOCAL RENIN-ANGIOTENSIN SYSTEMS
}




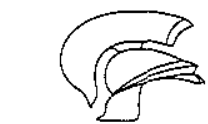

THESIS PUBLISHERS

AMSTERDAM 1992

\section{CIP-DATA KONINKLIJKE BIBLIOTHEEK, DEN HAAG}

Danser, Alexander Hessel Jan

Local Renin-Angiotensin Systems / Alexander Hessel Jan Danser. - Amsterdam: Thesis Publishers. - IIl.

Thesis Rotterdam, 1992. - With ref. - With summary in Dutch.

ISBN 90-5170-140-3

NUGI 742

Subject headings: hypertension / renin / angiotensin

Omslagontwerp: A.H.J. Danser, C. Swaab en M. Bode 


\title{
LOCAL RENIN-ANGIOTENSIN SYSTEMS
}

(LOKALE RENINE-ANGIOTENSINE SYSTEMEN)

\author{
PROEFSCHRIFT
}

TER VERKRIJGING VAN DE GRAAD VAN DOCTOR AAN DE ERASMUS UNIVERSITEIT ROTTERDAM OP GEZAG VAN DE RECTOR MAGNIFICUS PROF. DR. C.J. RIJNVOS

EN VOLGENS HET BESLUIT VAN HET COLLEGE VAN DEKANEN. DE OPENBARE VERDEDIGING ZAL PLAATSVINDEN OP WOENSDAG 29 APRIL 1992 OM 15.45.

door

ALEXANDER HESSEL JAN DANSER

geboren te AMSTERDAM 
Promotiecommissie:

Promotor: $\quad$ Prof. Dr. M.A.D.H. Schalekamp

Overige leden: $\quad$ Prof. Dr. P.D. Verdouw

Prof. Dr. P.R. Saxena

Prof. Dr. P.A. van Zwieten

Dit proefschrift werd bewerkt op de afdeling Inwendige Geneeskunde I van het Academisch Ziekenhuis Rotterdam Dijkzigt, Erasmus Universiteit Rotterdam.

Financial support by the Netherlands Heart Foundation for the publication of this thesis is gratefully acknowledged. 
Voor mijn ouders

Aan Romana 



\section{CONTENTS}

Chapter 1

General introduction

page

Chapter 2

Metabolism and production of angiotensin $I$ in different vascular beds in subjects with hypertension

Chapter 3

Metabolism of angiotensin I by different tissues in the intact animal

Chapter 4

Production of angiotensins I and II at tissue sites in the intact pig

\section{Chapter 5}

Renin, prorenin and immunoreactive renin in vitreous fluid from eyes with and without diabetic retinopathy

Chapter 6

Identification and quantification of renin and prorenin in the bovine eye

Chapter 7

Angiotensin levels in the eye

Chapter 8

Demonstration of renin-, angiotensinogen- and angiotensin converting enzyme-mRNA expression in human eyes by the polymerase chain reaction

Chapter 9

Summary and conclusions

Chapter 10

Samenvatting en conclusies

Publications and Abstracts

Dankwoord

Curriculum Vitae 


\section{This thesis is based on the following articles:}

1. Admiraal PJJ, Derkx FHM, Danser AHJ, Pieterman H, Schalekamp MADH. Metabolism and production of angiotensin I in different vascular beds in subjects with hypertension. Hypertension 15: 44-55, 1990.

2. Danser AHJ, Koning MMG, Admiraal PJJ, Derkx FHM, Verdouw PD, Schalekamp MADH. Metabolism of angiotensin I by different tissues in the intact animal. Provisionally accepted $A m J$ Physiol.

3. Danser AHJ, Koning MMG, Admiraal PJJ, Sassen LMA, Derkx FHM, Verdouw PD, Schalekamp MADH. Production of angiotensins I and II at tissue sites in the intact pig. Provisionally accepted $A m J$ Physiol.

4. Danser AHJ, van den Dorpel MA, Deinum J, Derkx FHM, Franken AAM, Peperkamp $\mathrm{E}$, de Jong PTVM, Schalekamp MADH. Renin, prorenin, and immunoreactive renin in vitreous fluid from eyes with and without diabetic retinopathy. J Clin Endocrinol Metab 68: 160-167, 1989.

5. Deinum J, Derkx FHM, Danser AHJ, Schalekamp MADH. Identification and quantification of renin and prorenin in the bovine eye. Endocrinology 126: 1673-1682, 1990.

6. Danser AHJ, Derkx FHM, Admiraal PJJ, Deinum J, de Jong PTVM, Schalekamp $\mathrm{MADH}$. Angiotensin levels in the eye. In preparation.

7. Wagner J, Danser AHY, Paul M, Derkx FHM, de Jong PTVM, Schalekamp MADH, Ganten D. Demonstration of renin-, angiotensinogen- and angiotensin converting enzyme-mRNA expression in human eyes by the polymerase chain reaction. In preparation. 


\section{GENERAL INTRODUCTION}

\subsection{History}

In 1898 Tigerstedt and Bergman (1) found that crude saline extracts of rabbit kidneys contained a pressor substance, which they named renin. More than 30 years later, in 1934, Goldblatt and his colleagues recognized the significance of this finding when they discovered that it was possible to produce persistent hypertension in dogs by clamping the renal artery (2). In 1940, BraunMenendez and his co-workers in Argentina (3) and Page and Helmer at the Cleveland Clinic in the United States (4) reported that renin was an enzyme that acted on a plasma protein substrate to catalyze the formation of the actual pressor material, a peptide, which was named hypertensin by the former group and angiotonin by the latter. These 2 terms were used for nearly 20 years, until it was agreed to rename the pressor substance angiotensin and to call the plasma protein substrate angiotensinogen. In 1954 two forms of angiotensin were recognized (5): the first a decapeptide (angiotensin $I$ ) and the second an octapeptide (angiotensin II), formed from angiotensin I by cleavage by another enzyme, termed angiotensin converting enzyme. Since these discoveries, ample evidence for the involvement of the renin-angiotensin system in the pathogenesis of various forms of clinical and experimental hypertension has been obtained by many investigators.

\subsection{Circulating and tissue renin-angiotensin system(s)}

Circulating renin-angiotensin system. The renin-angiotensin system has traditionally been viewed as an endocrine system. Circulating renin, released from the kidney by a variety of stimuli (of which the most important are hypotension and diminished delivery of sodium to the distal tubular macula densa sites), continuously produces angiotensin I from circulating liver-derived angiotensinogen (Figure 1). Angiotensin $I$ is converted to angiotensin $I$ as the blood passes through the lungs and other vascular beds where angiotensin converting enzyme (ACE) is present in high concentrations on vascular endothelial cells. Circulating angiotensin II controls blood pressure directly by arteriolar vasoconstriction and indirectly by regulating sodium and potassium homeostasis. The latter action of angiotensin II functions via a direct effect on renal sodium reabsorption (6) and via stimulation of adrenal aldosterone biosynthesis (7) and secretion (8), which, in turn, promotes renal sodium reabsorption and potassium secretion. 


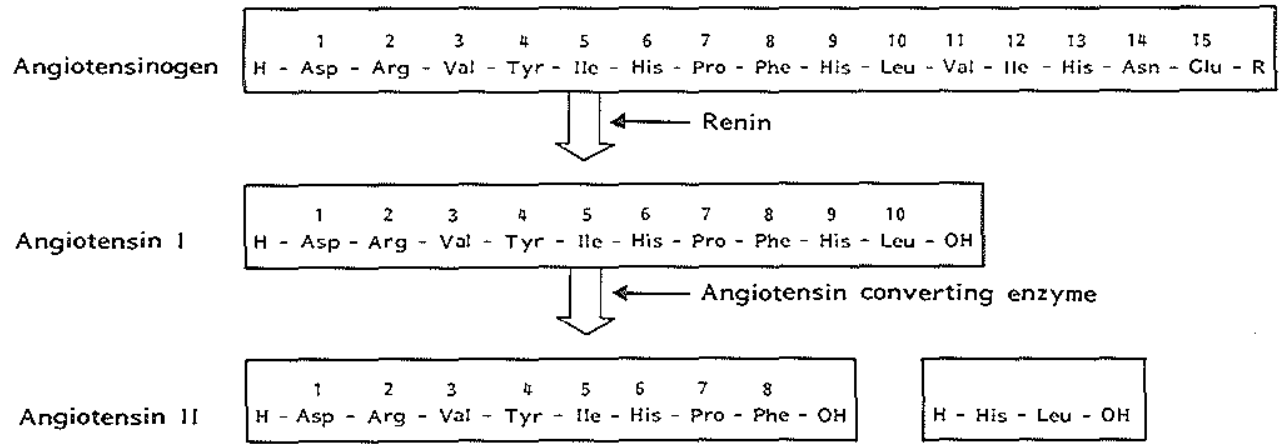

Figure 1. Outline of the biochemistry of the human renin-angiotensin system. Renin cleaves its substrate (angiotensinogen) between leucine 10 and valine 11 to form the decapeptide angiotensin I. Angiotensin converting enzyme removes residues histidine 9 and leucine 10 to form the octapeptide angiotensin II, the biologically active endproduct of the system.

Local renin-angiotensin systems. Recent evidence suggests that besides a circulating renin-angiotensin system of renal origin, there also exist tissue or local renin-angiotensin systems in different organ sites. Renin-like enzymatic activity, angiotensinogen, ACE, angiotensin I, angiotensin II and angiotensin receptors have been demonstrated in multiple tissues. In addition, molecular biologic techniques have clearly shown that both renin and angiotensinogen genes are expressed in organs involved in cardiovascular homeostasis (i.e. kidney, adrenal, heart, brain and blood vessels) $(9,10)$ as well as in reproductive organs (testis and ovary) (10). Thus, an emerging concept is that angiotensin may be produced locally in many tissues, independent of the circulating system, and that locally generated angiotensin may play an important role in influencing the function of these target organs. Locally generated angiotensin may even reach the circulating blood and thus contribute to the angiotensin levels found in plasma (11).

Metabolism of angiotensins. Extensive metabolism of angiotensins is known to occur in peripheral tissues, due to the enzymatic activity of so-called 'angiotensinases' (Figure 2): aminopeptidases ('angiotensinase A': aminopeptidase $A$, aminopeptidase $B$, aminopeptidase $M$, leucine aminopeptidase, dipeptidyl peptidase) (12-14), endopeptidases ('angiotensinase $B^{\prime}$ : prolyl-endopeptidase, neutral endopeptidase 24.11) (15) and 
carboxypeptidases ('angiotensinase $C^{\prime}$ : carboxypeptidase $\mathbb{P}$, prolylcarboxypeptidase, ACE, cathepsin A) $(16,17)$. Yet, despite this high degree of metabolism, the concentrations of angiotensin I and angiotensin II in venous blood are similar to those in arterial blood $(11,18)$. Angiotensin generation in blood alone seems to be too low to account for the levels of angiotensin $I$ and angiotensin II in venous blood $(\mathbf{1 1}, 18)$. Peripheral tissues may therefore indeed be a major site of angiotensin production. Possibly, the venous plasma levels of angiotensins I and II represent a spillover from the tissue sites of production (Figure 3).

However, plasma angiotensin levels in anephric subjects are usually low or undetectable (19), suggesting that it is mainly kidney-derived renin that is responsible for the presence of angiotensins in plasma. Tissue production and subsequent release of angiotensins into the circulation may therefore largely depend upon uptake of circulating kidney-derived renin by the tissues. The local tissue concentration of $\mathrm{ACE}$ and angiotensin degrading enzymes would then determine how much of the locally generated angiotensin $\mathrm{I}$ and angiotensin II is released into the circulation.

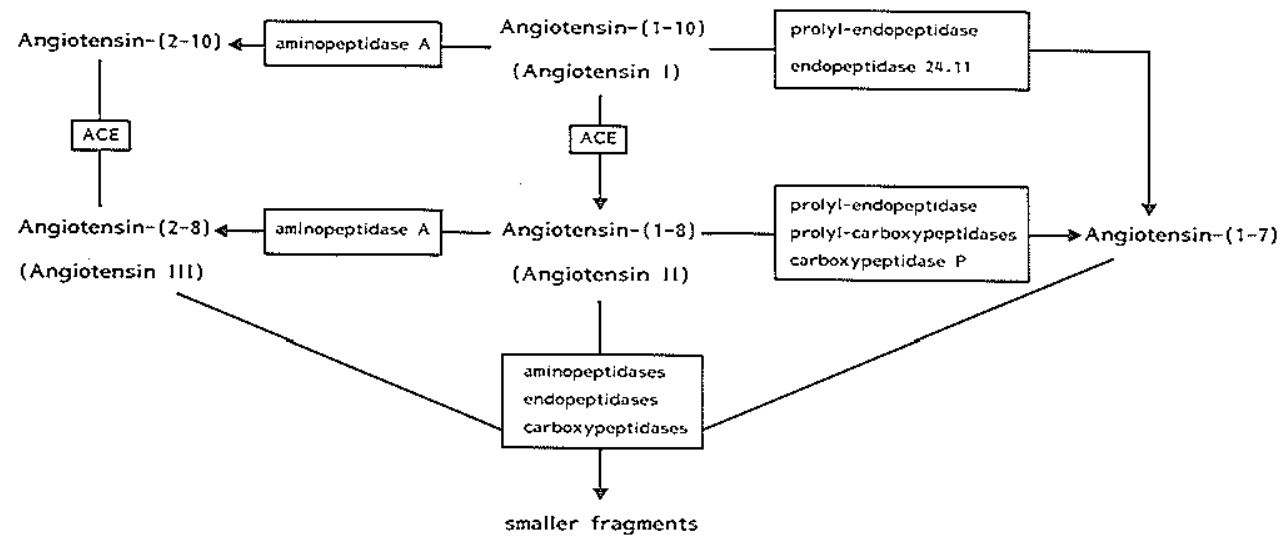

Figure 2. Schematic outline of altemate enzymatic cascades participating in the metabolism of angiotensins. 


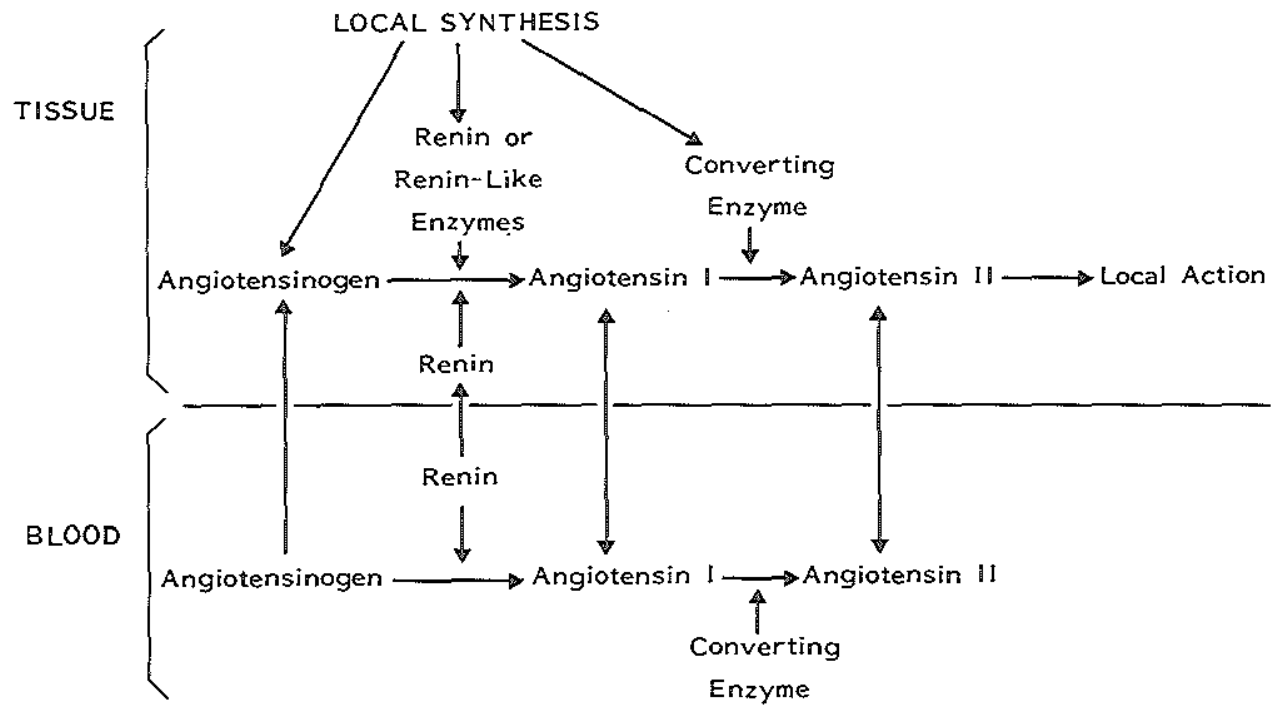

Figure 3. Circulating renin-angiotensin system vs. local renin-angiotensin system: interactions and possible angiotensin generation sites.

Prorenin. In contrast with the low levels of angiotensin (and renin) in plasma from nephrectomized subjects, the plasma concentrations of prorenin, the inactive precursor of renin, in these subjects are still in the (low) normal range (20). This shows that a substantial fraction of plasma prorenin is produced at extrarenal sites. Indeed the release of prorenin, but not renin, into the circulation has now been shown for the ovary, testis and adrenal $(21,22)$. Cultured smooth muscle cells (23), theca cells (24) and adrenal glomerulosa cells (25) have also been reported to secrete prorenin, but not renin, into the medium.

Prorenin has always been considered to have no biological function except being the inactive precursor of renin. Several proteases have been shown to be capable of activating prorenin in vitro (26-29), but the enzyme responsible for in vivo processing of prorenin has not been identified. In man, under normal circumstances approximately $90 \%$ of plasma renin is present in its inactive form (30). This percentage increases even further (up to 95-99\%) under certain conditions, for instance pregnancy (30) and diabetes mellitus complicated by microvascular complications (31). There is now good evidence 
that the ovary is the main source of this increase in plasma prorenin in pregnant women (32). The elevated levels in diabetic subjects with microvascular complications are more difficult to explain. Again, an extrarenal source of prorenin may be involved. Renin is often within the normal range in these patients $(31,33)$. In a recent study Franken and colleagues showed that the elevated levels of prorenin in diabetic subjects were related to the presence of retinopathy, particularly the proliferative type, and were independent of sex, age, duration of diabetes, blood pressure, neuropathy and blood levels of glucose and hemoglobin-A1c (33). Possibly the eye and other organs affected by microvascular complications are the unknown extrarenal sources of the increase in plasma prorenin in diabetic subjects. Elevated levels of plasma prorenin may perhaps be used as a marker for the activation of tissue reninangiotensin systems ( 34 ).

In this view it is of interest to know that it has recently been shown that prorenin is able to become reversibly catalytically active, a proces that is most likely due to a change in the conformation of the prorenin molecule and unfolding of the prosegment from a "closed" to an "open" position (35-37). Assuming that a dynamic equilibrium exists between the "open" and "closed" forms of prorenin (Figure 4), with the "open" form being catalytically active, one may hypothesize that under certain circumstances (receptor-binding, low $\mathrm{pH}$ ), for instance at a local level, stabilization of the "open" form may occur, allowing prorenin to cleave angiotensin I from angiotensinogen. A (pro)renin receptor has so far not been identified.
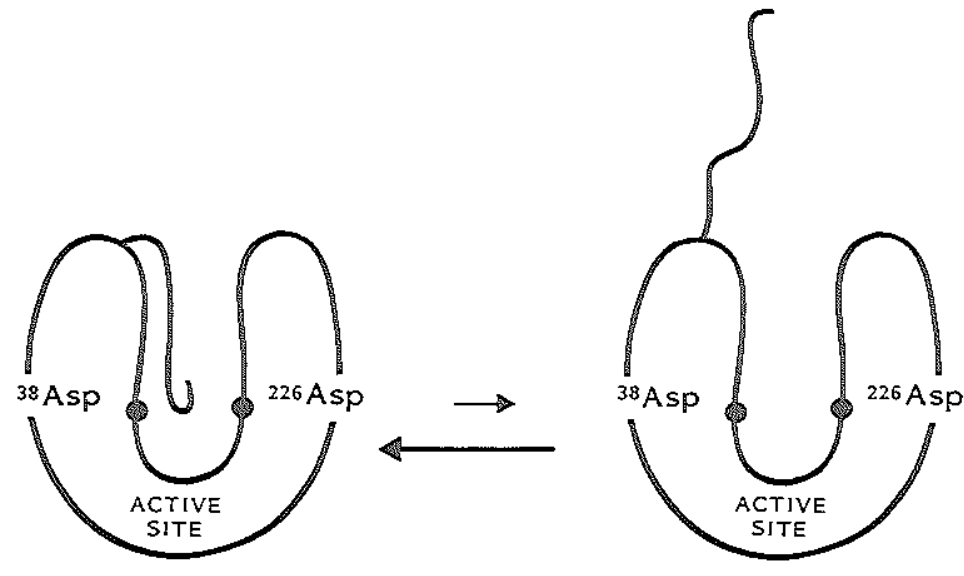

PRORENIN

'CLOSED'

PRORENIN

'OPEN'

POSITION

POSITION

Figure 4. Hypothetical activation of prorenin by unfolding the prosegment. 
The release of locally produced angiotensins into the circulation is, as discussed above, probably largely due to local uptake of kidney-derived renin. Local production of angiotensins not being released into the circulation (i.e. remaining local, for instance intracellular) may very well be due to locally synthesized renin or prorenin. Possibly kidney-derived renin is limited to the extracellular fluid (or bound to the cell-membrane) and cleaves angiotensinogen in plasma or interstitial fluid only, whereas locally synthesized prorenin or renin acts intracellularly only.

Function of local renin-angiotensin systems. The function of most, if not all, local renin-angiotensin systems is not yet clear. Locally produced angiotensin II may influence vascular tone, both through a direct effect via angiotensin II receptors and by enhancing norepinephrine release from noradrenergic nerve endings in blood vessels (38). It may also stimulate prostaglandin biosynthesis (39). In the heart, angiotensin II possesses positive inotropic (40) properties, while at the same time it may constrict coronary blood vessels. In the kidney, angiotensin II plays a role in regulating tubuloglomerular feedback, vasa recta blood flow and sodium reabsorption. In addition, mesangial cell contractility and glomerular filtration pressure may be influenced by local angiotensin production (41-43). An adrenal renin-angiotensin system probably regulates aldosterone biosynthesis (25). Similar to this effect of angiotensin II on adrenal steroid hormone synthesis, a local renin-angiotensin system in reproductive organs could be involved in the regulation of steroid hormone production $(21,44)$. Brain angiotensin may contribute to the regulation of blood pressure, thirst and vasopressin as well as catecholamine release (45). Angiotensin II has recently been reported to have growth promoting effects (46-48); it stimulates neovascularization in the rabbit cornea model (49).

\subsection{Blockers of the renin-angiotensin system}

$A C E$ inhibitors. ACE inhibitors, which block the formation of angiotensin II from angiotensin I, are now widely used in the treatment of hypertension and congestive heart failure. The design of captopril, the first commercially available ACE inhibitor, resulted from a rational and systemic study of the interaction of carboxypeptidase A and ACE with their substrates and inhibitors (50). Very productive research undertaken by several drug companies has led to the development of a whole range of new ACE inhibitors, some of which are now commercially available as well: enalapril, lisinopril, quinapril, perindopril, ramipril and cilazapril. Their hemodynamic profile is characterized by vasodilatation devoid of an accompanying tachycardia or a reduction in cardiac output (51). Not only were ACE inhibitors found to be effective for treating high renin-dependent forms of hypertension, but unexpectedly, they were also active in normal or low renin hypertension (52). 
Long-term treatment by ACE inhibitors does not seem to completely suppress the circulating renin-angiotensin system, as plasma angiotensin II and aldosterone tend to return toward pretreatment values (53). This finding has led to speculations on the presence of local renin-angiotensin systems and their importance in the maintenance of high blood pressure. Tissue renin-angiotensin systems may explain why there is no correlation between plasma renin before treatment and the effect on blood pressure.

Renin inhibitors. ACE is not a specific enzyme: it can hydrolyze substrates other than angiotensin $\mathbb{I}$, such as bradykinin, substance $\mathbb{P}$, and enkephalins. The side-effects observed with all ACE inhibitors, such as angioneurotic edema, urticaria and cough, may be related to this lack of selectivity. The development of renin inhibitors was thus thought to be an interesting alternative to $\mathrm{ACE}$ inhibitors for 2 reasons: 1 ) the first step in the angiotensin II forming cascade, the hydrolysis of angiotensinogen by renin, is rate limiting; and 2) renin has a unique specificity for angiotensinogen as there is no other known substrate for this enzyme (54). Knowledge of the molecular structures of both renin and angiotensinogen and the molecular mechanisms of action of aspartyl proteases such as renin has speeded up the development of high-affinity inhibitors specific for renin. Most of the recently developed inhibitors are peptidic angiotensinogen analogues. Their oral availability is usually extremely low. The first reports showing that renin inhibitors are indeed effective blood pressure lowering agents in hypertensive subjects are now available $(\mathbf{5 5 , 5 6 )}$. Their hypotensive effect was not accompanied by reflex tachycardia and outlasted the suppression of plasma angiotensin II levels. The latter finding again underlines the importance of tissue renin-angiotensin systems. However, much work, including improvement of oral availability and comparison of the blood pressure lowering effect of renin inhibitors with the blood pressure lowering effect of $\mathrm{ACE}$ inhibitors, still has to be done. The latter comparison could also shed light on the still unanswered question whether the hypotensive effect of ACE inhibitors is due solely to the blockade of angiotensin II formation or to the combination of a blockade of angiotensin II formation and a blockade of bradykinin degradation.

Angiotensin II antagonists. Even renin inhibitors may not totally eliminate the influence of the renin-angiotensin system, because angiotensin forming enzymes other than renin may cleave angiotensinogen as well (57). To get round this problem, recently attention has been drawn to the development of non-peptide angiotensin II receptor-antagonists. Since the early 1970 s the angiotensin II receptor-antagonist saralasin, a peptide analogue of angiotensin II, has been available. Saralasin lowers blood pressure in conditions characterized by high renin levels (e.g. renovascular hypertension) (58), but this effect is only reached after intravenous administration. Saralasin has a short half life and displays partial agonist properties (59), thus complicating 
the interpretation of results obtained with this peptide analogue. In the past few years several non-peptide angiotensin II antagonists without agonistic properties have been developed, and some were shown to lower blood pressure in spontaneously hypertensive rats after oral administration (60). At least 2 different subtypes of angiotensin II receptors, $\mathrm{AT}_{1}$ (formally known as $\mathrm{AII}-1$ or AII-B) and $\mathrm{AT}_{2}$ (formally known as AII-2 or AII-A), have been characterized based upon their differential affinities for non-peptide angiotensin II antagonists currently available (61). The proto-typical antagonist of the $\mathrm{AT}_{1}$ receptor is DuP 753 (62). The proto-typical antagonists of the $\mathrm{AT}_{2}$ receptor are CGP 42112A, PD 123177, and PD 123319 (63-65). The functions of the $\mathrm{AT}_{2}$ subtype receptors are presently not known (66), but those of the $\mathrm{AT}_{1}$ receptor subtype have already been characterized extensively. $\mathrm{AT}_{1}$ receptors mediate most of the well-known effects of angiotensin $\mathrm{M}$, such as vasoconstriction (peripheral or centrally induced), smooth muscle contraction or hypertrophy, aldosterone secretion, and catecholamine release (67). Binding of angiotensin $\mathrm{II}$ to the $\mathrm{AT}_{1}$ receptor activates phospholipase $\mathrm{C}$, which hydrolyses phosphatidylinositol biphosphate to inositol 1,4,5-triphosphate $\left(\mathbb{P}_{3}\right)$ and diacylglycerol (68-70). $\mathrm{IP}_{3}$ mobilizes calcium from the endoplasmatic reticulum, while diacylglycerol activates protein kinase $\mathrm{C}$. In hepatocytes angiotensin II was found not only to activate phospholipase $\mathrm{C}$, but to inhibit adenylate cyclase as well (68). Both responses were mediated through the $\mathrm{AT}_{1}$ receptor. Very recently two groups succeeded in cloning the adrenal (71) and vascular (72) $\mathrm{AT}_{1}$ receptor subtype. Human studies with non-peptide angiotensin II receptor-antagonists, specifically those inhibiting the $A T_{1}$ receptor subtype (DuP 753), so far have been performed in normotensive subjects only (73). DuP 753 appeared to be a well-tolerated, orally active, potent and long-lasting antagonist of angiotensin II.

\subsection{Aim of the thesis}

The aim of this thesis was twofold. First, the regional metabolism and production of angiotensin I and angiotensin II were quantified in vivo in man and in anesthetized pigs. This was done by giving constant infusions of radiolabeled 125 -angiotensin $I$ into either a peripheral vein (man) or into the left cardiac ventricle (pig). Blood samples were taken under steady state conditions from various arterial and venous sampling sites. By measuring in each sample the levels of intact radiolabeled angiotensin $I$ and angiotensin II and of endogenous angiotensin I and angiotensin II one can calculate both the degree of regional metabolism of angiotensin $I$ and angiotensin $I$ and the 
amount of angiotensin I and angiotensin II that is generated in a certain vascular bed. Additional measurements of plasma renin activity (PRA) and calculations of the regional conversion of ${ }^{125} \mathrm{I}$-angiotensin I to ${ }^{125}$ I-angiotensin II make it possible to calculate the amount of locally generated angiotensin I that can be attributed to the action of circulating renin on circulating renin substrate and the amount of locally generated angiotensin II that can be accounted for by regional conversion of arterially delivered angiotensin I. Our data show clearly that part of angiotensin I in plasma is produced locally, probably in vascular tissue, and not in circulating plasma by PRA, and that most of the renin responsible for this local production is kidney-derived. Part of circulating angiotensin II also appeared to be produced locally, independent of plasma angiotensin $\mathrm{I}$.

The second aim of this thesis was to investigate the existence of a local reninangiotensin system in the eye. This was done based upon previous findings in diabetic subjects (33), which showed that a relationship existed between the high plasma prorenin levels and the presence of retinopathy, especially the proliferative type, in these subjects. Ocular fluid samples obtained from human subjects (both diabetic and non-diabetic) during eye surgery were examined for this purpose. Additionally, angiotensin and renin/prorenin measurements were performed in ocular tissue extracts from both cows and pigs. Human vitreous and subretinal fluid were found to contain prorenin levels too high to be explained by leakage from plasma only. This was not the case with angiotensinogen, angiotensin I or angiotensin II in these ocular fluids. Renin levels were in the low to undetectable range. In contrast, angiotensin $\mathbb{I}$, angiotensin II, renin and prorenin levels in bovine and porcine ocular tissues were far too high to be explained by the presence of plasma in these tissues only. It seems therefore that indeed the eye contains its own renin-angiotensin system. The only component of the ocular renin-angiotensin system which is being released from the tissues into the vitreous fluid appears to be prorenin. Since prorenin was twofold higher in vitreous fluid obtained from eyes affected by proliferative diabetic retinopathy than in vitreous fluid from eyes of non-diabetic patients, one may hypothesize that the renin-angiotensin system is involved in the development of diabetic retinopathy. The final proof for the existence of an intraocular renin-angiotensin system was obtained by the demonstration of renin-, angiotensinogen- and ACE-mRNA expression in human eyes by the polymerase chain reaction.

\subsection{References}

1. Tigerstedt R, Bergman PG. Niere und Kreislauf. Scand Arch Physiol 8: 223-271, 1898.

2. Goldblatt H, Lynch J, Hanzal RF, Summerville WW. Studies on experimental hypertension. I. The production of persistent elevation of systolic blood pressure by means of renal ischaemia. J Exp Med 59: 347-379, 1934. 
3. Braun-Menendez E, Fasciolo IC, Leloir LF, Munoz JM. The substance causing renal hypertension. J Physiol 98: 283-298, 1940.

4. Page $\mathrm{IH}, \mathrm{Helmer} \mathrm{OH}$. Angiotonin-activator, renin- and angiotonin-inhibitor, and the mechanism of angiotonin tachyphylaxis in normal, hypertensive and nephrectomized animals. $J$ Exp Med 71: 495-519, 1940.

5. Skeggs LT, Marsh WH, Kahn J, Shumway NP. The existence of two forms of hypertensin. J Exp Med 99: 275-282, 1954.

6. Shuster VL. Effects of angiotensin on proximal tubular reabsorption. Fed Proc 45: 1444-1447, 1986.

7. Shier DN, Kusano E, Stoner GD, Franco-Saenz R, Mulrow PJ. Production of renin, angiotensin II and aldosterone by adrenal explant cultures: response to potassium and converting enzyme inhibition. Endocrinology 125: 2907-2913, 1989.

8. Pratt $\mathbb{J H}$, Rothrock $\mathrm{JK}$, Dominguez JH. Evidence that angiotensin $\mathrm{II}$ and potassium collaborate to increase cytosolic calcium and stimulate the secretion of aldosterone. Endocrinology 125: 2463-2469, 1989.

9. Dzau VJ, Ingelfinger JR, Pratt RE. Regulation of tissue renin and angiotensinogen gene expressions.J Cardiovasc Pharmacol 8 (suppl 10): S1I-S16, 1986.

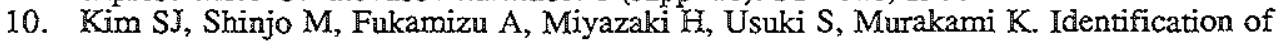
renin and renin messenger RNA sequence in rat ovary and uterus. Biochem Biophys Res Commun 142: 169-175, 1987.

11. Campbell DJ. The site of angiotensin production. J Hypertens 3: 199-207, 1985.

12. Abhold RH, Harding JW. Metabolism of angiotensins II and III by membrane-bound peptidases from rat brain. J Pharmacol Exp Ther 245: 171-177, 1988.

13. Ahmad S, Ward PE. Role of aminopeptidase activity in the regulation of the pressor activity of circulating angiotensins. J Pharmacol Exp Ther 252: 643-650, 1990.

14. Lee CM, Snyder SH. Dipeptidyl-aminopeptidase $\mathrm{M}$ of rat brain. Selective affinity for enkephalin and angiotensin. J Biol Chem 257: 12043-12050, 1982.

15. Stephenson SL, Kenny AJ. Metabolism of neuropeptides. Hydrolysis of the angiotensins, bradykinin, substance $\mathrm{P}$ and oxytocin by pig kidney microvillar membranes. Biochem $J$ 241: 237-247, 1987.

16. Hedeager-Sorensen S, Kenny AJ. Proteins of the kidney microvillar membrane. Purification and properties of carboxypeptidase P from pig kidneys. Biochem $J 229$ : 251-257, 1985.

17. Miller JJ, Changaris DG, Levy RS. Conversion of angiotensin $I$ to angiotensin II by cathepsin A isoenzymes of porcine kidney. Biochem Biophys Res Commun 154: $1122-1129,1988$.

18. Fei DTW, Scoggins BA, Tregear GT, Coghlan JP. Angiotensin I, II and $\mathrm{II}$ in sheep. A model of angiotensin production and metabolism. Hypertension 3: 730-737, 1981.

19. Campbell DI, Kladis A, Skinner SL, Whitworth JA. Characterization of angiotensin peptides in plasma of anephric man. $J$ Hypertens 9: 265-274, 1991.

20. Sealey JE, White RP, Laragh JH, Rubin AL. Plasma prorenin and renin in anephric patients. Circ Res 41 (suppl II): 17-21, 1977.

21. Lenz T, Sealey JE. Tissue renin systems as a possible factor in hypertension. In: Hypertension: Pathophysiology, Diagnosis, and Management, edited by $\mathrm{JH}$ Laragh and BM Brenner. Raven Press, Ltd, New York. 1990, p. 1319-1328.

22. Sealey JE, Goldstein M, Pitarresi T, Kudlak TT, Glorioso N, Fiamengo SA, Laragh JH. Prorenin secretion from human testis: no evidence for secretion of active renin or angiotensinogen. J Clin Endocrinol Metab 66: 974-978, 1988.

23. Ohashi H, Matsunaga M, Kuwahara T, Pak CH, Kawai C. Production and release of inactive renin by human vascular smooth muscle cells. Clin Exp Hypertension Theory Pract A7: 1395-1407, 1985.

24. Brunswig-Spickenheimer B, Mukhopadhyay AK: Inhibitory effects of a tumor-promoting phorbol ester on luteinizing hormone-stimulated renin and prorenin production by cultured bovine theca cells. Endocrinology 127: 2157-2165, 1990. 
25. Yamaguchi T, Naito Z, Stoner GD, Franco-Saenz R, Mulrow PJ: Role of the adrenal renin-angiotensin system on adrenocorticotropic hormone- and potassium-stimulated aldosterone production by rat adrenal glomerulosa cells in monolayer culture. Hypertension 16: 635-641, 1990.

26. Morris BJ. Activation of human inactive ('pro-') renin by cathepsin D and pepsin. $J$ Clin Endocrinol Metab 46: 153-157, 1978.

27. Derkx FHM, Bouma BN, Schalekamp MPA, Schalekamp MADH. An intrinsic factor XII-prekalliktein-dependent pathway activates the human plasma renin-angiotensin system. Nature 280: 315-316, 1979.

28. Dzau VJ, Gonzalez D, Kaemper C, Dubin D, Wintroub BU. Human neutrophils release serine proteases capable of activating prorenin. Circ Res 60: 595-601, 1987.

29. Wang PH, Do YS, Macaulay L, Shinagawa $T$, Anderson PW, Baxter JD, Hsueh WA. Identification of renal cathepsin B as a human prorenin-processing enzyme. J Biol Chem 266: 12633-12638, 1991.

30. Derkx FHM, Stuenkel C, Schalekamp MPA, Visser W, Huisveld IH, Schalekamp $\mathrm{MADH}$. Immunoreactive renin, prorenin and enzymatically active renin in plasma during pregnancy and in women taking oral contraceptives. $J$ Clin Endocrinol Metab 63: $1008-1015,1986$.

31. Luetscher JA, Kraemer FB, Wilson DM, Schwartz HC, Bryer-Ash M. Increased plasma inactive renin in diabetes mellitus: a marker of microvascular complications. $N$ Engl $J$ Med 312: 1412-1417, 1985.

32. Derkx FHM, Alberda AT, de Jong FH, Zeilmaker FH, Makovitz JW, Schalekamp MADH. Source of plasma prorenin in early and late pregnancy: observations in a patient with primary ovarian failure. $J$ Clin Endocrinol Metab 65: 349-354, 1987.

33. Franken AAM, Derkx FHM, Man in 't Veld AJ, Hop WCJ, van Rens GH, Peperkamp E, de Jong PTVM, Schalekamp MADH. High plasma prorenin in diabetes mellitus and its correlation with some complications. J Clin Endocrinol Metab 71: 1008-1015, 1990.

34. Derkx FHM, Schalekamp MADH. Human prorenin: pathophysiology and clinical implications. Clin Exp Hypertension Theory Pract A10: 1213-1225, 1988.

35. Heinrikson RL, Hui J, Zürcher-Neely H, Poorman RA. A structural model to explain the partial catalytic activity of human prorenin. Am J Hypertens 2: 367-380, 1989.

36. Sealey JE, Rubattu S. Prorenin and renin as separate mediators of tissue and circulating systems. Am J Hypertens 2: 358-366, 1989.

37. Derkx FHM, Schalekamp MPA, Schalekamp MADH. Prorenin-renin conversion. Isolation of an intermediary form of activated prorenin. $J$ Biol Chem 262: 2472-2477, 1987.

38. Zimmerman BG. Adrenergic facilitation by angiotensin: does it serve a physiological function? Clin Sci 60: 343-348, 1981.

39. Toda N, Ayazaki K, Okamura $\mathrm{T}$. Modifications by endogenous prostaglandins of angiotensin II-induced contractions in dog and monkey cerebral and mesenteric arteries. $J$ Pharmacol Exp Ther 252: 374-379, 1990.

40. Schomisch Moravec C, Schluchter MD, Paranandi L, Czerska B, Stewart RW, Rosenkranz E, Bond M. Inotropic effects of angiotensin II on human cardiac muscle in vivo. Circulation 82: 1973-1984, 1990.

41. Levens NR, Peach MJ, Carey RM. Role of the intrarenal renin-angiotensin system in the control of renal function. Circ Res 48: 157-167, 1981.

42. Navar LG. Physiological role of the intrarenal renin-angiotensin system. Fed Proc 45: $1411-1413,1986$.

43. Mitchell $\mathrm{KD}$, Navar LG. Influence of intrarenally generated angiotensin $\mathrm{I}$ on renal hemodynamics and tubular reabsorption. Renal Physiol Biochem 14: 155-163, 1991.

44. Itskovitz J, Rubattu S, Rosenwaks Z, Liu HC, Sealey JE. Relationship of follicular fluid prorenin to oocyte maturation, steroid levels, and outcome of in vitro fertilization. J Clin Endocrinol Metab 72: 165-171, 1991.

45. Unger $T$, Badoer $\mathrm{E}$, Ganten $\mathrm{D}$, Lang RE, Rettig R. Brain angiotensin: pathways and pharmacology. Circulation 77 (suppl I): 40-54, 1988. 
46. Griffin SA, Brown WCB, MacPherson F, McGrath JC, Wilson VG, Korsgaard N, Mulvany MJ, Lever AF. Angiotensin II causes vascular hypertrophy in part by a non-pressor mechanism. Hypertension 17: 626-635, 1991.

47. Le Noble FAC, Hekking JWM, van Straaten HWM, Slaaf DW, Struyker-Boudier HAJ. Angiotensin II stimulates angiogenesis in the chorio-allantoic membrane of the chick embryo. Eur J Pharmacol 195: 305-306, 1991.

48. Daemen MJAP, Lombardi DM, Bosman FT, Schwartz SM. Angiotensin II induces smooth muscle cell proliferation in the normal and injured rat arterial wall. Circ Res 68: 450-456, 1991.

49. Fernandez LA, Twickler J, Mead A. Neovascularization produced by angiotensin II. $J$ Lab Clin Med 105: 141-145, 1985.

50. Ondetti MA, Rubin B, Cushman DW. Design of specific inhibitors of angiotensin I-converting enzyme: new class of orally active antihypertensive agents. Science 196: 441-444, 1977.

51. Gavras H, Gavras I. Angiotensin converting enzyme inhibitors. Properties and side effects. Hypertension (suppl II) 11: 37-41, 1988.

52. Gavras H, Brunner HR, Turini GA, Kershaw GR, Tifft CP, Cuttelod S, Gavras I, Vukovich RA, McKinstry DN. Antihypertensive effect of the oral angiotensin converting enzyme-inhibitor SQ 14225 in man. N Engl J Med 298: 991-995, 1978.

53. Nussberger J, Brunner DB, Waeber B, Brunner HR. Specific measurement of angiotensin metabolites and in vitro generated angiotensin II in plasma. Hypertension 8: 476-482, 1986.

54. Ondetti MA, Cushman DW. Inhibition of the renin-angiotensin system. A new approach to the therapy of hypertension. J Med Chem 24: 335-361, 1981.

55. van den Meiracker AH, Admiraal PJJ, Man in 't veld AJ, Derkx FHM, Ritsema van Eck, Mulder P, van Brummelen P, Schalekamp MADH. Prolonged blood pressure reduction by orally active renin inhibitor Ro $42-5892$ in essential hypertension. $\mathrm{Br} \mathrm{Med} \mathrm{J} \mathrm{301:}$ 205-210, 1990.

56. Weber MA, Neutel JM, Essinger I, Glassman H, Boger R, Luther R. Assessment of renin dependency of hypertension with a dipeptide renin inhibitor. Circulation 81 : 1768-1771, 1990.

57. Dzau VJ. Significance of the vascular renin-angiotensin system. Hypertension 8: $553-559,1986$.

58. Brunner HR, Gavras H, Laragh $\mathrm{H}$, Keenan R. Hypertension in man: exposure of the renin and sodium components using angiotensin II blockade. Circ Res 34 (suppl I): 35-43, 1974.

59. Streeten DHP, Anderson GH, Freiberg JM, Dalakos TG. Use of an angiotensin II antagonist (saralasin) in the recognition of 'angiotensinergic' hypertension. $N E n g l J M e d$ 292: 657-662, 1975.

60. Wong PC, Price WA, Chiu AT, Duncia JV, Carini DJ, Wexler RR, Johnson AL, Timmermans PBMWM. Hypotensive action of DuP 753, an angiotensin II antagonist, in spontaneously hypertensive rats. Hypertension 15: 459-468, 1990.

61. Bumpus FM, Catt KJ, Chiu AT, de Gasparo M, Goodfriend $T$, Husain A, Peach MJ, Taylor DG, Timmermans PBMWM. Nomenclature for angiotensin receptors. A report of the nomenclature committee of the council for high blood pressure research. Hypertension 17: $720-721,1991$.

62. Chiu AT, Herblin WF, McCall DE, Ardecki RJ, Carini DJ, Duncia JV, Pease LJ, Wong PC, Wexler RR, Johnson AL, Timmermans PBMWM. Identification of angiotensin II receptor subtypes. Biochem Biophys Res Commun 165: 196-203, 1989.

63. Chang RS, Lotti VJ. Two distinct angiotensin II receptor binding sites in rat adrenal revealed by new selective nonpeptide ligands. Mol Pharmacol 29: 347-351, 1990.

64. Dudley DT, Panek RL, Major TC, Lu GH, Bruns RF, Klinkefus BA, Hodiges JC, Weishaar RE. Subclasses of angiotensin II binding sites and their functional significance. Mol Pharmacol 38: 370-377, 1990. 
65. Whitebread S, Mele M, Kamber B, de Gasparo M. Preliminary biochemical characterization of two angiotensin II receptor subtypes. Biochem Biophys Res Commun 163: 284-291, 1989.

66. Pucell AG, Hodges JC, Sen I, Bumpus FM, Husain A. Biochemical properties of the ovarian granulosa cell type 2-angiotensin II receptor. Endocrinology 128: 1947-1959, 1991.

67. Chiu AT, McCall DE, Aldrich PE, Timmermans PBMWM. 3H-Dup 753, a highly potent and specific radioligand for the angiotensin II-1 receptor subtype. Biochem Biophys Res Commun 172: 1195-1202, 1990.

68. Garcia-Sainz JA, Macias-Silva M. Angiotensin II stimulates phosphoinosotide turnover and phosphorylase through AII-I receptors in isolated rat hepatocytes. Biochem Biophys Res Commun 172: 780-785, 1990.

69. Pfeilschifter J. Angiotensin II B-type receptor mediates phosphoinositide hydrolysis in mesangial cells. Eur J Pharmacol 184: 201-202, 1990.

70. Bauer PH, Chiu AT, Garrison JC. DuP 753 can antagonize the effects of angiotensin II in rat liver. J Pharmacol Exp Ther 39: 579-585, 1991.

71. Sasaki K, Yamano Y, Bardhan S, Iwai N, Murray J, Hasegawa M, Matsuda Y, Inagami $\mathrm{T}$. Cloning and expression of a complementary DNA encoding a bovine adrenal angiotensin II type-I receptor. Nature 351: 230-233, 1991.

72. Murphy TJ, Alexander RW, Griendling KK, Runge MS, Bernstein KE. Isolation of a CDNA encoding the vascular type-1 angiotensin II receptor. Nature 351: 233-236, 1991.

73. Christen Y, Waeber B, Nussberger J, Porchet M, Borland RM, Lee RJ, Maggon K, Shum L, Timmermans PBMWM, Brunner HR. Oral administration of DuP 753, a specific angiotensin II receptor antagonist, to normal male volunteers. Inhibition of pressor response to exogenous angiotensin I and II. Circulation 83: 1333-1342, 1991. 


\section{METABOLISM AND PRODUCTION OF ANGIOTENSIN I IN DIFFERENT VASCULAR BEDS IN SUBJECTS WITH HYPERTENSION}

\subsection{Summary}

To study the metabolism and production of angiotensin I, highly purified mono-iodinated ${ }^{25} \mathrm{I}$-angiotensin I was given by constant systemic intravenous infusion, either alone $(n=7)$ or combined with unlabeled angiotensin $I(n=5)$, to subjects with essential hypertension, who were treated with the angiotensin converting enzyme inhibitor captopril ( $50 \mathrm{mg}$ b.i.d.). Blood samples were taken from the aorta and the renal, antecubital, femoral and hepatic veins. ${ }^{125 I}$ angiotensin I and angiotensin I were extracted from plasma, separated by high performance liquid chromatography and quantitated by gamma counting and radioimmunoassay. Plasma renin activity was measured at $\mathrm{pH} 7.4$. The plasma decay curves after discontinuation of the infusions of $125 \mathrm{I}$-angiotensin $\mathrm{I}$ and unlabeled angiotensin I were similar for the two peptides. The regional extraction ratio of 125 I-angiotensin I was $47 \pm 4 \%$ (mean \pm SEM) across the forearm, $59 \pm 3 \%$ across the leg, $81 \pm 1 \%$ across the kidneys and $96 \pm 1 \%$ across the hepatomesenteric vascular bed. These results were not different from those obtained for infused unlabeled angiotensin I. Despite the rapid removal of arterially delivered angiotensin I, no difference was found between the venous and arterial levels of endogenous angiotensin $I$ across the various vascular beds, with the exception of the liver where angiotensin $I$ in the vein was $50 \%$ lower than in the aorta. Thus, $50-90 \%$ of endogenous angiotensin I in the veins appeared to be derived from regional de novo production. The blood transit time is $0.1-0.2 \mathrm{~min}$ in the limbs and in the kidneys and $0.3-0.5$ $\mathrm{min}$ in the hepatomesenteric vascular bed. This is too short for plasma renin activity to account for the measured de novo angiotensin I production. It was calculated that less than $20-30 \%$ in the limbs and in the kidneys and approximately $60 \%$ in the hepatomesenteric region of de novo produced angiotensin $I$ could be accounted for by circulating renin. These results indicate that a high percentage of plasma angiotensin I may be produced locally (i.e., not in circulating plasma)

\subsection{Introduction}

Renin (EC 3.4.23.15); an aspartyl protease synthesized mainly by the kidneys, 
acts on renin substrate (angiotensinogen) to form the decapeptide angiotensin I (ANG I), which is then converted to the octapeptide angiotensin II (ANG II) by angiotensin converting enzyme (ACE). All these components of the reninangiotensin system are present in plasma. Plasma renin activity (PRA), which is the rate of ANG I formation in vitro, is considered to be a measure of the production of plasma ANG I in vivo. However, there is evidence from animal studies to suggest that the rate of angiotensin metabolism is too high for PRA to maintain the actual plasma levels of ANG I and II (1-3). Thus, part of plasma ANG I may be formed locally rather than in circulating plasma.

The source of renin involved in local ANG I production is not known. It is possible that the circulating renin-angiotensin system not only serves to deliver ANG I to the blood vessel wall for conversion to ANG II but that it also serves to deliver renin for local ANG I production. Through binding or uptake of plasma renin by vascular tissue or through local activation of plasma prorenin, the local concentration of renin may reach levels higher than in circulating plasma. Another possibility is that local production of ANG I depends on locally synthesized rather than systemically delivered renin.

Renin is synthesized by various tissues apart from the kidney and there is evidence for local angiotensin generation in some of these tissues $(2,4)$. In culture, bovine and canine vascular smooth muscle cells and bovine endothelial cells synthesize ANG II and secrete this peptide into the medium $(5,6)$. Isolated rat mesenteric arteries, when perfused with solutions free of renin and renin substrate, release ANG II into the perfusate (7), and in similar experiments, isolated rat hindlegs were found to release both ANG I and ANG II (8). Thus, part of ANG I and ANG II circulating in plasma may have been generated locally in the interstitium or in the cells of vascular tissue, and it has been postulated that a vascular renin-angiotensin system is important for the regulation of vascular tone and the maintenance of hypertension (9-12).

The production rate of angiotensins in different vascular beds cannot be simply derived from the regional blood flow and the arteriovenous concentration gradient, because a high rate of production may be matched by a high rate of metabolism. Studies using tracer amounts of radiolabeled angiotensins for measuring ANG I-II conversion and ANG I and II degradation are scarce because of the difficulty to measure the angiotensins separately from their metabolites and also because of the instability of some earlier radiolabeled iodine angiotensin preparations. More recent studies in dogs using highly purified mono-iodinated ${ }^{125} \mathrm{I}$-ANG I have demonstrated that this preparation can be used for measuring intrarenal ANG I-II conversion and ANG I degradation $(13,14)$. Mono-iodinated ${ }^{125}$ I-ANG $I I$ is a potent, full agonist analog of ANG II $(15,16)$.

The present study was undertaken to explore the possibility of measuring the rate of metabolism of ANG I in humans by intravenous infusion of monoiodinated 125I-ANG I. These infusions were given to hypertensive subjects at the time renal vein renin sampling was performed as part of the diagnostic 
workup for renovascular hypertension while the subjects were treated with the ACE inhibitor captopril. 125I-ANG I and 125I-ANG II and endogenous ANG I and ANG II were isolated from aortic plasma and from renal, antecubital, femoral and hepatic venous plasma, and separated by high performance liquid chromatography (HPLC). The isolated radiolabeled angiotensins were quantitated in the gamma counter and the concentrations of endogenous angiotensins were measured by radioimmunoassay. Regional extraction of ANG I was calculated from measurements of the arterial and venous levels of 125I-ANG I. From this and from measurements of the concentrations of endogenous ANG I, information could be obtained on ANG I production in different vascular beds. Parallel measurements of ${ }^{125}$ I-ANG II provided information on ANG I-II conversion.

\subsection{Materials and methods}

\section{Chemicals}

[Mle5]-ANG-(1-10) decapeptide, [Ile5]-ANG-(1-8) octapeptide, [Ile5]-ANG-(28) heptapeptide and [Mle5]-ANG-(1-7) heptapeptide, which are denoted here as ANG I, ANG II, ANG III and ANG-(1-7) respectively, were obtained from Bachem, Bubendorf, Switzerland. [Ile5]-ANG-(2-10) nonapeptide was from Senn Chemicals, Dielsdorf, Switzerland. [Ile5]-ANG-(3-8) hexapeptide, [Me5]ANG-(4-8) pentapeptide and ANG-(1-4) tetrapeptide were from Peninsula Laboratories, Belmont, CA, USA. The World Health Organization (WHO) standards of ANG I and ANG II (86/536 and 86/538) were from the National Institute for Biological Standards and Control, London, UK. Methanol and ortho-phosphoric acid (both analytical grade) were from Merck, Darmstadt, Germany. Bovine serum albumin (BSA) was from Sigma, St. Louis, MO, USA. Human serum albumin (HSA) was from Merieux, Lyon, France. Water for HPLC was prepared with a Milli-Q system from Waters, Millford, MA, USA. The statine containing renin inhibitor CGP 29,287 was a kind gift of Dr. K. Hofbauer (Ciba-Geigy, Basel, Switzerland).

\section{Preparation of angiotensin antisera}

ANG I and ANG II antisera were produced in New Zealand White rabbits by intracutaneous injections of $330 \mu \mathrm{g}$ of either ANG I or ANG II coupled to BSA with 1-ethyl-3-(3-dimethylamino)propyl-carbodiimide $\mathrm{HCl}$ and suspended in Freund's complete adjuvant. Booster injections of the conjugates suspended in Freund's incomplete adjuvant were given at 4 week intervals. The ANG I antiserum was used in the radioimmunoassay in a final dilution of $1: 250.000$. This antiserum gave a B/Bo ratio of 0.9 at 2 fmol ANG I and a B/Bo ratio of 0.5 at 20 fmol ANG I. The antiserum also reacted (100\%) with ANG-(2-10) 
nonapeptide but did not react (less than $0.1 \%$ ) with ANG II, ANG III, ANG(3-8) hexapeptide and ANG-(4-8) pentapeptide. The ANG II antiserum was used in a final dilution of $1: 200.000$. It gave a $B / B$ o ratio of 0.9 at $1.5 \mathrm{fmol}$ ANG II and a B/Bo ratio of 0.5 at $16 \mathrm{fmol}$ ANG $\mathbb{I}$. This antiserum also reacted with ANG III (55\%), ANG-(3-8) hexapeptide (73\%) and ANG-(4-8) pentapeptide $(100 \%)$ but virtually not with ANG I (0.3\%) and ANG-(2-10) nonapeptide $(0.2 \%)$. The renin inhibitor CGP 29,287 , in concentrations up to $100 \mu \mathrm{M}$, did not react with either ANG I or ANG II antisera.

\section{Blood sampling}

Blood for angiotensin measurements was rapidly $(7-13 \mathrm{sec})$ drawn by a plastic syringe containing the following inhibitors $(0.5 \mathrm{~mL}$ inhibitor solution in 10 $\mathrm{mL}$ blood), $6.25 \mathrm{mM}$ disodium EDTA, $1.25 \mathrm{mM}$ 1,10-phenantroline and 100 $\mathrm{nM}$ of the renin inhibitor CGP 29,287 (final concentrations in blood) and transferred into prechilled polystyrene tubes. These inhibitors were used in order to prevent ANG I generation, ANG I-II conversion and ANG I and II degradation during blood collection and handling of the samples. The blood samples were centrifuged at $3000 \mathrm{~g}$ for $10 \mathrm{~min}$ at $4{ }^{\circ} \mathrm{C}$. Plasma was stored at $70^{\circ} \mathrm{C}$, extracted within two days and assayed within two weeks. The renin inhibitor CGP 29,287 is a renin substrate analog. At a concentration of approximately $1 \mathrm{nM}$ it inhibits PRA by $50 \%$ (17). We chose to use the inhibitor in a final concentration of $100 \mathrm{nM}$ on the basis of experiments, in which we added the inhibitor in concentrations ranging from 0.1 to $1000 \mathrm{nM}$ to a plasma sample with normal PRA $(12 \mathrm{pmol} / \mathrm{L} \cdot \mathrm{min})$ and to plasma samples with elevated PRA (77 and $260 \mathrm{pmol} / \mathrm{L}$. min). ANG I formation during incubation was inhibited by $98 \%$ at $37^{\circ} \mathrm{C}$ and by $100 \%$ at $20^{\circ} \mathrm{C}$, both at an inhibitor concentration of $100 \mathrm{nM}$.

Blood for PRA measurements was collected into polystyrene tubes containing EDTA $(0.2 \mathrm{~mL}$ disodium EDTA in $10 \mathrm{~mL}$ blood, final concentration $6.25 \mathrm{mM}$ ). The samples were centrifuged at room temperature at $3000 \mathrm{~g}$ for $10 \mathrm{~min}$, and plasma was stored at $-20^{\circ} \mathrm{C}$.

\section{Extraction of angiotensins}

Solid phase extraction cartridges (SepPak C18, Waters, Millford, MA, USA) were conditioned with $4 \mathrm{~mL}$ methanol and then equilibrated with two times 4 $\mathrm{mL}$ of cold water. Thawed plasma samples $(2 \mathrm{~mL})$ were applied to the cartridges. After the bound peptides were washed two times with $4 \mathrm{~mL}$ cold water, they were eluted with $2 \mathrm{~mL}$ methanol and collected into conical polypropylene tubes. The methanol extracts were evaporated at $4{ }^{\circ} \mathrm{C}$ with a Savant Speed Vac concentrator (Savant Instruments, Farmingdale, NY, USA). Recovery of labeled and unlabeled ANG I and II from the SepPak cartridges was $95-98 \%$. 


\section{Separation of angiotensins by HPLC}

Separation of the peptides in the methanol extracts was performed by HPLC using the method of Nussberger et al (18) with some modifications. We used a reversed phase Nucleosil C18 steel column of $250 \times 4.6 \mathrm{~mm}$ and $10 \mu \mathrm{m}$ particle size equipped with a direct-connect guard column (Alltech, Eke, Belgium). The HPLC equipment consisted of a LKB 2150 pump, a 2152 controller, a 2122 fraction collector and a 2155 column oven (LKB, Bromma, Sweden). Samples were injected with a Rheodyne 7125 injection valve equipped with a $250 \mu \mathrm{L}$ loop (Rheodyne, Cotati, CA, USA). Mobile phase A was $0.085 \%$ orthophosphoric acid containing $0.02 \%$ sodium azide ( $\mathrm{pH} 2.33$ ). Mobile phase $\mathrm{B}$ was methanol. The flow was $1 \mathrm{~mL} / \mathrm{min}$ and the working temperature was $45^{\circ} \mathrm{C}$. The column was calibrated with pure ${ }^{125}$ I-Iabeled standards of ANG I and ANG II and with unlabeled ANG I, ANG II, ANG III and some of their metabolites. The vacuum dried plasma extracts were dissolved in $100 \mu \mathrm{L} \mathrm{HPLC}$ solvent $(65 \% \mathrm{~A} / 35 \% \mathrm{~B}, \mathrm{vol} / \mathrm{vol})$, centrifuged and injected with a $100 \mu \mathrm{L}$ Hamilton syringe (no. 1710, Hamilton, Bonaduz, Switzerland). Elution was performed as follows: $65 \% \mathrm{~A} / 35 \% \mathrm{~B}$ from 0 to 9 min followed by a lineair gradient to $45 \% \mathrm{~A} / 55 \% \mathrm{~B}$ until $18 \mathrm{~min}$. The eluate was collected in $20-\mathrm{sec}$ fractions into polystyrene tubes coated with BSA.

The concentrations of ${ }^{125}$ I-ANG I and 125I-ANG II in the HPLC fractions were measured in the gamma counter for $20 \mathrm{~min}$. The fractions containing ANG I and ANG II were pooled separately. They were neutralized with $0.5 \mathrm{M}$ sodium hydroxide and evaporated in the Savant concentrator. The concentrations of ANG I and ANG II were measured by radioimmunoassay. Recoveries for the HPLC separation alone were 90 - $95 \%$ for both labeled and unlabeled ANG I and II. The overall recoveries of ANG I and ANG II added to plasma samples were $85 \pm 7 \%$ and $84 \pm 8 \%$ (mean $\pm \mathrm{SD}, \mathrm{n}=6$ ). Similar values were obtained for ${ }^{125 I-A N G ~ I ~ a n d ~}{ }^{125 I-A N G ~ I I . ~ R e s u l t s ~ w e r e ~ n o t ~}$ corrected for incomplete recovery.

\section{Radioimmunoassay of angiotensins}

The dried HPLC fractions were dissolved in $0.25 \mathrm{M}$ Tris buffer, pH 7.4, containing $0.35 \%$ BSA and $0.02 \%$ sodium azide. They were then incubated with $125 \mathrm{I}$-ANG I or ${ }^{125} \mathrm{I}-\mathrm{ANG} \mathrm{II}$ and the appropriate antiserum at $4{ }^{\circ} \mathrm{C}$ for 3 days. Separation of bound and free angiotensin was achieved by charcoal adsorption, and both the supernatant and the pellet were counted to a counting error of less than $1 \%$. The concentrations of ANG I and ANG II (from Bachem) in the standard solutions of the radioimmunoassay were checked by comparison with the WHO ANG I and ANG II reference standards. The concentrations of angiotensins are expressed as picomoles per liter plasma. The lower limit of detection ( $2 \times \mathrm{SD}$ difference from Bo) was $1.2 \mathrm{fmol} /$ tube for 
ANG I and $0.7 \mathrm{fmol} / \mathrm{tube}$ for ANG II. The normal level of ANG I in antecubital venous plasma from healthy individuals in supine position was 20.9 $\mathrm{pmol} / \mathrm{L}$ (geometric mean), range $12.3-42.4 \mathrm{pmol} / \mathrm{L}(\mathrm{n}=18)$. The normal level of $A N G ~ I I$ in these individuals was $4.8 \mathrm{pmol} / \mathrm{L}$ (geometric mean), range $2.5-8.2 \mathrm{pmol} / \mathrm{L}(\mathrm{n}=18)$.

\section{Measurement of plasma renin activity}

PRA was measured by incubating of the plasma at $37{ }^{\circ} \mathrm{C}$ for $0,15,30$ and 60 min. During the 60 -min incubation $\mathrm{pH}$ varied from 7.1 at $\mathrm{t}=0 \mathrm{~min}$ to 7.5 at $\mathrm{t}$ $=60 \mathrm{~min}$. PRA measurements under these conditions gave results not different from measurements in the presence of $100 \mathrm{mM}$ imidazol buffer, $\mathrm{pH} 7.4$. With this buffer $\mathrm{pH}$ remained 7.4 during incubation. In order to prevent ANG I-II conversion, ANG I degradation, prorenin-renin conversion and bacterial growth, the following mixture of inhibitors was added to plasma before incubation ( $35 \mu \mathrm{L}$ of inhibitor solution/ $\mathrm{mL}$ plasma): $5 \mathrm{mM}$ disodium EDTA, $3.4 \mathrm{mM}$ 8-hydroxyquinoline sulfate, $2.4 \mathrm{mM}$ phenylmethylsulfonylfluoride, $2.2 \mathrm{nM}$ aprotinin and $1 \mathrm{mg} / \mathrm{mL}$ neomycin sulfate (final concentrations in plasma).

The inhibitors do not interfere with the reaction of renin with substrate. The kinetic constants, $V_{\max }$ and $\mathrm{K}_{\mathrm{m}}$, of this reaction are not modified when these inhibitors are added to mixtures of highly purified human renin and human substrate. The measured levels of PRA are not different from those calculated from these kinetic constants and from the concentrations of renin and substrate measured in plasma (19). ANG I that was generated during incubation was quantitated by radioimmunoassay. ANG I generation in the PRA assay was linear in the first $30 \mathrm{~min}$ of incubation but in some samples the rate of ANG I generation was somewhat lower in the following $30 \mathrm{~min}$. Only the first linear part of the ANG I generation curve was used for calculating PRA. The recovery of renin or ANG I added to plasma prior to assay was $98-100 \%$.

PRA is expressed as picomoles ANG I per liter plasma per minute of incubation ( $\mathrm{pmol} / \mathrm{L} \cdot \mathrm{min})$. The normal level of PRA in antecubital venous plasma was $12.7 \mathrm{pmol} / \mathrm{L}$ - min (geometric mean), range $2.3-66.7 \mathrm{pmol} / \mathrm{L}$. $\min (n=74)$. This is in close agreement with the results obtained by the "antibody-trapping" technique $(20,21)$.

\section{Measurement of renal plasma flow}

Renal plasma flow was determined by measurement of the clearance of ${ }^{131}$ Ihippurate (Amersham Intl., Amersham, UK), which was given by constant intravenous infusion at the time the procedure of renal vein sampling was performed. Renal plasma flow was calculated by dividing the clearance of $131 \mathrm{I}$ hippurate by the renal extraction ratio (22). 
ANG I was radiolabeled by the chloramine $T$ method (23). All solutions were made in sterile pyrogene free water. The whole procedure was carried out under aseptic conditions. In short, $4 \mathrm{nmol}$ ANG I in $20 \mu \mathrm{L}$ of $0.25 \mathrm{M}$ sodium phosphate buffer, $\mathrm{pH} 7.5$, was mixed with $1 \mathrm{mCi}(37 \mathrm{MBq}){ }^{125 I}$-sodium iodide (Amersham Intl.). The reaction, which occurred at room temperature, was started by the addition of $20 \mu \mathrm{L}$ of $7.0 \mathrm{mM}$ chloramine $\mathrm{T}$. After $25-30$ seconds the reaction was stopped with $20 \mu \mathrm{L}$ of $11.0 \mathrm{mM}$ sodium metabisulfite. Free 125I-iodide and labeled peptide were separated on a $5 \times 50 \mathrm{~mm}$ Dowex-AG-IX8 column (50-100 mesh, Bio-Rad, Richmond, CA, USA). Elution was carried out with $0.1 \mathrm{M}$ acetic acid containing $0.1 \%$ HSA. Labeled ANG I does not bind to the column under these conditions. Fractions of $0.5 \mathrm{~mL}$ were collected and the fractions containing labeled peptide were pooled.

To obtain mono-iodinated ${ }^{125}$ I-ANG I, the labeled peptide was applied to a $1.6 \times 100 \mathrm{~cm}$ Biogel P-4 column (200-400 mesh, Bio-Rad) and eluted with $0.05 \mathrm{M}$ acetic acid containing $0.1 \mathrm{M} \mathrm{NaCl}$ and $0.1 \% \mathrm{HSA}$. Fractions of $2.5 \mathrm{~mL}$ were collected and counted in a gamma counter. The ${ }^{125 I-A N G ~ I ~ w a s ~ e l u t e d ~}$ from the Biogel P-4 column in two separate peaks. The first peak represented mono-iodinated $125 \mathrm{I}$-ANG I and the second peak consisted of di-iodinated $125 \mathrm{I}$ ANG I. Fractions from the first peak were pooled, sterilized by filtration through a $0.22 \mu \mathrm{m}$ Millipore membrane filter (Waters, Millford, MA, USA) and stored at $-20^{\circ} \mathrm{C}$ until use. The specific radioactivity of the 125I-ANG I preparation was approximately $3.6 \times 10^{6} \mathrm{cpm} / \mathrm{pmol}(74 \mathrm{kBq} / \mathrm{pmol})$. To obtain information about the purity of the mono-iodinated ${ }^{125}$ I-ANG I, a sample of the pooled fractions of the first peak was injected into the HPLC column. The HPLC elution profile of the radioactive material indicated that $98 \%$ consisted of mono-iodinated ${ }^{125} \mathrm{I}-\mathrm{ANG} \mathrm{I}$.

\section{Subjects}

Ten subjects with hypertension (four men, six women mean age 48, range 26 67 years) were studied at the time they were undergoing renal vein renin sampling followed by renal angiography for diagnostic purposes. The renal vein renin ratio was normal $(<1.5)$ as was the renal angiogram. Blood pressure in the outpatient clinic was repeatedly above $160 / 100 \mathrm{~mm} \mathrm{Hg}$ despite antihypertensive medication. Routine urine analysis, serum creatinine and serum electrolytes were normal, and the subjects were considered to have essential hypertension. Seven subjects received an infusion of ${ }^{125}$ I-ANG I, and three subjects received an infusion of both 125I-ANG I and ANG I. Two additional subjects with essential hypertension (one woman 47 years old and one man 58 years old) were studied at the end of a 24-hour period of intraarterial blood pressure recording. Renal vein renin sampling and renal angiography had been performed some months before and were normal. These 
two subjects received an infusion of both $125 \mathrm{I}-\mathrm{ANG}$ I and ANG I.

All subjects received $5 \mathrm{~mL}$ Lugol's solution/day from 2 days before to 4 days after the angiotensin infusion. The subjects were treated with the ACE inhibitor captopril (50 mg p.o., b.i.d.). The infusion studies were performed 46 hours after administration of the morning dose of captopril.

\section{Infusion protocol}

125I-ANG I was infused at a rate of approximately $3.0 \times 10^{6} \mathrm{cpm} / \mathrm{min}$, and ANG I at a rate of approximately $1.2 \mathrm{nmol} / \mathrm{min}$ for $20 \mathrm{~min}$. An indwelling needle for blood sampling was placed in the antecubital vein of the left arm. After insertion of the catheters into the abdominal aorta and the inferior caval vein via the femoral artery and vein by the Seldinger technique, angiotensin was infused via the antecubital vein of the right arm. A blood sample was taken from the abdominal aorta before the infusion. Ten minutes after the infusion had been started, samples were taken from the aorta, the hepatic vein and the antecubital vein of the left arm. In the following 10 minutes, a second and third series of samples were taken simultaneously from the aorta, the antecubital vein and a renal vein, first from one kidney and then from the other. A sample from the femoral vein was taken shortly before discontinuation of the infusion. The arterial plasma levels of 125 I-ANG I, 125I-ANG II, ANG I and ANG II remained constant between 8 and 20 min after the start of the infusion (coefficient of variation $<4 \%$ ). For measuring the elimination half life of 125I-ANG I and infused ANG I, samples were taken from the antecubital vein or from the aorta at approximately $0.5,1,2,3$ and $4 \mathrm{~min}$ after the infusion had been stopped. After the last blood sample had been collected the radiocontrast injection for renal angiography was given.

The two subjects studied some months after renal vein catheterization received an i.v. infusion of ${ }^{125 I-A N G ~} \mathrm{I}$ and ANG $\mathrm{I}$ in one arm, and blood samples were taken from the brachial artery and the antecubital vein of the other arm before the infusion and at 10,15 and $20 \mathrm{~min}$ after the start of the infusion. For measuring the elimination half life of the infused peptides, samples were taken from the brachial artery at the above mentioned times after the infusion had been stopped.

Urinary excretion of radioactivity was followed over a period of 96 hours. Ninety percent of the administered radioactivity was excreted within 24 hours and 98 percent was recovered in the 96 hour period. The calculated exposure to radioactivity was $0.24 \mu \mathrm{Gy}$ (or $0.6 \mathrm{mRad}$ ) from the ${ }^{125}$-ANG I infusion and $12 \mu \mathrm{Gy}$ (or $30 \mathrm{mRad}$ ) from the ${ }^{131}$ I-hippurate infusion (24). The protocol was approved by the Hospital Ethical Review Committee.

\section{Calculations}

The regional extraction ratio of 125 I-ANG I was calculated as follows: 
$\mathrm{ER}=1-\left[{ }^{125} \mathrm{I}-\mathrm{ANG} \Pi\right]_{\text {ven }} /\left[{ }^{125} \mathrm{I}-\mathrm{ANG}\right]_{\text {art }}$

The same formula was used for the calculation of the extraction ratio of infused ANG I. In this case the plasma level of ANG I before infusion was subtracted from the level during infusion.

The venous plasma level of ANG I derived from de novo regional production was calculated as follows:

$[\mathrm{ANG} \mathrm{I}]_{\text {ven }}$ from de novo production $=[\mathrm{ANG} \mathrm{I}]_{\mathrm{ven}}-(1-\mathrm{ER}) \cdot[\mathrm{ANG} \mathrm{I}]_{\text {art }}$

For the renal vascular bed it was possible to calculate the net de novo production rate of ANG I because we determined not only the renal extraction ratio of 125 I-ANG I and the renal arteriovenous difference in endogenous ANG I but also the renal extraction ratio and clearance of ${ }^{131}$ I-hippurate. The renal extraction ratio of 131 I-hippurate was calculated as follows:

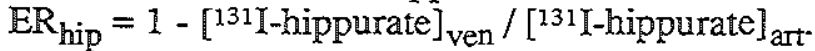

$\mathrm{ER}_{\text {hip }}$ was $0.72 \pm 0.02$ for the left kidney and $0.75 \pm 0.03$ for the right kidney ( $\mathrm{p}>0.05$ ). If it is assumed that the renal plasma flow is equal on both sides, the single kidney plasma flow can be calculated as follows:

Single kidney plasma flow $=$

clearance of ${ }^{131}$ I-hippurate/(ER hip left $\left.+E R_{\text {hip right }}\right)$.

The single kidney net de novo production of ANG I is then obtained by multiplication of single kidney plasma flow by the renal venous plasma level of intrarenally de novo produced ANG I.

\subsection{Results}

\section{HPLC separation of angiotensin peptides}

Under the conditions specified in Methods, satisfactory separations were obtained between ANG I, ANG II and their metabolites as well as their radiolabeled counterparts (Fig. 1). Apart from the metabolites shown in Fig. 1, we also tested 125I-ANG-(1-4) and ${ }^{125}$ I-ANG-(1-7). These metabolites had a retention time of approximately $4 \mathrm{~min}$. Assessment of injection to injection and day to day variability of the retention times of 125 I-ANG I and 125I-ANG II demonstrated excellent stability of the chromatographic conditions. Separation patterns for radiolabeled angiotensins of plasma extracts from patients who had received an intravenous infusion of ${ }^{125} \mathrm{I}-\mathrm{ANG}$ I showed four peaks with retention times of 4.2,9.9,13.0 and $16.2 \mathrm{~min}$ (Fig. 2). Until now, the material in the first peak has not been identified. The other peaks were $125 \mathrm{I}$-ANG $\mathrm{I}$, ${ }^{125}$ I-ANG (2-10) and ${ }^{125}$ I-ANG I . The retention times of ${ }^{125}$ I-ANG I and 125IANG II differed from the retention times of any of the metabolites we tested, and the difference was sufficient to obtain adequate separations. 


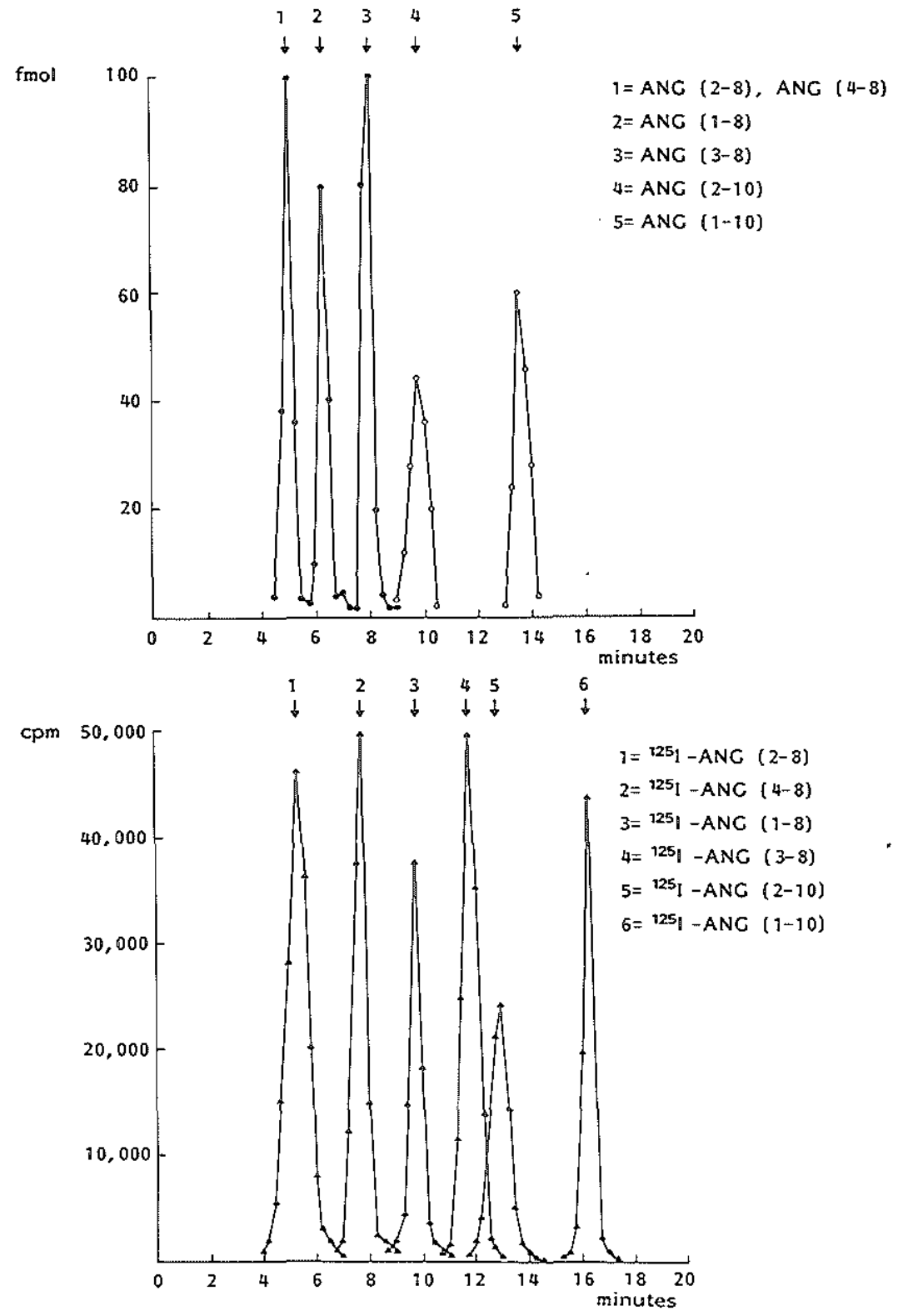

Figure 1. Line graph showing separation of standard angiotensin peptides (upper panel) and ${ }^{125}$ I-labeled angiotensin peptides (lower panel) by reversed phase high performance liquid chromatography. Detection by radioimmunoassay with angiotensin I antiserum (peaks 4 and 5) or with angiotensin II antiserum (peaks 1-3) (upper panel) or by gamma counting (lower panel). 


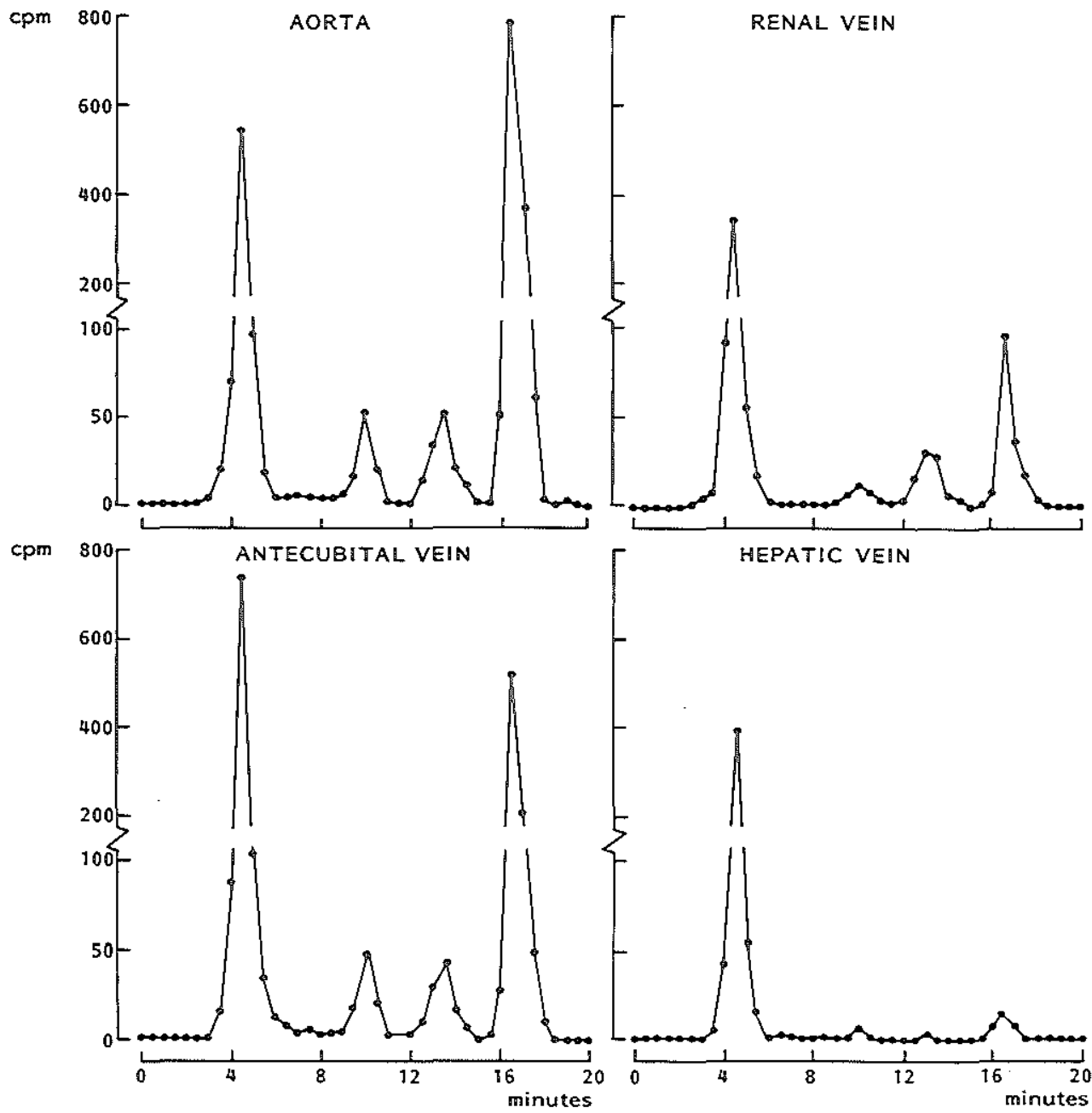

Figure 2. Line graph showing HPLC separation of ${ }^{125} \mathrm{I}$-labeled angiotensins in plasma of subject who received a constant intravenous infusion of 125 I-ANG I. Stationary and mobile phases as described under Fig. 1. Detection by gamma counting. Peaks with retention times of $9.9,13.0$ and 16.2 min correspond with ${ }^{125}$ I-ANG (1-8) $={ }^{125}$ I-ANG II, ${ }^{125}$ I-ANG $(2-10)$ and ${ }^{125}$ I-ANG $(1-10)=125$ I-ANG I respectively. Material in the first peak with a retention time of $4.2 \mathrm{~min}$ was not identified. 
Table 1. Plasma levels of 125 I-ANG I, ANG I and plasma renin activity during constant intravenous infusion of both 125 I-ANG I and ANG I.

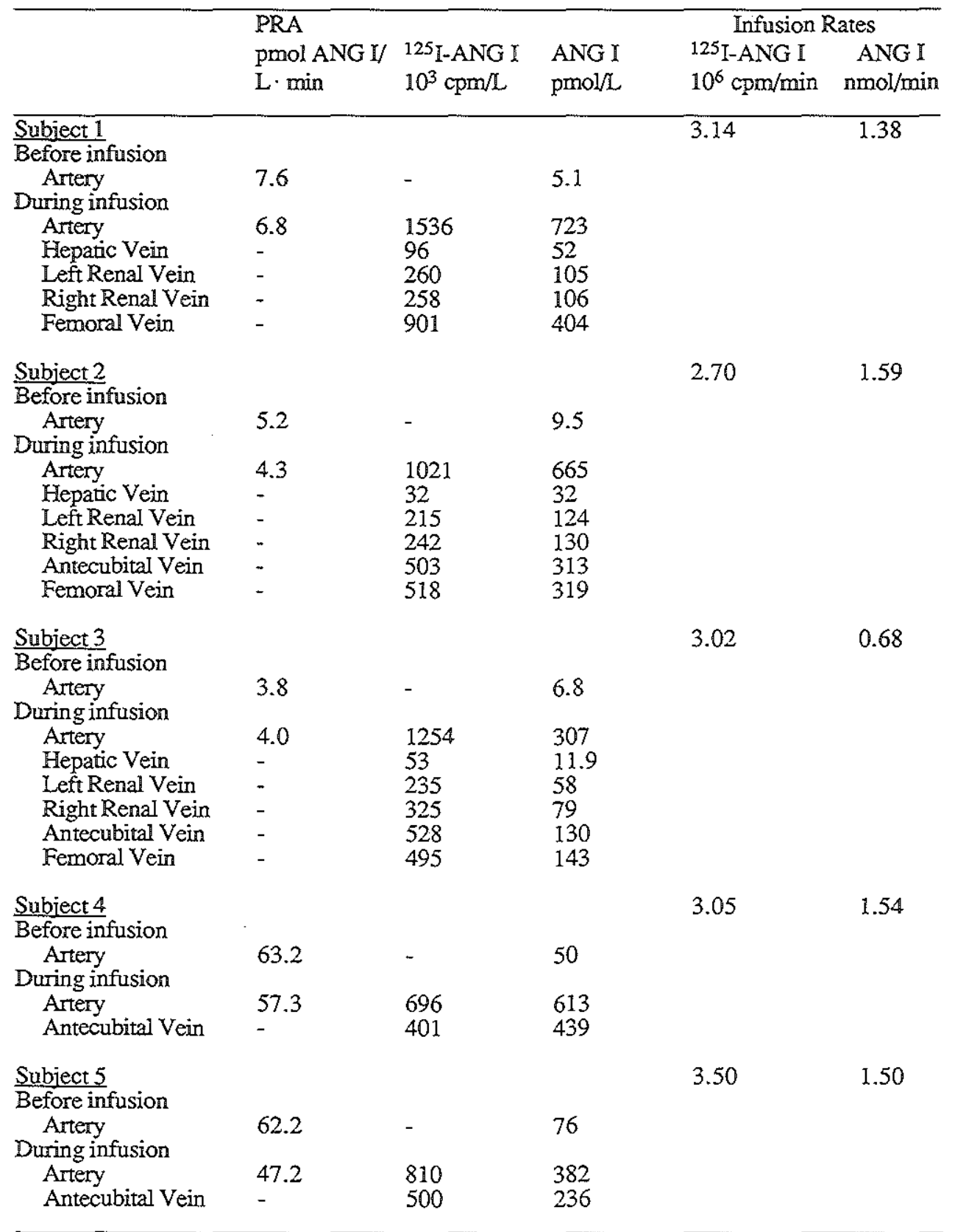

In subjects 1-3, "Artery" is the abdominal aorta. In subjects 4-5, "Artery" is the brachial artery. 


\section{Regional extraction of angiotensin I}

An important question is whether or not the rate of metabolism of $125 \mathrm{I}-\mathrm{ANG}$ I in our subjects differed from the metabolism of unlabeled ANG I. To answer this question unlabeled ANG I was infused together with ${ }^{125}$ I-ANG I. Results obtained with these combined infusions are summarized in Table 1. Because of ACE inhibitor treatment, the infusions of ANG I did not result in a significant reduction of PRA. The preinfusion level of ANG I was therefore taken as a measure of the contribution of endogenous ANG I to the level of ANG I during infusion of this peptide. Thus, for calculation of the regional extraction of infused ANG I, the preinfusion level of ANG I was subtracted from the level during infusion. From measurements of the arterial and venous plasma levels of $125 \mathrm{I}-\mathrm{ANG} I$ and unlabeled ANG $I$ it appeared that, during infusion of the two peptides, the regional extraction ratios for labeled and unlabeled ANG I were not different (Fig. 3). In most patients the plasma concentrations of $125 \mathrm{I}$ ANG I and unlabeled ANG I fell mono-exponentially after discontinuation of the infusion. Some curves, however, showed a delay. This delay can be explained, at least in part, by the passage time of blood from the infusion site to the sampling site but the delay could also represent the exit of 125 I-ANG I and ANG I from tissue sites. Estimates of the elimination half life of ${ }^{125}$ I-ANG I and ANG I were therefore made from the steepest straight portion of the decay curves and the results were not different for the two peptides (Fig. 4). The estimated elimination half life of 125 I-ANG I, which was determined in all subjects, was $0.73 \pm 0.06 \mathrm{~min}$ (mean $\pm \mathrm{SEM}$ ).

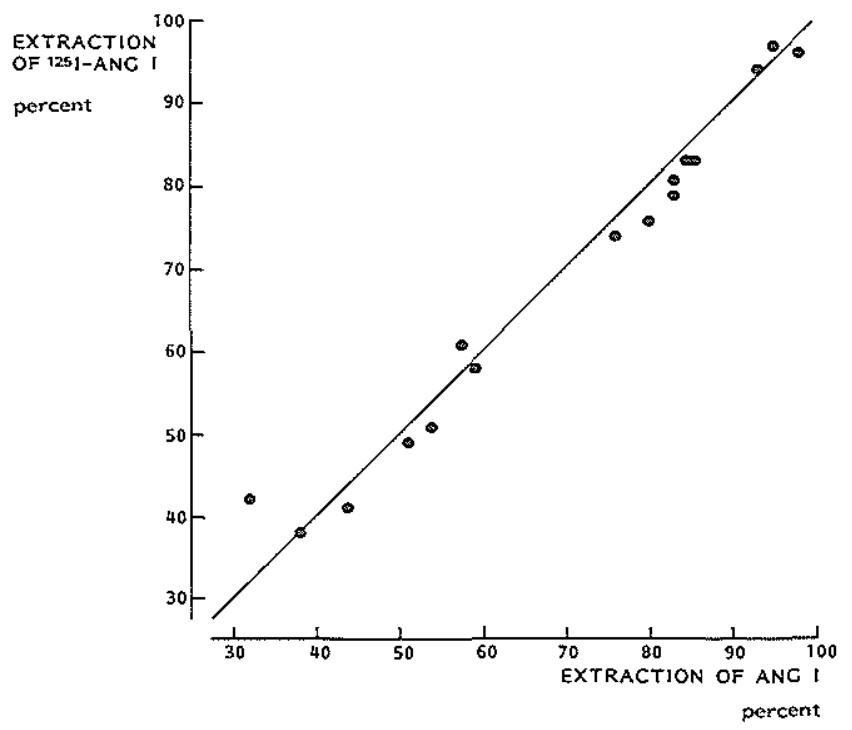

Figure 3. Scatter plot showing comparison of the regional extraction of ${ }^{125} \mathrm{I}-\mathrm{ANG}$ I with that of ANG I during constant intravenous infusion of the two peptides in five subjects. Data are expressed as percentage of arterial plasma concentration. 
Table 2. Arterial and venous plasma levels of angiotensins in seven hypertensive subjects during constant intravenous infusion of 125 I-ANG I.

\begin{tabular}{|c|c|c|c|c|}
\hline Sampling site & $\begin{array}{l}125 \mathrm{Y}-\mathrm{ANG} \mathrm{I} \\
10^{3} \mathrm{cpm} / \mathrm{L}\end{array}$ & $\begin{array}{l}\text { ANG I } \\
\mathrm{pmol} / \mathrm{L}\end{array}$ & $\begin{array}{c}125 \mathrm{I}-\mathrm{ANG} \mathrm{II} \\
10^{3} \mathrm{cpm} / \mathrm{L}\end{array}$ & $\begin{array}{l}\text { ANG II } \\
\mathrm{pmol} / \mathrm{L}\end{array}$ \\
\hline & 335) & 142) & 133( & 2.1 \\
\hline ubital vein & $341 *(234$ & 34.10 & $114^{*}(72-199)$ & 2.3 \\
\hline al vein & $123 *(62-225)$ & $33.0(9.0-124)$ & $23^{*}(14-33)$ & $0.8 *(0.4-1.5)$ \\
\hline renal vein & $129 *(61-191)$ & $31.7(9.1-120)$ & $21 * \quad(11-38)$ & $0.8 *(0.4-1.9)$ \\
\hline Femoral vein & $265^{*}(158-617)$ & $33.9(7.8-134)$ & $109 *(62-199)$ & $1.8 \quad(0.8-4.3)$ \\
\hline Hepatic vein $(n=5)$ & $31 *(22-44)$ & $17.2 *(4.9-59)$ & $5^{*} \quad(2-7)$ & $0.4 *(0.2-0.6)$ \\
\hline
\end{tabular}

125 I-ANG I infusion rate was $3.28(2.46-4.31) \times 10^{6} \mathrm{cpm} / \mathrm{min}$. Values are geometric mean (range). * significantly different from corresponding aortic levels $(p<0.02)$, Wilcoxon signed rank test.

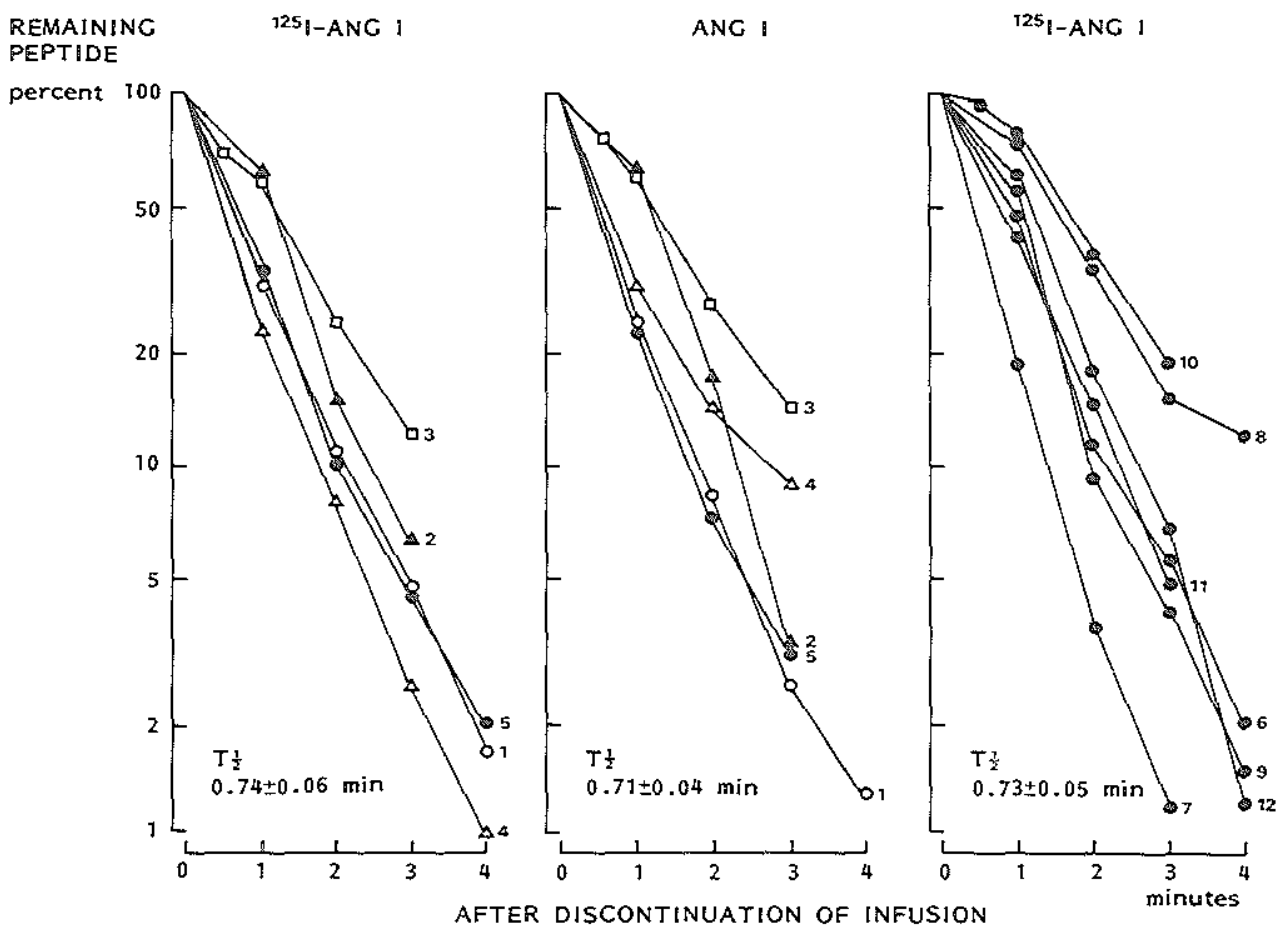

Figure 4. Line graphs showing in vivo elimination of ${ }^{125}$ I-ANG I and ANG I after discontinuation of a constant intravenous infusion of both 125I-ANG I and ANG I (left and middle panel) or a constant intravenous infusion of ${ }^{125}$ I-ANG I only (right panel). Plasma ANG I levels in the middle panel were corrected for preinfusion ANG I levels. Each patient in Ieft and middle panel is denoted by a different symbol and number. Numbers in these panels refer to subjects in Table 1. Blood was sampled from the aorta in subjects $1,3,6$ and 7, from the brachial artery in subjects 4 and 5 , or from the antecubital vein in subjects 2 and 8-12. 
PRA and angiotensin levels vary widely among subjects with essential hypertension. This was also the case in our study. PRA in the aorta ranged from $3.8-122 \mathrm{pmol} / \mathrm{L} \cdot \min$. The plasma levels of ${ }^{125} \mathrm{I}-\mathrm{ANG}$ I and II and endogenous ANG $I$ and II in the aorta and in the veins of the kidneys, forearm, leg and liver during infusion of $125 \mathrm{I}$-ANG I, are presented in Table 2.

Regional extraction of arterially delivered $125 \mathrm{I}-\mathrm{ANG}$ I was not influenced by the infusion of unlabeled ANG I (Fig. 5). The extraction ratio of 125 I-ANG I was $80 \pm 2 \%$ for the right kidney, $82 \pm 1 \%$ for the left kidney, $47 \pm 4 \%$ for the forearm, $59 \pm 3 \%$ for the leg and $96 \pm 1 \%$ for the hepatomesenteric vascular bed. We did not measure the ${ }^{125}$ I-ANG I levels in mixed venous plasma but an approximation was made by assuming an overall extraction of systemically delivered ${ }^{125}$ I-ANG I of $60 \%$. The mixed venous level upstream from the site where the infused 125I-ANG I enters the central venous compartment can then be obtained by dividing the infusion rate by the cardiac output, which was taken to be $3 \mathrm{~L}$ plasma per minute per $1.73 \mathrm{~m}^{2}$ body surface area, and by adding to this quotient $40 \%$ of the arterial level of ${ }^{125 I}$ ANG I. In this way it was caIculated that approximately $30-40 \%$ of the ${ }^{125}$ IANG I delivered to the cardiopulmonary circulation was extracted by this vascular bed. From this and from a systemic extraction of $60 \%$ a whole body extraction of about $75 \%$ can be calculated. Because of this high extraction rate, the "true" half life of ANG I in the body must be shorter than the whole body transit time of blood (about $0.5 \mathrm{~min}$ ). The "true" half life of ANG I must therefore be shorter than the half life $(0.73 \mathrm{~min})$ we estimated from the plasma 125I-ANG I and ANG I decay curves after the infusion of these peptides had been stopped. This difference again may represent the exit of ${ }^{125 I-A N G ~ I ~ a n d ~}$ ANG I from tissue sites.

\section{Regional angiotensin I-II conversion}

We did not measure the ${ }^{125}$ I-ANG II levels in mixed venous plasma, but they are likely to be lower than in aortic plasma, because the 125I-ANG II levels we measured in the renal, antecubital, femoral and hepatic veins were lower than in the aorta (Table 2) and because observations in animals demonstrated extraction of ANG II in the circulation of the head (1). One may therefore assume that $125 \mathrm{I}$-ANG I-II conversion had occurred in the cardiopulmonary region, presumably the lungs, despite the fact that our subjects were on $\mathrm{ACE}$ inhibitor treatment. Since the extraction of ${ }^{225}$ I-ANG II by the various vascular beds was not measured, it was not possible to calculate the degree of 125 I-ANG I-II conversion in these regions.

\section{Regional production of angiotensin I}

In spite of the rapid extraction of arterially delivered ANG I, the arterial and venous plasma levels of endogenous ANG I across the kidneys and the limbs 
showed little difference (Fig. 5). The vein-to-artery ANG I concentration ratio was $0.98 \pm 0.05$ across the kidneys, $1.01 \pm 0.03$ across the forearm, and $1.00 \pm$ 0.03 across the leg. ANG I concentration in the hepatic vein was lower than in the aorta. The vein-to-artery ANG I concentration ratio across the hepatomesenteric vascular bed was $0.52 \pm 0.03$. From these data and from the regional extraction ratio of ANG I, the venous concentration of ANG I derived from regional de novo production could be calculated. Figure 6 clearly illustrates the point that a high proportion of venous ANG I originated from regional de novo production. For the renal vascular bed it was possible to calculate the net de novo production rate of ANG I because renal plasma flow was measured. Single kidney plasma flow was $0.283 \pm 0.020 \mathrm{~L} / \mathrm{min}$ and single kidney net de novo production of ANG I was calculated to be $7.1 \mathrm{pmol} / \mathrm{min}$ (geometric mean), range $2.4-29.5 \mathrm{pmol} / \mathrm{min}$.

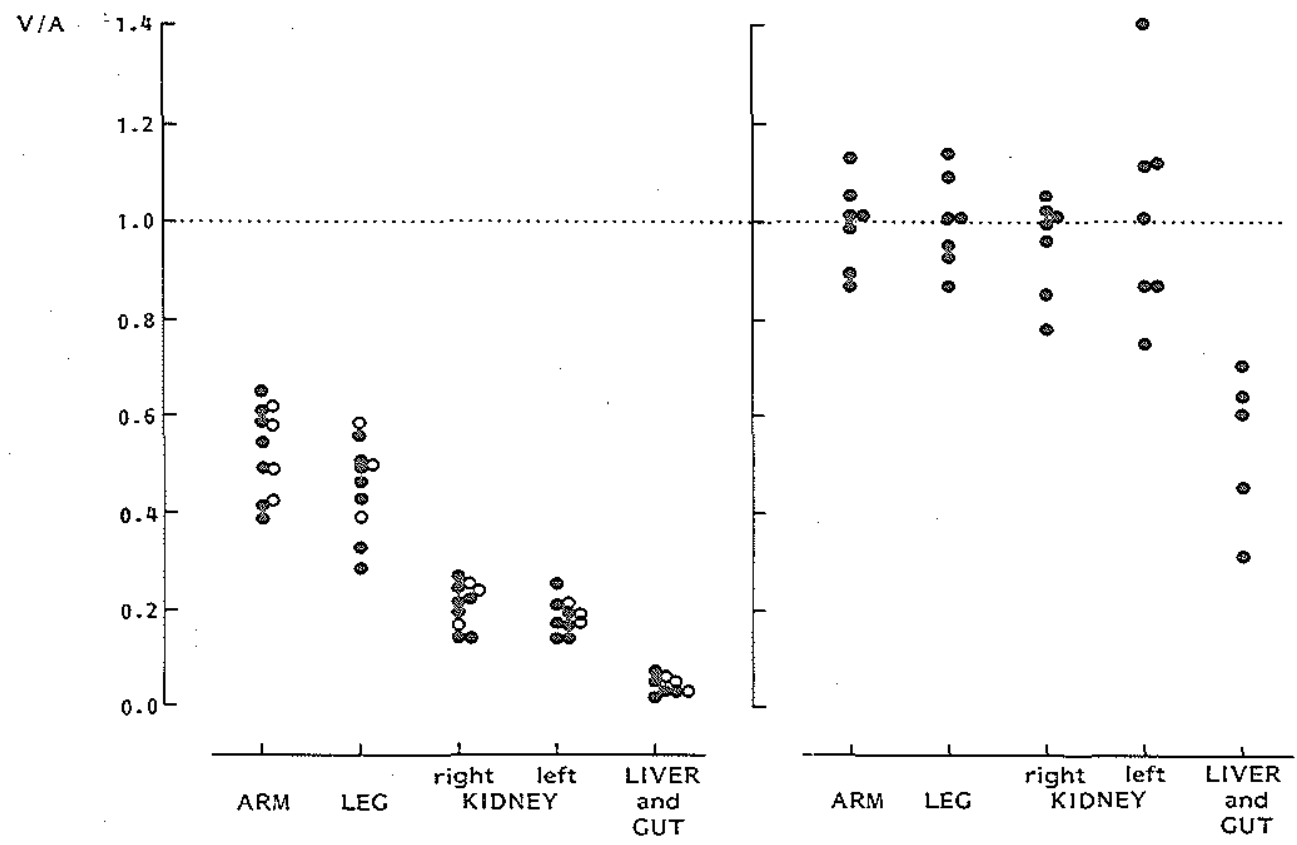

Figure 5. Scatter plots showing vein-to-artery ratios of ${ }^{125}$ I-ANG I (left panel) and endogenous ANG $\mathbb{I}$ (right panel) across various vascular beds during constant i.v. infusion of ${ }^{125} \mathrm{I}$-ANG I. Open circles represent data obtained during infusion of both $125 \mathrm{I}-\mathrm{ANG}$ I and ANG I. 


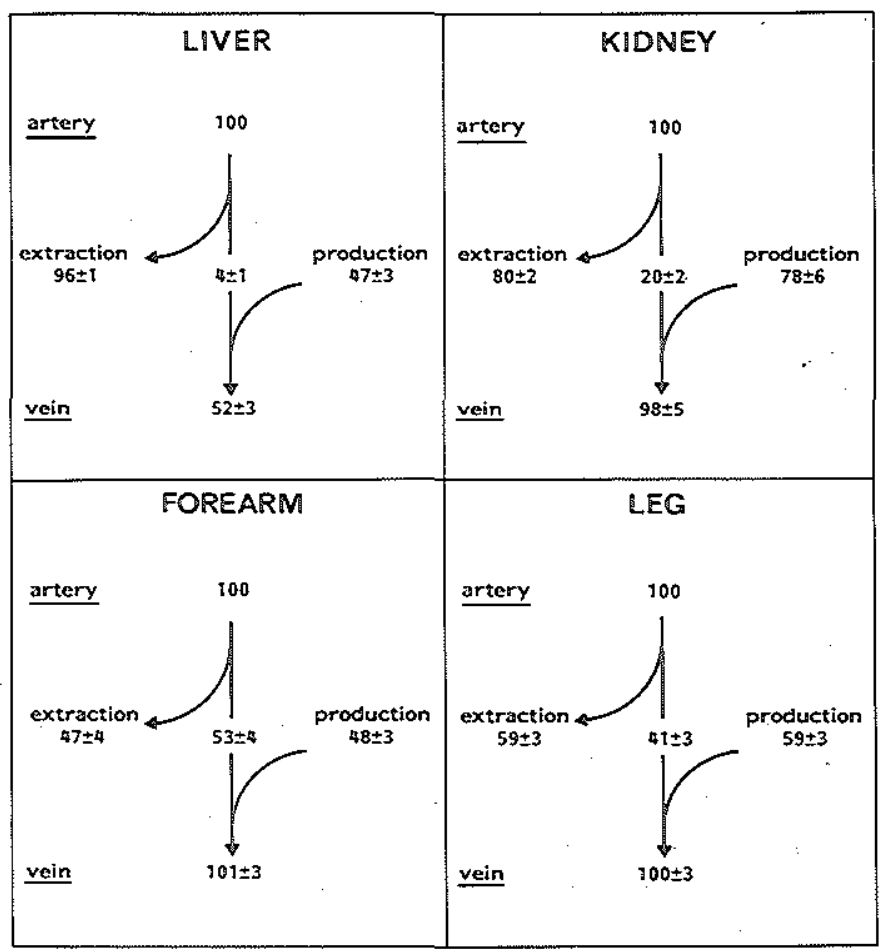

Figure 6. Schematic drawing showing regional venous plasma concentration of ANG I originating from de novo production of ANG $I$ in various vascular beds. Data (mean \pm SEM) are expressed as a percentage of the arterial plasma concentration of ANG I.

Table 3. Contribution of plasma renin activity to venous levels of ANG I in seven hypertensive subjects.

\begin{tabular}{|c|c|c|c|c|}
\hline . & Kidney & Forearm & Leg & Liver and Gut* \\
\hline Mean blood transit time (min) & 0.17 & 0.17 & 0.17 & 0.42 \\
\hline Anterial PRA (pmol ANG $\mathrm{L} / \mathrm{L} \cdot \min$ ) & $24.0(7.3-117)$ & $24.2(6.7-122)$ & $24.5(8.9-119)$ & $\begin{array}{l}\text { see under } \\
\text { 'Forearm' }\end{array}$ \\
\hline Venous PRA (pmol ANG $I / L \cdot \min )$ & $30.6(7.3-211)$ & $25.1(7.2-119)$ & $26.3(8.1-135)$ & $23.0(6.2-82)$ \\
\hline $\begin{array}{l}\text { Venous ANG I originating from de novo } \\
\text { production (pmol/L) }\end{array}$ & $25.7(7.4-102)$ & $16.1(4.3-63)$ & $20.0(4.9-71)$ & $15.8(4.5-53)$ \\
\hline $\begin{array}{l}\text { Venous ANG I produced by circulating } \\
\text { PRA (pmol/L) } \\
\text { \% of de novo produced ANG I }\end{array}$ & $\begin{array}{l}5.3(1.3-33) \\
21 \pm 3\end{array}$ & $\begin{array}{l}4.2(1.2-20) \\
27 \pm 3\end{array}$ & $\begin{array}{l}4.1(1.1-18) \\
22 \pm 3\end{array}$ & $\begin{array}{l}8.9(2.5-42) \\
62 \pm 9\end{array}$ \\
\hline
\end{tabular}

Values are geometric mean (range) or mean \pm SEM. Mean blood transit times are from the literature $(25,26)$. Three arterial samples were collected from the abdominal aorta during the steady state phase: sample 1 simultaneously with the antecubital vein and hepatic vein samples, sample 2 simultaneously with a left or a right renal vein sample, and sample 3 simultaneously with a renal vein sample on the opposite site. The femoral vein sample was taken immediately after aortic sample 3. The left and right renal vein levels of PRA and ANG I were averaged as were the two corresponding aortic levels of PRA. * $n=5$. 
The mean transit time of blood is $0.1-0.2 \mathrm{~min}$ in the kidneys and the limbs and $0.3-0.5 \mathrm{~min}$ in the hepatomesenteric vascular bed $(25,26)$. From this and the measured levels of PRA, we can calculate the contribution of circulating PRA to the total regional production of ANG I. In the classical concept of the renin-angiotensin system circulating renin should fully account for this production. The calculations, however, showed that circulating PRA only accounted for less than $20-30 \%$ of ANG I production in the kidneys, the forearm and the leg. In the hepatomesenteric vascular bed circulating PRA accounted for about $60 \%$ of the ANG I production in this region (Table 3).

\subsection{Discussion}

Circulating ANG I and ANG II are rapidly metabolized by the action of peptidases. ANG I is converted to what is considered to be the most important biologically active endproduct of the renin-angiotensin system, ANG II. Both ANG I and ANG II are degraded into smaller inactive peptides. The term "metabolism" is used here to denote both conversion and degradation. There are very few reports on measurements of ANG I metabolism in intact animals $(13,14,27)$, and we are not aware of any such data in humans.

The present study addressed the question whether in humans the rate at which ANG I is generated by the reaction of circulating renin with circulating renin substrate, is sufficiently high to maintain the actual plasma level of ANG I in the face of the rapid metabolism of this peptide. We studied ANG I metabolism in different vascular beds by measuring the extraction of arterially delivered 125I-ANG I during constant intravenous infusion of this peptide. Again, the term "extraction" includes the processes of conversion and degradation. In our hypertensive subjects on captopril treatment the regional extraction of ${ }^{125}$ I-ANG I by the kidneys, the limbs and the hepatomesenteric vascular bed was not different from the extraction of simultaneously infused unlabeled ANG I. Also, the plasma decay curves after discontinuation of the 125I-ANG I and ANG I infusions, were very similar. This supports the validity of using our measurements of 125I-ANG I metabolism for estimation of the metabolism and production of endogenous ANG I, at least in subjects on ACE inhibitor treatment. With such treatment, ANG I metabolism is mainly due to degradation into smaller inactive fragments. Apparently there is little or no difference in the rate of degradation between labeled and unlabeled ANG I. Whether the conversion rates of the two peptides are also similar has to be established by measurements in subjects not on ACE inhibitor treatment.

Extraction of arterially delivered ANG I by the vascular beds we studied ranged from 47 to $96 \%$. The plasma levels of ACE and angiotensinase activity are by far too low to account for the rapid removal of ANG I. Thus, it 
appears that most of ANG I metabolism takes place at the surface of blood vessels or in the vascular tissue. In studies in dogs, ${ }^{125}$ I-ANG I was infused into the renal artery and it was found that about $80 \%$ was removed during a single passage of blood through the kidney (13). This was for the most part due to degradation rather than conversion. Our results in humans are in agreement with these data.

From the regional extraction ratios of ANG I and from the arteriovenous differences in ANG I it was calculated that approximately 50 - $90 \%$ of ANG I in the regional veins was not derived from arterially delivered ANG I but from regional de novo production. In the dog it was found that $70-80 \%$ of ANG I in the renal veins was derived from de novo production in the kidney (13), which is similar to what we found for the human kidney.

With the exception of the hepatomesenteric vascular bed, where the plasma level of ANG I in the hepatic vein was found to be much lower than in the aorta, there was little or no arteriovenous difference in ANG I. Thus, the rapid removal of plasma ANG I was matched by a high rate of production. By taking into consideration the blood transit time in the various vascular beds, one can easily see that circulating levels of PRA were not sufficient to account for this high rate of ANG I production. The mean transit time of blood in the kidneys and the limbs is $0.1-0.2 \mathrm{~min}$ or less $(25,26)$. From this and from the measurements of PRA, the extraction of arterially delivered ANG I and the arteriovenous difference in the plasma levels of ANG I, it was calculated that less than $20-30 \%$ of ANG I produced in the kidneys, the forearm and the leg could be accounted for by the generation of ANG I by circulating PRA (Table $3)$. For the renal vascular bed it was possible to calculate the net de novo production rate of ANG I, because renal plasma flow was known. The single kidney intravascular plasma volume is approximately $40 \mathrm{~mL}$ (25). From this and from the level of PRA in the renal vein it was calculated that less than 10 $\%$ of ANG I produced in the kidney could be accounted for by circulating PRA. The calculated contribution of PRA is a maximum value, because it is quite likely that part of regionally produced ANG I is metabolized before it can reach the veins. The blood transit time in the hepatomesenteric vascular bed is $0.3-0.5 \mathrm{~min}(26)$, and in this region the $A N G$ I production could be largely accounted for by circulating PRA.

The conclusion of this study, that a high proportion of ANG I in plasma appears not to be generated by the action of circulating renin on circulating renin substrate, depends on the validity of using PRA in vitro as a precise measure of the generation of ANG I by plasma in vivo. We therefore performed the PRA assay at near physiological $\mathrm{pH}$ under conditions that did not cause denaturation of renin, activation of prorenin and conversion and degradation of ANG I and did not interfere with the reaction of renin with its substrate.

From the data presented in Table 2 it is evident that a discrepancy exists between the ${ }^{125}$ I-ANG I/ 125 I-ANG II and ANG I/ANG II ratios. One 
possibility might be that the ${ }^{125} \mathrm{I}-\mathrm{ANG}$ II peak is contaminated by some metabolite. We are confident, however, that the $125 \mathrm{I}-\mathrm{ANG}$ II peak is not contaminated by the possible aminopeptidase breakdown products, $125 \mathrm{I}$-ANG-

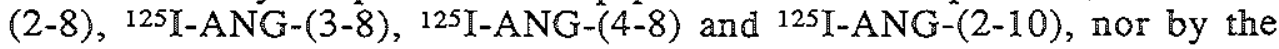
prolyl- or neutral-endopeptidase breakdown products, ${ }^{125}$ I-ANG-(1-4) and 125I-ANG-(1-7). However, we did not measure the retention time of ${ }^{125}$ I-ANG(1-9), a possible product of carboxypeptidase attack on ${ }^{125}$ I-ANG $\mathrm{I}$. We did not observe any heterogeneity in the 125I-ANG II peak when plasma samples were analyzed under different chromatographic conditions, also indicating that $125 \mathrm{I}$ ANG II was the only radiolabeled peptide in this peak. Because we did not compare the rates of metabolism of $125 \mathrm{I}$-ANG II and ANG II, our study only provides semi-quantitative information of ANG I-II conversion in the various vascular beds. At any rate our, measurements of the arterial and venous plasma concentrations of $125 \mathrm{I}$-ANG I and 125I-ANG II indicate that, despite ACE inhibitor treatment, ANG I-II conversion had occurred in the cardiopulmonary vascular bed, presumably the lungs.

The results of the present study add new evidence to previously published data supporting the hypothesis that a major fraction of ANG I in circulating plasma is produced locally rather than in circulating plasma itself. The local production of ANG I may depend on synthesis of renin in situ. Binding or uptake of plasma renin or prorenin and subsequent activation of prorenin and local production of ANG I are other possibilities. Whatever the exact mechanism, vascular production of ANG I may contribute to the control of vascular tone and this contribution may be independent, at least in part, of the circulating levels of renin and renin substrate.

\subsection{References}

1. Campbell DI. The site of angiotensin production. J Hypertens 3: 199-207, 1985.

2. Campbell DI. Circulating and tissue angiotensin systems. $J$ Clin Invest 79: $1-6,1987$.

3. Fei DTW, Scoggins BA, Tregear GW, Cochlan JP. Angiotensin I, II and II in sheep. A model of angiotensin production and metabolism. Hypertension 3: 730-737, 1981.

4. Beboben A, Inagami T, Ganten D. Tissue renin. In: Hypertension: Physiopathology and Treatment, edited by Genest J, Kuchel O, Hamet $P$ and Cantin M. McGraw-Hill, New York 1983, pp. 194-209.

5. Dzau VJ. Vascular renin-angiotensin: a possible autocrine or paracrine system in control of vascular function. $J$ Cardiovasc Pharmacol 6 (suppl 2): S377-S382, 1984.

6. Kifor I, Dzau VJ. Endothelial renin-angiotensin pathway: evidence for intracellular synthesis and secretion of angiotensins. Circ Res 60: 422-428, 1987.

7. Nakamaru M, Jackson EK, Inagami T. B-Adrenoceptor-mediated release of angiotensin II from mesenteric arteries. Am J Physiol 250: H144-H148, 1986.

8. Mizuno $K$, Nakamaru M, Higashimori $K$, Inagami $T$. Local generation and release of angiotensin $\mathbb{I}$ in peripheral vascular tissue. Hypertension 11:223-229, 1988.

9. Swales ID. Arterial wall or plasma renin in hypertension. Clin Sci 56: 293-298, 1979.

10. Thurston H, Swales JD, Bing RF, Hurst BC, Marks ES. Vascular renin-like activity and blood pressure maintenance in the rat. Hypertension 1: 643-649, 1979. 
11. Dzau VJ. Significance of the vascular renin-angiotensin pathway. Hypertension 8: 553-559, 1986.

12. Okamura $T$, Miyazaki $M$, Inagami $T$, Toda $N$. Vascular renin-angiotensin system in two-kidney, one clip hypertensive rats. Hypertension 8: 560-565, 1986.

13. Rosivall L, Rinder DF, Champion J, Khosla MC, Navar LG, Oparil S. Intrarenal angiotensin I conversion at normal and reduced blood flow in the dog. Am J Physiol 245: F408-F415, 1983.

14. Navar LG, Rosivall L, Carmines PK, Oparil S. Effects of locally formed angiotensin II on renal hemodynamics. Federation Proc 45: 1448-1453, 1986.

15. Gunther S, Gimbrone MA, Alexander RW. Identification and characterization of the high affinity vascular angiotensin II receptors in rat mesenteric arteries. Circ Res 47: 278-286, 1980.

16. Husain A, Pajka SF, Taylor SM, Speth RC. Mono-iodinated angiotensin II is a potent, full agonist analog of angiotensin II. $J$ Pharm Exp Ther 239: 71-77, 1986.

17. Wood JM, Gulati N, Forgiarini P, Fuhrer W, Hofbauer KG. Effects of a specific and long acting renin inhibitor in the marmoset. Hypertension 7: 797-803, 1985.

18. Nussberger J, Brunner DB, Waeber B, Brunner HR. True versus immunoreactive angiotensin II in human plasma. Hypertension 7 (suppl I): 1-7, 1985.

19. Derkx FHM, Stuenkel C, Schalekamp MPA, Visser W, Huisveld IH, Schalekamp MADH. Immunoreactive renin, prorenin, and ezymatically active renin in plasma during pregnancy and in women taking oral contraceptives. $J$ Clin Endocrinol Metab 63: $1008-1015,1986$.

20. Poulson $\mathrm{K}$, Jorgensen $\mathrm{J}$. An easy radioimmunological microassay of renin activity, concentration and substrate in human and animal plasma and tissues based on angiotensin I trapping by antibody. J Clin Endocrinol Metab 39: 816-825, 1974.

21. Nussberger J, Brunner DB, Waeber B, Brunner HR. Specific measurement of angiotensin metabolites and in vitro generated angiotensin $I$ in plasma. Hypertension 8: 476-482, 1986.

22. Wenting GJ, Tan-Tjiong HL, Derkx FHM, de Bruyn JHB, Man in 't Veld AJ, Schalekamp MADH. Split renal function after captopril in unilateral renal artery stenosis. Br Med J 288: 886-890, 1984.

23. Greenwood FC, Hunter WM, Glover IS. The preparation of 131 I-labelled human growth hormone of high specific radioactivity. Biochem $J$ 89: 114-123, 1963.

24. Radiation protection, ICRP publication 17, Protection of the patient in tadionuclide investigations. Pergamon Press, Oxford 1971 pp. 42-47.

25. Ladefoged J, Pedersen F. Renal blood flow, circulation times and vascular volume in normal man measured by the intra-arterial injection-external counting technique. Acta Physiol Scand 69: 220-229, 1967.

26. Wegener OH. In: Whole Body Computerized Tomography, edited by Karger S. New York 1981, pp. 4.32-4.35.

27. Fernley RT, Coghlan JP, Cran EJ, Fei TW, Scoggins BA, McGregor A. Conversion of angiotensin I to angiotensin II in sheep. Clin Exp Pharmacol Physiol 5: 439-448, 1978. 



\section{METABOLISM OF ANGIOTENSIN \\ I BY DIFFERENT TISSUES IN THE INTACT ANIMAL}

\subsection{Summary}

To quantify in the intact animal the regional conversion of angiotensin (ANG) I to ANG II and its degradation to peptides other than ANG II, mono-iodinated 125I-ANG I (alone and in combination with unlabeled ANG I) was given to anesthetized pigs by constant infusion into the left cardiac ventricle. Blood samples were taken to measure the plasma levels of ${ }^{125}$ I-ANG I, ${ }^{125}$ I-ANG II, ANG I and ANG II. Sampling sites were: aorta, right and left atrium, pulmonary artery, great cardiac vein and femoral, renal, jugular and ear lobe veins. The metabolic degradation rate in the various vascular beds was the same for ${ }^{125}$ I-ANG $I$ and ANG I, but the conversion rate was 2 times higher for ${ }^{125 I-A N G ~ I . ~ A N G ~ I ~ a p p e a r e d ~ t o ~ b e ~ d i s t r i b u t e d ~ o v e r ~ a ~ c o m p a r t m e n t ~ w i t h ~ a ~}$ size corresponding to $18-32$ (mean 24 ) $\%$ of total body weight. Whereas the vein/artery ${ }^{125}$ I-ANG I ratios across the systemic vascular beds were $<0.5$, the total radioactivity ratios were close to 1.0 , indicating that elimination of ${ }^{125}$ IANG I was due to rapid metabolism. After ACE inhibitor treatment, fractional ANG I metabolism (the fraction of arterially delivered ANG I that was metabolized during a single passage of blood) was $10 \%$ in the lungs (conversion $4 \%$ ), as compared to $56 \%$ in the combined systemic vascular beds (conversion $1 \%$ ). Fractional ANG I metabolism during ACE inhibition was 93 $\%$ in the kidney, 50-70\% in myocardium, skeletal muscle, head and skin, and $21 \%$ in the left and $14 \%$ in the right cardiac cavity. Without ACE inhibition, fractional ANG I metabolism was $29 \%$ in the lungs (conversion $25 \%$ ), $49 \%$ in the combined systemic vascular beds (conversion $10 \%$ ), $38 \%$ in the left cardiac cavity (conversion $11 \%$ ) and $14 \%$ in the right cardiac cavity (conversion $0 \%$ ). Thus, vascular beds other than the lungs make an important contribution to the conversion of circulating ANG I. ANG II formation in vivo appears to depend on ACE, but ANG I-II conversion does not seem to be a critical intermediary step in ANG I metabolism. Reduction of ANG I conversion by ACE inhibitor treatment does not cause significant ANG I accumulation. Our study shows that the rates of ANG I conversion and degradation in different tissues can be measured by using mono-iodinated 125IANG I as a tracer. The present results can serve as a basis for future measurements of regional ANG I production rates in the intact animal. 


\subsection{Introduction}

Angiotensin II (ANG II), the most important biologically active product of the renin-angiotensin system, is a powerful hypertensive agent. It acts on specific receptors in vascular smooth muscle, kidney, adrenal, brain and other tissues $(7,12,13)$. The ANG II that reaches these receptors is derived from angiotensin $I$ (ANG $I$ ), which is produced both in circulating blood and in the tissues $(1,3)$. To better understand the workings of the tissue renin-angiotensin systems, as opposed to the circulating renin-angiotensin system, it is essential to determine how ANG I is handled by the tissues. Arterially delivered ANG I is rapidly extracted from the circulation by the tissues, due to the hydrolytic attack by peptidases that degrade ANG I into smaller biologically inactive peptides or convert ANG I to ANG II. To date however few studies have been performed in intact animals to address this issue. In one such study ${ }^{125}$ I-labeled ANG I was infused into the renal artery of the dog to measure intrarenal ANG I degradation and ANG I-II conversion $(14,19)$. We administered 125I-ANG I, via systemic intravenous infusion, to subjects with essential hypertension who were being treated with the angiotensin converting enzyme (ACE) inhibitor captopril. We found that the extraction of 125 I-ANG I by the kidney, the leg, the forearm and the liver did not differ from the extraction of unlabeled native ANG I (1).

The aim of the present study was to examine further whether ${ }^{125}$ I-ANG I is a suitable tracer to assess the distribution of endogenous ANG I and to quantify ANG I-II conversion and ANG I metabolic degradation in the intact organism. For this purpose we administered 125I-ANG I, alone or in combination with unlabeled ANG I, via a constant infusion into the left cardiac ventricle of the pig and studied the whole body as well as the regional metabolism of the two peptides, both during $\mathrm{ACE}$ inhibitor treatment and without such treatment.

\subsection{Materials and methods}

\section{Chemicals}

[Ile5]-ANG-(1-10) decapeptide (ANG I), [Ile5]-ANG-(1-8) octapeptide (ANG II), and [Ile5]-ANG-(2-8) heptapeptide (ANG III) were obtained from Bachem, Bubendorf, Switzerland. [Ile5]-ANG-(2-10) nonapeptide (ANG-(2-10)) was from Senn Chemicals, Dielsdorf, Switzerland. [lle5]-ANG-(3-8) hexapeptide (ANG-(3-8)), [Ile5]-(4-8) pentapeptide (ANG-(4-8)), and [Ile5]-ANG-(1-7) heptapeptide (ANG-(1-7)) were from Peninsula Laboratories, Belmont, CA, USA. Methanol, ortho-phosphoric acid (both analytical grade) and 1,10phenantroline were from Merck, Darmstadt, Germany. Bovine serum albumin (BSA) was from Sigma, St. Louis, MO, USA. Water for high performance liquid chromatography (HPLC) was prepared with a Milli-Q system from 
Waters, Millford, MA, USA. The renin inhibitor Ro 42,5892 was a kind gift of Dr. P. van Brummelen (Hoffmann-La Roche, Basel, Switzerland).

\section{Preparation of radiolabeled angiotensins}

Mono-iodinated 125I-ANG I was prepared with the chloramine-T method and purified as described previously (5). ${ }^{125}$ I-labeled preparations of ANG II, ANG II, ANG-(3-8), ANG-(4-8), ANG-(2-10), ANG-(1-7) and tyrosine were also made.

\section{Separation of angiotensins by HPLC}

Angiotensins and their metabolites were extracted from plasma by reversible adsorption to octadecylsilyl silica (SepPak C18, Waters, Millford, MA, USA) and separated by reversed phase HPLC, according to the method of Nussberger et al (15) with some modifications (1). Separations were performed on a reversed phase Nucleosil C18 steel column of $250 \times 4.6 \mathrm{~mm}$ and $10 \mu \mathrm{m}$ particle size. Mobile phase A was $0.085 \%$ ortho-phosphoric acid containing $0.02 \%$ sodium azide. Mobile phase $\mathrm{B}$ was methanol. The flow was $1.5 \mathrm{~mL} / \mathrm{min}$ and the working temperature was $45^{\circ} \mathrm{C}$. SepPak plasma extracts were dissolved in 100 $\mu \mathrm{L}$ of HPLC solvent and injected. Elution was performed as follows: $65 \%$ $\mathrm{A} / 35 \% \mathrm{~B}$ from 0 to $6 \mathrm{~min}$ followed by a linear gradient to $45 \% \mathrm{~A} / 55 \% \mathrm{~B}$ until $12 \mathrm{~min}$. The eluate was collected in $20-\mathrm{sec}$ fractions into polystyrene tubes coated with BSA. The concentrations of 125 I-ANG I and its metabolites in the HPLC fractions were measured in the gamma counter. The fractions containing unlabeled ANG I and ANG II were neutralized with $0.5 \mathrm{M}$ sodium hydroxide and vacuum dried at $4{ }^{\circ} \mathrm{C}$. Recovery after HPLC separation alone was 90-95\% for both labeled and unlabeled ANG I and ANG II. The overall recovery of 125I-ANG I and 125I-ANG II added to plasma samples was 85 (7) \% and 84 (8) $\%$ (mean and $\mathrm{SD}, \mathrm{n}=6$ ) respectively. Similar values were obtained for $\mathrm{ANG}$ I and ANG II. Results were not corrected for incomplete recovery.

\section{Assay of angiotensins}

ANG I and ANG II concentrations were measured by radioimmunoassay (1) after SepPak extraction and HPLC separation. The ANG I antiserum crossreacted with ANG-(2-10) (100\%) but not (less than $0.1 \%$ ) with ANG II, ANG III, ANG-(3-8), ANG-(4-8) and ANG-(1-7). The ANG II antiserum crossreacted with ANG III (55\%), ANG-(3-8) (73 \%) and ANG-(4-8) (100 $\%$ ), but not (less than $0.2 \%$ ) with ANG I, ANG-(2-10) or ANG-(1-7). These patterns of crossreactivity show that the antibodies in both antisera were directed against the C-terminal sequences of ANG I and ANG II. 
Studies were carried out in twenty female pigs (crossbred Yorkshire $\mathrm{x}$ Landrace, Hedelse Varkens Combinatie, Hedel, The Netherlands) with a body weight of $23-31 \mathrm{~kg}$. The pigs were kept on a normal sodium diet. Twelve pigs had been treated with captopril, $25 \mathrm{mg}$ twice daily, for 3 days. The experiments in these pigs were performed $3-4$ hours after the last captopril dose.

The pigs were sedated with azaperone (Stresnil, Janssen Pharmaceutics, Beerse, Belgium), $5 \mathrm{mg} / \mathrm{kg}$ i.m., $15 \mathrm{~min}$ later followed by metomidate (Hypnodil, Janssen Pharmaceutics), $3 \mathrm{mg} / \mathrm{kg}$ i.v.. Subsequently the pigs were intubated for artificial ventilation with a mixture of oxygen and nitrous oxide (1:2). Respiratory rate and tidal volume were adjusted to keep arterial blood gases within the normal range. In order to maintain an adequate anesthesia, a catheter was placed in the superior caval vein via the external jugular vein for the administration of $160 \mathrm{mg} / \mathrm{kg} \alpha$-chloralose (Merck, Darmstadt, Germany). Fluid losses were corrected with saline, also via this catheter. A peripheral ECG-lead was monitored throughout the experiment. An 8F catheter inserted into the descending aorta, via a femoral artery, was used to measure central aortic pressure (50 AD pressure transducer, Spectramed, Bilthoven, The Netherlands). A $7 \mathrm{~F}$ catheter was manipulated into the left ventricle, via the carotid artery, under X-ray control, for the infusion of 125 I-ANG I and unlabeled ANG I. After the heart had been exposed by a midstemal split, electromagnetic flow probes (Skalar, Delft, The Netherlands) were placed around the ascending aorta and the left anterior descending coronary artery.

Blood for angiotensin measurements was collected from the aorta, pulmonary artery, left and right atrium and great cardiac vein in 8 captopriltreated and 8 untreated pigs. An $8 \mathrm{~F}$ catheter was placed in the aorta, via a femoral artery. A 7F catheter was introduced into the pulmonary artery under radiographic control, via a femoral vein. The left and the right atrial appendages were catheterized each with an $8 \mathrm{~F}$ catheter. The vein accompanying the left anterior descending coronary artery (great cardiac vein) was cannulated with a polyethylene catheter. In 4 additional captopril-treated pigs, blood was collected from the aorta and the femoral, renal, jugular vein and ear lobe veins. A 7F catheter was inserted into the right femoral vein and subsequently positioned in the right renal vein under fluoroscopy. An $7 F$ catheter was placed in the left femoral vein. The left jugular vein was cannulated with a 7F catheter. The ear lobe vein was cannulated with a polyethylene catheter.

After a stabilization period of $45 \mathrm{~min}$, following the completion of instrumentation, the pigs were given a constant infusion of ${ }^{125 I-A N G ~ I, ~} 3.6 \mathrm{x}$ $10^{6}\left(0.5 \times 10^{6}\right) \mathrm{cpm} / \mathrm{min}$ (mean and SD), either alone (9 captopril-treated pigs, 5 untreated pigs) or combined with unlabeled ANG I, 0.9 (0.3) $\mathrm{nmol} / \mathrm{min}(3$ 
captopril-treated pigs, 3 untreated pigs), into the left cardiac ventricle. During the infusion, which lasted 20 minutes, hematocrit measurements were performed in arterial blood to enable us to convert blood flow into plasma flow. Blood samples $(5 \mathrm{~mL})$ to measure ${ }^{125}$-labeled and unlabeled angiotensins were taken from each sampling site at $2 \mathrm{~min}$ before and at 9,14 and $19 \mathrm{~min}$ after the start of the infusion. To determine the half lives of 125I-ANG I and unlabeled ANG I blood samples were taken in the first 2-3 min period after the infusion had been stopped.

The blood was rapidly drawn with a plastic syringe containing the following inhibitors ( $0.25 \mathrm{~mL}$ inhibitor solution in $5 \mathrm{~mL}$ blood), $0.01 \mathrm{mM}$ Ro 42,5892, $6.25 \mathrm{mM}$ disodium EDTA and $1.25 \mathrm{mM}$ 1,10-phenantroline (final concentrations in blood). Previous measurements of plasma renin activity in porcine plasma had shown that a concentration of $0.01 \mathrm{mM}$ of the renin inhibitor Ro 42,5892 was sufficient to cause complete inhibition of ANG I production (unpublished results). The blood samples were immediately transferred into prechilled polystyrene tubes and centrifuged at $3000 \mathrm{~g}$ for 10 min at $4{ }^{\circ} \mathrm{C}$. Plasma was stored at $-70^{\circ} \mathrm{C}$ and assayed within two weeks.

\section{In vitro studies on angiotensin I metabolism}

Since the results of our in vivo studies raised the possibility that the rate of of 125I-ANG I-II conversion might be different from the rate of ANG I-II conversion, the in vitro elimination rate of ${ }^{125} \mathrm{I}-\mathrm{ANG}$ I in porcine plasma was compared with that of unlabeled ANG I under standardized conditions, both in the presence and absence of captopril. In the presence of captopril the elimination of ${ }^{125} \mathrm{I}-\mathrm{ANG} I$ and ANG I is due to degradation, whereas in the absence of captopril the elimination is due both to ${ }^{125}$ I-ANG I and ANG I degradation and ${ }^{125}$ I-ANG I-II and ANG I-II conversion.

Forty $\mathrm{mL}$ blood was collected from 4 female pigs, with a body weight of 24$29 \mathrm{~kg}$. The blood was collected into polystyrene tubes containing trisodium citrate $(0.2 \mathrm{~mL}$ in $10 \mathrm{~mL}$ blood, final concentration $0.013 \mathrm{M})$. The blood samples were immediately centrifuged at $3000 \mathrm{~g}$ for $10 \mathrm{~min}$ at room temperature. Plasma was stored at $-20^{\circ} \mathrm{C}$.

Prior to the experiment, the renin inhibitor Ro 42,5892 was added to plasma (final concentration $0.01 \mathrm{mM}$ ), in order to prevent ANG I formation. Captopril (final concentration $0.4 \mathrm{mM}$ ) was added to study degradation separately from conversion.

After the plasma containing the inhibitors had been brought to a temperature of $37^{\circ} \mathrm{C}$ in a waterbath, the experiment was started by adding at $\mathrm{t}=0$ either $10^{6}$ cpm ${ }^{125} \mathrm{I}$-ANG I or 2 pmol ANG I (both in a volume of $100 \mu \mathrm{L}$ ) to $2 \mathrm{~mL}$ plasma. Plasma aliquots of $200 \mu \mathrm{L}$ were taken at $0.25,1,2,5,10,20$ and 40 min and immediately mixed with an inhibitor solution containing the following inhibitors $(20 \mu \mathrm{L}$ inhibitor solution in $200 \mu \mathrm{L}$ plasma) $1.25 \mathrm{mM} 1,10$ phenantroline and $6.25 \mathrm{mM}$ disodium EDTA (final concentrations in plasma). 
The samples were kept on ice and SepPak extraction of angiotensins was performed within one hour. The SepPak extracts were applied to the HPLC column and 125I-ANG I and ANG I were measured as described before.

Captopril, in the concentration we used, caused complete blockade of conversion. Experiments in which 125I-ANG II or ANG II was added to plasma, demonstrated that angiotensin degradation was not altered by captopril.

\section{Calculations}

Regional extraction of ANG I. The ANG I extraction ratio, E, is defined as follows:

$\mathrm{E}=1-\mathrm{ANG} \mathrm{I}_{\text {out }} / \mathrm{ANG} \mathrm{I}_{\text {in }}$,

in which ANG $I_{\text {in }}$ is the steady state concentration of exogenous ANG I in inflowing (arterial) plasma and ANG $\mathrm{I}_{\text {out }}$ the concentration in outflowing (venous) plasma during the infusion of ANG I into the left cardiac ventricle.

Extraction ratios of ${ }^{125}$ I-ANG I and unlabeled ANG I were calculated for the following vascular beds: 1) left cardiac cavity (left atrium to aorta), 2) combined systemic vascular beds (aorta to right atrium), 3) myocardium (aorta to great cardiac vein), 4) right cardiac cavity (right atrium to pulmonary artery), 5) lungs (pulmonary artery to left atrium), 6) skeletal muscle (aorta to femoral vein), 7) kidney (aorta to renal vein), 8) head (aorta to jugular vein), and 9) skin (aorta to ear lobe vein).

The clearance of ANG I from the blood during its passage in a given vascular bed is given by the following equation:

Plasma clearance $=\mathrm{Q} \cdot \mathrm{E}=\mathrm{Q} \cdot\left(\mathrm{ANG} \mathrm{I}_{\text {in }}-\mathrm{ANG} \mathrm{I}_{\text {out }}\right) / \mathrm{ANG} \mathrm{I}_{\mathrm{in}}$,

in which $Q$ is the plasma flow.

The clearance rate calculated in this way is not the total clearance by a given tissue because only part of the intracardially infused and arterially delivered ANG I reaches the tissue sites where it is metabolized. Therefore the term intrinsic clearance is introduced $(\mathbf{1 8 , 2 0 , 2 1})$. Intrinsic clearance is a measure of the inherent ability of the tissues to metabolize ANG I, i.e. the maximal eliminating capacity in the absence of flow limitations. To calculate the intrinsic clearance, it is assumed that the ANG I concentration in the tissue compartment from which ANG I is eliminated equals its concentration in outflowing plasma, so that:

Intrinsic clearance $=\mathrm{Q} \cdot \mathrm{E} /(1-\mathrm{E})=\mathrm{Q} \cdot\left(\mathrm{ANG} \mathrm{I}_{\text {in }}-\mathrm{ANG} \mathrm{I}_{\text {out }}\right) / A N G \mathrm{I}_{\text {out }} \cdot$ 
This equation is based upon the so-called 'venous equilibrium' model, in which the vascular bed between the arterial and venous sampling sites is considered to be a single, well-stirred compartment $(18,21)$. For most vascular beds, ANG $I_{\text {in }}$ and ANG $I_{\text {out }}$ are the concentrations of exogenous ANG I in plasma of arterial and venous blood respectively. For the right cardiac cavity, ANG $I_{\text {in }}$ is the concentration of exogenous ANG I in the right atrium and ANG $\mathbb{I}_{\text {out }}$ the concentration in the pulmonary artery. For the left cardiac cavity, ANG $I_{\text {in }}$ was calculated as follows:

$A N G I_{\text {in }}=A N G I_{\text {left atrium }}+$ Infusion rate/Cardiac output of plasma.

ANG $I_{\text {out }}$ for the left cardiac cavity is the concentration of exogenous ANG I in the aorta.

Regional degradation and conversion of ANG $I$. The regional ANG I extraction ratio, $\mathrm{E}$, is determined by the metabolic rate constant, $\mathrm{k}$, and the time, $t$, during which the arterially delivered ANG I is exposed to peptidases during the passage of the blood from the arterial to the venous side of the vascular bed. $E$ can be written as a function of $k$ and $t$, as follows:

$\mathrm{E}=1-\mathrm{e}^{-\mathrm{kt}}$.

The metabolism of ANG I comprises both ANG I degradation and ANG I-II conversion, so that:

$\mathrm{k}=\mathrm{k}_{1}+\mathrm{k}_{2}$,

in which $k_{1}$ is the first order rate constant for ANG I degradation and $k_{2}$ the first order rate constant for conversion. Substitution of equation (6) into (5) gives:

$E=1-e^{-\left(k_{1} t+k_{2} t\right)}$,

in which $t$ is the time during which ANG $I$ is exposed to the degrading and converting enzymes as the blood flows from the arterial side to the venous side.

From equation (7) it follows that:

$\mathrm{k}_{1} \mathfrak{t}+\mathrm{k}_{2} \mathrm{t}=-\ln (1-\mathrm{E})=-\ln \left(\mathrm{ANG} \mathrm{I}_{\text {out }} / \mathrm{ANG} \mathrm{I}_{\text {in }}\right)$.

Assuming $\mathrm{k}_{1}$ to be the same for ANG II as for ANG $\mathrm{I}, \mathrm{k}_{1}$ t can be calculated as 
follows:

$\mathrm{k}_{1} \mathrm{t}=-\ln \left[\left(\mathrm{ANGI}_{\text {out }}+\mathrm{ANG} \mathrm{I}_{\text {out }}\right) /\left(\mathrm{ANG} \mathrm{I}_{\text {in }}+\mathrm{ANG} \mathrm{I}_{\mathrm{in}}\right)\right]$.

Subsequently $k_{2} t$ can be calculated by subtracting $k_{1} t$ from $k_{1} t+k_{2} t$ as follows:

$\mathrm{k}_{2} t=\ln \left[\left(\mathrm{ANG}_{\text {out }}+\mathrm{ANG} \mathrm{I}_{\text {out }}\right) /\left(\mathrm{ANG} \mathrm{I}_{\text {in }}+\mathrm{ANG} \mathrm{I}_{\text {in }}\right)\right]-\ln \left(\mathrm{ANG} \mathrm{I}_{\text {out }} / \mathrm{ANG} \mathrm{I}_{\text {in }}\right)$.

The fractional degradation of arterially delivered ANG I was defined as follows:

Fractional degradation $=\mathrm{E} \cdot \mathrm{k}_{1} \mathrm{t} /\left(\mathrm{k}_{1} \mathrm{t}+\mathrm{k}_{2} \mathrm{t}\right)$.

The fractional conversion of arterially delivered ANG I was defined as follows:

Fractional conversion $=E \cdot k_{2} t /\left(k_{1} t+k_{2} t\right)$.

Statistical evaluation. Differences in metabolism between ${ }^{125} \mathrm{I}-\mathrm{ANG}$ I and ANG I were evaluated for statistical significance $(p<0.05)$ by using Student's $t$-test for paired observations. Differences in metabolism of ANG I between captopril-treated and untreated pigs were analysed with Student's t-test for unpaired observations.

\subsection{Results}

Hemodynamic effects of ${ }^{125 I-A N G ~ I ~ a n d ~ A N G ~ I ~ i n f u s i o n s ~}$

Heart rate and cardiac output of plasma did not change during the infusion experiments (Fig. 1). Coronary plasma flow, as judged from the left anterior descending coronary artery flow, also remained constant. The mean value of cardiac output of plasma was used to calculate ${ }^{125}$ I-ANG I and ANG I clearance rates in the pulmonary and combined systemic vascular beds respectively. Arterial pressure showed a tendency to fall during the experiment but the change was not statistically significant. Coronary plasma flow tended to be higher with captopril treatment than without treatment, but again the difference did not reach statistical significance.

Identification of ${ }^{25} I-A N G I, 125 I-A N G I I$ and other $125 I$-labeled peptides present in plasma during ${ }^{125} I-A N G$ I infusion

HPLC separation patterns of ${ }^{125}$ I-labeled peptides in plasma from captopril- 
MEAN

ARTERIAL

PRESSURE

$\mathrm{mmHg}$
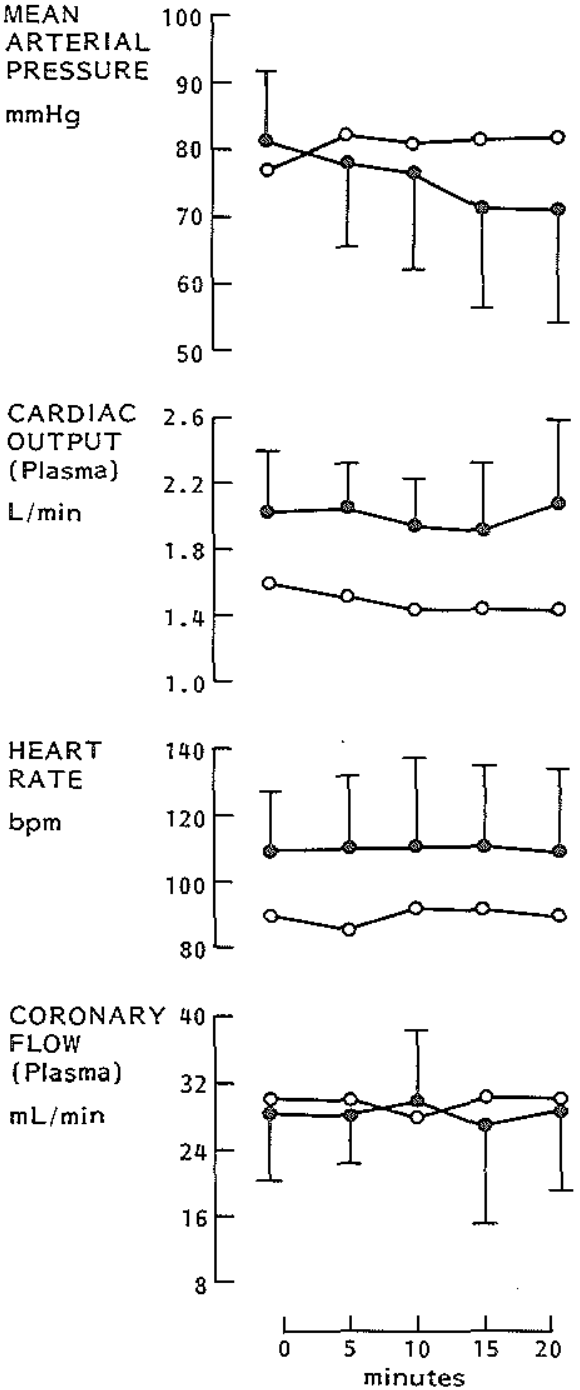
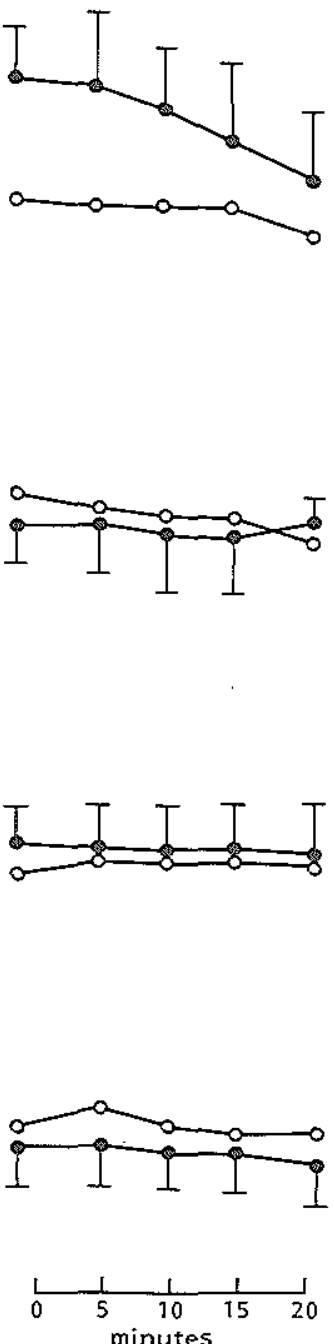

Figure 1. Hemodynamic parameters (mean and SD) in captopril-treated and untreated pigs before, during and after constant infusion into the left cardiac ventricle of either ${ }^{125} \mathrm{I}$-ANG I alone (closed circles, $n=5$ in both groups) or ${ }^{125} \mathrm{I}-\mathrm{ANG} \mathrm{I}$ in combination with ANG I (open circles, $n=3$ in both groups). 'Coronary flow' means the flow in the left anterior descending coronary artery. 
treated and untreated pigs are shown in Fig. 2. Satisfactory separations were obtained between ${ }^{125}$ I-ANG I and 125I-ANG II, and between these peptides and their ${ }^{125}$ I-labeled metabolites. A comparison with the retention times of the various 125 I-labeled standards demonstrated that the 125I-ANG I and 125I-ANG II peaks were virtually free of 125 I-tyrosine, ${ }^{125}$ I-ANG-(1-7), 125I-ANG III, 125I-ANG-(3-8), 125I-ANG-(4-8) or 125I-ANG-(2-10). In addition, the ANG I antiserum was able to bind $90-100 \%$ of the radioactivity in the 125 I-ANG I peak (and less than $3 \%$ in the 125I-ANG II peak), whereas the ANG II antiserum bound more than $90 \%$ of the radioactivity in the ${ }^{125}$ I-ANG II peak (and less than $5 \%$ in the ${ }^{125}$ I-ANG I peak).
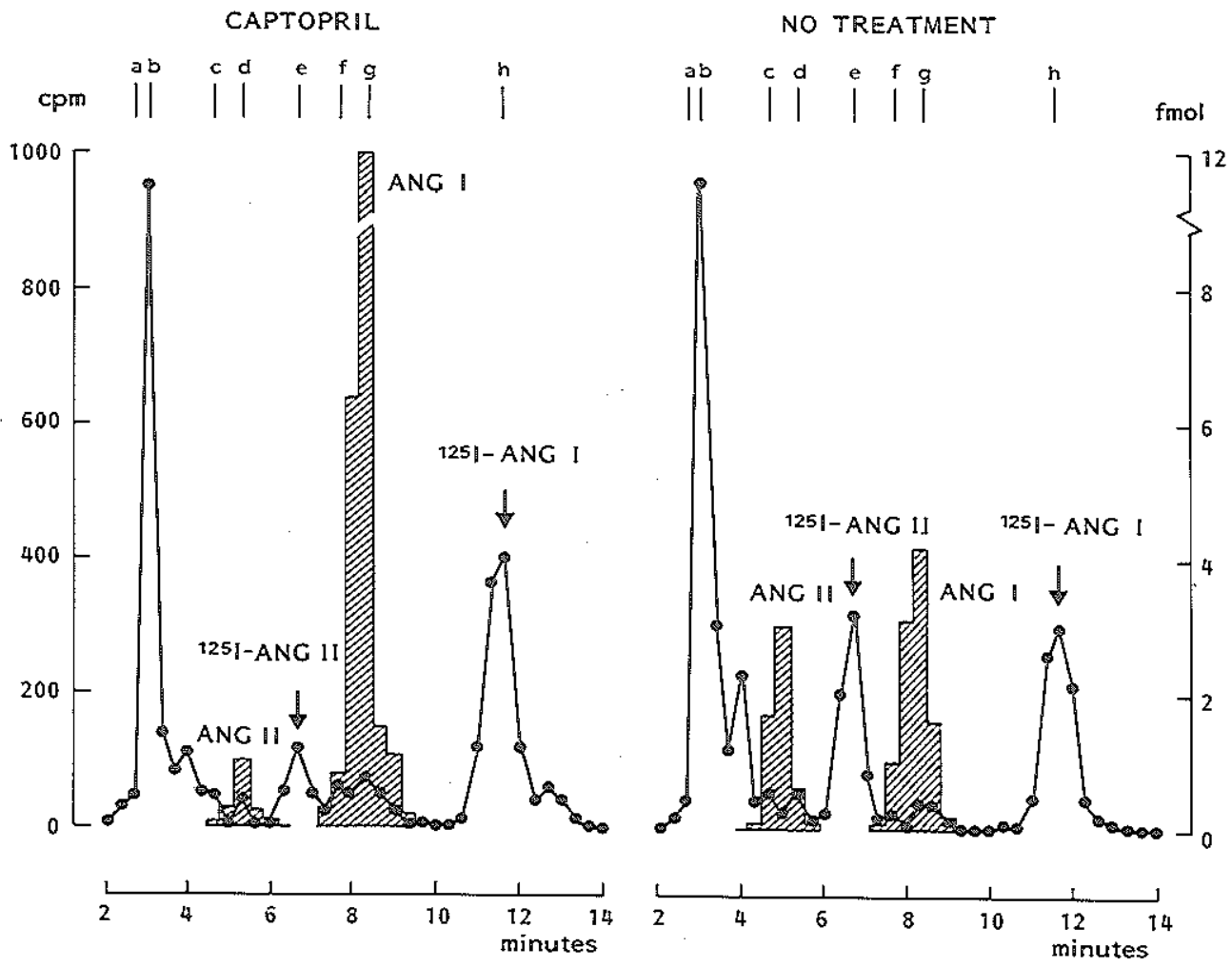

Figure 2. HPLC elution profile of ${ }^{125}$ I-labeled and endogenous angiotensins in aortic plasma of a captopril-treated (left) and an untreated (right) pig, during constant infusion of 125 I-ANG I into the left cardiac ventricle. Radiolabeled peptides (line) were measured by gamma counting, and endogenous angiotensins (bars) were measured by radioimmunoassay. Details on the HPLC elution program are given in the text (see Methods section). a, ${ }^{125}$ I-ANG-(1-7); b, ${ }^{125}$ I-tyrosine; c, ${ }^{125}$ I-ANG II; d, ${ }^{125}$ I-ANG(4-8); e, ${ }^{125}$ I-ANG II; f, ${ }^{125}$ I-ANG-(2-10); g, ${ }^{125}$ I-ANG-(3-8); h, ${ }^{125}$ I-ANG $I$. 
In addition to the ${ }^{125}$ I-ANG I and ${ }^{125}$ I-ANG II peaks, separate peaks with retention times corresponding with ${ }^{125} \mathrm{I}$-tyrosine (and possibly also ${ }^{125} \mathrm{I}-\mathrm{ANG}$ (1-7)) and 125I-ANG-(2-10) could be readily identified in plasma. Peaks corresponding with other metabolites, such as 125I-ANG III and 125I-ANG-(48 ), were very low or absent.

Not only radiolabeled ANG I and ANG II, but also unlabeled ANG I and ANG II were satisfactorily separated from each other and from either tyrosine, ANG-(1-7), ANG III, ANG-(3-8), ANG-(4-8) and ANG-(2-10). The small amounts of radioactivity present in the HPLC fractions containing unlabeled ANG I and ANG II did not interfere with the radioimmunoassays of these peptides.

\section{Plasma levels of ${ }^{125}$ I-ANG I during and following ${ }^{125}$ I-ANG I infusion}

The arterial and venous plasma levels of ${ }^{125}$ I-ANG I remained constant from the 9th minute of ${ }^{125}$ I-ANG I infusion (the first time blood was sampled during the infusion) until the end of the infusion, which demonstrates that a steady state was reached. The steady state plasma levels of $125 \mathrm{I}$-ANG I across the various vascular beds (mean value of the three samples taken at 9,14 and 19 minutes from each sampling site) were used to calculate the 125I-ANG I extraction ratios of these beds. Tables 1 and 2 summarize the results obtained in 8 captopril-treated and 8 untreated pigs. The high extraction ratios of $125 \mathrm{I}$ ANG I document the rapid metabolism of ${ }^{125}$ I-ANG I by the tissues. It should be noted that 125 I-ANG I was extracted not only in vascular beds where the arterially delivered blood has to pass the capillaries to reach the veins, but also in the right and left cardiac cavities (right atrium to pulmonary artery and left atrium to aorta). The $125 \mathrm{I}-\mathrm{ANG}$ I extraction ratios of the combined systemic vascular beds (aorta to right atrium) and the myocardium (aorta to great cardiac vein) were not significantly altered by captopril treatment. In contrast, the $125 \mathrm{I}$-ANG I extraction ratio of the lungs (pulmonary artery to left atrium) was greatly reduced by captopril ( $p<0.01$ ), confirming that ANG I-II conversion is the main pathway by which ANG I is eliminated by the lungs.

In contrast with 125 I-ANG I, the total radioactivity levels in plasma kept increasing during the infusion, at all sampling sites, indicating accumulation of one or more radiolabeled metabolites. At the end of the infusion more than 95 $\%$ of the total radioactivity of inflowing plasma was recovered in the outflowing plasma across the cardiac cavities and lungs. Across the other vascular beds we studied $90-95 \%$ of arterially delivered radioactivity was recovered in venous plasma. These findings document that the extraction of 125I-ANG I by the tissues we studied is mainly, if not wholly, due to its local metabolism. There was no indication of local accumulation of unmetabolized 125I-ANG I. 
Table $\mathbb{1}$. Steady state plasma levels of ${ }^{125}$ I-ANG I and ${ }^{125}$ I-ANG II in captopril-treated and untreated pigs during constant ${ }^{125}$ I-ANG I infusion into the left cardiac ventricle.

$$
125 \mathrm{I}-\mathrm{ANG} \mathrm{I} \mathrm{cpm} / \mathrm{mL} \quad 125 \mathrm{I}-\mathrm{ANG} \text { II } \mathrm{cpm} / \mathrm{mL}
$$

\begin{tabular}{lllll}
\hline & CAPTOPRIL & NO & CAPTOPRIL & $\begin{array}{l}\text { NO } \\
\text { SAMPLING SITE }\end{array}$ \\
TREATMENT & TREATMENT & $\begin{array}{l}\text { TREATMENT } \\
\text { TREATMENT }\end{array}$ \\
\hline Aorta & $1861(553)$ & $1197(267)$ & $189(166)$ & $922(145)$ \\
Right Atrium & $769(169)$ & $534(129)$ & $128(114)$ & $710(134)$ \\
$\begin{array}{l}\text { Pulmonary Artery } \\
\text { Left Atrium }\end{array}$ & $656(102)$ & $466(105)$ & $107(100)$ & $595(95)$ \\
Great Cardiac Vein & $568(114)$ & $259(102)$ & $161(152)$ & $771(121)$ \\
& $959(145)$ & $585(215)$ & $166(149)$ & $993(226)$ \\
\hline
\end{tabular}

Data are means and SD ( $\mathrm{n}=8)$. ${ }^{125} \mathrm{I}$-ANG I infusion rate was $3.08(0.34) \times 10^{6} \mathrm{cpm} / \mathrm{min}$ in the captopril-treated pigs and $3.36(0.60) \times 10^{6} \mathrm{cpm} / \mathrm{min}$ in the untreated pigs.

Table 2. Regional extraction ratios of ${ }^{125}$ I-ANG I in captopril-treated and untreated pigs during constant ${ }^{125} \mathrm{I}-\mathrm{ANG}$ I infusion into the left cardiac ventricle.

\begin{tabular}{lll}
\hline VASCULAR BED & $\begin{array}{l}\text { CAPTOPRI } \\
\text { TREATMENT }\end{array}$ & $\begin{array}{l}\text { NO } \\
\text { TREATMENT }\end{array}$ \\
\hline Left Cardiac Cavity & & \\
Right Cardiac Cavity & $0.22(0.16)$ & $0.46(0.13)^{*}$ \\
Combined Systemic Vascular Beds & $0.14(0.09)$ & $0.14(0.09)$ \\
Lungs & $0.57(0.11)$ & $0.55(0.06)$ \\
Myocardium & $0.14(0.10)$ & $0.47(0.12)^{*}$ \\
Head & $0.45(0.11)$ & $0.52(0.13)$ \\
Skeletal Muscle & $0.58(0.47-0.67)$ & $\mathrm{ND}$ \\
Kidney & $0.70(0.58-0.84)$ & $\mathrm{ND}$ \\
Skin & $0.94(0.86-0.98)$ & $\mathrm{ND}$ \\
& $0.52(0.47-0.56)$ & $\mathrm{ND}$ \\
\hline
\end{tabular}

Data on the left and right cardiac cavities, the combined systemic vascular beds, lungs and myocardium are means and SD $(n=8)$. Data on head, skeletal muscle, kidney and skin are means and ranges $(n=4)$. ND, not done $* \mathrm{p}<0.05$, captopril treatment $v s$. no treatment. 
The disappearance of ${ }^{125}$ I-ANG I from plasma after the ${ }^{125 I-A N G ~ I ~ i n f u s i o n ~}$ had been stopped was followed in the aorta in all animals (Fig. 3). In the first $0.5 \mathrm{~min}$ the level fell rapidly by more than $50 \%$. Thereafter it fell more gradually, in a mono-exponential way, with a $t_{1 / 2}$ of $0.82(0.12)$ min with captopril and $0.38(0.17)$ min without captopril (means and $\mathrm{SD}, \mathrm{n}=8$ in both groups, $\mathrm{p}<0.01$ ).

In 2 animals the disappearance of 125 I-ANG I after the 125I-ANG I infusion had been stopped was followed both in the pulmonary artery and in the aorta. At steady state during the infusion, the level of 125 I-ANG I in the aorta was higher than in the pulmonary artery but, within $30 \mathrm{sec}$ after the infusion had been stopped, 125I-ANG I in the aorta fell to a level close to the level in the pulmonary artery (Fig. 4). Thereafter ${ }^{25}$ I-ANG I both in the aorta and in the pulmonary artery fell in a mono-exponential way, and the slopes of the two elimination curves were not different. At the moment the infusion was stopped, the level of 125 I-ANG I in the aorta that was derived by extrapolation of the mono-exponential curve, was not different from the level in the left atrium at steady state during the infusion. The pulmonary artery/aorta ${ }^{125}$ I-ANG I concentration ratio in the elimination phase was not different from the steady state pulmonary artery/left atrium ratio during the infusion. Thus, in contrast with the arteriovenous ${ }^{125}$ I-ANG I concentration ratio across the combined systemic vascular beds, the arteriovenous ratio across the lungs during the infusion was maintained after the infusion. These results are in agreement with the assumption that in the combined systemic vascular beds ANG $I$ is cleared from a single well-stirred compartment that is larger than the blood compartment ('venous equilibrium' model, vide supra), whereas in the pulmonary vascular bed ANG I is mainly cleared from the blood compartment.

Plasma levels of ${ }^{225} I-A N G I$ and $A N G I$ during and following combined ${ }^{125 I-}$ ANG $I$ and $A N G I$ infusion

The plasma levels of ANG I at the various sampling sites (aorta, right atrium, pulmonary artery, left atrium, great cardiac vein) prior to the infusion were similar, both in the captopril-treated and untreated animals (Table 3). They were 20.1-23.3 pM in the former group, as compared to $2.5-4.9 \mathrm{pM}$ in the latter group. The ANG II levels prior to the infusion were 2.1-3.3 and 1.9-3.0 $\mathrm{pM}$ respectively. These results show that reduced ANG I-II conversion after ACE inhibition is overcome by the elevated ANG I levels.

ANG I and ANG II rose by a factor of 7 or more during the infusion in the captopril-treated group, and by more than 100 in the untreated group. From the steady state plasma levels of ANG I during the infusion, the ANG I extraction ratios across the various vascular beds were calculated and compared with the ${ }^{125} \mathrm{I}-\mathrm{ANG}$ I extraction ratios. The results are summarized in Table 4. 


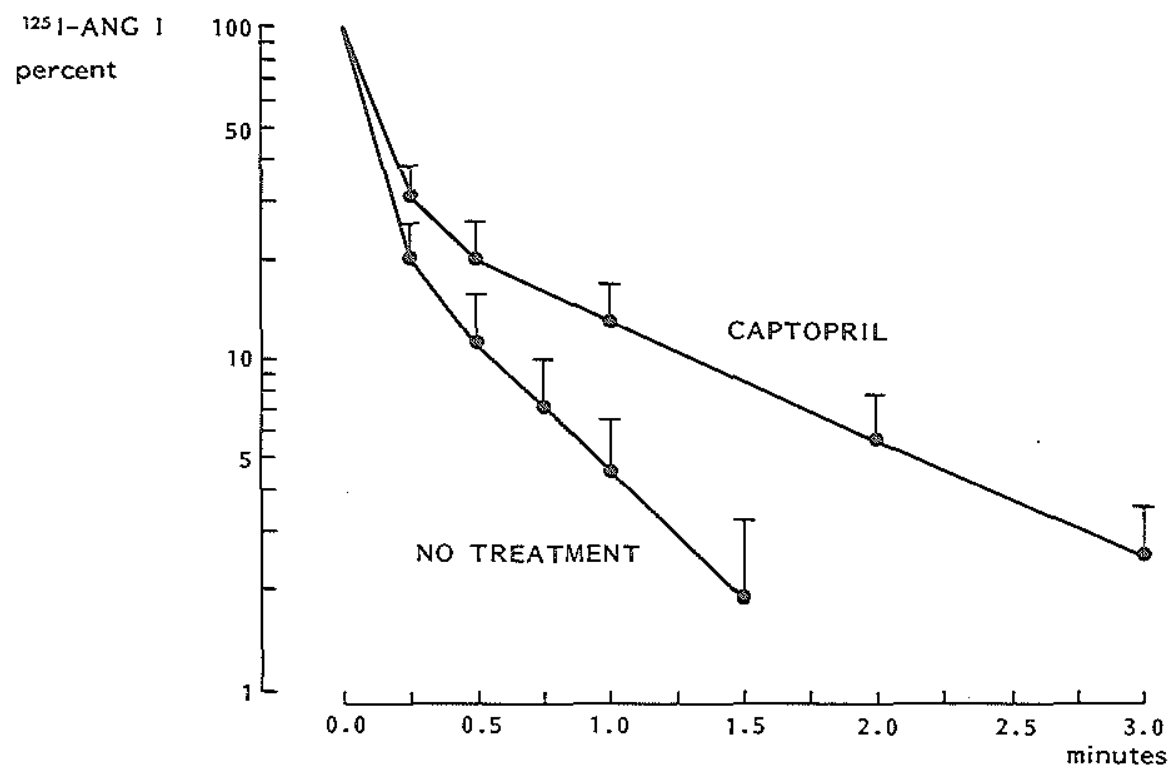

Figure 3. Elimination of ${ }^{125}$ I-ANG I from aortic plasma in captopril-treated and untreated pigs (mean and $S D, n=8$ in both groups), after discontinuation of a constant infusion of ${ }^{125}$ I-ANG I into the left cardiac ventricle.

Table 3. Steady state plasma levels of ANG I and ANG II in captopril-treated and untreated pigs before and during constant ANG I infusion into the left cardiac ventricle.

\begin{tabular}{|c|c|c|c|c|}
\hline & \multicolumn{2}{|c|}{ ANGI pM } & \multicolumn{2}{|c|}{$\mathrm{ANGM} \mathrm{pM}$} \\
\hline & CAPTOPRI & NO & CAPTOPRW & NO \\
\hline SAMPLNA SITE & TREATMENT & TREATMENT & TREATMENT & TREATMENT \\
\hline Aorta & $21.4->376$ & $3.6->541$ & $3.3->36.6$ & $2.6->229$ \\
\hline Right Atrium & $23.3->201$ & $4.9->285$ & $2.3->24.8$ & $2.2->175$ \\
\hline Pulmonary Artery & $21.9 \rightarrow 170$ & $3.6->249$ & $2.1->21.5$ & $1.9->149$ \\
\hline Left Atrium & $20.1 \rightarrow 146$ & $2.5->187$ & $3.0->32.1$ & $3.0->218$ \\
\hline Great Cardiac Vein & $21.1 \rightarrow 175$ & $3.4->330$ & $3.2 \rightarrow>29.5$ & $2.3 \rightarrow 272$ \\
\hline
\end{tabular}

Data (means, $\mathrm{n}=3$ ) before and during infusion are given. ANG I infusion rate was 0.77 $\mathrm{mmol} / \mathrm{min}$ in the captopril-treated pigs and $1.07 \mathrm{nmol} / \mathrm{min}$ in the untreated pigs. 


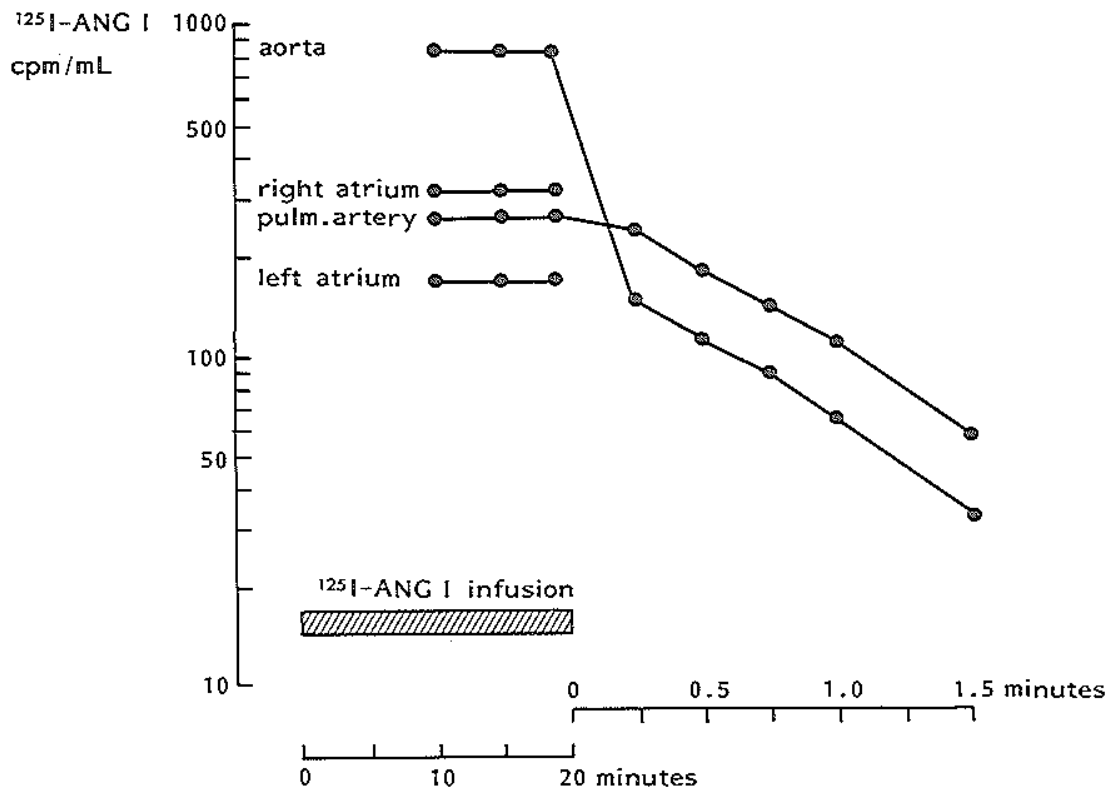

Figure 4. Plasma levels of ${ }^{125}$ I-ANG I in the aorta, right atrium, pulmonary artery and left atrium at steady state during constant infusion of ${ }^{125}$ I-ANG I into the left cardiac ventricle and in the elimination phase (aorta and pulmonary artery) after discontinuation of the infusion. Data are from a representative experiment in an untreated pig.

Table 4. Regional extraction ratios of ${ }^{125}$ I-ANG I and ANG I in captopril-treated and untreated pigs during constant combined infusion of ${ }^{125} \mathrm{I}-\mathrm{ANG} \mathrm{I}$ and ANG I into the left cardiac ventricle.

$\begin{array}{ll}\text { CAPTOPRIL } & \text { NO } \\ \text { TREATMENT } & \text { TREATMENT }\end{array}$

VASCULAR BED

125I-ANG I ANG I 125I-ANG I ANG I

Left Cardiac Cavity

0.35

0.37

0.45

$0.33 *$

Right Cardiac Cavity

$0.20 \quad 0.15$

0.07

0.49

0.46

0.55

0.12

Combined Systemic Vascular Beds

0.17

0.14

Lungs

0.54

0.51

0.38

$0.46^{*}$

0.44

$0.27 *$

0.40

Data are means $(n=3)$.

* The extraction ratio for ${ }^{125}$ I-ANG I was higher than for ANG I in all three experiments 
With captopril treatment no difference in extraction by the various vascular beds was observed between ${ }^{125}$ I-ANG I and ANG I. Without captopril treatment however, the extraction by the lungs, the combined systemic vascular beds and the left cardiac cavity was higher for ${ }^{125 I-A N G ~ I ~ t h a n ~ f o r ~}$ ANG I. The elimination half lives of 125 I-ANG I and ANG I were not significantly different in the captopril-treated nor in the untreated animals (Fig. 5).
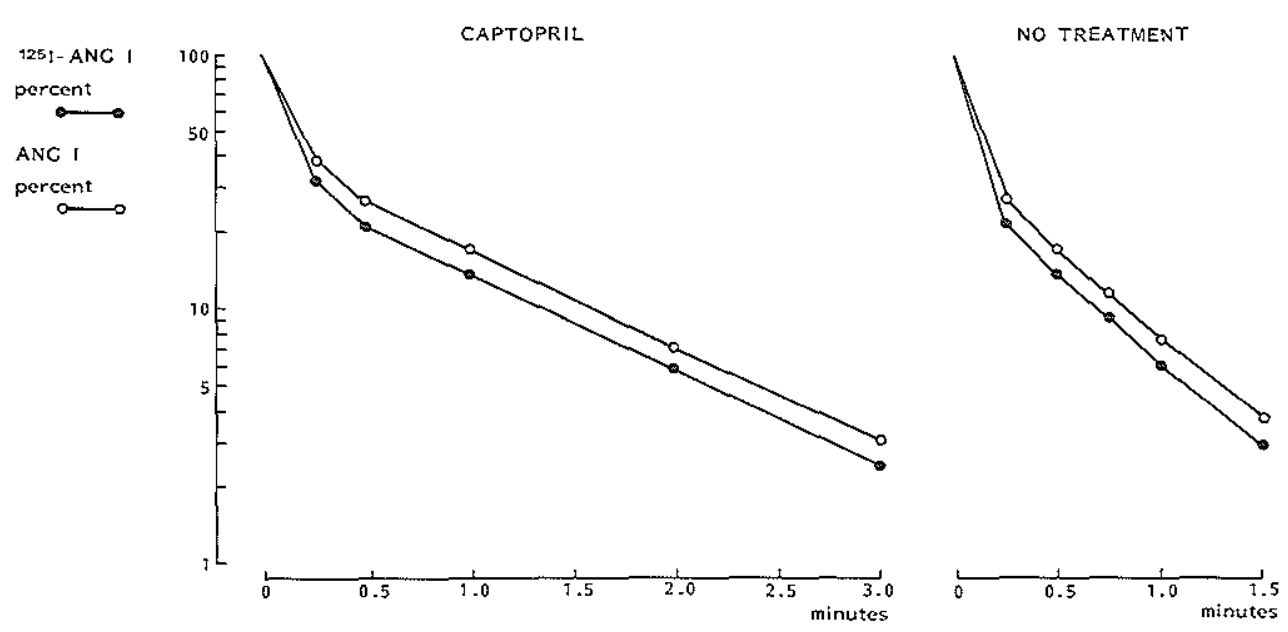

Figure 5. Plasma levels (means, $n=3$ ) of ${ }^{125}$ I-ANG I (closed symbols) and ANG I (open symbols) in the aorta in the elimination phase after discontinuation of a constant combined infusion of ${ }^{125}$ I-ANG I and ANG I into the left cardiac ventricle.

Regional ${ }^{225} I-A N G$ I degradation and ${ }^{225} I-A N G$ I-II conversion as compared with regional ANG I degradation and ANG I-II conversion

The metabolism of ANG I can be divided into two enzymatic processes, ANG I degradation and ANG I-II conversion. The reaction kinetics of these two processes are characterized by the first order rate constants $k_{1}$ and $k_{2}$ for degradation and conversion, respectively. As can be seen from Table 5, $\mathrm{k}_{\mathrm{l}}$ for ${ }^{125} \mathrm{I}-\mathrm{ANG} \mathrm{I}$ and $\mathrm{k}_{1}$ for ANG I were similar. In contrast, $\mathrm{k}_{2}$ for ${ }^{125} \mathrm{I}-\mathrm{ANG}$ I was 1.3-2.7 times $\mathrm{k}_{2}$ for ANG $\mathrm{I}$, which indicates that the ${ }^{125} \mathrm{I}$-ANG I-II conversion rate was approximately two times the ANG I-II conversion rate. These findings explain why in the untreated pigs the 125 I-ANG I extraction ratios were higher than the ANG I extraction ratios. 
Table 5. Regional ${ }^{125} \mathrm{I}-\mathrm{ANG} \mathrm{I}$ and ANG I degradation and conversion constants, $\mathrm{k}_{1} \mathrm{t}$ and $k_{2} t$ respectively, in captopril-treated and untreated pigs during constant combined infusion of 125I-ANG I and ANG I into the left cardiac ventricle.

\begin{tabular}{|c|c|c|c|c|c|c|c|c|}
\hline \multirow[b]{3}{*}{ VASCULAR BED } & \multicolumn{4}{|c|}{ CAPTOPRIL TREATMENT } & \multicolumn{4}{|c|}{ NO TREATMENT } \\
\hline & \multicolumn{2}{|c|}{$125 \mathrm{Y}$-ANGI } & \multicolumn{2}{|c|}{ ANG I } & \multicolumn{2}{|c|}{125 I-ANG I } & \multicolumn{2}{|c|}{ ANGI } \\
\hline & $\mathrm{k}_{1} \mathrm{t}$ & $\overline{k_{2} t}$ & $\overline{k_{1} t}$ & $\mathrm{k}_{2} \mathrm{t}$ & $\mathrm{k}_{1} \mathrm{t}$ & $k_{2} t$ & $\mathrm{k}_{1} \mathrm{t}$ & $\mathrm{k}_{2^{\mathrm{t}}}$ \\
\hline Left Cardiac Cavity & 0.36 & 0.09 & 0.47 & $0.05^{*}$ & 0.37 & 0.26 & 0.29 & $0.12 *$ \\
\hline Right Cardiac Cavity & 0.23 & 0.01 & 0.17 & 0.00 & $0.1 \mathrm{I}$ & 0.00 & 0.15 & 0.01 \\
\hline Combined Systemic Vascular Beds & 0.66 & 0.05 & 0.62 & $0.02^{*}$ & 0.53 & 0.29 & 0.51 & $0.12^{*}$ \\
\hline Lungs & 0.02 & 0.17 & 0.07 & $0.08^{*}$ & 0.06 & 0.45 & 0.01 & $0.35^{*}$ \\
\hline Myocardium & 0.72 & 0.11 & 0.74 & $0.04 *$ & 0.24 & 0.36 & 0.27 & $0.25 *$ \\
\hline
\end{tabular}

Data are means $(\mathrm{n}=3)$

* $\mathrm{k}_{2} \mathrm{t}$ for ANG I was smaller than for ${ }^{125}$ I-ANG I in all three experiments.

Table 6. Regional ANG I degradation and conversion constants, $k_{1} t$ and $k_{2} t$ respectively, calculated from the steady state plasma levels of ${ }^{125}$ I-ANG I in captopril-treated and untreated pigs during constant infusion of ${ }^{125} \mathrm{I}$-ANG I into the left cardiac ventricle.

\begin{tabular}{|c|c|c|c|c|}
\hline \multirow[b]{3}{*}{ VASCULAR BED } & $\mathrm{k}_{1} \mathrm{t}$ & $k_{1} t$ & $k_{2} t$ & $\mathrm{k}_{2} \mathrm{t}$ \\
\hline & CAPTOPRIL & NO & CAPTOPRIL & NO \\
\hline & TREATMENT & TREATMENT & TREATMENT & TREATMENT \\
\hline Left Cardiac Cavity & $0.23(0.17)$ & $0.35(0.15)$ & $0.02(0.02)$ & $0.15(0.06)^{*}$ \\
\hline Right Cardiac Cavity & $0.15(0.11)$ & $0.15(0.12)$ & $0.00(0.00)$ & $0.00(0.01)$ \\
\hline Combined Systemic Vascular Beds & $0.84(0.23)$ & $0.54(0.11)^{*}$ & $0.02(0.01)$ & $0.14(0.03)^{*}$ \\
\hline Lungs & $0.07(0.10)$ & $0.04(0.04)$ & $0.05(0.04)$ & $0.30(0.10)^{*}$ \\
\hline Myocardium & $0.59(0.26)$ & $0.32(0.21)^{*}$ & $0.03(0.02)$ & $0.23(0.05)^{*}$ \\
\hline Head & $0.77(0.56-1.07)$ & & $0.05(0.02-0.10)$ & \\
\hline Skeletal Muscle & $1.04(0.68-1.65)$ & & $0.12(0.08-0.19)$ & \\
\hline Kidney & $2.58(1.51-3.49)$ & & $0.24(0.20-0.26)$ & \\
\hline Skin & $0.69(0.64-0.74)$ & & $0.02(0.00-0.04)$ & \\
\hline
\end{tabular}

Data on the left and right cardiac cavities, the combined systemic vascular beds, lungs and myocardium are means and $S D(n=8)$. Data on head, skeletal muscle, kidney and skin are means and ranges $(n=4)$.

${ }^{*} p<0.05$, captopril treatment $v s$. no treatment. 
In vitro experiments, in which $125 \mathrm{~T}$-ANG I and ANG I were added to plasma and the elimination of the two peptides was followed, also showed a higher conversion rate for 125I-ANG I than for ANG I. Elimination followed first order kinetics, with a rate constant $\mathrm{k}$ of $0.68(0.04) \mathrm{min}^{-1}$ for ${ }^{125 I-A N G ~ I ~ a n d ~}$ $0.41(0.02) \mathrm{min}^{-1}$ for ANG I (means and SD, n=5). After complete blockade of the conversion by the addition of captopril, $\mathrm{k}$ was reduced to $0.17(0.02) \mathrm{min}^{-1}$ for ${ }^{125 I-A N G ~ I ~ a n d ~} 0.14(0.01) \mathrm{min}^{-1}$ for ANG I $(n=5)$. The slow elimination of $125 \mathrm{I}-\mathrm{ANG} I$ and ANG I in plasma containing captopril as compared to plasma without captopril shows that the in vitro elimination of 125I-ANG I and ANG I from plasma in the absence of captopril was mainly caused by $125 \mathrm{I}$ ANG I-II conversion and ANG I-II conversion respectively. In the presence of captopril $k$ equals the first order rate constant for degradation, $k_{1}$. By subtracting $k_{1}$ from the value of $k$ measured in the absence of captopril, one obtains the first order rate constant for conversion, $k_{2}$. For ${ }^{125 I-A N G ~ I, ~} k_{2}$ was $0.51(0.03) \mathrm{min}^{-1}$, and for ANG I it was $0.27(0.02) \mathrm{min}^{-1}$. It appeared that $\mathrm{k}_{2}$ was $1.9(0.3)$ times higher for ${ }^{125}$ I-ANG I than for ANG I. These in vitro findings are in good agreement with the in vivo results described above.

Table 6 gives the calculated regional degradation and conversion constants, $k_{1} t$ and $k_{2} t$ respectively, for ANG I. Calculations were based on equations (8), (9) and (10), which give the $k_{1} t$ and $k_{2} t$ values for ${ }^{125 I-A N G ~ I . ~ B e c a u s e ~ o f ~ t h e ~}$ results of the above experiments in which the conversion rates of 125 I-ANG I and ANG I were compared, $\mathrm{k}_{2}$ t for ${ }^{125}$ I-ANG I was multiplied by 0.5 to give $\mathrm{k}_{2} \mathrm{t}$ for ANG I. In the combined systemic vascular beds but not in the lungs and the cardiac cavities, blockade of ANG I-II conversion by captopril treatment was associated with a rise in the ANG I degradation constant.

From the data presented in Table 6, the fractional degradation and conversion of arterially delivered ANG I in the various vascular beds can be calculated by using equations (11) and (12). The results are shown in Fig. 6 . In the untreated animals, 25 (7) percent of the arterially delivered ANG I was converted to ANG II during a single passage of blood in the lungs and 10 (2) percent in the combined systemic vascular beds (means and $S D, n=8$ ). Fractional ANG I degradation in these animals was only 4 (3) percent in the lungs as compared to 39 (6) percent in the combined systemic vascular beds. In the captopril-treated animals fractional ANG I-II conversion was reduced to very low levels, 4 (4) percent in the lungs and 1 (1) percent in the combined systemic vascular beds. Fractional degradation during captopril treatment remained low in the lungs, $6(8)$ percent, but rose to $55(11)$ in the combined systemic vascular beds. Thus the captopril-induced reduction in ANG I-II conversion in the combined systemic vascular beds was associated with a compensatory rise in ANG I degradation. 


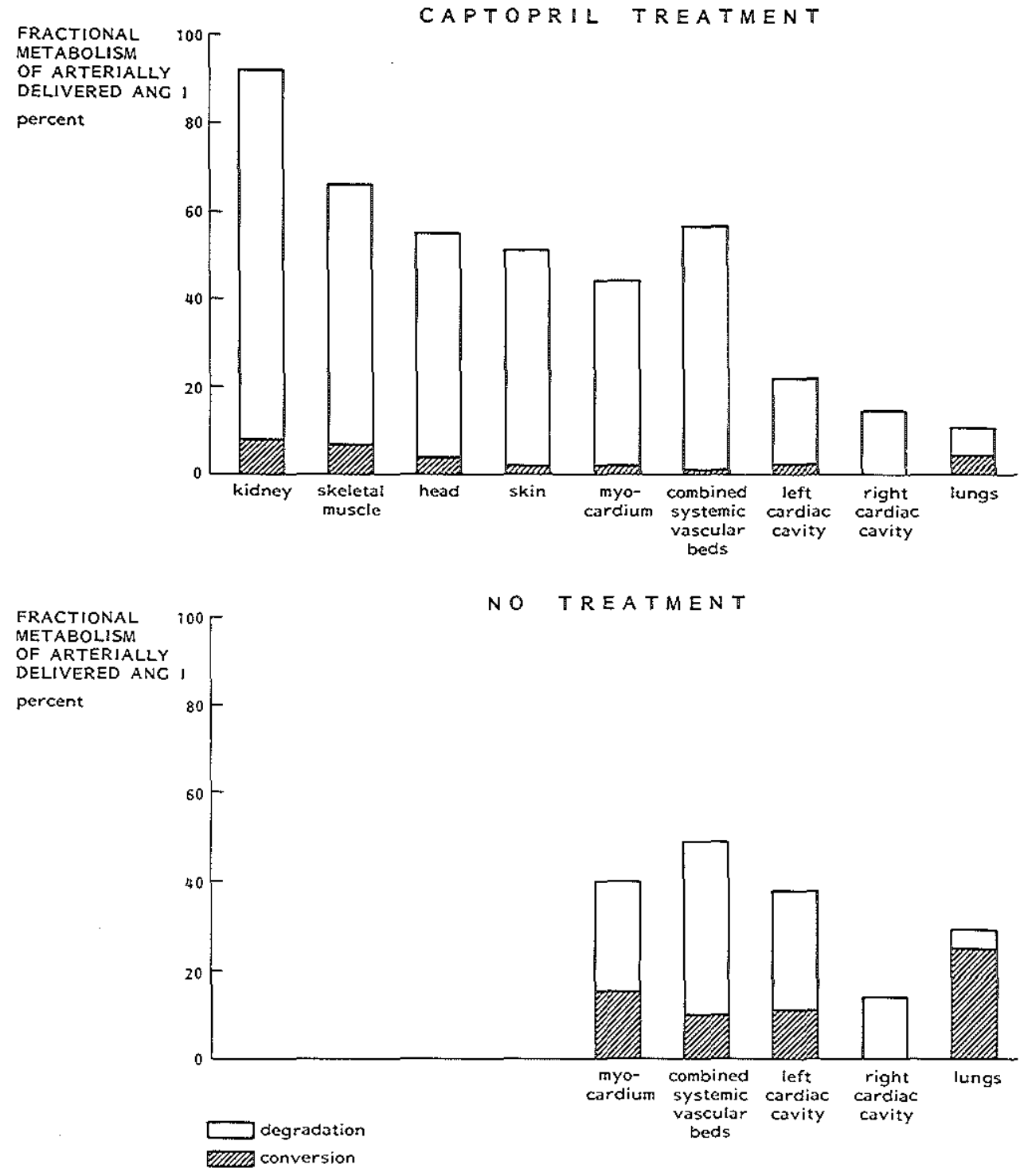

Figure 6. Fractional degradation (open bars) and fractional conversion (hatched bars) of arterially delivered ANG I in different vascular beds. Data (means) on myocardium, combined systemic vascular beds, lungs, and right and left cardiac cavity were obtained in 8 captopril-treated and 8 untreated pigs. Data on other vascular beds were obtained in 4 captopril-treated pigs. 


\section{ANG I clearance rates and distribution volume}

Clearance calculations included a correction for the higher conversion rate of 125I-ANG I as compared to ANG I (see above). Pulmonary clearance of ANG I was $0.15(0.16) \mathrm{L} / \mathrm{min}$ in the captopril-treated animals and $0.49(0.16) \mathrm{L} / \mathrm{min}$ in the untreated animals ( $n=8$ in both groups, $p<0.01$ ). Intrinsic clearance of ANG I in the combined systemic vascular beds was $2.51(0.94) \mathrm{L} / \mathrm{min}$ with captopril and $1.70(0.61) \mathrm{L} / \mathrm{min}$ without captopril $(\mathrm{n}=8$ in both groups, difference not significant). Thus, with captopril treatment, the contribution of the lungs to the whole body clearance of ANG $I$ appears to be negligible. Under these circumstances the whole body clearance of ANG I can be calculated, according to the single compartment model, as (Infusion rate of $\left.{ }^{125} \mathrm{I}-\mathrm{ANG} \mathrm{I}\right) /\left({ }^{125} \mathrm{I}-\mathrm{ANG} \mathrm{I}_{\text {left atrium }}\right)$, in which ${ }^{125} \mathrm{I}$-ANG $\mathrm{I}_{\text {left atrium }}$ is the steady state concentration of ${ }^{125}$ I-ANG $I$ in the left atrium during the infusion of 125 IANG I into the left cardiac ventricle. Whole body clearance was 5.60 (1.07) $\mathrm{L} / \mathrm{min}(\mathrm{n}=8)$. Distribution volume, calculated as (whole body clearance $\left.\mathrm{t}_{1 / 2}\right) / \ln 2$, was $6.47(0.93)$ L. This value represents $18-32$ (mean 24) $\%$ of total body weight. These results show that ANG I is not limited to the intravascular compartment, since the plasma volume is only $4-5 \%$ of total body weight ( 6 ).

\subsection{Discussion}

Earlier reports have raised some doubt as to whether ${ }^{125}$ I-labeled angiotensins can be used as a tracer for in vivo metabolic studies $(9,11)$. The aim of the present work was to address this point specifically with regard to ANG I, because this peptide is the direct product of renin's enzymatic action and because little quantitative data are available on ANG I metabolism by the tissues in vivo. Such data are relevant particularly in the light of recent evidence of renin's action at tissue sites as opposed to renin in circulating plasma (1,3).

We used highly purified mono-iodinated $125 \mathrm{I}-\mathrm{ANG} \mathrm{I}$ in our experiments. It was infused directly into the left cardiac ventricle to obtain immediate mixing of the tracer with the arterial blood delivered to the tissues. We performed our experiments in pigs, because in these animals it is possible to collect enough blood from multiple sampling sites and to collect these samples quickly enough to prevent metabolism ex vivo. The arterial and venous plasma levels of 125IANG I at steady state were used to quantify the metabolism of endogenous ANG I by the various vascular beds. Total radioactivity, which includes ${ }^{125}$ IANG I as well as its radiolabeled metabolites, was also measured in arterial and venous plasma. Our results demonstrated that the low ${ }^{125}$ I-ANG I vein/artery ratios as measured across the various vascular beds are indeed due to rapid metabolism and not to local accumulation of $125 \mathrm{I}$-ANG I. 
Our results in pigs in which ANG I was infused simultaneously with 125IANG I demonstrate that the metabolism of 125 I-ANG I was different from that of ANG I. It appeared that the extraction ratios across the pulmonary and the combined extrapulmonary vascular beds were higher for ${ }^{125}$ I-ANG I than for ANG I, a phenomenon that was observed in untreated pigs, but not in pigs treated with the ACE inhibitor captopril. The metabolism of ANG I comprises ANG I-M conversion and ANG I degradation. By the latter process peptides other than ANG $\mathrm{II}$ are formed. The above results indicate that the rate of 125IANG I-II conversion was higher than the rate of ANG I-II conversion but that the rate of degradation was the same for ${ }^{25} \mathrm{I}$-ANG I and ANG I. This was further confirmed by expressing the extraction ratios, $E$, as a function of $k_{1} t$ and $k_{2} t, k_{1}$ and $k_{2}$ being the first order rate constants for degradation and conversion respectively, and the time 125I-ANG I or ANG I is exposed to the degrading and converting enzymes. By doing so it was found that $\mathrm{k}_{2} \mathrm{t}$ for ${ }^{125 \mathrm{I}}$ ANG I-II conversion in the pulmonary and the combined extrapulmonary vascular beds was indeed higher than $k_{2} t$ for ANG I-II conversion, and that $k_{1} t$ for ${ }^{125} \mathrm{I}$-ANG I degradation was not different from $k_{1} t$ for ANG I degradation. As expected, it was conversion and not degradation that was reduced by captopril treatment. The first order rate constant for ${ }^{125}$ I-ANG I-II conversion in vivo appeared to be approximately 2 times that of ANG I-II conversion. In vitro experiments with plasma demonstrated that the $\mathrm{V}_{\max } / \mathrm{K}_{\mathrm{m}}$ ratio of angiotensin converting enzyme (ACE) with ${ }^{125 I-A N G ~ I ~ a s ~ t h e ~ s u b s t r a t e ~ w a s ~}$ also 2 times higher than with ANG $I$ as the substrate. This is probably the explanation for our findings in vivo. To calculate ANG I extraction by the vascular beds, the measurements of 125 I-ANG I extraction were corrected for the difference between ${ }^{125 I-A N G ~ I-I I ~ a n d ~ A N G ~ I-I I ~ c o n v e r s i o n ~ r a t e s . ~ T h i s ~ w a s ~}$ done by multiplying the first order rate constant for ${ }^{125 I-A N G ~ I-I I ~ c o n v e r s i o n ~}$ by a factor of 0.5 . In these calculations it was assumed that $k_{1} t$ for ${ }^{125} \mathrm{I}$-ANG I degradation was not different from $k_{1} t$ for ${ }^{125} \mathrm{I}-\mathrm{ANG}$ II degradation. Preliminary experiments in which we infused ${ }^{125}$ I-ANG II instead of 125 I-ANG $I$, showed indeed little difference in degradation rate between ${ }^{125}$ I-ANG $I$ and ${ }^{125}$ I-ANG II, both across the pulmonary and the combined systemic vascular beds (unpublished results). In our calculations it was further assumed that $k_{1} t$ for ANG I degradation was not different from $k_{1} t$ for ANG II degradation.

The intrinsic clearance of ANG I in the combined systemic vascular beds was calculated to be approximately 1-2 times the cardiac output of plasma. This is much too high to be explained by metabolism in the circulating blood and elimination via glomerular filtration. The high clearance rate is caused by rapid metabolism in the tissues. It is interesting to note that, in the heart, the rapid metabolism of plasma ANG I does not seem to depend on the passage of blood through the capillaries. Probably the endocardium, like the vascular 
endothelium, is a site of ANG I metabolism. The presence of ACE on the surface of the cardiac valves has indeed been demonstrated $(8,22)$.

In the combined systemic vascular beds about 20 percent of the metabolism of arterially delivered ANG I was due to ANG I-II conversion, whereas in the pulmonary vascular bed about 90 percent of the metabolism was due to ANG III conversion. It is well known that the lungs are not the only site of ANG I-II conversion $(4,10,16)$. Our study provides quantitative information on the extrapulmonary ANG I-II conversion and shows in fact that about half of the conversion of circulating ANG I occurs outside the lungs. There was not only considerable conversion in the combined systemic vascular beds, but also in the left cardiac cavity.

After ACE inhibitor treatment there was little ANG II generation from infused ANG I. The ACE inhibitor-induced decrease in $k_{2} t$ for ANG I-II conversion was associated with an increase in $\mathrm{k}_{1} \mathrm{t}$ for $\mathrm{ANG} I$ degradation in the combined systemic vascular beds, but not in the cardiac cavities and the lungs. The mechanism of this increase in $k_{1} t$ is unknown. Our study indicates that systemically delivered ANG $I$ is rapidly distributed over a compartment with a size corresponding to $24 \%$ of total body weight, which is also the size of the extracellular fluid volume. There may be some degree of compartmentalization of the processes of conversion and degradation in the sense that it is mainly the blood-borne ANG I that is subject to conversion, whereas interstitial fluid ANG I is mainly subject to degradation. Our calculations of $k_{1} t$ and $k_{2} t$ do not account for this, but it is conceivable that such compartmentalization may explain why, in contrast with the combined systemic vascular beds, in the cardiac cavities and the lungs no rise in $\mathrm{k}_{1} \mathrm{t}$ was observed after $\mathrm{ACE}$ inhibitor treatment. In the cardiac cavities and the lungs the ANG I delivered by the inflowing blood is primarily exposed to the endocardium and the endothelial surface of the lung vessels. The lung is known to contain relatively little interstitial fluid as compared to other tissues (17), so that in the lung the arterially delivered ANG I is mainly restricted to the blood compartment. Our results are supported by experiments, in which isolated rabbit aorta was incubated with ANG I. Also in these experiments inhibition of ACE was associated with increased degradation (2). Anyhow, our results show that decreased conversion during captopril treatment was associated with increased degradation. Thus, there was little or no ANG I accumulation during ACE inhibitor treatment. Renin stimulation is therefore by far the most important, if not the only, cause for the rise in plasma ANG I that is usually observed after ACE inhibitor treatment.

We conclude that mono-iodinated ${ }^{125}$ I-ANG I is a suitable tracer for the type of metabolic studies we did, with the proviso that one has to account for the fact that $125 \mathrm{I}-\mathrm{ANG} \mathrm{I}$ is converted by $\mathrm{ACE}$ at a higher rate than ANG I. Our study indicates that ANG I infused into the circulation is rapidly distributed over a compartment corresponding in size with the extracellular fluid volume. 
The large arteriovenous concentration gradients of $125 \mathrm{I}-\mathrm{ANG}$ I that were observed across the various vascular beds during ${ }^{125 I-A N G ~ I ~ i n f u s i o n ~ a r e ~}$ caused by rapid metabolism in the tissues. ANG II formation depends on ACE, but ANG I conversion is not a critical intermediary step in ANG I metabolism. The present results may be used as a basis for further studies aimed at quantifying in the intact animal ANG I production at tissue sites versus ANG I production in the circulation.

\subsection{References}

1. Admiraal PIJ, Derkx FHM, Danser AHJ, Pieterman H, Schalekamp MADH. Metabolism and production of angiotensin $I$ in different vascular beds in subjects with hypertension. Hypertension 15: 44-55, 1990.

2. Bünning P, Bunek W, Escher R, Schönherr E. Characteristics of angiotensin converting enzyme and its role in the metabolism of angiotensin I by endothelium. $J$ Cardiovasc Pharmacol 8 (suppl 10): S52-S57, 1986.

3. Campbell DJ. The site of angiotensin production. J Hypertens 3: 199-207, 1985.

4. Egleme C, Cressier F, Wood JM. Local formation of angiotensin II in the rat aorta: effect of endothelium. Br J Pharmacol 100: 237-240, 1990.

5. Greenwood FC, Hunter WM, Glover JS. The preparation of 131I-labeled human growth hormone of high specific radioactivity. Biochem $J 89: 114-123,1963$.

6. Hannon JP, Bossone CA, Rodkey WG. Splenic red cell sequestration and blood volume measurements in conscious pigs. Am J Physiol 248: R293-R301, 1985.

7. Healy KP, Maciejewski AR, Printz MP. Autoradiographic localization of 125 I-angiotensin II binding sites in the rat adrenal gland. Endocrinology 116: 1221-1223, 1985.

8. Jackson B, Fabris B, Kohzuki M, Mendelsohn FAO, Johnston CI. Angiotensin converting enzyme in the myocardium of rats with heart failure following myocardial infarct. J Hypertens 8 (suppl. 3): S40, 1990.

9. Kurcbart H, Coli A, Vancheri L, Rosa U. Chemical and biological effects associated with the iodination of angiotensin II. Biochem Biophys Acta 230: 160-169, 1971.

10. Lembeck F, Griesbacher $T$, Eckhardt M. Demonstration of extrapulmonary activity of angiotensin converting enzyme in intact tissue preparations. Br J Pharmacol 100:49-54, 1990.

11. Lin SY, Ellis H, Weisblum B, Goodfriend TL. Preparation and properties of iodinated angiotensins. Biochemical Pharmacology 19: 651-662, 1970.

12. Mendelsohn FAO, Quiron R, Saavedra $\mathrm{MM}$, Aguilera $\mathrm{G}$, Catt $\mathrm{KJ}$. Autoradiographic localization of angiotensin II receptors in rat brain. Proc Natl Acad Sci USA 81: 1575-1579, 1984.

13. Mendelsohn FAO, Dunbar M, Allen A, Chou ST, Millan MA, Aguilera G, Catt KJ. Angiotensin II receptors in the kidney. Fed Proc 45: 1420-1425, 1986.

14. Navar LG, Rosivall L, Carmines PK, Oparil S. Effects of locally formed angiotensin II on renal hemodynamics. Fed Proc 45: 1448-1453, 1986.

15. Nussberger J, Brunner DB, Waeber B, Brunner HR. Specific measurement of angiotensin metabolites and in vitro generation of angiotensin II in plasma. Hypertension 8: 476-482, 1986.

16. Pipili E, Manolopoulos VG, Catravas JD, Maragoudakis ME. Angiotensin converting enzyme activity is present in the endothelium-denuded aorta. Br J Pharmacol 98: 333-335, 1989.

17. Prichard JS, Lee G de J. The pulmonary circulation. In: Oxford Textbook of Medicine (second edition), edited by Wheaterall DJ, Ledingham JGG, Warrell DA. Oxford University Press 1987, p. 13.335. 
18. Rowland M, Benet LZ, Graham GG. Clearance concepts in pharmacokinetics. $J$ Pharmacokinet Biopharm 1: 123-136, 1973.

19. Rosivall L, Rinder DF, Champion $J$, Khosla MC, Navar LG, Oparil S. Intrarenal angiotensin I conversion at normal and reduced blood flow in the dog. Am J Physiol 245: F408-F415, 1983.

20. Wilkinson GR, Shand DG. A physiological approach to hepatic drug clearance. Clin Pharmacol Ther 18: 377-390, 1975.

21. Wilkinson GR. Clearance concepts in pharmacology. Pharmacol Rev 39: 1-47, 1987.

22. Yamada H, Fabris B, Allen AM, Jackson B, Johnston CI, Mendelsohn FAO. Localization of angiotensin converting enzyme in rat heart. Circ Res 68: 141-149, 1991. 


\section{PRODUCTION OF ANGIOTENSINS II AND II AT TISSUE SITES IN THE INTACT PIG}

\subsection{Summary}

Angiotensins (ANG) are known to be generated in circulating plasma and at tissue sites. It is not known to what extent generation of ANG I outside the blood stream and conversion of this locally generated ANG I to ANG M contribute to the circulating levels of ANG I and ANG II. To answer these questions, the plasma levels ANG I, ANG II, 125I-ANG I, and 125I-ANG II were measured in arterial and venous blood across a number of vascular beds, during constant infusion of mono-iodinated 125I-ANG I into the left cardiac ventricle of anesthetized pigs with unstimulated and stimulated renin production. From the vein/artery ratios of $125 I-A N G ~ I$ and II and the arteriovenous gradients of ANG I and II it could be calculated what fraction of ANG I and II in regional venous plasma was arterially delivered and what de novo produced, and what fraction of venous ANG II was derived from regional conversion of arterially delivered ANG I. By parallel measurements of plasma renin activity (PRA) and by taking into account the regional blood transit time, it was possible to estimate the contribution of circulating PRA to the de novo production of ANG I and II. De novo ANG I production in the combined systemic vascular beds was increased during treatment with the angiotensin converting enzyme (ACE) inhibitor captopril $(n=12)$ or the diuretic furosemide $(n=4)$, as compared with untreated animals $(n=8)$. ANG II production in the combined systemic vascular beds was greater than in the lungs, demonstrating the importance of extrapulmonary ANG I-II conversion. In the lungs virtually no ANG I but $31 \%$ of ANG II in venous plasma was derived from de novo production, and de novo produced ANG II could fully be accounted for by conversion of circulating ANG I. In myocardium, head, skin, skeletal muscle and kidney, respectively $40,58,55,67$, and $94 \%$ of venous $A N G I$, and $32,49,40,59$ and $85 \%$ of venous $A N G$ II was derived from de novo production. In these vascular beds a substantial fraction of de novo produced ANG I could not be accounted for by circulating PRA ( $>25 \%$ in myocardium, $>80 \%$ in the other regions, if blood transit time $=10 \mathrm{sec}$ ). In addition, de novo produced venous ANG II was too high to be attributed only to conversion of circulating ANG $I$. These results indicate that indeed production of ANG I at tissue sites contributes to its circulating level, and that some circulating ANG II may not be derived from circulating ANG I. 


\subsection{Introduction}

The classical view of renin and angiotensins as circulating hormones has been challenged by a number of investigators in recent years. It is now recognized that many tissues contain a complete renin-angiotensin system (8), and there is increasing evidence that part of the angiotensin I (ANG I) in circulating plasma does not originate from the catalytic action of circulating renin on circulating angiotensinogen $(\mathbb{1}, 3,10)$. Some plasma ANG $I$ is probably produced by renin that is present in vascular tissue (19). Vascular renin may be plasma-derived $(17,22)$ or is perhaps synthesized in situ $(8,14)$. It is not known how much ANG I is produced outside the circulating blood and how much of this extracirculatory ANG I enters the circulation.

Angiotensin II (ANG II), the most important biologically active product of the renin-angiotensin system in circulating plasma, is commonly thought to be derived from the conversion of circulating ANG I by membrane-bound angiotensin converting enzyme (ACE) of the vascular endothelium. $\mathrm{ACE}$ however, is not only present in the vascular endothelium but also elsewhere in vascular tissue $(2,9,18)$ and it is therefore conceivable that part of circulating ANG II is derived from the conversion of ANG I that is produced at tissue sites outside the circulating blood.

Both ANG I and ANG II are rapidly eliminated by the tissues, due to degradation by peptidases into peptides with little or no biological activity. ANG $I$ is also eliminated by its conversion to ANG $\mathrm{II}$. In a previous study we measured degradation and conversion in different vascular beds in intact pigs (5). This was done by administering ${ }^{125}$ I-ANG I via constant infusion into the left cardiac ventricle and by measuring the steady state plasma levels of 125 ANG I and 125 I-ANG $\mathbb{I I}$ in the inflowing (arterial) and outflowing (venous) blood of different vascular beds. Here we report on the results of simultaneous measurements of the plasma levels of endogenous ANG I and ANG II and radiolabeled ANG I and ANG II, during the constant infusion of $125 \mathrm{I}$-ANG I. From these results combined with data presented in the previous paper we were able to estimate what proportion of ANG I is produced in circulating plasma and what at tissue sites. It was also possible to estimate what proportion of ANG II is produced by the conversion of arterially delivered ANG I and what not.

\subsection{Materials and methods}

\section{Assay of angiotensins}

The materials that were used and the methods for measuring the plasma levels of labeled and unlabeled ANG I and ANG II are described in the previous paper (5). 


\section{Measurement of plasma renin activity}

Plasma renin activity (PRA) was measured by incubating plasma for $10,20,30$ and $60 \mathrm{~min}$ at $\mathrm{pH} 7.4$ and $37{ }^{\circ} \mathrm{C}$ in the presence of a mixture of inhibitors to block ANG I degradation, ANG I-II conversion and prorenin-renin conversion and to prevent bacterial growth (6). Preliminary experiments showed that ANG I generation was linear in the first $30 \mathrm{~min}$ of incubation. Thereafter ANG I generation tended to decrease slightly. Only the first linear part of ANG I generation was used for measuring PRA.

\section{Infusion Protocol}

Twentyfour female pigs (crossbred Yorkshire $\mathrm{x}$ Landrace, Hedelse Varkens Combinatie, Hedel, The Netherlands) with a body weight of $23-31 \mathrm{~kg}$ were included in the study. The pigs were kept on a normal sodium diet. In 12 pigs the renin production was stimulated by treatment with captopril $(25 \mathrm{mg}$ twice daily, for 3 days), and in 4 pigs by treatment with furosemide ( $40 \mathrm{mg}$ twice daily, for 3 days). The experiments in the captopril-treated and furosemidetreated pigs were performed 3-4 hours after dosing.

The pigs were anesthetized, and arterial and venous catheters were installed as described before (5). Blood pressure, heart rate, cardiac output and left anterior decending coronary artery blood flow were monitored continuously during the infusion. Hematocrit measurements were performed in arterial blood to enable us to convert blood flow measurements into plasma flow values. Sampling sites were: aorta, pulmonary artery, left and right atrium, great cardiac vein, and renal, femoral, jugular and ear lobe veins.

After a stabilization period of $45 \mathrm{~min}$ following the completion of instrumentation, the pigs were given a constant infusion of 125I-ANG I, $3.6 \mathrm{x}$ $10^{6}\left(0.9 \times 10^{6}\right) \mathrm{cpm} / \mathrm{min}$ (mean and SD), into the left cardiac ventricle during 20 min. The infusion did not influence blood pressure, heart rate, cardiac output or coronary blood flow.

Blood samples for measuring the plasma levels of 125 I-labeled and unlabeled angiotensins were taken from the various sampling sites at $2 \mathrm{~min}$ before and at steady state during the infusion of $125 \mathrm{I}$-ANG I as described before (5).

Blood samples for measuring PRA were also taken during the infusion. The blood was collected into polystyrene tubes containing disodium EDTA $(0.1 \mathrm{~mL}$ EDTA solution in $3 \mathrm{~mL}$ blood, final concentration in blood $10 \mathrm{mM}$ ). The samples were centrifuged at $3000 \mathrm{~g}$ for $10 \mathrm{~min}$ at room temperature. Plasma was stored at $-20^{\circ} \mathrm{C}$.

\section{Calculations}

Regional production of angiotensin I. Regional ANG I production was 
calculated for the following vascular beds: 1) lung (pulmonary artery to left atrium), 2) combined systemic vascular beds (aorta to right atrium), 3) myocardium (aorta to great cardiac vein), 4) head (aorta to jugular vein), 5) skin (aorta to ear lobe vein), 6) skeletal muscle (aorta to femoral vein) and 7) kidney (aorta to renal vein).

Regional ANG I production will be referred to in two ways: 1) total regional ANG I production, and 2) regional ANG I production by circulating PRA. Total regional ANG I production in the systemic vascular beds was calculated as the product of the regional intrinsic clearance and the plasma level of ANG I in outflowing (venous) blood:

Total regional ANG I production $=\mathrm{Q} \cdot\left[\mathrm{E}_{\mathfrak{I}} /\left(1-\mathrm{E}_{\mathrm{I}}\right)\right] \cdot \mathrm{ANG} \mathrm{I}_{\text {out }}$,

in which ANG $I_{\text {out }}$ is the concentration of endogenous ANG I in outflowing (venous) plasma. $\mathrm{Q}$ is the regional plasma flow. For the combined systemic vascular beds $\mathrm{Q}$ equals the cardiac output of plasma. $\mathrm{E}_{\mathrm{I}}$ is the extraction ratio of ANG I, which according to our previous paper (5) is given by the following formula:

$\mathrm{E}_{\mathbb{I}}=1-\mathrm{e}^{-\left(* \mathrm{k}_{1} \mathrm{t}+0.5 \cdot * \mathrm{k}_{2} \mathrm{t}\right)}$

in which $* \mathrm{k}_{1}$ and ${ }^{*} \mathrm{k}_{2}$ are the first order rate constants of ${ }^{125}$ I-ANG I degradation (to peptides other than 125I-ANG II) and 125I-ANG I-II conversion respectively, and $t$ is the time during which $25 I-A N G I$ is exposed to the degrading and converting enzymes as the blood flows from the arterial to the venous side. Equation (2) accounts for the difference in conversion rate between labeled and unlabeled ANG I (5).

Equation (1) is based on the 'venous equilibrium' model. In this model the vascular bed between the arterial and venous sampling sites is considered to be a single, well-stirred compartment with an ANG I concentration equal to that in outflowing (venous) plasma (25).

As shown previously (5), the 'venous equilibrium' model can be applied to the systemic vascular beds but not to the pulmonary vascular bed. For the lungs it can be assumed that the clearance of ANG I equals its clearance from plasma, so that:

Total pulmonary ANG I production $=\mathrm{Q} \cdot\left[\mathrm{ANG} \mathrm{I}_{\text {out }}-\left(1-\mathrm{E}_{\mathrm{I}}\right) \cdot \mathrm{ANG} \mathrm{I}_{\mathrm{in}}\right]$,

in which ANG $I_{\text {out }}$ and ANG $I_{\text {in }}$ are the plasma concentrations of endogenous ANG I in the left atrium and the pulmonary artery respectively. Q equals the cardiac output of plasma. 
The regional ANG I production by PRA was calculated as follows:

Regional ANG I production by PRA $=\mathrm{Q} \cdot \mathrm{PRA} \cdot$ transit time,

in which transit time is the transit time of plasma as it flows from the arterial to the venous side of the vascular bed.

Regional venous ANG I originates in part from arterially delivered ANG I and is in part derived from de novo production. Regional venous ANG I from arterial delivery is given by the following equation:

$A N G I_{\text {out }}$ from $A N G I_{\text {in }}=\left(1-\mathbb{E}_{\mathrm{I}}\right) \cdot A N G I_{\text {in }}$.

Regional production of angiotensin II. Regional production of ANG II was calculated for the same vascular beds as for ANG I. In analogy with regional ANG I production, the regional production of ANG II will be referred to as 1) total regional ANG M production, and 2) regional ANG II production by conversion of arterially delivered ANG I. Total regional ANG II production in the systemic vascular beds was calculated as the product of the regional intrinsic clearance of ANG II and the plasma level of ANG II in outflowing (venous) blood:

Total regional ANG II production $=\mathrm{Q} \cdot\left[\mathrm{E}_{\mathrm{II}} /\left(1-\mathrm{E}_{\mathrm{II}}\right)\right] \cdot \mathrm{ANG} \Pi_{\text {out }}$,

in which ANG $\mathrm{I}_{\text {out }}$ is the concentration of endogenous ANG II in outflowing (venous) plasma. $\mathrm{E}_{\mathbb{I}}$ is the extraction ratio of $A N G \mathbb{I I}$, which is given by the following formula:

$E_{\text {II }}=1-e^{-* k_{1} t}$

This equation is analogous with equation (2) for $E_{\mathrm{I}}$, the extraction ratio of ANG I. The difference between the two equations is related to the fact that ANG I is subject to both conversion and degradation, whereas ANG II is only subject to degradation. Equation (7) is based upon the assumption that the first order rate constants for 125 I-ANG II degradation and 125I-ANG I degradation are equal. It further accounts for the fact that the degradation rates for labeled and unlabeled ANG I are not different (5).

In analogy with pulmonary ANG I production, the total pulmonary ANG II production was calculated as follows:

Total pulmonary ANG II production $=\mathrm{Q} \cdot\left[\mathrm{ANG} \mathrm{M}_{\mathrm{out}}-\left(1-\mathrm{E}_{\mathrm{II}}\right) \cdot \mathrm{ANG} \mathrm{M}_{\mathrm{in}}\right] \cdot(8)$ 
The regional ANG II production from arterially delivered ANG I was calculated as the product of regional plasma flow, the plasma level of ANG I in inflowing (arterial) blood, and the fractional conversion of arterially delivered ANG I. Fractional conversion of arterially delivered ANG I is given, according to our previous paper (5), by the following equation:

Fractional conversion $=\mathrm{E}_{\mathrm{I}} \cdot\left[0.5 \cdot * \mathrm{k}_{2} \mathrm{t} /\left(* \mathrm{k}_{1} \mathrm{t}+0.5 \cdot * \mathrm{k}_{2} \mathrm{t}\right)\right]$,

so that:

Regional ANG II production from arterially delivered ANG I =

$\mathrm{Q} \cdot \mathrm{ANG} \mathrm{I}_{\mathrm{in}} \cdot \mathrm{E}_{\mathrm{I}} \cdot\left[0.5 \cdot * \mathrm{k}_{2} \mathrm{t} /\left(* \mathrm{k}_{1} \mathrm{t}+0.5 \cdot * \mathrm{k}_{2} \mathrm{t}\right)\right]$.

Regional venous ANG II originates in part from arterially delivered ANG II and is in part derived from regional de novo production. Regional conversion of arterially delivered ANG I is, at least partly, responsible for this de novo production. Regional venous ANG II from arterial delivery is given by the following equation:

ANG $I_{\text {out }}$ from $A N G I_{\text {in }}=\left(1-E_{I I}\right) \cdot A N G \Pi_{\text {in }}$.

If, as mentioned above, it is assumed that the first order rate constants for ${ }^{125}$ IANG II degradation and 125I-ANG I degradation are equal, and that the degradation rates for labeled and unlabeled ANG I are also equal (5), the regional venous ANG II produced by regional conversion of arterially delivered ANG I is given by the following equation:

ANG $\mathbb{I}_{\text {out }}$ from $A N G I_{\text {in }}=\left(E_{I}-E_{I I}\right) \cdot A N G I_{\text {in }}$.

Statistical evaluation. Differences in ANG I and ANG II concentration between the various sampling sites were evaluated for statistical significance $(p<0.05)$ by using Scheffé's test for multiple comparison. Differences between total regional ANG I production and regional ANG I production by PRA, and differences between total regional ANG II production and regional ANG II production from arterially delivered ANG I were evaluated for statistical significance $(p<0.05)$ by using Student's t-test for paired observations. Differences between the various groups of pigs were evaluated for statistical significance $(p<0.05)$ by using either Student's t-test or Mann-Whitney's Utest for unpaired observations. 


\subsection{Resultis}

Plasma levels of angiotensin I, angiotensin II and PRA

The plasma levels of ANG I, ANG II and PRA were stable over the experimental period the blood samples were collected. As expected, the levels of PRA and ANG I were increased in the captopril-treated and furosemidetreated pigs as compared to the untreated animals (Table 1). The levels of ANG I and PRA were linearly correlated, and the regression line in the captopriltreated group was not significantly different from that in the other two groups (Fig. 1). The levels of ANG I and ANG II were also correlated, but for a given level of ANG I, ANG II was lower in the captopril-treated group than in the other two groups (Fig. 2).

Plasma ANG I in the untreated and the furosemide-treated pigs was higher in the right atrium than in the aorta, and it was lower in the left atrium than in the pulmonary artery (Table 1). Thus, there was net ANG I delivery to the systemic circulation by the combined systemic vascular beds, and net ANG I extraction from the systemic circulation by the lungs. These arteriovenous differences were not seen in the captopril-treated pigs.

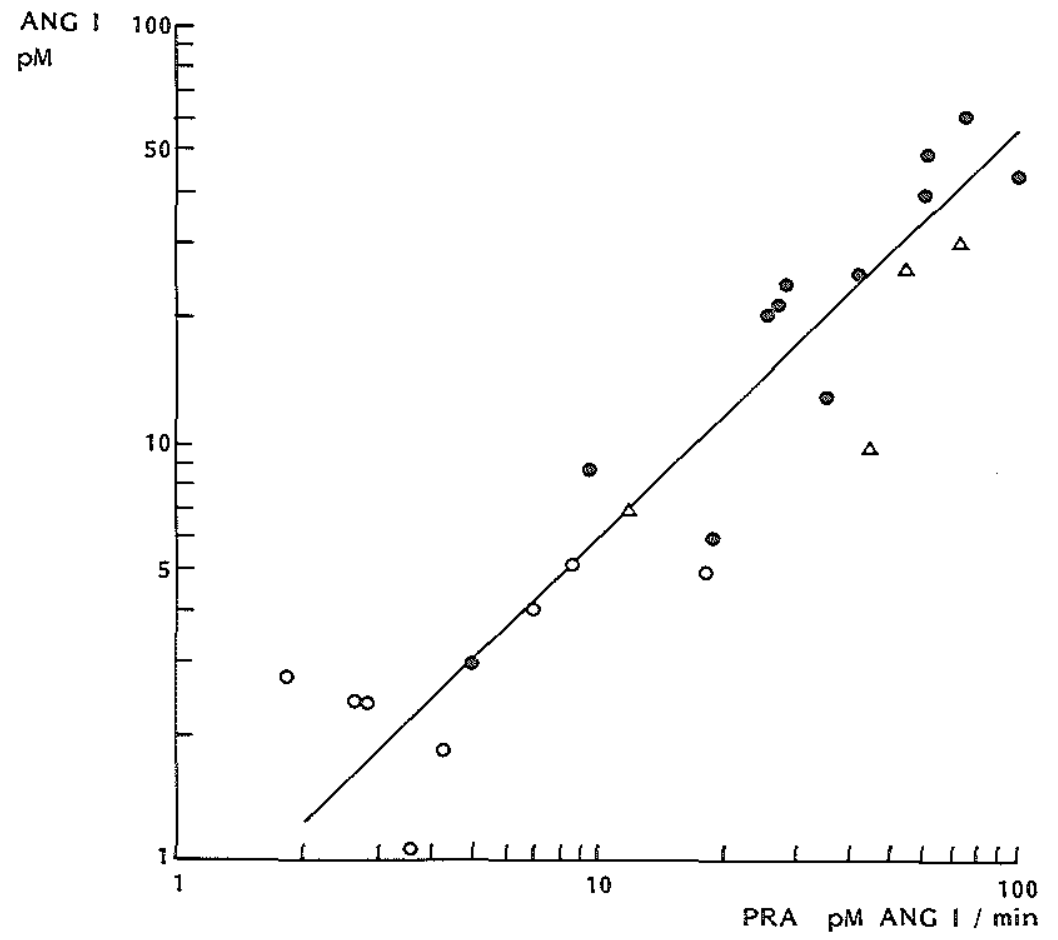

Figure 1 . Relationship between the a o r t i c pl a s m a levels of PRA and ANG $I$ in untreated (o), captopril-treated

(•) and furosemidetreated $(\Delta)$ pigs (log ANG $\mathrm{I}=$ $0.89 \cdot \log$ PRA - 0.12, $\mathrm{r}=0.92$ ). 


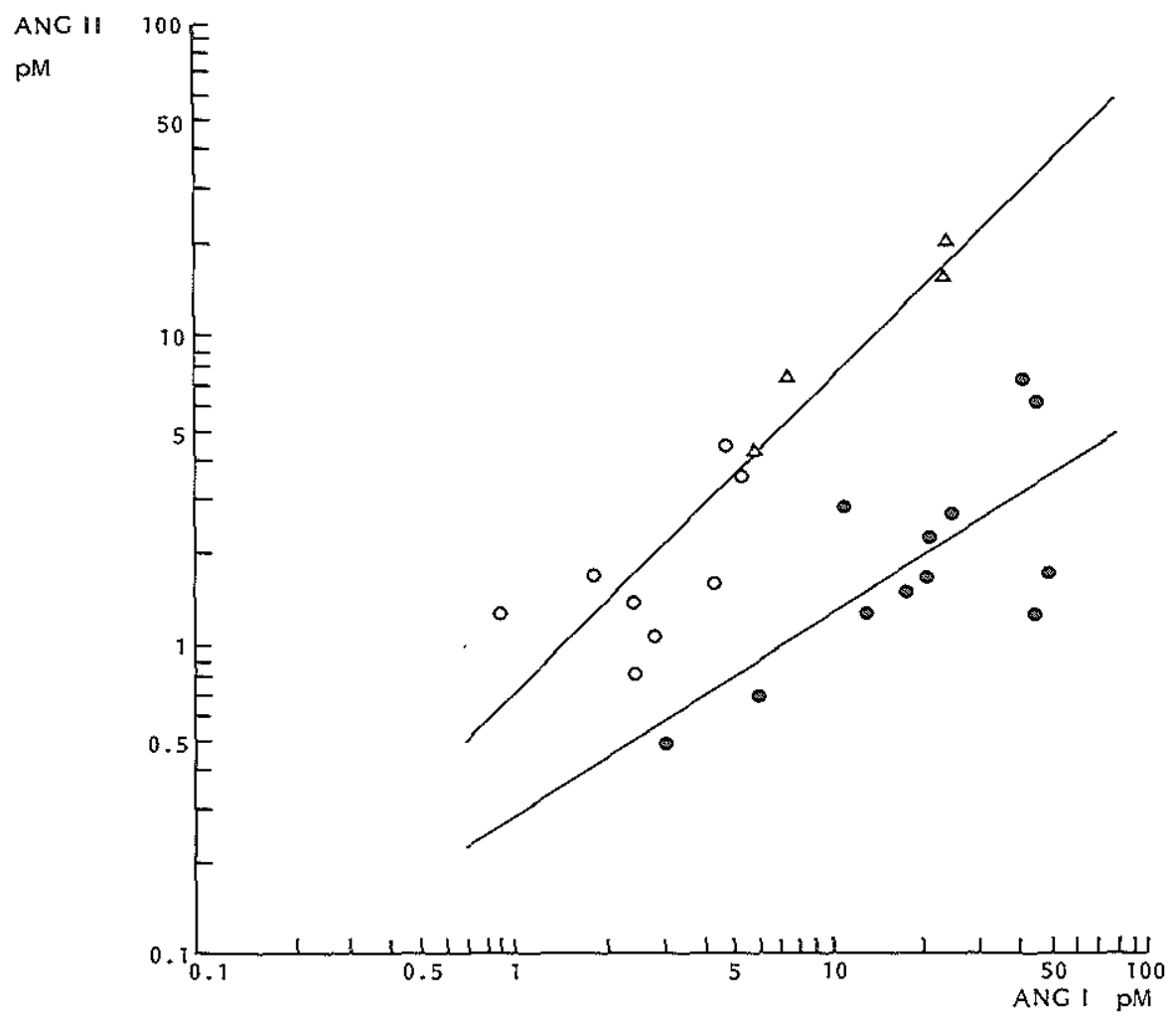

Figure 2. Relationship between the aortic plasma levels of ANG I and ANG $I$ in untreated $(o)$ and furosemide-treated $(\Delta)$ pigs (upper line; $\log$ ANG $I I=1.03 \cdot \log$ ANG I -0.17 , $r=0.91$ ) and in captopril-treated pigs ( $($ ) (lower line; $\log$ ANG II $=0.63 \cdot \log$ ANG I - 0.53, $\mathrm{r}=0.70$ ).

In contrast with ANG I, plasma ANG II was lower in the right atrium than in the aorta, and it was higher in the left atrium than in the pulmonary artery (Table 1). Again, these arteriovenous differences were seen in the untreated and furosemide-treated animals but not in the captopril-treated pigs. Thus, in the absence of ACE inhibition, there was net removal of ANG II from the systemic circulation by the combined systemic vascular beds, and net delivery of ANG II to the systemic circulation by the lungs. Across the lungs, the venoarterial difference in ANG II was close to the arteriovenous difference in ANG I. This is in accordance with our previous work, showing little degradation of both ANG I and ANG II in the lungs (5), so that most of the arterial ANG I delivered to the lungs and converted in this organ is recovered as ANG II in the blood of the left atrium. 
Table 1. Plasma levels of ANG I, ANG II and PRA.

\begin{tabular}{|c|c|c|c|c|}
\hline & $\begin{array}{l}\text { NO } \\
\text { TREATMENT } \\
n=8\end{array}$ & $\begin{array}{l}\text { CAPTOPRIL } \\
\text { GROUP } 1 \\
\mathrm{n}=8\end{array}$ & $\begin{array}{l}\text { CAPTOPRIL } \\
\text { GROUP } 2 \\
n=4\end{array}$ & $\begin{array}{l}\text { FUROSEMIDE } \\
n=4\end{array}$ \\
\hline \multicolumn{5}{|l|}{ ANG I DM } \\
\hline Aorta & $2.9(1.4)$ & $21.5(14.7)$ & $30.4(16.6)$ & $14.2(7.9)$ \\
\hline Right Atrium & $3.5(2.0)^{*}$ & $23.2(14.9)$ & - & $18.8(10.6)^{*}$ \\
\hline Pulmonary Artery & $3.4(1.7)^{*}$ & $22.2(15.0)$ & - & 18.0 (11.0)* \\
\hline Left Atrium & $2.1(0.9)$ & $20.9(15.5)$ & - & $13.4(7.9)$ \\
\hline Great Cardiac Vein & $2.9(1.2)$ & $20.8(13.9)$ & - & $12.8(7,1)$ \\
\hline Jugular Vein & - & - & $29.8(14.0)$ & $18.4(11.3)^{* * *}$ \\
\hline Ear Lobe Vein & - & - & $33.7(18.2)$ & - \\
\hline Femoral Vein & - & - & $31.5(18.0)$ & - \\
\hline Renal Vein & - & - & $45.6(28.5)^{* * *}$ & - \\
\hline \multicolumn{5}{|l|}{ ANG II DM } \\
\hline Aorta & $2.0(1.3)$ & $2.2(2.2)$ & 3.1 (1.9) & $\mathrm{I} 2.4(6.5)$ \\
\hline Right Atrium & $1.7(1.1)^{*}$ & $1.8(1.3)$ & - & $10.3(5.2)^{*}$ \\
\hline Pulmonary Artery & $1.4(0.9)^{*}$ & $1.5(1.4)$ & - & $8.9(4.7)^{*}$ \\
\hline Left Atrium & $2.2(1.8)$ & $2.2(2.0)$ & - & $13.3(7.6)$ \\
\hline Great Cardiac Vein & $1.8(0.8)$ & $2.3(2.1)$ & - & $13.0(6.9)$ \\
\hline Jugular Vein & - & - & $3.3(2.5)$ & $12.0(6.7)$ \\
\hline Ear Lobe Vein & - & . & $2.8(1.2)$ & - \\
\hline Femoral Vein & - & - & $2.8(1.5)$ & - \\
\hline Renal Vein & - & - & $2.0(1.2)^{* * *}$ & - \\
\hline \multicolumn{5}{|c|}{ PRADM ANG $\mathrm{l} / \mathrm{min}$} \\
\hline Aorta & $7.4(5.7)$ & $48.8(39.8)$ & $37.6(18.8)$ & $59.8(31.5)$ \\
\hline Right Atrium & $7.7(6.5)$ & $49.9(39.3)$ & - & $55.8(26.0)$ \\
\hline Pulmonary Artery & $7.8(6.7)$ & $50.4(37.7)$ & - & $59.8(29.7)$ \\
\hline Left Atrium & $7.4(5.8)$ & $46.5(32.9)$ & - & $56.0(26.6)$ \\
\hline Great Cardiac Vein & $7.9(7.5)$ & $49.5(37.8)$ & - & $60.0(30.7)$ \\
\hline Jugular Vein & - & - & $37.5(19.7)$ & $51.1(26.3)$ \\
\hline Ear Lobe Vein & . & - & $38.8(17.5)$ & - \\
\hline Femoral Vein & - & - & $33.6(16.7)$ & - \\
\hline Renal Vein & - & - & $75.8(50.2)^{* * *}$ & - \\
\hline
\end{tabular}

Data are means and SD.

* in untreated and furosemide-treated pigs, angiotensin plasma levels in right atrium and pulmonary artery were significantly different from plasma levels in aorta and left atrium $(\mathrm{p}<$ 0.05 , Scheffé's test for multiple comparison).

** levels were higher than in aorta in all 4 experiments.

$* * *$ levels were lower than in aorta in all 4 experiments. 


\section{Regional production of angiotensin I}

As demonstrated by the data in Fig. 3, the regional production rates in the systemic vascular beds were high enough to compensate for the rapid elimination of this peptide. In the lungs all ANG I in venous plasma appears to be derived from arterial delivery and not from de novo production. In the combined systemic vascular beds, and in myocardium, head, skin, skeletal muscle and kidney, respectively 59 (14), 40 (13), 58 (6), 55 (11), 67 (11) and 94 (5) \% of venous ANG I was derived from de novo production (mean and SD). In Table 2, the ANG I production rates in the combined systemic vascular beds, the lungs and the myocardium are given. ANG I production was increased about 10 -fold in the captopril- and furosemide-treated pigs as compared with the untreated pigs.

Table 2. ANG I and ANG II production rates in the combined systemic vascular beds, the lungs and the myocardium.

\begin{tabular}{|c|c|c|c|c|}
\hline & & $\begin{array}{l}\text { NO } \\
\text { TREATMENT }\end{array}$ & CAPTOPRIL & FUROSEMDE \\
\hline \multicolumn{5}{|c|}{ Combined Systemic Vascular Beds } \\
\hline ANG I production & $(\mathrm{pmol} / \mathrm{min})$ & $3.5(2.2-12.8)$ & $43.0(8.6-180)^{*}$ & $50.1(27.2-85.0)^{*}$ \\
\hline ANG II production & $(\mathrm{pmol} / \mathrm{min})$ & $1.6(0.8-5.1)$ & $3.6(0.5-7.3)$ & $21.7(11.6-30.6)^{*}$ \\
\hline \multicolumn{5}{|l|}{ Lungs } \\
\hline ANG I production & $(\mathrm{pmol} / \mathrm{min})$ & $0.2(0.0-0.6)$ & $0.3(0.0-3.6)$ & $0.7(0.0-1.5)$ \\
\hline ANG II production & (pmol/min) & $0.8(0.4-4.7)$ & $1.0(0.2-3.4)$ & $7.4(2.2-16.5)^{*}$ \\
\hline \multicolumn{5}{|l|}{ Myocardium } \\
\hline ANG I production & $(\mathrm{fmol} / \mathrm{min})$ & $39.4(12.2-71.5)$ & $319(95.4-1035)^{*}$ & $252(78.8-741)^{*}$ \\
\hline ANG II production & $(\mathrm{fmol} / \mathrm{min})$ & $9.1(2.9-23.1)$ & $18.7(7.3-157)$ & $151(49.5-397)^{*}$ \\
\hline
\end{tabular}

Data are medians and ranges.

Calculations for the combined systemic vascular beds and the myocardium were based on equations (1) and (6), and for the lungs on equations (3) and (8). The cardiac output of plasma was $1.71(0.28) \mathrm{L} / \mathrm{min}$ in the no treatment group, $1.79(0.43) \mathrm{L} / \mathrm{min}$ in the captopril group, and $2.30(0.52) \mathrm{L} / \mathrm{min}$ in the furosemide group (means and $\mathrm{SD}$ ). Left anterior descending coronary artery plasma flow, which was used for the calculations of ANG I and ANG II production by the myocardium, was $20.3(5.7) \mathrm{mL} / \mathrm{min}$ in the no treatment group, $29.2(8.5) \mathrm{mL} / \mathrm{min}$ in the captopril group, and $24.7(8.9) \mathrm{mL} / \mathrm{min}$ in the furosemide group. Since total coronary plasma flow is larger than the left anterior descending coronary artery plasma flow, the actual myocardial production rates will be larger than the figures presented here.

* significantly different from no treatment group $(p<0.005$, Mann-Whitney U-test for unpaired observations). 
The ANG I extraction ratios across the combined systemic vascular beds in these groups of animals were not significantly different (Fig. 3). As mentioned above, the arterial ANG I/PRA ratios in the various animal groups were also not different. The ANG I production rates were therefore linearly correlated with the circulating levels of PRA, and for a given level of PRA, the regional ANG I production rates in the untreated and furosemide-treated groups were not different from the production rate in the captopril-treated group.

When the ANG I production in the systemic vascular beds by circulating PRA (equation 4) is expressed as a percentage of the total regional ANG I production (equation 1), one does not need to know the regional plasma flow but one needs to know the blood transit time. Table 3 gives for a number of systemic vascular beds the percent contribution of circulating PRA to total regional ANG I production, assuming a blood transit time of $10 \mathrm{sec}$ $(13,15,23)$. Probably, the capillaries are the main site where ANG I is removed from the circulation by diffusion into the interstitium and peptidase attack. This is also the site where ANG I from the interstitium equilibrates with circulating ANG I. The blood transit times in the capillary beds is $1-3 \mathrm{sec}$ (11). Our estimate of $10 \mathrm{sec}$ is therefore probably too high, but this overestimation strengthens the conclusion that a substantial part of ANG I production in the systemic vascular beds we studied could not be accounted for by circulating PRA. There was little ANG I production in the pulmonary vascular bed; the small amount that was produced could be accounted for by PRA assuming a pulmonary blood transit time of $3 \mathrm{sec}$.

Table 3. Percentage of the total regional ANG I production in different beds that can be attributed to circulating PRA.

ANG I production by circulating PRA

(\% of total regional production)

VASCULAR BED

NO CAPTOPRIL

CAPTOPRIL

$\begin{array}{lll}\text { Lungs } & 119(70) & 109(67) \\ \text { Combined Systemic Vascular Beds } & 38(18)^{*} & 31(17)^{*} \\ \text { Myocardium } & 76(24)^{*} & 64(40)^{*} \\ \text { Head } & 44(14)^{*} & 18(7)^{*} \\ \text { Skin } & - & 16(4)^{*} \\ \text { Skeletal Muscle } & - & 11(5)^{*} \\ \text { Kidney } & - & 2(2)^{*}\end{array}$

Data are means and SD.

The 'no captopril' group comprises both the untreated and the furosemide-treated pigs. Calculations were based on equations (1), (3) and (4), assuming a blood transit time of 10 $\mathrm{sec}$ in the systemic vascular beds and $3 \mathrm{sec}$ in the lungs (see Results section).

$*$ significantly different from 100 ( $p<0.05$, Student's $t$-test for paired observations). 
(ANG $I_{\text {ven }}$ derived from ANG $\mathrm{I}_{\text {art }}$ ) / (ANG $\mathrm{l}_{\text {art }}$ )

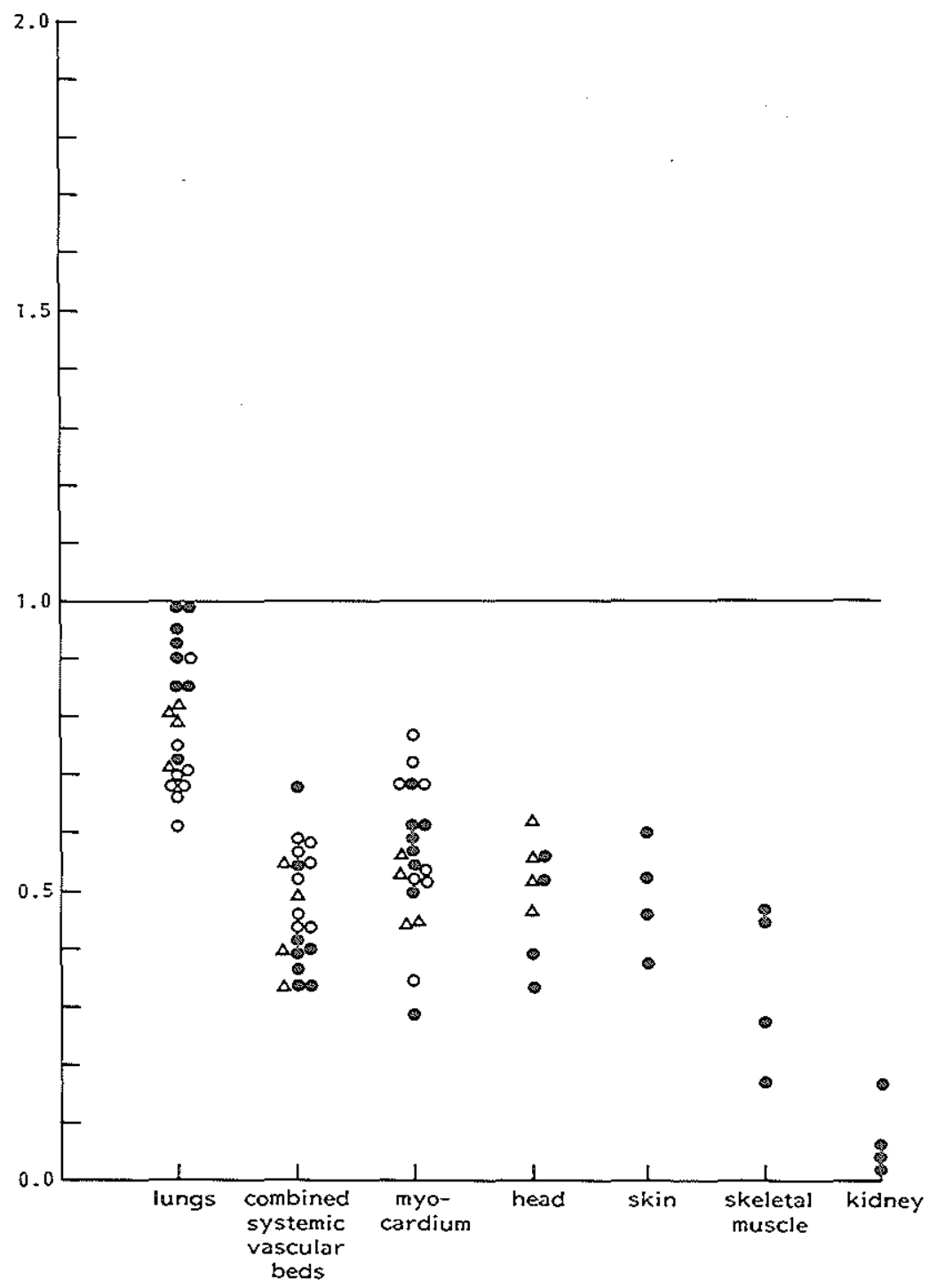

Figure 3. Calculated venous plasma levels of ANG I derived from arterially delivered ANGI (left panel) $v s$. the actually measured venous plasma levels of ANG I (right 
(ANG $I_{\text {ven }}$ ) / (ANG Iart)

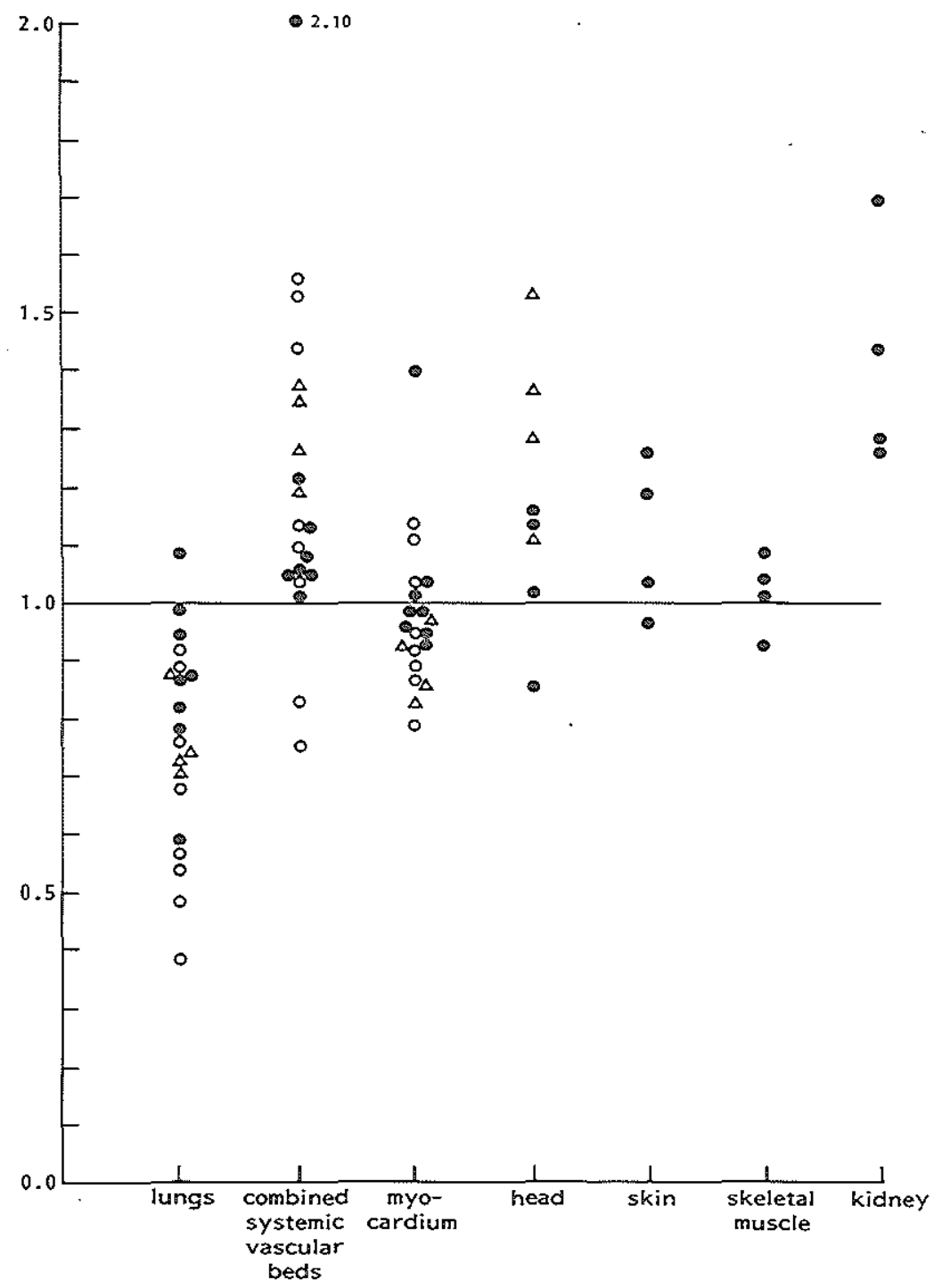

panel) in different vascular beds in untreated (o), captopril-treated $(\bullet)$ and furosemidetreated $(\Delta)$ pigs. Calculations were made on the basis of equation (5). The venous ANG llevels are expressed as a fraction of the arterial level of ANG I. 


\section{Regional production of angiotensin II}

The rapid elimination of ANG II in the systemic vascular beds was compensated for by regional production of this peptide, with the kidney as an exception (Fig. 4). The ANG $\mathbb{I}$ level in the renal vein was 60-70 percent of that in the artery. In the present study the renal extraction of ANG II and the arterial and venous levels of ANG II across the kidney were only measured in pigs on captopril treatment, but studies in humans also showed that the levels of ANG II in the renal vein are lower than those in the renal artery, both during captopril treatment and without such treatment $(1,21)$. There is also net ANG II extraction from the systemic circulation by the liver (1). Since about 40 percent of the cardiac output flows through kidneys and liver, the net extraction by these organs of systemically delivered ANG II explains why the ANG II level in the right atrium was lower than in the aorta, despite the absence of an arteriovenous ANG II gradient across the other vascular beds.

In the lungs, in the combined systemic vascular beds, and in myocardium, head, skin, skeletal muscle and kidney, respectively 31 (22), 39 (19), 32 (20), 49 (8), 40 (11), 59 (15) and 85 (8) \% of ANG II in venous plasma was derived from de novo production (mean and SD). In Table 2 the ANG II production rates in the combined systemic vascular beds, the lungs and the myocardium are given. The ANG II production rate in the combined systemic vascular beds was about 2 times higher than that in the lungs, which may illustrate the important contribution of extrapulmonary ANG I-II conversion to the whole body ANG II production.

Table 4. Fractional conversion of arterially delivered ANG I in different vascular beds.

\begin{tabular}{llll}
\hline VASCULAR BED & NO & CAPTOPRU & FUROSEMIDE \\
& TREATMENT & \\
\hline Lungs & $0.25(0.07)$ & $0.04(0.04)^{*}$ & $0.22(0.04)$ \\
Combined Systemic Vascular Beds & $0.10(0.02)$ & $0.01(0.01)^{*}$ & $0.12(0.04)$ \\
Myocardium & $0.17(0.02)$ & $0.02(0.02)^{*}$ & $0.18(0.02)$ \\
Head & - & $0.04(0.02)^{* *}$ & $0.16(0.01)$ \\
Skin & - & $0.02(0.02)$ & - \\
Skeletal Muscle & - & $0.07(0.02)$ & - \\
Kidney & - & $0.08(0.02)$ & - \\
\hline
\end{tabular}

Data are means and SD.

Fractional conversion was calculated by using equation (9).

* significantly different from 'no treatment' group $(\mathrm{p}<0.01$, Student's t-test for unpaired observations).

** significantly different from 'furosemide' group $(p<0.01$, Student's $t$-test for unpaired observations). 
Data on fractional ANG I-II conversion in the various systemic vascular beds we studied are presented in Table 4 . On the basis of these data, the percent contribution of conversion of arterially delivered ANG I to the total regional production of ANG II was calculated. The results are shown in Table 5. They indicate that a substantial part of ANG II production in the systemic vascular beds could not be accounted for by conversion of arterially delivered ANG I. ANG II production in the lungs could fully be accounted for by the conversion of ANG I from the circulation.

Table 5. Percentage of the total regional ANG II production in different vascular beds that can be attributed to conversion of arterially delivered ANG I.

\begin{tabular}{|c|c|c|c|c|}
\hline \multirow[b]{3}{*}{ VASCULAR BED } & \multicolumn{4}{|c|}{$\begin{array}{l}\text { ANG I production by conversion of circulating } \\
\text { ANG I ( } \% \text { of total regional production) }\end{array}$} \\
\hline & \multicolumn{2}{|c|}{ NOCAPTOPRIL } & \multicolumn{2}{|c|}{ CAPTOPRM } \\
\hline & $\begin{array}{l}\text { production } \\
\text { by } \\
\text { conversion } \\
\text { of } \\
\text { arterially } \\
\text { delivered } \\
\text { ANG I }\end{array}$ & $\begin{array}{l}\text { production } \\
\text { by } \\
\text { conversion } \\
\text { of } \\
\text { ANG I } \\
\text { from } \\
\text { PRA }\end{array}$ & $\begin{array}{l}\text { production } \\
\text { by } \\
\text { conversion } \\
\text { of } \\
\text { arterially } \\
\text { delivered } \\
\text { ANG I }\end{array}$ & $\begin{array}{l}\text { production } \\
\text { by } \\
\text { conversion } \\
\text { of } \\
\text { ANG I } \\
\text { from } \\
\text { PRA }\end{array}$ \\
\hline Lungs & $116(79)$ & $13(13)^{*}$ & $117(73)$ & $10(16) *$ \\
\hline Combined Systemic Vascular Beds & $26(18)^{*}$ & $10(4)^{*}$ & $16(14)^{*}$ & $6(5)^{*}$ \\
\hline Myocardium & $57(27)^{*}$ & $17(22) *$ & $41(30) *$ & $18(13)^{*}$ \\
\hline Head & $35(3)^{*}$ & $18(2)^{*}$ & $33(7)^{*}$ & $7(2)^{*}$ \\
\hline Skin & - & - & $38(27)^{*}$ & $8(6)^{*}$ \\
\hline Skeletal Muscle & _- & _ & $42(16) *$ & $9(5) *$ \\
\hline Kidney & - & - & $12(4)^{*}$ & $4(1) *$ \\
\hline
\end{tabular}

Data are means and SD.

The 'no captopril' group comprises both the untreated and the furosemide-treated pigs. ANG II production by conversion of arterially delivered ANG I was calculated by using equation (10). ANG II production by conversion of ANG I from PRA was calculated by multiplying the regional ANG I production by PRA (equation 4) with the fractional conversion of arterially delivered ANG I (data presented in Table 4). Blood transit times were assumed to be $10 \mathrm{sec}$ in the systemic vascular beds and $3 \mathrm{sec}$ in the lungs (see Results section).

* significantly different from 100 ( $p<0.05$, Student's $t$-test for paired observations). 
(ANG 11 ven cierived from ANG Ilart and from

regional conversion of ANG 1 art) / (ANG 11 art)

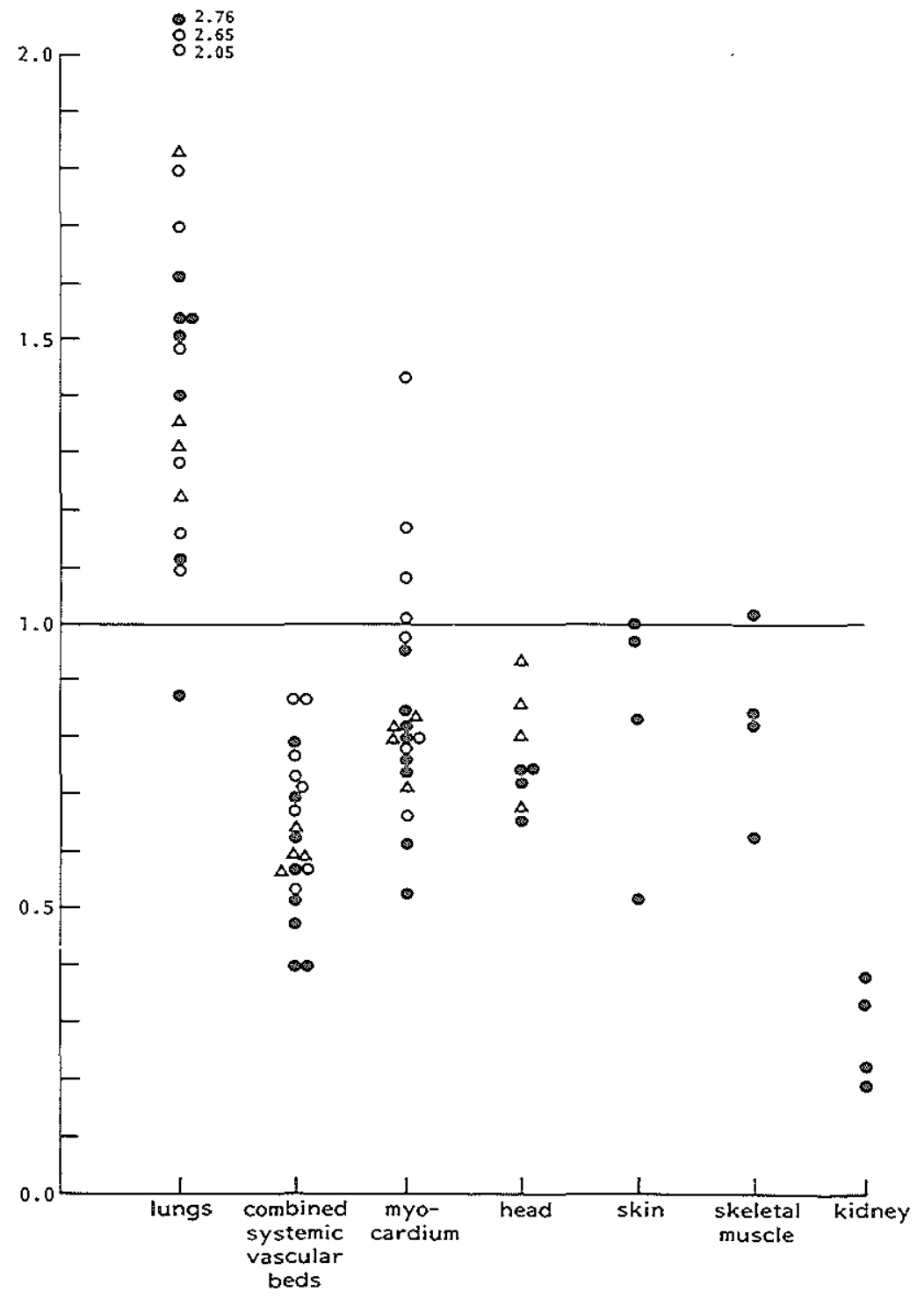

Figure 4. Calculated regional venous plasma levels of ANG II derived from arterially delivered ANG II and from conversion of arterially delivered ANG I (left panel) vs. actually measured venous plasma levels of ANG II (right panel) in different vascular beds in 
(ANG $\|$ ven $) /($ ANG $\|$ art $)$

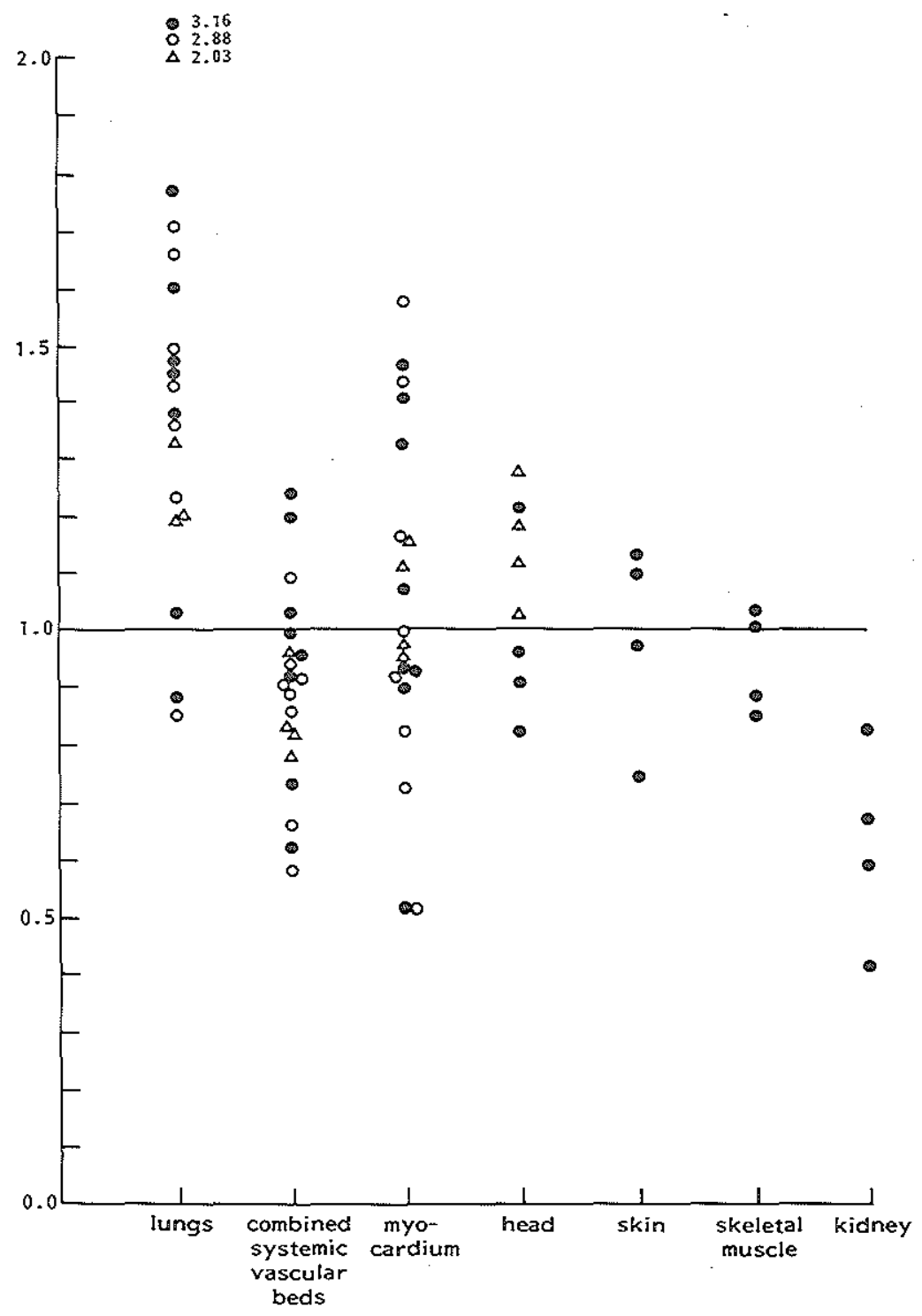

untreated (o), captopril-treated $(\bullet)$ and furosemide-treated $(\Delta)$ pigs. Venous ANG II derived from arterially delivered ANG II and from regional conversion of arterially delivered ANG I was calculated on the basis of equations (11) and (12). The venous ANG II levels are expressed as a fraction of the arterial level of ANG M. 
Conversion in a vascular bed of ANG I generated by PRA during the transit of blood through that bed would also contribute to the regional de novo production of ANG II. Assuming that in a vascular bed the fractional conversion of this regionally produced ANG I is the same as the fractional conversion of ANG I that is arterially delivered to that bed, one can calculate the contribution of PRA to the total regional production of ANG II. As shown in Table 5, this contribution of PRA is small and does not make up for the difference between total regional ANG II production and regional ANG II production from arterially delivered ANG I. Thus, part of ANG II production in the circulation does not appear to originate from ANG I in the circulation; it may originate from the conversion of ANG I produced at tissue sites.

\subsection{Discussion}

Estimates of ANG I and ANG II production rates were made from measurements of the arterial and venous plasma levels of labeled ANG I and ANG II as well as endogenous ANG I and ANG II during constant infusion of 125I-ANG I. ${ }^{125}$ I-ANG I was infused directly into the left cardiac ventricle. We assumed that by this way of administration the route followed by exogenous ANG I resembled that of endogenous ANG I as closely as possible. 125 I-ANG I was extensively metabolized in all systemic vascular beds we studied (5). However, the venous levels of endogenous ANG I were similar to or even higher than the arterial levels of ANG I. Venous ANG I is therefore largely derived from regional de novo ANG I production. By measuring the circulating levels of plasma renin activity (PRA) in conjunction with those of radiolabeled and endogenous ANG I we were able to calculate how much of the regional de novo production of ANG I was due to circulating PRA and how much was not. Our results indicated that a major part of the de novo production of ANG I in the systemic vascular beds we studied did not originate from the action of circulating renin on circulating angiotensinogen. These calculations were based on a blood transit time of $10 \mathrm{sec}$. As mentioned under 'Results', this is probably an underestimation, but it only strengthens our conclusion that PRA could not account for the de novo ANG I production. This appeared to be the case not only in the kidneys but also in a number of other vascular beds.

The evidence for local ANG I production, i.e. ANG I production not in circulating blood, which was obtained in pigs treated with the ACE inhibitor captopril as well as in untreated animals, confirms our earlier observations in humans, all on captopril (1). Some untreated pigs had plasma ANG I levels as low as 2-3 times the detection limit of the assay. We therefore also studied a group of furosemide-treated animals. Results in these animals confirmed the conclusions drawn from the measurements in the untreated group.

The local production of ANG I in extrarenal tissues, i.e. ANG I production 
not due to circulating PRA, may still depend on the presence of kidney-derived renin in vascular tissue rather than on in situ synthesized renin $(17,22)$. In bilaterally nephrectomized patients the plasma levels of renin and ANG I are known to be very low $(4,7,20)$. The production of ANG I in plasma and at tissue sites in these patients may therefore be expected to be low as well. Thus, kidney-derived renin may indeed be responsible for most of the extrarenal production of ANG I at tissue sites, at least for that fraction of ANG I in the tissues that equilibrates with circulating ANG I. In accordance with this conclusion is the fact that the spontaneous release of angiotensins by isolated perfused organs is very low (rat hindquarter) (12) or even undetectable (rat heart) (16). Perfusion of rat hindquarters and heart with renin results in a dose-dependent release of ANG I and ANG II $(12,16)$.

Our calculations are based on the so-called 'venous equilibrium' model for the intrinsic clearance of exogenous and endogenous substances by tissues (25). This model considers the distribution volume of these substances to be a single, well-stirred compartment; their concentration in this compartment equals that in the venous effluent. The volume of blood present in the conduit vessels is not taken into consideration. The implicit assumption in our calculations is therefore that the arterial and venous plasma levels of the radiolabeled and endogenous angiotensins we measured are representative for the levels at the arterial and venous side of the microcirculation. This assumption is probably valid, because there is little metabolism of angiotensins in the large vessels and because PRA may be expected to cause only small gradients in ANG I and ANG $I$ along the large vessels. Indeed, in a study in humans we found no differences in the levels of ${ }^{125} \mathrm{I}$-ANG I, ${ }^{125 I-A N G ~ I I, ~ a n d ~ A N G ~ I ~ a n d ~ A N G ~ I I ~}$ between blood samples taken deeply from the femoral vein and from the iliac vein and inferior caval vein just under the entrance of the renal veins (Admiraal, unpublished results). We also found no differences in plasma levels between the ascending aorta and the femoral artery in captopril-treated pigs (data not shown).

From our data it could be calculated that not only ${ }^{125 I-A N G ~ I ~ b u t ~ a l s o ~}{ }^{125}$ IANG II was rapidly metabolized in the systemic vascular beds we studied. Again, as for ANG I, the venous levels of $A N G$ II were similar to the arterial levels, indicating that ANG II is regionally produced. The lungs are an important site of ANG II production, but it is of some interest that the rate of de novo production of ANG II in the combined systemic vascular beds was higher than in the lungs. ANG II production in the pulmonary and the combined systemic vascular beds in the captopril-treated pigs was not lower than in the untreated pigs, despite the fact that ANG I-II conversion was greatly reduced. Thus, the inhibition of ANG I-II conversion by captopril was overcome by increased ANG I production.

Regional de novo production of ANG II may be due to conversion of circulating ANG I, i.e. ANG I that is arterially delivered or ANG I that is regionally produced by PRA. De novo production of ANG II in the lungs could 
be fully attributed to conversion of circulating ANG I. In contrast, a substantial part of the de novo production of ANG II in the systemic vascular beds we studied did not originate from the conversion of circulating ANG I. In the kidneys by far the most of the de novo produced ANG II does not seem to originate from circulating ANG I. ANG I-II conversion is probably the main pathway of ANG II production. In the systemic vascular beds some of the ANG II production, and in the kidneys probably most of it, may therefore originate from the conversion of ANG I produced at tissue sites. However, alternative pathways for ANG II generation (e.g. direct cleavage from angiotensinogen) have been described (24).

Whereas our results do provide evidence for the local formation of ANG I and ANG II in a number of tissues and for the release of these locally formed angiotensins into the circulation, the results do not militate against the fact that most of the circulating ANG I is formed by the action of circulating renin on circulating angiotensinogen and that most of the circulating ANG II is derived from circulating ANG I. Our calculations of ANG I and ANG II production at tissue sites did not include the production of these peptides in the blood of the large arteries and veins. The volume of blood in the microcirculation of the tissues is only a small fraction of the total blood volume in the body. The total amount of circulating renin in the large arteries and veins is therefore much greater than in the microcirculation, and its contribution to the whole body production of ANG $I$ is therefore also much greater. The local formation of both ANG I and II in tissues may have important physiological implications, in that it may serve to generate sufficiently high angiotensin concentrations at tissue receptor sites, concentrations that could well be higher than in the circulation.

\subsection{References}

1. Admiraal PJJ, Derkx FHM, Danser AHJ, Pieterman H, Schalekamp MADH. Metabolism and production of angiotensin I in different vascular beds in subjects with hypertension. Hypertension 15: 44-55, 1990.

2. Andre $P$, Schott $C$, Nehlig H, Stoclet JC. Aortic smooth muscle cells are able to convert angiotensin I to angiotensin II. Biochem Biophys Res Commun 173: 1137-1142, 1990.

3. Campbell DJ. Circulating and tissue angiotensin systems. J Clin Invest 79: 1-6, 1987.

4. Campbell DJ, Kladis A, Skinner SL, Whitworth JA. Characterization of angiotensin peptides in plasma of anephric man. J Hypertens 9: 265-274, 1991.

5. Danser AHJ, Koning MMG, Admiraal PJJ, Derkx FHM, Verdouw PD, Schalekamp MADH. Metabolism of angiotensin I by different tissues in the intact animal. Submitted for publication.

6. Derkx FHM, Stuenkel C, Schalekamp MPA, Visser W, Huisveld IH, Schalekamp MADH. Immunoreactive renin, prorenin and enzymatically active renin in plasma in plasma during pregnancy and in women taking oral contraceptives. J Clin Endocrinol Metab 63: 1008-1015, 1986. 
7. Derkx FHM, Wenting GJ, Man in 't Veld AJ, Verhoeven RP, Schalekamp MADH. Control of enzymatically inactive renin in man under various pathological conditions: implications for the interpretation of renin measurements in peripheral and renal venous plasma. Clin Sci Mol Med 54: 529-538, 1978.

8. Dzau VJ, Ellison KE, Brody T, Ingelfinger J, Pratt RE. A comparative study of the distribution of renin and angiotensinogen messenger ribonucleic acids in rat and mouse tissues. Endocrinology 120:2334-2338, 1987.

9. Egleme C, Cressier F, Wood MM. Local formation of angiotensin II in the rat aorta: effect of endothelium. Br J Pharmacol 100: 237-240, 1990.

10. Fei DTW, Scoggins BA, Tregear GT, Coghlan JP. Angiotensin I,II and III in sheep. A. model of angiotensin production and metabolism. Hypertension 3: 730-737, 1981.

11. Guyton AC. Overview of the circulation, and medical physics of pressure, flow, and resistance. In: Textbook of Medical Physiology (eighth edition), edited by M.J. Wonsiewicz. W.B. Saunders Company, Philadelphia 1990, p. 150.

12. Hilgers KF, Kuczera M, Wilhelm MJ, Wiecek A, Ritz E, Ganten D, Mann JFE. Angiotensin formation in the isolated rat hindlimb. J Hypertens 7: 789-798, 1989.

13. Hirche $\mathrm{HT}$, Lochner $\mathrm{W}$. Messung der Durchblutung und der Blutfülling des coronaren Gefässbettes mit der Teststoffinjektionsmethode am narkotisierten Hund bei geschlossenem Thorax. Pflügers Archiv 274: 624-632 (1962).

14. Iwai $N$, Matsunaga M, Kita T, Tei M, Kawai C. Regulation of renin-like enzyme in cultured human vascular smooth muscle cells. Jpn Circ J 52: 1338-1345, 1988.

15. Ladefoged $J$, Pedersen $F$. Renal blood flow, circulation times and vascular volume in normal man measured by the intra-arterial injection-external counting technique. Acta Physiol Scand 69: 220-229, 1967.

16. Lindpaintner $K$, Jin M, Niedermaier $N$, Wilhelm MJ, Ganten D. Cardiac angiotensinogen and its local activation in the isolated perfused beating heart. Circ Res 67: 564-573, 1990.

17. Loudon M, Bing RF, Thurston $\mathrm{H}$, Swales $\mathrm{JD}$. Arterial wall uptake of renal renin and blood pressure control. Hypertension 5: 629-634, 1983.

18. Pipili E, Manolopoulos VG, Catravas $\mathrm{JD}$, Maragoudakis ME. Angiotensin converting enzyme activity is present in the endothelium-denuded aorta. BrJ Pharmacol 98: 333-335, 1989.

19. Rosenthal J, Thurnreiter M, Plaschke M, Geyer M, Reiter W, Dahlheim H. Reninlike enzymes in human vasculature. Hypertension 15: 848-853, 1990.

20. Sealey JE, White RP, Laragh JH, Rubin AL. Plasma prorenin and renin in anephric patients. Circ Res 41 (suppI I): 17-21, 1977.

21. Semple RF, Cumming AMM, Millar JA. Angiotensins I and II in renal vein blood. Kidney Int 15: 276-282, 1979.

22. Swales JD, Samani NJ. Vascular renin and hypertension. Uptake versus synthesis. Am J Hypertens 3: 890-892, 1990.

23. Wegener OH. In: Whole Body Computerized Tomography, edited by Karger S. New York 1981, pp. 4.32-4.35.

24. Weintroub B, Klickstein LB, Dzau VJ, Watt KWK. Granulocyte-angiotensin system. Identification of angiotensinogen as substrate of leukocyte cathepsin G. Biochemistry 23: 227-232, 1984.

25. Wilkinson GR. Clearance concepts in pharmacology. Pharmacol Rev 39: 1-47, 1987. 



\section{RENIN, PRORENIN AND IMMUNOREACTIVE RENIN IN VITREOUS FLUID FROM EYES WITH AND WITHOUT DIABETIC RETINOPATHY}

\subsection{Summary}

Renin, prorenin and immunoreactive renin were present in vitreous and subretinal fluid of eyes from subjects with and without diabetic retinopathy. Renin substrate, albumin, transferrin and immunoglobulin $G$ were also found in these ocular fluids. In many samples renin levels were close to the detection limit of the assay. The levels of renin substrate, albumin, transferrin and immunoglobulin $G$ varied widely among ocular fluid samples, but in each individual sample the levels were, relative to each other, similar to those in plasma. In contrast, the prorenin level in ocular fluid was up to 100 times higher than expected on the basis of the plasma protein content of ocular fluid. Moreover, there was little difference in prorenin concentrations between samples with a low and a high plasma protein content. Prorenin, relative to albumin and other plasma proteins, was higher in vitreous fluid from eyes with proliferative diabetic retinopathy complicated by traction retinal detachment than in eyes of non-diabetic subjects with spontaneous retinal detachment. It appears that prorenin (and possibly renin) in ocular fluid is controlled by an active and specific process, possibly local synthesis within the eye. In view of the vascular actions of angiotensin II, an intraocular reninangiotensin system may play a role in diabetic retinopathy.

\subsection{Introduction}

The kidney secretes both renin and prorenin, an inactive precursor of renin, into the circulation. Plasma of nephrectomized patients contains little or no renin but it does contain prorenin $(1,2)$, in concentrations sometimes as high as those in normal individuals. It thus appears that extrarenal production can make a major contribution to the level of prorenin in plasma, whereas most, if not all, renin in plasma is secreted by the kidneys. Synthesis of renin or prorenin and other components of the renin-angiotensin system is known to occur at various extrarenal sites, for instance adrenal $(3,4)$ pituitary $(3,4)$, testis $(3,4)$, brain $(5)$, and ovary $(6-8)$. Cultured human chorionic cells $(9)$ 
and ovarian thecal cells ( 8 ) release prorenin into the medium and there is good evidence that in women with hyperstimulated cycles and during pregnancy, the ovary, probably the corpus luteum, releases prorenin into plasma $(7,10)$.

A common feature of the organs in which synthesis of renin or prorenin occurs is their extensive vascularization (11). The eye, particularly the retina and uveal tract, is such a highly vascularized organ. Angiotensin II-binding sites have been found in retinal blood vessels (12), and transvitreal infusion of angiotensin $I$ and $I I$ produces constriction of the retinal arteries (13). The retina contains angiotensin converting enzyme activity (14) and this enzyme is also found in aqueous fluid (15). Here we report measurements of renin, prorenin, immunoreactive renin, renin substrate and various plasma proteins in aqueous, vitreous and subretinal fluid. The ocular fluid samples were obtained at the time of cataract extraction or vitrectomy and the protein concentrations in these samples were compared with those in simultaneously obtained plasma. Our study included eyes affected by proliferative diabetic retinopathy because the renin-angiotensin system has been implicated in neovascularization (16).

\subsection{Subjects and methods}

\section{Non-diabetic subjects}

Aqueous fluid was collected at the time of cataract extraction from 21 subjects (15 women and 6 men; mean age, $68 \mathrm{yr}$; range, 26-86 yr). Four subjects were receiving a diuretic and six a $B$-adrenergic antagonist.

Vitreous fluid aspirates were obtained from 16 subjects ( 8 women and 8 men; mean age, $52 \mathrm{yr}$; range, 20-82 yr). The samples were collected at the time of pars plana vitrectomy, which was performed because of recurrent retinal detachment due to proliferative vitreoretinopathy. Four subjects were receiving a diuretic, in 3 of them combined with a $\beta$-adrenergic antagonist.

Subretinal fluid was obtained from 18 subjects ( 8 women and 10 men; mean age, $59 \mathrm{yr}$; range, $8-76 \mathrm{yr}$ ), with rhegmatogenous retinal detachment, which is a type of retinal separation precipitated by a hole or a tear in the retina. In this type of detachment fluid accumulates between the retinal pigment epithelial layer and the neural retina. The retinal detachments had occurred between 1 day and 3 months (median, one week) before subretinal fluid collection. Three subjects were receiving a diuretic, in 2 of them combined with a $B$-adrenergic antagonist.

\section{Diabetic subjects}

Vitreous fluid was obtained from 15 diabetic subjects with proliferative diabetic retinopathy ( 8 women and 7 men; mean age, $51 \mathrm{yr}$; range, 28-71 yr). Vitrectomy was performed because of traction retinal detachment. The 
duration of diabetes ranged from 6-32 yr. Twelve subjects were receiving insulin, 5 were receiving a diuretic and 1 was receiving a $B$-adrenergic antagonist.

Aqueous fluid can only be collected at the time of cataract extraction. In diabetic subjects, however, this procedure may stimulate proliferative retinopathy. Cataract extraction is therefore not performed in eyes affected by proliferative diabetic retinopathy. Consequently, aqueous fluid could not be collected from such eyes. We also were unable to collect subretinal fluid from diabetic subjects with traction retinal detachment because drainage of subretinal fluid is rarely performed in these subjects and, if it is performed, the approach is via the transvitreal route, so that the sample is heavily contaminated with material from the vitreous. In subjects with a rhegmatogenous retinal detachment, subretinal fluid is removed via the transscleral route, where no such contamination occurs.

\section{Collection of ocular fluid samples}

Approximately $0.1 \mathrm{~mL}$ aqueous fluid was collected with a tuberculin syringe and a 25-gauge needle. The needle was introduced at the limbus of the cornea through the groove of the cataract incision. A $0.3-1.0 \mathrm{~mL}$ sample of vitreous fluid was aspirated before substitution fluid was infused into the vitreous. Subretinal fluid was aspirated transsclerally, after local diathermic coagulation of the choroid.

The ocular fluid samples were free of macroscopically visible blood and were frozen at $-70^{\circ} \mathrm{C}$ immediately after collection. A peripheral venous blood sample was drawn simultaneously with the collection of ocular fluid. Blood for determination of renin, prorenin, immunoreactive renin, renin substrate, albumin, transferrin and immunoglobulin $\mathrm{G}$ (IgG) was collected in tubes containing 0.1 volume of $0.13 \mathrm{~mol} / \mathrm{L}$ trisodium citrate. The blood was immediately centrifuged at $3000 \times \mathrm{g}$ for 10 minutes at room temperature, and $1-\mathrm{mL}$ aliquots of plasma were stored at $-70^{\circ} \mathrm{C}$. Blood for determination of angiotensin II was collected in prechilled tubes containing 0.1 volume of 0.06 $\mathrm{mmol} / \mathrm{L}$ pepstatin- $\mathrm{A}, 0.125 \mathrm{~mol} / \mathrm{L}$ disodium EDTA and $0.025 \mathrm{~mol} / \mathrm{L}$ phenantroline in order to block renin, angiotensin converting enzyme and angiotensinases, respectively. The blood samples were immediately centrifuged at $3000 \mathrm{~g}$ for 10 minutes at $4{ }^{\circ} \mathrm{C}$, and $2-\mathrm{mL}$ aliquots of plasma were stored at $70^{\circ} \mathrm{C}$.

\section{Analytical methods}

Renin was measured in duplicate by enzyme-kinetic assay, in which the samples were incubated at $37^{\circ} \mathrm{C}$ and $\mathrm{pH} 7.5$ with saturating amounts of sheep renin substrate in the presence of inhibitors of angiotensinases and angiotensin converting enzyme. The generated angiotensin I was quantitated by RIA (17). 
For measuring prorenin in plasma, prorenin was converted into renin by incubation with Sepharose-bound trypsin $(0.25 \mathrm{mg} / \mathrm{mL})$ for 48 hours at $4{ }^{\circ} \mathrm{C}$. Previous studies, including measurements of total immunoreactive renin (renin plus prorenin), indicated that the prorenin to renin conversion in plasma is complete after incubation with the immobilized trypsin under these circumstances and that destruction of renin or prorenin does not occur (18). Experiments in which known quantities of purified human kidney renin were added to ocular fluid demonstrated that in some samples destruction of renin did occur with this method. This destruction might be due to the low content of serine protease inhibitors in ocular fluids as compared to plasma. Therefore, in ocular fluid we chose to use plasmin to convert prorenin into renin $(17,19)$. For this purpose the sample was incubated with plasmin at a final concentration of $0.5 \mu \mathrm{mol} / \mathrm{L}$ for 48 hours at $4{ }^{\circ} \mathrm{C}$ before the assay.

Comparison of the results of the enzyme-kinetic assay in plasmin-activated ocular fluid samples with the results of the assay of total immunoreactive renin in non-activated samples demonstrated that the conversion by plasmin was complete without any loss of prorenin or renin; the specific enzymatic activity of plasmin-activated prorenin in ocular fluid samples was not different from the specific activity of purified kidney renin and plasma renin (see Results). Plasmin at the concentration mentioned above cannot be used to activate prorenin in native whole plasma because of its high content of plasmin inhibitors.

The concentrations of renin and prorenin measured by the enzyme-kinetic assay were expressed as milliunits per L using the WHO human kidney renin standard 68/356 (WHO International Laboratory for Biological Standards, London, United Kingdom) as reference standard. The lower limit of detection was $0.5 \mathrm{mU} / \mathrm{L}$ and the interassay variability at low concentrations of renin or prorenin $(2-5 \mathrm{mU} / \mathrm{L})$ was $11 \%$ for both renin and prorenin. Immunoreactive renin was measured in duplicate with a sandwich assay $(\mathbf{1 8 , 2 0})$ using the monoclonal antibodies R 3-27-6 and R 3-36-16 (Ciba-Geigy, Basel, Switzerland). The two monoclonal antibodies recognize different epitopes of the renin molecule and react equally well with human kidney renin and chorionic cell culture prorenin. The assay was carried out in polystyrene tubes (Star Tubes, code 4-70319; Nunc, Roskilde, Denmark). The inner surface of these tubes was coated with antibody $\mathbb{R}$ 3-27-6 (21). Immunoreactive renin in the assay sample is quantitatively bound to this antibody. The amount of solid phase-bound immunoreactive renin was measured with antibody $R$ 3-36-16, which had been radiolabeled with 125 I. The results of this assay were expressed as nanograms per $\mathrm{L}$ using highly purified human kidney renin (Ciba-Geigy) as a standard. One milliunit of the WHO human kidney renin standard corresponded to $1.41 \mathrm{ng}$ of the Ciba-Geigy standard. The lower limit of detection was $5 \mathrm{ng} / \mathrm{L}$, and the interassay variability was $8 \%$.

The concentration of renin substrate was determined as the maximum quantity of angiotensin I that was generated during incubation at $37^{\circ} \mathrm{C}$ and $\mathrm{pH}$ 
7.5 with an excess of purified active human kidney renin in the presence of inhibitors of angiotensinases and angiotensin converting enzyme (18). The lower limit of detection was $1 \mathrm{nmol} / \mathrm{L}$ and the interassay variability was $10 \%$.

Immunoreactive angiotensin II was measured by radioimmunoassay after SepPak (Waters, Milford, MA, USA) extraction of the sample (22). The lower limit of detection was 2 pmol/L and the interassay variability was $15 \%$.

Albumin, transferrin and IgG were measured by single radial immunodiffusion (LC and NOR-Partigen plates, Behringwerke, Marburg, Germany) according to the method of Mancini et al (23).

\section{Data analysis}

Plasma proteins enter the vitreous mainly by diffusion. One of the reasons why the concentrations of these proteins are low in vitreous fluid is that they have to cross a relatively impermeable barrier. Breakdown of this so-called blood-retinal barrier leads to increased diffusion of plasma proteins into the eye. The rate of diffusion of a given protein is related to its molecular size and plasma concentration. In accordance with this is the fact that the concentrations of the different proteins relative to each other are similar in plasma and vitreous fluid $(24,25)$.

Thus, unless certain specific uptake processes exist, for which in the eye no evidence is available with regard to any of the proteins mentioned in this paper, one would expect a relatively high intraocular albumin concentration (due to partial breakdown of the blood-retinal barrier) to be accompanied by a proportionally high concentration of plasma proteins of comparable size. Therefore, we chose to take the vitreous fluid/plasma concentration ratio of albumin as an index of the integrity of the blood-retinal barrier, an abnormally high ratio being an indication of breakdown of this barrier. By multiplying this ratio with the level of a given protein in plasma, the level of this protein in ocular fluid can be estimated, assuming that, as mentioned above, this protein is transferred from the blood into the vitreous and vice versa by mechanisms that are qualitatively and quantitatively the same as those for the transfer of albumin. For example, for renin substrate the calculation would be as follows:

$$
\left[\mathrm{RS}_{\mathrm{Oc}}\right]=\left[\mathrm{RS}_{\mathrm{pl}}\right] \times\left[\mathrm{ALB}_{\mathrm{oc}}\right] /\left[\mathrm{ALB}_{\mathrm{p}}\right] \text {, }
$$

in which RS is renin substrate, ALB is albumin, oc is ocular fluid, pl is plasma, and brackets denote the concentration.

If our assumptions are correct, the calculated concentrations should be equal or at least closely correlated to the actually measured concentrations. Therefore, the two sets of data were analyzed by linear regression.

For analyzing differences between diabetic and nondiabetic subjects unpaired $\mathrm{t}$-tests were performed after logarithmic transformation of the data. 
Values were considered significant if $p<0.05$.

\subsection{Results}

\section{Non-diabetic subjects}

The levels of renin in many vitreous and aqueous fluid samples were at or below the detection limit of the assay $(0.5 \mathrm{mU} / \mathrm{L})$, which is less than $5 \%$ of the level in plasma. In subretinal fluid the renin level was about $20 \%$ of that in plasma (Table 1). Prorenin was detectable in all samples of vitreous and aqueous fluid; its level in vitreous fluid was about $20 \%$ and in aqueous fluid about $5 \%$ of that in plasma. In subretinal fluid the prorenin level was as high as in plasma. Renin and prorenin concentrations in the fluid compartments of the eye were in the order: subretinal fluid $>$ vitreous fluid $>$ aqueous fluid. The levels of renin substrate in subretinal, vitreous and aqueous fluid were 10, 5 and $0.5 \%$ of those in plasma, respectively. Thus, they too were in the order: subretinal fluid $>$ vitreous fluid $>$ aqueous fluid. This was also true for the levels of albumin, transferrin and $\operatorname{IgG}$ (Table 2). There was no correlation between the levels in ocular fluid and those in plasma for any of the proteins.

As described under Data analysis above, a theoretical concentration in ocular fluid for each protein was predicted based on the albumin content of the sample. For renin substrate, transferrin and $\mathrm{IgG}$ the calculated and measured values were linearly correlated in both vitreous and subretinal fluid, and the slopes of these correlation lines were not significantly different from 1.0 (Tables 3 and 4). Renin substrate and transferrin concentrations in ocular fluid could, in fact, be accurately predicted by these calculations. The IgG level measured was systematically about 2 times lower than that calculated, which may be due, at least in part, to its larger molecular size as compared to that of albumin and the other proteins.

For prorenin the findings were different. The prorenin levels in both vitreous and subretinal fluid varied much less than the levels of the other proteins (Tables 1 and 2). Furthermore, calculating prorenin concentrations on the basis of the albumin content of the sample yielded much lower (down to $1 / 100$ th) values than those actually measured, particularly in samples with a low plasma protein content (intact blood-retinal barrier). The prorenin level in subretinal fluid was higher than that in vitreous fluid, even when corrections were made for the higher plasma protein content in subretinal fluid samples (Fig. 1). In both vitreous and subretinal fluid the slopes of the regression lines describing the correlation between the measured and calculated prorenin concentrations were significantly different from 1.0 , thereby indicating the different behavior of prorenin as compared to albumin and other plasma proteins.

The data on prorenin shown in Tables 1, 3 and 4 and Figs. 1-3 were obtained 
Table 1. Levels of prorenin, renin, and renin substrate in ocular fluids.

\begin{tabular}{|c|c|c|c|c|c|c|c|}
\hline & \multirow{2}{*}{$\mathrm{n}$} & \multicolumn{2}{|c|}{ Prorenin (mU/L) } & \multicolumn{2}{|c|}{$\operatorname{Renin}(\mathrm{mU} / \mathrm{L})$} & \multicolumn{2}{|c|}{ Renin substrate $(\mathrm{nmol} / \mathrm{L})$} \\
\hline & & Eye & Plasma & Eye & Plasma & Eye & Plasma \\
\hline \multicolumn{8}{|l|}{ Non-diabetic subjects } \\
\hline Aqueous vs. plasma & 21 & $\begin{array}{l}4.4 \\
2.0-8.7\end{array}$ & $\begin{array}{l}163 \\
36.7-453\end{array}$ & $\begin{array}{l}<0.5 \\
\text { ND-0.5 }\end{array}$ & $\begin{array}{l}9.8 \\
1.5-62.9\end{array}$ & $\begin{array}{l}5.1 \\
1.6-15.4\end{array}$ & $\begin{array}{l}1080 \\
898-1430\end{array}$ \\
\hline Vitreous vs. plasma & 16 & $\begin{array}{l}34.5 \\
17.4-61.9\end{array}$ & $\begin{array}{l}174 \\
67.0-396\end{array}$ & $\begin{array}{l}<1.0 \\
\text { ND-2.8 }\end{array}$ & $\begin{array}{l}17.3 \\
3.7-51.0\end{array}$ & $\begin{array}{l}54.5 \\
3.0-630\end{array}$ & $\begin{array}{l}1120 \\
791-3030\end{array}$ \\
\hline Subretinal vs. plasma & 18 & $\begin{array}{l}132 \\
36.8-305\end{array}$ & $\begin{array}{l}128 \\
65.1-251\end{array}$ & $\begin{array}{l}2.4 \\
0.9-6.4\end{array}$ & $\begin{array}{l}14.3 \\
4.3-105\end{array}$ & $\begin{array}{l}107 \\
10-1430\end{array}$ & $\begin{array}{l}1230 \\
841-2250\end{array}$ \\
\hline Diabetic subjects & & & & & & & \\
\hline Vitreous vs. plasma & 15 & $\begin{array}{l}61.0 \\
19.0-172\end{array}$ & $\begin{array}{l}357 \\
121-679\end{array}$ & $\begin{array}{l}<2.0 \\
\text { ND-3.5 }\end{array}$ & $\begin{array}{l}17.7 \\
4.4-127\end{array}$ & $\begin{array}{l}61.0 \\
7.0-1000\end{array}$ & $\begin{array}{l}1030 \\
628-2040\end{array}$ \\
\hline
\end{tabular}

Shown are the geometric mean and range. ND, Not detectable. In vitreous fluid and plasma the levels of prorenin, but not those of renin substrate, were higher in diabetic than in non-diabetic subjects $(\mathrm{p}<0.01)$.

Table 2. Levels of albumin, IgG, and transferrin in ocular fluids.

\begin{tabular}{|c|c|c|c|c|c|c|c|}
\hline & \multirow{2}{*}{$\mathbf{n}$} & \multicolumn{2}{|c|}{ Albumin $(g / L)$} & \multicolumn{2}{|c|}{$\operatorname{IgG}(\mathrm{g} / \mathrm{L})$} & \multicolumn{2}{|c|}{ Transferrin $(g / L)$} \\
\hline & & Eye & Plasma & Eye & Plasma & Eye & Plasma \\
\hline \multicolumn{8}{|l|}{ Non-diabetic subjects } \\
\hline Aqueous ys. plasma & 21 & $\begin{array}{l}0.19 \\
0.06-0.45\end{array}$ & $\begin{array}{l}33.1 \\
28.3-39.4\end{array}$ & $\mathrm{ND}$ & ND & ND & $\mathrm{ND}$ \\
\hline Vitreous vs. plasma & 16 & $\begin{array}{l}1.55 \\
0.11-20.2\end{array}$ & $\begin{array}{l}33.0 \\
22.9-42.5\end{array}$ & $\begin{array}{l}0.19 \\
0.03-0.70\end{array}$ & $\begin{array}{l}11.0 \\
6.61-14.4\end{array}$ & $\begin{array}{l}0.18 \\
0.02-1.74\end{array}$ & $\begin{array}{l}2.44 \\
1.60-2.99\end{array}$ \\
\hline Subretinal vs. plasma & 18 & $\begin{array}{l}3.03 \\
0.39-28.5\end{array}$ & $\begin{array}{l}35.4 \\
29.2-41.9\end{array}$ & $\begin{array}{l}0.48 \\
0.07-5.10\end{array}$ & $\begin{array}{l}11.2 \\
7.0-18.2\end{array}$ & $\begin{array}{l}0.45 \\
0.06-3.97\end{array}$ & $\begin{array}{l}2.57 \\
2.08-3.44\end{array}$ \\
\hline \multicolumn{8}{|l|}{ Diabetic subjects } \\
\hline Vitreous vs. plasma & IS & $\begin{array}{l}1.51 \\
0.32-17.1\end{array}$ & $\begin{array}{l}29.2 \\
21.7-36.8\end{array}$ & $\begin{array}{l}0.19 \\
0.04-0.96\end{array}$ & $\begin{array}{l}9.2 \\
3.88-16.7\end{array}$ & $\begin{array}{l}0.14 \\
0.06-0.37\end{array}$ & $\begin{array}{l}2.06 \\
1.50-2.70\end{array}$ \\
\hline
\end{tabular}

Shown are the geometric mean and range. The levels of albumin, IgG, and transferrin in both vitreous and plasma did not differ between diabetic and non-diabetic subjects. ND, Not done. 


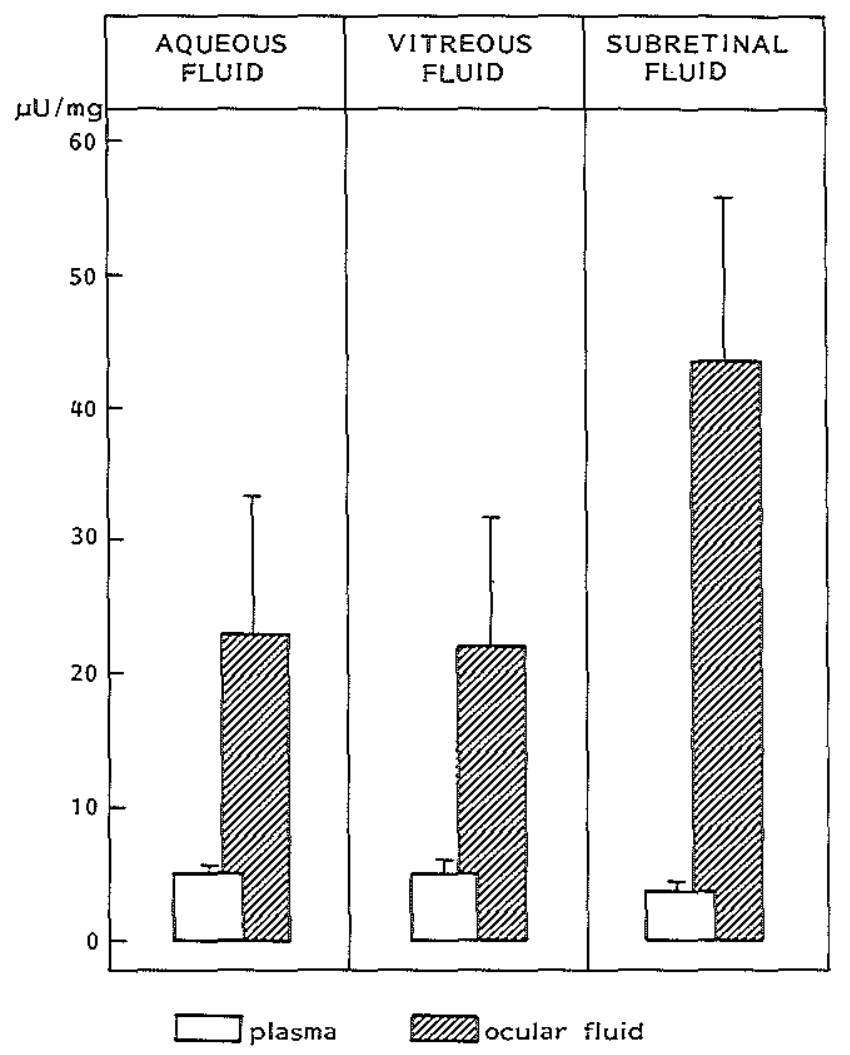

Figure 1. Mean $( \pm \mathrm{SE}$ ) prorenin/albumin concentration ratio in ocular fluids and plasma of nondiabetic patients.

by the enzyme-kinetic assay. That prorenin measured by this assay is, in fact, prorenin is supported by the excellent agreement with the measurements of immunoreactive renin (Fig. 4). The mean specific enzymatic activity of in vitro activated prorenin was $0.7 \pm 0.2( \pm S D) \mathrm{mU} / \mathrm{ng}(\mathrm{n}=9)$ in vitreous fluid and 0.6 $\pm 0.2 \mathrm{mU} / \mathrm{ng}(\mathrm{n}=10)$ in subretinal fluid. These values are not different from the specific activity of renin from plasma and kidney (18).

Immunoreactive angiotensin II was $11.1 \pm 1.8 \mathrm{pmol} / \mathrm{L}$ in vitreous fluid $(\mathrm{n}=12)$ compared to $17.5 \pm 1.3 \mathrm{pmol} / \mathrm{L}$ in plasma. In subretinal fluid $(\mathrm{n}=15)$ it was $14.8 \pm 1.6 \mathrm{pmol} / \mathrm{L}$ compared to $23.9 \pm 2.0 \mathrm{pmol} / \mathrm{L}$ in plasma. 

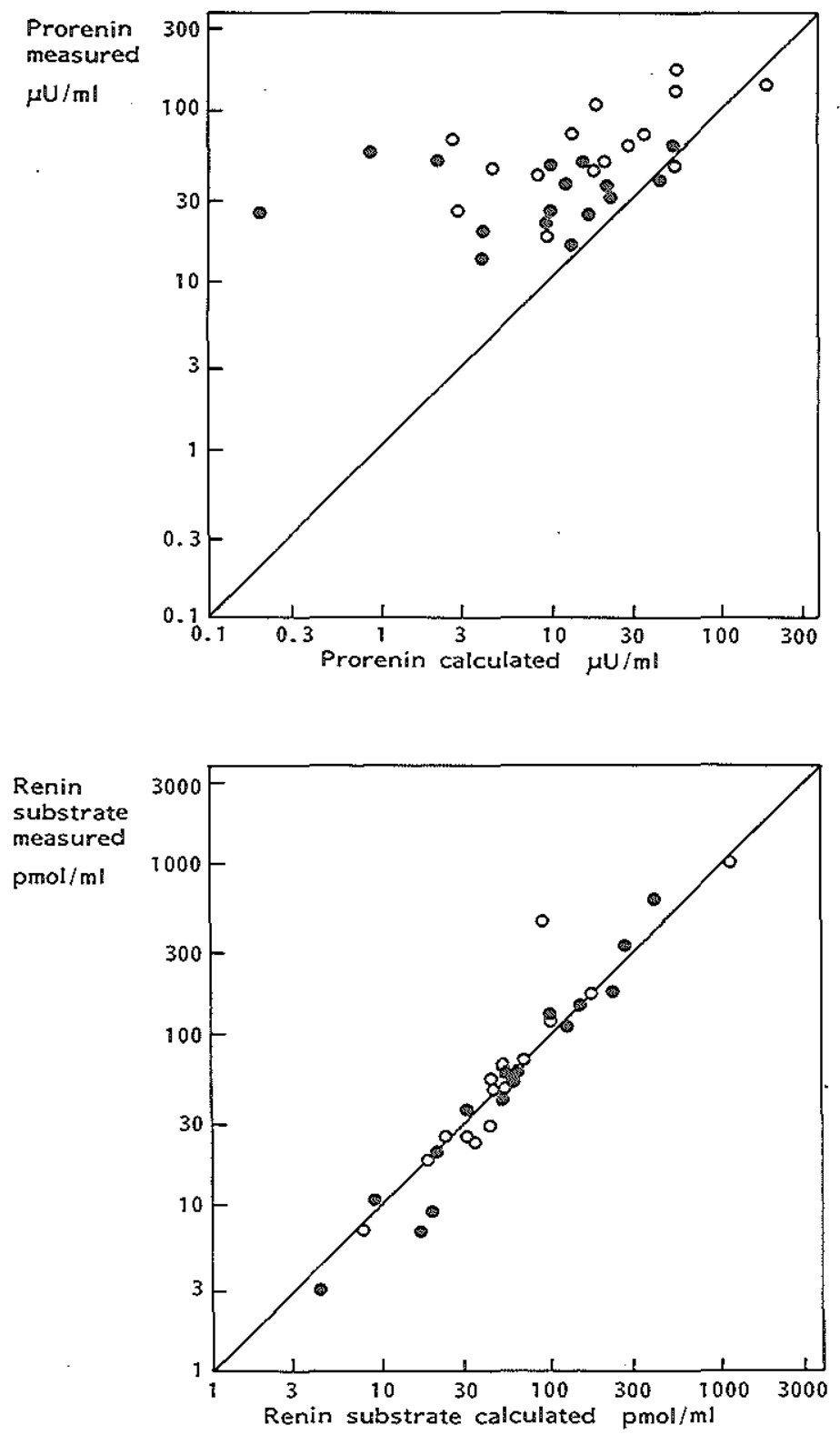

Figure 2. Measured versus calculated concentrations of prorenin (top panel) and renin substrate (bottom panel) in vitreous fluid. For an explanation of the calculation see text (Data analysis). The slopes and significance levels of the correlations are given in Table 3. o diabetic, non-diabetic. 

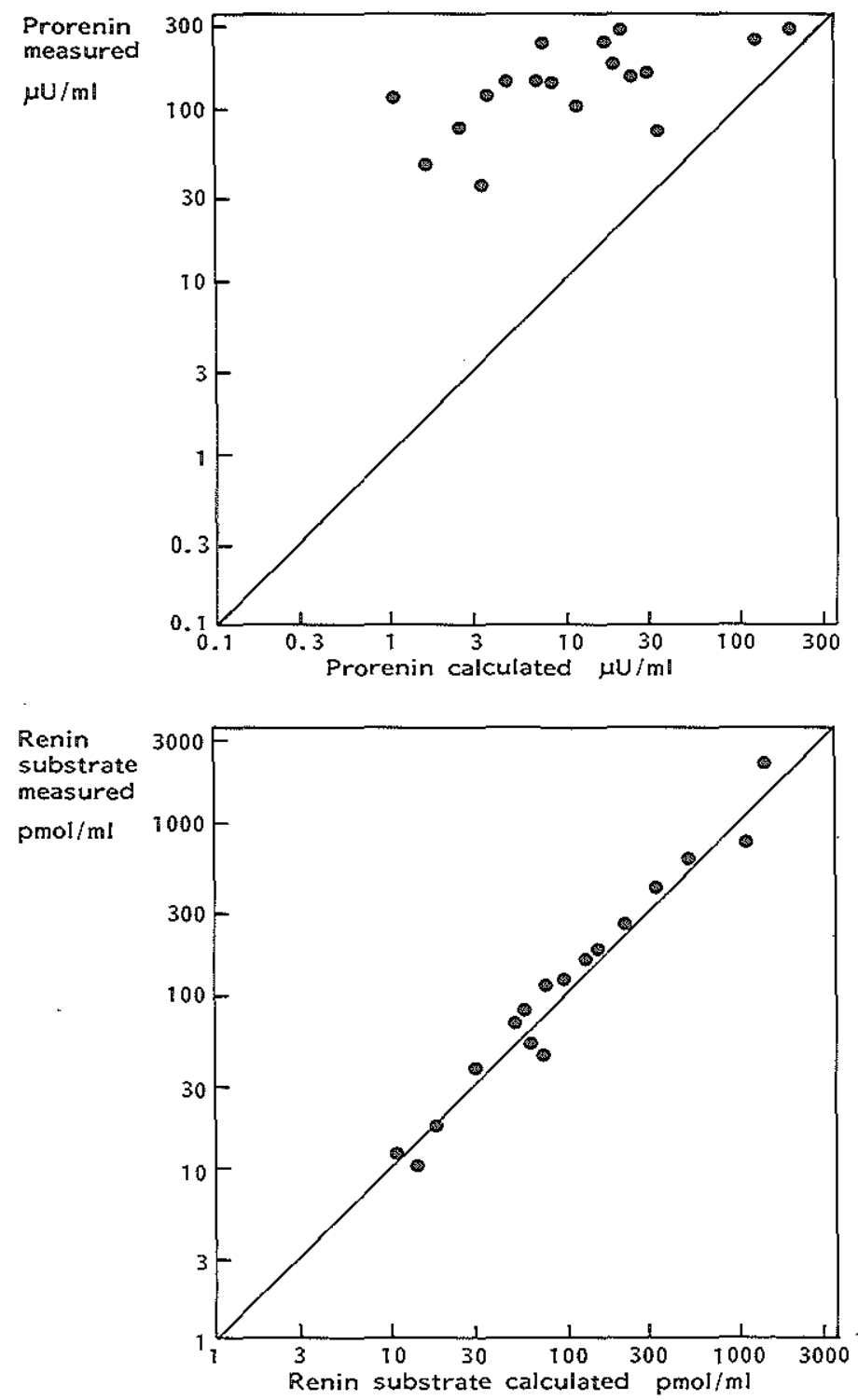

Figure 3. Measured versus calculated concentrations of prorenin (top panel) and renin substrate (bottom panel) in subretinal fluid. For an explanation of the calculation see text (Data analysis). The slopes and significance levels of the correlations are given in Table 4. 
Table 3. Correlations between the measured and calculated concentrations of proteins in vitreous fluid.

\begin{tabular}{llll}
\hline Protein & Regression Line & $\mathrm{r}$ & $\mathrm{p}$ \\
\hline Prorenin & & & \\
Non-diabetic subjects & $\mathrm{y}=0.015^{\mathrm{a}} \mathrm{x}+1.523$ & 0.05 & $\mathrm{NS}$ \\
Diabetic subjects & $\mathrm{y}=0.328^{\mathrm{a}} \mathrm{x}+1.370$ & 0.64 & $<0.05$ \\
Renin substrate & $\mathrm{y}=1.024 \mathrm{x}-0.028$ & 0.97 & $<0.0001$ \\
IgG & $\mathrm{y}=1.063 \mathrm{x}-0.344$ & 0.91 & $<0.0001$ \\
Transferrin & $\mathrm{y}=0.899 \mathrm{x}+0.066$ & 0.89 & $<0.0001$ \\
\hline
\end{tabular}

$\mathrm{y}$ is the $\log$ (measured concentration); $\mathrm{x}$ is the $\log$ (calculated concentration). For renin substrate, IgG, and transferrin, data from diabetic and nondiabetic subjects were combined because no differences were found for these proteins between the two groups (Tables 1 and 2).

a Slope different from $1.0, \mathrm{p}<0.0001$.

Table 4. Correlations between the measured and calculated concentrations of proteins in subretinal fluid.

\begin{tabular}{llll}
\hline Protein & Regression Line & $\mathrm{r}$ & $\mathrm{p}$ \\
\hline Prorenin & $\mathrm{y}=0.271^{\mathrm{a}} \mathrm{x}+1.839$ & 0.61 & $<0.01$ \\
Renin substrate & $\mathrm{y}=0.975 \mathrm{x}+0.064$ & 0.98 & $<0.0001$ \\
IgG & $\mathrm{y}=0.941 \mathrm{x}-0.302$ & 0.99 & $<0.0001$ \\
Transferin & $\mathrm{y}=0.934 \mathrm{x}+0.262$ & 0.94 & $<0.0001$ \\
\hline
\end{tabular}

$y$ is the $\log$ (measured concentration); $x$ is the $\log$ (calculated concentration).

a Slope different from $1.0, \mathrm{p}<0.0001$.

\section{Diabetic subjects}

The results of the renin substrate, albumin, transferrin, and IgG measurements in vitreous fluid and plasma of the diabetic subjects were similar to those in the non-diabetic subjects (Tables 1 and 2). The levels of renin and prorenin in vitreous fluid were higher in the diabetic than in the non-diabetic subjects. Prorenin was also higher when allowance was made for differences in plasma protein content of the samples. In the diabetic subjects the prorenin concentration of vitreous fluid correlated with the plasma prorenin concentration $(r=0.78, n=15, p<0.001)$. In the non-diabetic subjects there was no significant correlation between the levels of prorenin in vitreous fluid and plasma.

As in the non-diabetic subjects, prorenin in vitreous samples with low plasma protein content was much higher (up to 25 times) than expected on the basis of 
the albumin content of the samples.

Immunoreactive angiotensin II was $9.0 \pm 2.5 \mathrm{pmol} / \mathrm{L}$ in vitreous fluid $(\mathrm{n}=15)$ compared to $9.9 \pm 2.9 \mathrm{pmol} / \mathrm{L}$ in plasma.

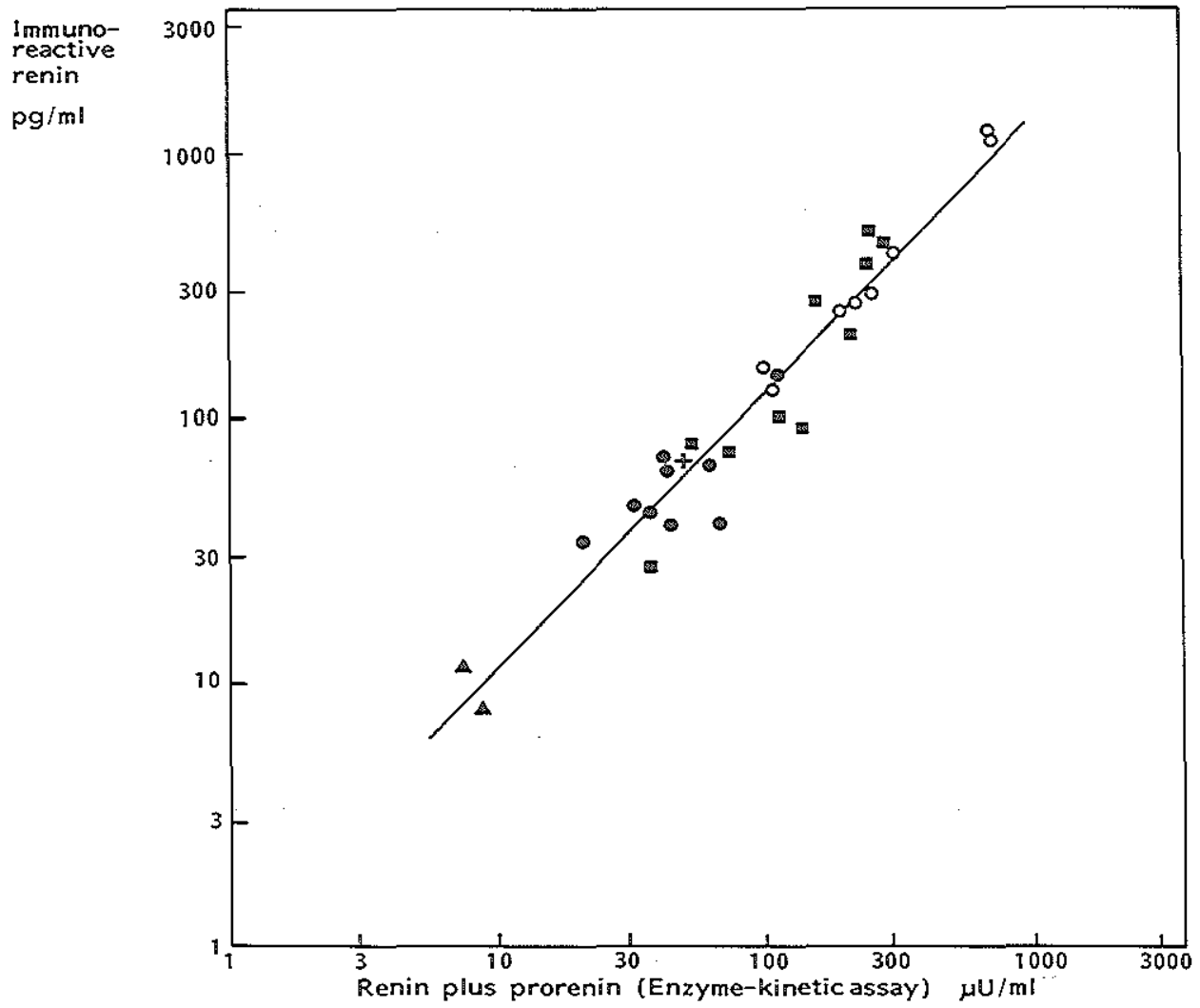

Figure 4. Total renin (prorenin plus renin) measured by enzyme-kinetic assay versus immunoreactive renin $(r=0.97, \mathrm{p}<0.0001)$. O plasma, subretinal fluid, ovitreous fluid, $\Delta$ aqueous fluid, + WHO human kidney renin standard.

\subsection{Discussion}

The levels of albumin ( $\mathrm{mol} \mathrm{wt}, 69 \mathrm{~K}$ ), transferrin (mol wt, $90 \mathrm{~K}$ ), IgG (mol $\mathrm{wt}, 150 \mathrm{~K}$ ) and renin substrate (mol wt, $65 \mathrm{~K}$ ) in vitreous fluid differed widely from sample to sample, but in each individual sample the levels were, relative 
to each other, comparable to those in plasma. The IgG level in vitreous fluid, relative to that of albumin, was systematically somewhat lower than in plasma, probably due to its larger molecular size (25). These results are in agreement with earlier findings that most soluble protein in the vitreous is derived from plasma (24-26).

The plasma protein content of normal vitreous fluid has been estimated to be $0.5-2 \%$ of that in plasma $(25,26)$. In our study vitreous fluid from eyes with recurrent retinal detachment due to proliferative vitreoretinopathy contained higher levels of plasma proteins. These higher values probably reflect partial breakdown of the blood-retinal barrier in such eyes (27).

The blood-retinal barrier is formed by the tight junctions between the endothelial cells of the retinal capillaries and the tight junctions between the retinal pigment epithelial cells, the latter restricting the transfer of plasma proteins escaping from the capillaries of the choroid (28). Proteins from plasma may enter the vitreous as a result of focal cellular necrosis, opening of the intercellular junctions, or vesicular transport and formation of transcellular channels. The rate of diffusion of proteins through such discontinuities in the blood-retinal barrier depends upon the concentration gradient across this barrier, the molecular size of the proteins and the number and area of discontinuities. Our results are in accordance with the contention that diffusion through these pores is the main mechanism of transfer of plasma proteins to the vitreous.

This process, however, does not appear to hold true for prorenin (mol wt, $54 \mathrm{~K}$ ). The concentration of prorenin, relative to that of albumin, was much higher in vitreous fluid than in plasma, and the prorenin level in vitreous fluid also was little influenced by its plasma protein content. Thus, prorenin may enter the vitreous by a mechanism that is different from that of albumin and other plasma proteins. This mechanism is selective for prorenin and may involve an active process. Receptor-mediated transcellular transport is such a selective mechanism, but as yet there is no evidence for the existence of cellmembrane receptors of prorenin. Our findings raise the possibility that not all the prorenin in the vitreous is derived from plasma but that some of it is produced in the eye.

As described under Data analysis above, the vitreous level of prorenin that has crossed the blood-retinal barrier by passive diffusion in the same way as albumin can be estimated by multiplying the vitreous/plasma concentration ratio of albumin by the plasma prorenin level. By subtracting this calculated level of plasma-derived prorenin from the level actually measured, we estimated the level of prorenin that entered the vitreous by some process that is different from diffusion out of the circulation. In most samples of vitreous fluid the estimated level of prorenin that had entered the vitreous by such a diffusion-independent process was more than 4 times higher than the estimated level of prorenin that had entered the vitreous by passive diffusion from blood. Thus, relative to the total amount of prorenin in vitreous fluid, the 
contribution of plasma-derived prorenin crossing the blood-retinal barrier merely by diffusion appears to be small. The implicit assumption underlying these calculations is that albumin and prorenin leave the vitreous in the same way, that is by free diffusion into the aqueous fluid (29), where the concentrations of these proteins were much lower than in the vitreous.

The concentrations of albumin, transferrin, IgG and renin substrate were 2-3 times higher in subretinal fluid than in vitreous fluid. This was to be expected, since subretinal fluid from eyes with retinal detachment is more or less a concentrate of vitreous fluid (27). Vitreous fluid enters the subretinal space through the hole(s) of the retina, and water is actively absorbed from the subretinal space by the retinal pigment epithelium. Again, the findings for prorenin were different. The concentration of prorenin, relative to albumin, was much higher in subretinal fluid than in plasma, particularly in subretinal samples with low plasma protein concentrations. Moreover, relative to albumin and other plasma proteins, prorenin was 2 times higher in subretinal than in vitreous fluid. If it is assumed, on the basis of the evidence discussed above, that most of the prorenin in the vitreous is not derived from plasma but is produced in the eye, the difference in prorenin content between subretinal and vitreous fluid may suggest that the subretinal compartment is closer to the site of prorenin production.

Not only were the prorenin concentrations of vitreous and subretinal fluid higher than expected, so too were the renin ( $\mathrm{mol} \mathrm{wt}, 48 \mathrm{~K}$ ) concentrations. The data on renin, however, are more difficult to interpret than those on prorenin because in many samples renin was at or below the detection limit of the assay and because some prorenin to renin conversion may have occurred during storage and handling of the samples. Even as little as $1 \%$ conversion will result in a large percentage increase of renin in these samples.

Immunoreactive angiotensin II also was found in samples of vitreous fluid, in concentrations comparable to those in plasma. Further work is needed to answer the question of its origin.

That the levels of albumin and IgG in vitreous fluid from eyes affected by proliferative diabetic retinopathy were higher than the levels in normal eyes can be explained by the increased permeability of the blood-retinal barrier in this condition (30). The higher vitreous level of prorenin, relative to those of albumin and other plasma proteins, in the diabetic subjects as compared to nondiabetic subjects is more difficult to explain. The same arguments in favor of the hypothesis that, generally, diffusion from the blood contributes little to the total amount of prorenin in the vitreous, apply to both diabetic and nondiabetic subjects. It seems, therefore, unlikely that the higher level of prorenin in vitreous fluid of the diabetic subjects ( 2 times that in non-diabetic subjects) was caused by the higher level in plasma (also 2 times that in non-diabetic subjects). It might be the other way around; increased release or leakage of prorenin from the eye affected by proliferative diabetic retinopathy may contribute to the increased prorenin level in plasma. 
This possibility is further supported by the finding that, in contrast with other proteins, the plasma concentration of prorenin in diabetic subjects correlated significantly with the concomitant vitreous prorenin concentration. Considering the fact that in some diabetic subjects the blood-retinal barrier for plasma proteins was still relatively intact (low vitreous/plasma albumin concentration ratio), whereas in others it was extremely leaky, no such correlation was to be expected, if diffusion from plasma into the vitreous was the main mechanism of transfer of prorenin.

An elevated plasma prorenin level in diabetic subjects has been found to be associated with microvascular complications, including retinopathy (31). Evidence is accumulating that neovascularization is initiated by diffusible chemical factors arising from ischemic areas of the retina (32). Renin and angiotensin have been found in cultured neuronal and glial cells from rat brain $(33,34)$; both cell types are abundantly present in the retina. Angiotensin II acts on vascular tone and has mitogenic and trophic actions on vascular smooth muscle and other cells (35). In fact, it has been reported to promote neovascularization (16). An intraocular renin-angiotensin system may, therefore, play a role in proliferative diabetic retinopathy.

\subsection{References}

1. Sealey JE, Moon C, Laragh JH, Atlas SA. Plasma prorenin in normal, hypertensive, and anephric subjects and its effect on renin measurements. Circ Res 40 (Suppl I) 41-45, 1977.

2. Derkx FHMM, Wenting GJ, Man in 't Veld AJ, Verhoeven RP, Schalekamp MADH. Control of enzymatically inactive renin in man under various pathological conditions: implications for the interpretation of renin measurements in peripheral and renal plasma. Clin Sci Mol Med 54: 529-538, 1978.

3. Naruse K, Murakoshi M, Osamura RY, Naruse M, Toma H, Watanabe $\mathrm{K}$, Demura $\mathrm{H}$, Inagami $\mathrm{T}$, Shizume $\mathrm{K}$. Immunohistochemical evidence for renin in human endocrine tissues. J Clin Endocrinol Metab 61: 172-177, 1985.

4. DeSchepper CF, Mellon SH, Cumin F, Baxter JD, Ganong WF. Analysis by immunohistochemistry and in situ hybridization of renin and its mRNA in kidney, testis, adrenal and pituitary of the rat. Proc Natl Acad Sci USA 83: 7552-7556, 1986.

5. Ganten D, Printz M, Phillips MI, Scholkens BA. The renin-angiotensin system in the brain. Exp Brain Res (Suppl 4) 48: 3-293, 1982.

6. Glorioso N, Atlas SA, Laragh JH, Jewelewicz R, Sealey JE. Prorenin in high concentrations in human ovarian follicular fluid. Science 233: 1422-1424, 1986.

7. Derkx FHM, Alberda AT, De Jong FH, Zeilmaker GH, Makovitz JW, Schalekamp $\mathrm{MADH}$. Source of plasma prorenin early and late in pregnancy. Observations in a patient with primary ovarian failure. J Clin Endocrinol Metab 65: 349-354, 1987.

8. Do YS, Sherrod A, Lobo RA, Paulson RJ, Shinagawa T, Chen S, Kjos S, Hsueh WA. Human ovarian theca cells are a source of renin. Proc Natl Acad Sci USA 85: 1957-1961, 1988.

9. Acker GM, Galen FX, Devaux C, Foote S, Papernik E, Pesty A, Menard J, Corvol P. Human chorionic cells in primary culture: a model for renin synthesis. $J$ Clin Endocrinol Metab 55: 902-909, 1982. 
10. Itskovitz J, Sealey JE, Glorioso N, Rosenwaks Z. Plasma prorenin response to human chorionic gonadotropin in ovarian-hyperstimulated women: correlation with the number of ovarian follicles and steroid hormone concentrations. Proc Natl Acad Sci USA 84: 7285-7289, 1987.

11. Fernandez LA, Olsen TG, Barwick KW, Sanders M, Kaliszewski C, Inagami T. Renin in angiolymphoid hyperplasia with eosinophilia. Its possible effect on vascular proliferation. Arch Pathol Lab Med 110: 1131-1135, 1986.

12. Rockwood EJ, Fantes F, Davis EB, Anderson DR. The response of retinal vasculature to angiotensin. Invest Ophthalmol Vis Sci 28: 676-682, 1987.

13. Ferrari-Dileo G, Davis EB, Anderson DR. Angiotensin binding sites in bovine and human retinal blood vessels. Invest Ophthalmol Vis Sci 28: 1747-1751, 1987.

14. Igic RP, Robinson CJG, Erdos EG. Central actions of angiotensin and related hormones. Pergamon Press, Oxford 1977, pp. 23-27.

15. Weinreb RN, Sandman R, Ryder MI, Friberg TR. Angiotensin-converting enzyme activity in human aqueous humor. Arch Ophthalmol 103: 34-36, 1985.

16. Femandez LA, Twickler J, Mead A. Neovascularization produced by angiotensin $I . J$ Lab Clin Med 105: 141-145, 1985.

17. Derkx FHM, Tan-Tjiong HU, Wenting GJ, Boomsma F, Man in 't Veld AJ, Schalekamp MADH. Asynchronous changes in prorenin and renin secretion after captopril in patients with renal artery stenosis. Hypertension 5: 244-256, 1983.

18. Derkx FHM, Stuenkel C, Schalekamp MPA, Visser W, Huisveld $\mathbb{I H}$, Schalekamp $\mathrm{MADH}$. Immunoreactive renin, prorenin, and enzymatically active renin in plasma during pregnancy and in women taking oral contraceptives. $J$ Clin Endocrinol Metab 63: 1008-1015, 1986.

19. Derkx FHM, Schalekamp MPA, Schalekamp MADH. Prorenin-renin conversion. Isolation of an intermediary form of activated prorenin. $J$ Biol Chem 262: 2472-2477, 1987.

20. Hofbauer KG, Wood JM, Gulati N, Heusser C, Menard J. Increased plasma renin during renin inhibition. Studies with a novel immunoassay. Hypertension 7 (Suppl 1): 61-65, 1985.

21. Nielsen MD, Rasmussen PH, Giese J. A highly sensitive and reproducible immunoradiometric assay for total human renin using monoclonal antibodies, iodogen labelling and polystyrene star tubes. Clin Exp Hypertension Theory Pract A9: 1391-1414, 1987.

22. Morton JJ, Webb DJ. Measurement of plasma angiotensin II. Clinical Science 68: 483-484, 1985.

23. Mancini $G$, Carbonara AO, Heremans JF. Immunochemical quantitation of antigens by single radial immunodiffusion. Immunochemistry 2: 235-254, 1965.

24. Wurster U, Rise K, Hoffman K. Enzyme activities and protein concentration in the intraocular fluids of ten mammals. Acta Ophthalmologica 60: 729-741, 1982.

25. Wurster U, Hoffman K. Glaskörper. In: Biochemie des Auges, edited by Hockwin $O$. Enke-Verlag, Stuttgart 1985, pp. 110-121.

26. Chen $\mathrm{CH}$, Chen SC. Studies on soluble proteins of vitreous in experimental animals. Exp Eye Res 32: 381-388, 1981.

27. Pederson JE, Toris CB. Experimental retinal detachment IX. Aqueous, vitreous, and subretinal protein concentrations. Arch Ophthalmol 103: 835-836, 1985.

28. Cunha-Vaz J. The blood-ocular bariers. Surv Ophthalmol 23:279-296, 1979.

29. Maurice DM. Protein dynamics in the eye studied with labeled proteins. Am J Ophthalmol 47: 361-368, 1959.

30. Cunha-Vaz J, Faria de Abreu JR, Campos AJ, Figo GM. Early breakdown of the blood-retinal barrier in diabetes. BrJ Ophthalmol 59: 649-656, 1975.

31. Luetscher JA, Kraemer FB, Wilson DM, Schwartz HC, Bryer-Ash M. Increased plasma inactive renin in diabetes mellitus. A marker of microvascular complications. $N E$ Engl $J$ Med 312: 1412-1417, 1985. 
32. Sebag J, McMeel JW. Diabetic retinopathy. Pathogenesis and the role of retina-derived growth factor in angiogenesis. Surv Ophthalmol 30: 377-384, 1986.

33. Hermann K, Raizada MK, Sumners C, Phillips MI. Presence of renin in primary neuronal and glial cells from rat brain. Brain Research 437: 205-213, 1987.

34. Hermann K, Raizada MK, Sumners C, Phillips MI. Immunocytochemical and biochemical characterization of angiotensin I and II in cultured neuronal and glial cells from rat brain. Neuroendocrinology 47: 125-132, 1988.

35. Lever AF. Slow pressor mechanisms in hypertension: a role for hypertrophy of resistance vessels. J Hypertens 4: 515-524, 1986. 


\section{IDENTIFICATION AND QUANTIFICATION OF RENIN AND PRORENIN IN THE BOVINE EYE}

\subsection{Summary}

Angiotensin II, the most important biologically active product of the reninangiotensin system, has been reported to play a role in neovascularization, and prorenin has been found in the vitreous of human eyes, particularly in those affected by proliferative diabetic retinopathy, a disease characterized by neovascularization. The prorenin level in these eyes was, relative to that of plasma albumin, higher than in eyes without neovascularization. These findings suggested that an intraocular renin-angiotensin system exists, which might be involved in the development of retinal neovascularization in diabetes mellitus. In this study angiotensin I-generating activity was measured in bovine aqueous humor and vitreous and in extracts of bovine retina, pigment epitheliumchoroid and anterior uveal tract, before and after subjecting these extracts to procedures known to convert prorenin to renin. The measurements were made by incubation at $37{ }^{\circ} \mathrm{C}$ with plasma from nephrectomized rats at $\mathrm{pH}$ ranging form 5.0-8.5. True renin in the ocular samples could be separated from nonrenin acid protease by $\alpha$-casein-Sepharose affinity column chromatography at $\mathrm{pH} 3.5$; true renin did not bind to the column, whereas acid protease did. True renin was further identified by its relatively high $\mathrm{pH}$ optimum (6.5-7.0) for angiotensin I generation, its complete inhibition with specific renin antiserum, and its high affinity for specific renin inhibitors. More than $75 \%$ of angiotensin I-generating activity of the ocular samples consisted of true renin. Approximately $90 \%$ or more of total renin (renin plus prorenin) in aqueous humor, vitreous, and ocular tissues could not be explained by trapped plasma. Total renin in aqueous humor and renin in vitreous were near the detection limit of the assay of angiotensin I-generating activity. In vitreous prorenin comprised $99 \%$ of total renin, in retina $81 \%$, and in pigment epithelium-choroid and anterior uveal tract less than $50 \%$. Prorenin in ocular fluids showed a concentration gradient, posterior vitreous $>$ anterior vitreous $>$ aqueous humor, suggesting that the main source of extracellular prorenin was in the posterior eye. These data support the contention of local renin and/or prorenin synthesis in the eye and are in accordance with the observations in other tissues that extrarenal synthesis of renin is often associated with the release of mainly, or exclusively, prorenin into extracellular fluid. 


\subsection{Introduction}

The aspartyl protease renin is the key enzyme in the formation of angiotensin II, an octapeptide with well known functions in blood pressure regulation and fluid and electrolyte homeostasis. Classically, renin is considered a blood-borne enzyme synthesized and secreted by the kidney together with its inactive precursor, prorenin. Plasma from nephrectomized subjects predictably contains little or no renin but it does contain prorenin, in some cases in concentrations as high as in normal individuals (1). Apparently most, if not all, renin in plasma originates from the kidney, whereas a large proportion of plasma prorenin is produced at extrarenal sites.

Synthesis of renin or prorenin and other components of the reninangiotensin system (RAS) is known to occur in many organs besides the kidney, for instance adrenal $(2,3)$, pituitary $(2,3)$, testis $(2,3)$, brain $(4)$ and ovary (5-7). In the luteal phase of the menstrual cycle and during pregnancy the ovary, probably the corpus luteum, secretes prorenin into the circulation (5). Certain renal and extrarenal tumors secrete prorenin in large amounts (8), and in some patients carrying these tumors plasma renin is elevated as well. Finally, cultured smooth muscle cells (9), chorionic cells (10) and ovarian follicular theca cells (6) have been shown to secrete prorenin into the medium.

It has been postulated that a correlation exists between the degree of vascularization of tissues and their renin content (11), and there is evidence to suggest that angiotensin II has a role in angiogenesis (12). Because neovascularization is a hallmark of progressed diabetic retinopathy, we wondered whether renin might also be synthesized in the eye. Recently we described the presence of prorenin in the human eye (13). Levels of prorenin in vitreous and subretinal fluid obtained during eye surgery were, relative to albumin and other plasma proteins, up to 100 times higher than in plasma. These results lend support to the hypothesis that synthesis of prorenin may occur in the eye. Presumably synthesis takes place in one or more of the surrounding tissues of the vitreous, since vitreous itself is virtually acellular. In the present study we attempted to identify and to measure renin and prorenin in extracts of different parts of freshly obtained bovine eyes and in simultaneously taken plasma.

\subsection{Materials and methods}

\section{Buffers and reagents}

Bovine serum albumin (BSA), 8-hydroxyquinoline, bovine $\alpha$-casein, bovine cathepsin D and bovine hemoglobin were obtained from Sigma (St. Louis, MO). Trichloroacetic acid (TCA), phenylmethylsulfonylfluoride (PMSF) and 
sodium azide $\left(\mathrm{NaN}_{3}\right)$ were purchased from Merck (Darmstadt, Germany). EDTA, glycine and polyvinylpyrrolidone (PVP) were purchased from Riedel de Haën (Scelze, Germany), trypsin from Serva (Heidelberg, Germany), Nethylmaleimide (NEM) from Aldrich (Milwaukee, WI, USA), sodium tetrathionate from Fluka (Buchs, Switzerland), plasmin from Kabi Vitrum (Stockholm,Sweden) and CNBr-activated Sepharose 4B from Pharmacia (Uppsala, Sweden). Aprotinin was purchased from Bayer (Leverkusen, Germany). Antiserum against BSA was obtained from Dakopatts (Glostrup, Denmark). Rabbit antiserum against bovine pituitary renin was a gift by Dr. Murakami, University of Tsukuba, Japan (14). The renin inhibitor Ro 42,5892 was a gift from Dr. van Brummelen (Hoffmann-La Roche, Basel, Switzerland). The statin-containing renin inhbitor CGP 29,287 was a gift from Dr. Hofbauer (Ciba-Geigy, Basel, Switzerland). The World Health Organization (WHO) human kidney renin standard 68/356 was obtained from the WHO International Laboratory for Biological Standards (London, United Kingdom). For studying the optimal conditions for in vitro activation of prorenin the following buffers were used: buffer A, pH 3.3, consisting of $0.05 \mathrm{M}$ glycine, $0.001 \mathrm{M}$ EDTA and $0.095 \mathrm{M} \mathrm{NaCl}$, and buffer $\mathrm{B}, \mathrm{pH} 7.4$, consisting of $0.1 \mathrm{M}$ phosphate, $0.001 \mathrm{M}$ EDTA and $0.075 \mathrm{M} \mathrm{NaCl}$. Buffer $\mathrm{C}, \mathrm{pH} 7.4$ was used for washing tissues and for homogenization; it consisted of $0.01 \mathrm{M}$ phosphate and $0.15 \mathrm{M} \mathrm{NaCl}$.

\section{Collection of blood and ocular tissues}

Blood was obtained from cows at the local slaughterhouse immediately after death. Blood was collected in tubes containing sodium citrate (final concentration, $0.013 \mathrm{M}$ ). At the same time both eyes were enucleated. Eyes and blood were kept on ice and were processed within $60 \mathrm{~min}$. Blood was centrifuged at $4{ }^{\circ} \mathrm{C}$ for $10 \mathrm{~min}$ at $3000 \mathrm{~g}$, and plasma was frozen at $-20^{\circ} \mathrm{C}$. Eyes were dissected as described below. Dissection and extraction procedures were performed at $4{ }^{\circ} \mathrm{C}$.

Aqueous humor was drawn using a tuberculin syringe with a fine needle. The eye was cut equatorially at the ora serrata and the anterior segment was lifted off. The vitreous body was isolated by gently shaking it out of the eye cup. Care was taken to remove all vitreous. The neural retina was cautiously teased away from the pigment epithelium with a thin glass rod and isolated by cutting it at the optic nerve. The choroid with adhering pigment epithelium layer was isolated by dissecting it from the sclera with a pair of fine scissors. The anterior uveal tract, consisting of iris and ciliary body, was isolated by removing the lens from the anterior eye cup, then gently pulling the anterior uveal tract loose from the sclera and blotting it on dry paper to remove any adhering vitreous. Cornea, lens and sclera were discarded.

For the chemical and immunological identification of renin and prorenin in the ocular tissue extracts and in plasma, either the retina, the pigment epi- 
thelium-choroid or the anterior uveal tract of 60 bovine eyes, the vitreous bodies of 4 eyes or $70 \mathrm{~mL}$ of bovine plasma were pooled. Tissues were minced with scissors into small pieces and washed three times in two volume weights of ice-cold buffer $\mathrm{C}$ in order to remove as much plasma as possible. Tissues were homogenized in one volume weight of buffer $C$ with a Polytron PT10/35 (Kinematica, Luzern, Switzerland) with $215-\mathrm{sec}$ bursts at level 10. The Polytron was also used to break the gel structure of the vitreous. Homogenates were rapidly frozen and thawed three times and then centrifuged at $4{ }^{\circ} \mathrm{C}$ for 1 $\mathrm{h}$ at $13000 \mathrm{~g}$. Supernatants were decanted and stored at $-20^{\circ} \mathrm{C}$. Pellets were discarded. Preliminary experiments had shown that there was no difference in renin content in extracts that had been made in buffer $\mathrm{C}$ alone and those made in buffer C containing the protease inhibitors PMSF (0.0005 M), EDTA $(0.001$ $\mathrm{M})$ and sodium tetrathionate $(0.00025 \mathrm{M}$; final concentrations) (15). Apparently, inadvertent activation of prorenin during the extraction procedures did not take place in these extracts.

The extracts of retina, pigment epithelium-choroid and anterior uveal tract were divided into two portions. One portion of each extract was dialyzed against buffer $\mathrm{A}$ to $\mathrm{pH} 3.3$ for $48 \mathrm{~h}$ and subsequently against buffer $\mathrm{B}$ to $\mathrm{pH} 7.4$ for $48 \mathrm{~h}$, both at $4{ }^{\circ} \mathrm{C}$, after which denatured protein was removed by centrifugation. The resulting supernatants were dialyzed for $6 \mathrm{~h}$ in distilled water, lyophilized and stored at $-20^{\circ} \mathrm{C}$. The acidification step removed effectively much of the angiotensinase activity, which in preliminary experiments was found to interfere with the renin assay in non-acidified lyophilized extracts despite the use of angiotensinase inhibitors. These lyophilisates were used for the experiments with renin antiserum or the renin inhibitor Ro 42,5892 or for $\alpha$-casein-Sepharose affinity chromatography, as described below. The other portion of each homogenate was dialyzed against buffer $\mathrm{B}, \mathrm{pH} 7.4$, only. The dialyzed homogenates were centrifuged and used to establish the optimal method for activating prorenin.

For quantification of renin and prorenin in eyes and simultaneously taken plasma, eyes from eight cows were studied. Isolated parts of one eye were pooled with the corresponding parts of the other eye of the same animal, aqueous and vitreous in equal volumes. No washing procedure to remove plasma was included so as not to lose tissue renin. Tissues were weighed and one volume weight of buffer $\mathrm{C}$ was added. Homogenization was performed as described above.

To examine whether a concentration gradient exists for prorenin in the vitreous, the vitreous bodies of five eyes were rapidly frozen in liquid nitrogen immediately after enucleation and then divided into posterior, central and anterior parts after the surrounding tissues had been peeled off. Aqueous of these eyes was collected just before freezing.

Bovine kidney was homogenized in one volume weight of buffer $\mathrm{C}$ and submitted to $\mathrm{pH} 3.3$ dialysis against buffer $\mathrm{A}$ for $48 \mathrm{~h}$; $\mathrm{pH}$ was restored to $\mathrm{pH}$ 7.4 by dialysis against buffer $\mathrm{B}$ for $48 \mathrm{~h}$. Denatured protein was removed by 
centrifugation. The resulting supernatant contained renin at a concentration of about $20.000 \mathrm{ng}$ angiotensin $\mathrm{I} / \mathrm{mL} \cdot \mathrm{h}$, as assessed by incubation at $\mathrm{pH} 7.4$ with plasma from nephrectomized rats as a source of renin substrate. In most experiments this extract was diluted 300 -fold in $0.1 \mathrm{M}$ phosphate buffer, $\mathrm{pH}$ 7.4. No acid protease activity was detectable at this dilution.

\section{Identification of renin}

Affinity chromatography on $\alpha$-casein-Sepharose. Aspartyl proteases bind to $\alpha$ casein at low pH. Renin, however, is an exception because of its relatively high $\mathrm{pH}$ optimum. This property of renin can be used for separating renin from other aspartyl proteases by affinity chromatography on $\alpha$-casein-Sepharose (16). $\alpha$-casein was coupled to CNBr-activated Sepharose 4B (16), and a column of $10 \times 1 \mathrm{~cm}$ was prepared. The column was equilibrated with $0.05 \mathrm{M}$ HAc-Ac- buffer, $\mathrm{pH} 3.5$, containing $0.075 \mathrm{M} \mathrm{NaCl}$. A lyophilized extract of pigment epithelium-choroid was dissolved in this buffer and $1 \mathrm{~mL}$ of this extract was applied to the column and left to stand for $5 \mathrm{~h}$. Elution was started with adsorption buffer at a flow rate of approximately $10 \mathrm{~mL} / \mathrm{h}$. After a washout volume of $90 \mathrm{~mL}$, a $0.1 \mathrm{M}$ Tris-HAc buffer, $\mathrm{pH} 8.6$, containing $1.0 \mathrm{M}$ $\mathrm{NaCl}$, was applied and elution was continued at a flow rate of $10 \mathrm{~mL} / \mathrm{h}$. Fractions of $3 \mathrm{~mL}$ were collected. All procedures were carried out at $4^{\circ} \mathrm{C}$. All fractions were assayed for angiotensin I-generating activity at $\mathrm{pH} 7.4$ and for acid protease activity at $\mathrm{pH} 3.5$.

pH optimum study. Plasma from nephrectomized rats, which served as a source of substrate for renin and activated prorenin, and the samples to be tested for angiotensin I-generating activity were brought to appropriate $\mathrm{pH}$ by overnight dialysis in separate dialysis bags at $4^{\circ} \mathrm{C}$ in $0.1 \mathrm{M}$ phosphate buffers ranging from $\mathrm{pH}$ 5.0-8.5. Angiotensin I-generating activity was assessed at these $\mathrm{pH}$ values; incubation conditions were the same as in the renin assay described below, except for $\mathrm{pH}$. The $\mathrm{pH}$ of the incubation mixture did not change more than $0.05 \mathrm{pH}$ unit during incubation. The following samples were tested: 1) pool of bovine plasma, which was treated with trypsin-Sepharose for activating prorenin (see below); 2) dilute bovine kidney extract; 3) bovine vitreous fluid, which was treated with acid and plasmin for activating prorenin (see below); 4) renin from bovine pigment epithelium-choroid purified by $\alpha$-casein-Sepharose chromatography (see below); and 5) purified bovine cathepsin D.

Inhibition of renin by renin antiserum or renin inhibitors. The rabbit antiserum against bovine pituitary renin at 1:320 dilution caused $50 \%$ inhibition of the angiotensin I-generating activity at $\mathrm{pH} 7.4$ of a bovine kidney extract with a renin concentration of $70 \mathrm{ng}$ angiotensin $\mathrm{I} / \mathrm{mL} \cdot \mathrm{h}$.

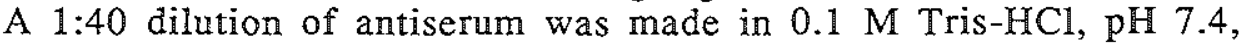


containing $0.1 \% \mathrm{BSA}$ and $0.02 \% \mathrm{NaN}_{3}$. Equal volumes of test sample and dilute antiserum were mixed and left to stand for $20 \mathrm{~h}$ at $4{ }^{\circ} \mathrm{C}$. The following samples were tested: 1) bovine plasma, after treatment with trypsin-Sepharose for activating prorenin (see below); 2) vitreous fluid, which was treated with acid and plasmin for activating prorenin (see below); 3) lyophilized extracts of retina, pigment epithelium-choroid and anterior uveal tract diluted in distilled water; 4) bovine kidney extract; and 5) renin from pigment epitheliumchoroid, purified by $\alpha$-casein-Sepharose affinity chromatography (see below).

To assess the specificity of the antiserum, inhibition experiments were also conducted with bovine cathepsin D. Renin assays that followed preincubation

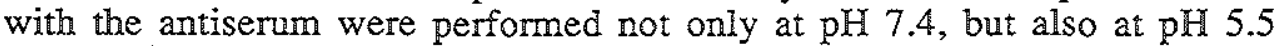
because cathepsin $\mathrm{D}$ has little angiotensin I-generating activity at neutral $\mathrm{pH}$, whereas renin does have angiotensin I-generating activity at neutral $\mathrm{pH}$ as well as at $\mathrm{pH}$ 5.5. Controls were samples incubated with preimmune rabbit serum. Results were corrected for the presence of renin in the antiserum and preimmune serum (approximately 3 ng angiotensin $\mathrm{I} / \mathrm{mL} \cdot \mathrm{h}$ ).

Inhibition of angiotensin I-generating activity by two renin inhibitors was assessed by performing the renin assay in the presence of different inhibitor concentrations, ranging from $10^{-11}$ to $10^{-5} \mathrm{~mol}$ per liter (final concentration). One inhibitor was Ro 42,5892 from Hoffmann-La Roche, a substrate analogue, which is claimed to be enzyme specific for renin. The concentration at which it causes $50 \%$ inhibition $\left(\mathrm{IC}_{50}\right)$ of human renin is $0.5 \times 10^{-9} \mathrm{M}$ in the plasma renin activity assay, in which plasma renin is allowed to react with endogenous renin substrate at $\mathrm{pH}$ 7.4. The $\mathrm{IC}_{50}$ of this inhibitor for bovine cathepsin $\mathrm{D}$ is $3.7 \times 10^{-5} \mathrm{M}$, when assessed by proteolysis of denatured hemoglobin at $\mathrm{pH} 3.5$ (information provided by the manufacturer). The other renin inhibitor was CGP 29,287 from Ciba-Geigy, also a substrate analogue, which has been described previously (17). CGP 29,287 is a potent inhibitor of human renin but appears to be less effective against dog or rat plasma renin, with an $\mathbb{I C}_{50}$ of $1 \times 10^{-9}, 2 \times 10^{-7}$ and $3 \times 10^{-5} \mathrm{M}$ respectively, in the plasma renin activity renin assay (17). Its $I_{50}$ for bovine cathepsin $\mathrm{D}$ is $4 \times 10^{-5} \mathrm{M}$, again assessed by proteolysis of denatured hemoglobin at $\mathrm{pH}$ 3.5. The samples tested with the renin inhibitors were the same as those used for the antiserum inhibition experiments, except for renin purified from ocular tissues by $\alpha$-caseinSepharose chromatography, which was only used in the antiserum experiments.

To assess the specificity of the inhibitors for bovine renin, the effect of the inhibitors on angiotensin I-generating activity of bovine kidney renin was compared with their effect on the angiotensin I-generating activity of bovine cathepsin D. As in the antisenum inhibition experiments, this was done at $\mathrm{pH}$ 5.5. The effects of the inhibitors on the angiotensin I-generating activity of human kidney renin in our renin assay were also tested and this was done both at $\mathrm{pH} 5.5$ and 7.4 . 
Assays of renin and activated prorenin. Different procedures were attempted for activating prorenin in bovine plasma, vitreous and extracts of retina, pigment epithelium-choroid and anterior uveal tract. We used three methods that were proven to be successful in activating human prorenin. One can either make use of endogenous proteolytic activators of prorenin, such as factor XII/kallikrein, plasmin, or pepsin-like proteases, or one can add activators, for instance plasmin or trypsin. In two of our methods we used an acidification step. Acidification has several effects: 1) prorenin undergoes a reversible conformational change of the molecule by which it becomes more susceptible to limited proteolysis necessary for irreversible activation (18);2) acidification destroys inhibitors of proteases that activate prorenin at neutral $\mathrm{pH}$, like kallikrein or plasmin (18); and 3) pepsin-like acid proteases, capable of activating prorenin, may become active at low $\mathrm{pH}$, like for example in human amniotic fluid (18). The first method of activation we tested in this study consisted of acidification followed by neutralization; no exogenous activator was added. Two $\mathrm{mL}$ of sample were dialyzed in buffer $\mathrm{A}$ for $48 \mathrm{~h}$ at $4{ }^{\circ} \mathrm{C}$. Then the dialysis buffer was changed to buffer $\mathrm{B}$, which after $36 \mathrm{~h}$ was replaced by buffer B containing $6 \%$ PVP to prevent dilution due to colloidosmosis. Dialysis in the presence of PVP proceeded for another $12 \mathrm{~h}$ after which the content of dialysis bags was collected by rinsing the interior with buffer $\mathrm{B}$. Volumes were adjusted to $2 \mathrm{~mL}$ with the same buffer. The second method involved incubation at $4{ }^{\circ} \mathrm{C}$ with immobilized trypsin as previously described (19). Trypsin had been coupled to CNBr-activated Sepharose 4B. The final concentration of trypsin was $4.4 \times 10^{3}$ Na-benzoyl-L-arginine ethyl ester units $/ 500 \mu \mathrm{L}$ sample. Activation of prorenin in plasma with this method does not require prior acidification. After $48 \mathrm{~h}$ incubation trypsin was removed by centrifugation. This method is similar to the often used trypsinsoybean trypsin inhibitor combination (15), with the advantage that destructive proteolysis of prorenin and renin is less likely to occur. The third method was an acidification step followed by incubation with plasmin at $\mathrm{pH}$ 7.4. After plasmin inhibitors have been removed at low $\mathrm{pH}$, exogenous plasmin will cause activation of prorenin at neutral $\mathrm{pH}$ without destruction of prorenin or renin, a problem which is sometimes encountered with trypsin and acid proteases. After dialysis for $48 \mathrm{~h}$ at $4{ }^{\circ} \mathrm{C}$ in buffer A, samples were rapidly adjusted to pH 7.4 with $1 \mathrm{M} \mathrm{NaOH}$. Then 0.1 volume of plasmin solution in $0.15 \mathrm{M} \mathrm{NaCl}$ was added to a final concentration of 1 casein unit per mL. Incubation with plasmin was for $48 \mathrm{~h}$ at $4^{\circ} \mathrm{C}$. With each sample all three procedures were performed in duplicate.

Renin and activated prorenin were assayed in duplicate by measuring the rate of angiotensin I generation at $\mathrm{pH} 7.4$ and $37^{\circ} \mathrm{C}$ in the presence of the protease inhibitors PMSF $(0.0024 \mathrm{M})$, EDTA $(0.005 \mathrm{M})$, 8-hydroxyquinoline $(0.0034$ $\mathrm{M})$, aprotinin $\left(2.2 \times 10^{-9} \mathrm{M}\right)$ and $\mathrm{N}$-ethylmaleimide $(0.005 \mathrm{M}$; final concentrations) $(15,19)$. The incubation mixture consisted of one volume of $0.1 \mathrm{M}$ phosphate buffer, one volume sample, two volumes of renin substrate 
and 0.14 volume of inhibitor solution. Plasma from nephrectomized rats was the source of renin substrate. The renin activity of this plasma was less than 0.1 $\mathrm{ng}$ angiotensin $\mathrm{I} / \mathrm{mL} \cdot \mathrm{h}$. The final substrate concentration in the incubate was $2.9 \mu \mathrm{g}$ angiotensin I equivalents $/ \mathrm{mL}$, which was about four times the $\mathrm{K}_{\mathrm{m}}$. The mixtures were incubated for $1,2,3$ and, in some cases, $6 \mathrm{~h}$ at $37^{\circ} \mathrm{C}$. Angiotensin $I$ was measured by radioimmunoassay (19). Only incubations in which angiotensin I generation was linear with time were used for renin assay. Recovery of angiotensin I added to the incubation mixture was $98 \%$ after $6 \mathrm{~h}$ incubation, demonstrating effective inhibition of angiotensinase activity.

Assays of serum albumin and acid protease. Albumin, as a measure of trapped plasma in the ocular tissue extracts, was determined with a single radial immunodiffusion technique, as described by Mancini et al. (20). One $\mathrm{mL}$ of the BSA antiserum precipitated $900 \mathrm{mg}$ of BSA. Dilutions of samples were made in $0.07 \mathrm{M}$ barbital, $0.003 \mathrm{M}$ calcium lactate and $0.3 \%$ Tween $20, \mathrm{pH}$ 8.6. Standard BSA solutions ranged from 5 to $100 \mathrm{mg} / \mathrm{L}$. Diffusion into the agar gel plates was allowed to proceed for two days in humidified air at room temperature. The agar plates were then stained with Coomassie blue. Recovery of added albumin ranged from $90-100 \%$ in the ocular tissue extracts.

The acid protease assay was a modification of the method by Anson (21). Briefly, $200 \mu \mathrm{L}$ sample, which had been brought to $\mathrm{pH} 3.5$ with $1 \mathrm{M} \mathrm{HCl}$, was added to $1 \mathrm{~mL}$ hemoglobin $(1 \%)$ in $0.1 \mathrm{M}$ glycine/HAc, pH 3.5 , at $37^{\circ} \mathrm{C}$. At $\mathrm{t}=0$ and $\mathrm{t}=20 \mathrm{~min} 500 \mu \mathrm{L}$ of this mixture was mixed with $500 \mu \mathrm{L}$ ice-cold $10 \%$ TCA. Denatured protein was removed by centrifugation and the absorption at $280 \mathrm{~nm}$ of the supernatant was read in an Uvikon 810 spectrophotometer (Kontron, Zurich, Switzerland). The difference in absorption at $280 \mathrm{~nm}$ between 20 and $0 \mathrm{~min}$ at $37^{\circ} \mathrm{C}$ was taken as a measure of acid protease activity. Acid protease activity is expressed in units; one unit is the proteolytic activity that causes a change in extinction of $1000 / \mathrm{min}$ at $280 \mathrm{~nm}$ by TCA-soluble products at $\mathrm{pH} 3.5$ and a temperature of $37^{\circ} \mathrm{C}$, with denatured hemoglobin as a substrate.

\subsection{Results}

\section{Affinity chromatography}

The protein concentration (absorption at $280 \mathrm{~nm}$ ), the acid protease activity at pH 3.5 and the angiotensin I-generating activity at $\mathrm{pH} 7.4$ of the eluted fractions from the $\alpha$-casein-Sepharose column are depicted in Fig. 1. Reninlike activity was eluted later than the bulk of protein. Most angiotensin Igenerating activity was found in a broad peak eluted at pH 3.5 (peak I). 


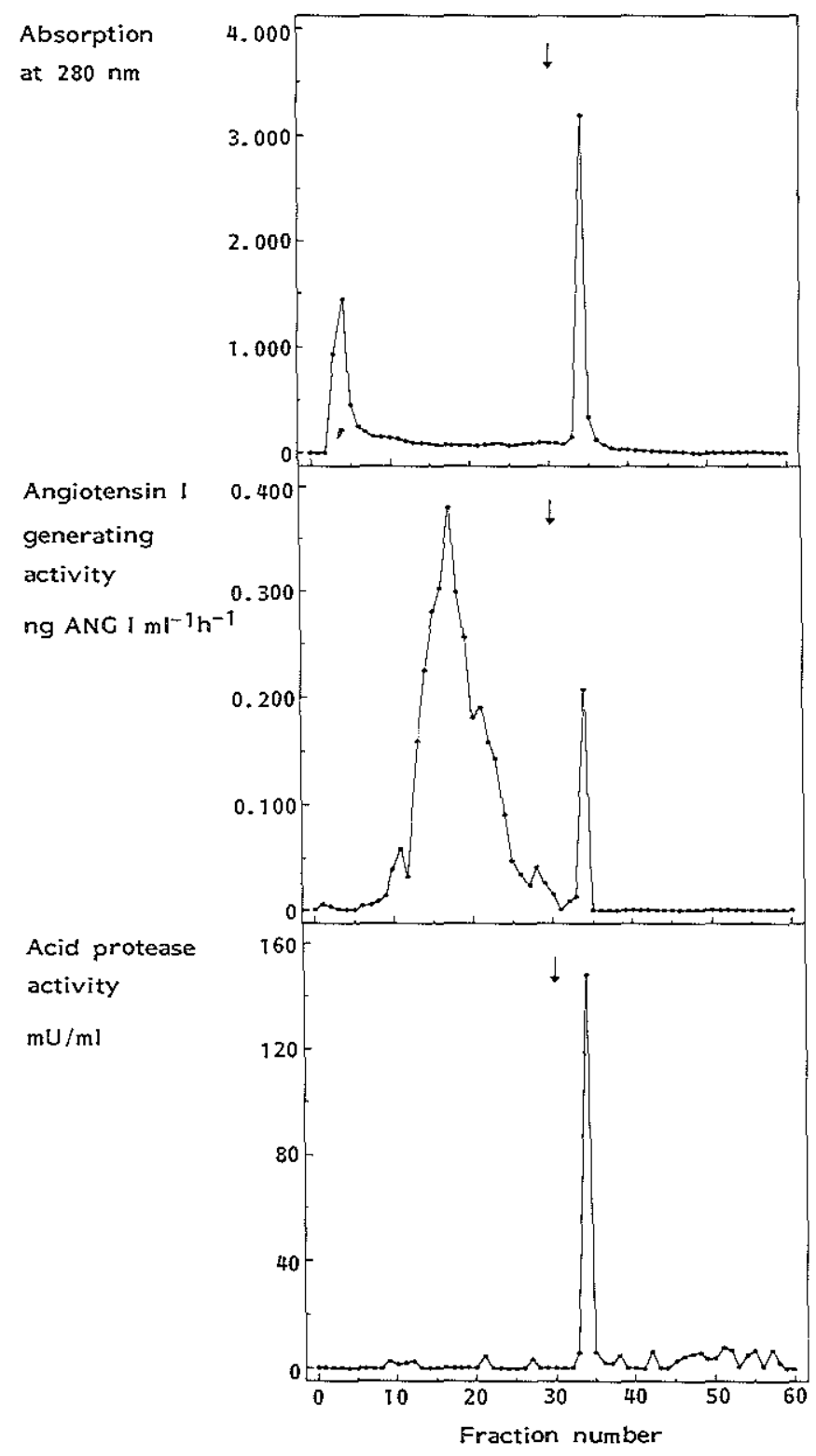

Figure 1. Separation of renin from non-renin acid protease in extract of bovine pigment epithelium-choroid by affinity chromatography on $\alpha$-casein-Sepharose. Arrow indicates change of $0.05 \mathrm{M}$ HAc-Ac- buffer, containing $0.05 \mathrm{M} \mathrm{NaCl}$, pH 3.5, to $0.1 \mathrm{M}$ Tris-HAc buffer, containing I $\mathrm{M} \mathrm{NaCl}$, pH 8.6. 
A small amount of angiotensin I-generating activity (peak II) was eluted after changing the $\mathrm{pH}$ to 8.6. Peak I contained renin activity but no acid protease activity. Peak II contained acid protease activity. Fractions 13-24 (peak I) were dialyzed against distilled water for $6 \mathrm{~h}$ and lyophilized. This preparation was used for determining the $\mathrm{pH}$ optimum of angiotensin I generation and for inhibition with renin antiserum. Peak II was not further evaluated because of its small volume and low renin-like activity.

\section{Identification of renin}

For preparing the extracts that were used for identification studies the tissues were washed to remove trapped plasma. Measurement of albumin in these extracts showed that washing with buffer $C$ had removed $70-85 \%$ of plasma. More than $90 \%$ of the angiotensin I-generating activity of these extracts could not be accounted for by contamination with plasma or by simple diffusion of renin from plasma.

Angiotensin I

generating activity

(\% of maximum)

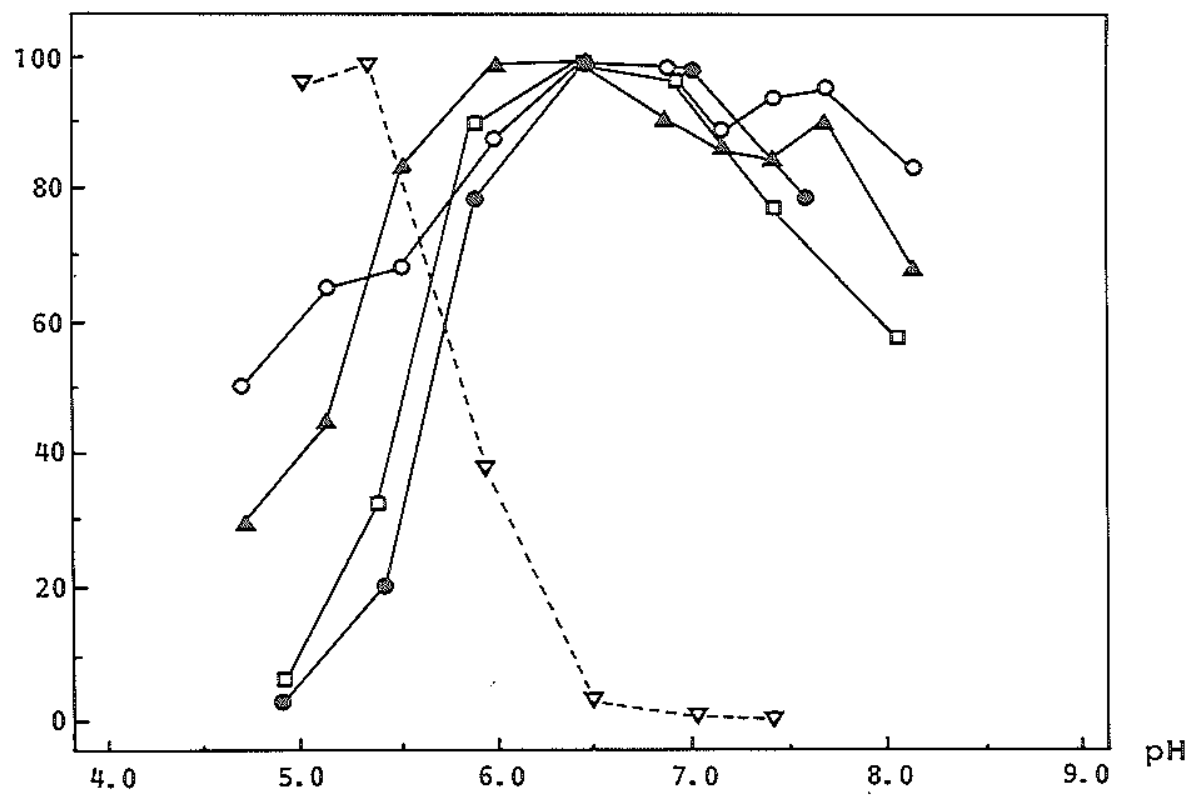

Figure 2. $\mathrm{pH}$ optimum curves for angiotensin I-generating activity of purified renin from bovine pigment epithelium-choroid ( $a$ ), activated prorenin from bovine vitreous ( $\Delta$ ), activated prorenin from bovine plasma ( $\circ)$, bovine kidney extract $(\bullet)$ and bovine cathepsin $D(\nabla)$. 
Table 1 . Angiotensin I-generating activity of various bovine specimens and its inhibition by renin antiserum.

\begin{tabular}{|c|c|c|c|c|}
\hline \multirow[b]{2}{*}{ Sample } & \multicolumn{2}{|c|}{$\begin{array}{l}\text { ANG I generation } \\
\text { (ng ANG } / / \mathrm{ml}^{-} \cdot \mathrm{h} \text { ) }\end{array}$} & \multicolumn{2}{|c|}{ \% Inhibition } \\
\hline & $\overline{\mathrm{pH} 7.4}$ & $\mathrm{pH} 5.5$ & $\overline{\mathrm{pH} 7.4}$ & $\mathrm{pH} 5.5$ \\
\hline Plasma & 5.8 & & 71 & \\
\hline Vitreous & 6.4 & & 70 & \\
\hline Retina & 23.4 & & 83 & \\
\hline Pigment epithelium-choroid & 40.4 & & 83 & \\
\hline Anterior uveal tract & 76.7 & & 93 & \\
\hline Kidney & 70.1 & 20.1 & 97 & 94 \\
\hline Purified ocular tissue renin & 10.6 & 2.9 & 83 & 95 \\
\hline Cathepsin D & $\mathrm{ND}$ & 3.8 & & 3 \\
\hline
\end{tabular}

Plasma was treated with trypsin-Sepharose to activate prorenin. Vitreous was treated with plasmin after an acidification step in order to activate prorenin. Extracts of pools of bovine retina, pigment epithelium-choroid and anterior uveal tract were dialyzed to $\mathrm{pH} 3.3$ for $48 \mathrm{~h}$ and then to $\mathrm{pH} 7.4$ for $48 \mathrm{~h}$, before being lyophilized. Bovine kidney extract was treated in a similar manner as the eye tissue extracts, but was not lyophilized. Purified ocular tissue renin was from pigment epithelium-choroid (peak I of $\alpha$-casein column). For details on preparation of samples, see text. Renin assays were performed at $\mathrm{pH} 7.4$ or $\mathrm{pH} 5.5$ with and without preincubation with antiserum at $\mathrm{pH}$ 7.4. Experiments were carried out in duplicate. ND, not detectable.

Table 2. Renin in bovine plasma and various ocular tissue extracts after different procedures for activating prorenin.

\begin{tabular}{lllll}
\hline & \multicolumn{4}{c}{ Renin activity (ng ANG I/mL $\cdot h$ ) } \\
\cline { 2 - 5 } Sample & No activation & pH3.3->pH7.4 & $\begin{array}{l}\text { Trypsin- } \\
\text { Scpharose }\end{array}$ & $\begin{array}{l}\text { pH3.3->pH7.4 + } \\
\text { plasmin }\end{array}$ \\
\hline Plasma & 1.6 & 3.0 & 5.9 & 4.1 \\
Vitreous & 0.04 & 4.7 & 4.8 & 6.1 \\
Retina & 0.3 & 1.6 & 1.2 & 2.1 \\
Pigment epithelium-choroid & 3.0 & 3.1 & 3.2 & 4.4 \\
Anterior uveal tract & 1.5 & 2.9 & 2.2 & 3.0 \\
\hline
\end{tabular}

For details on the activation procedures of prorenin, see text. Experiments were carried out in duplicate. 
The $\mathrm{pH}$ optimum curves of angiotensin I-generating activity for kidney extract, activated prorenin of vitreous and plasma, and purified pigment epithelium-choroid renin (peak I of $\alpha$-casein-Sepharose column) are shown in Fig. 2. During incubation $\mathrm{pH}$ did not shift more than $0.05 \mathrm{pH}$-unit. Results are expressed as a percentage of maximal angiotensin I-generating activity. Curves were similar, with a $\mathrm{pH}$ optimum of 6.5-7.0. Activated prorenin in plasma and in vitreous appears to have a shoulder in the curve at $\mathrm{pH} 8.0 \mathrm{pH}$ optimum curves were clearly different from the curve of cathepsin D angiotensin Igenerating activity.

Angiotensin I-generating activity in kidney, retina, pigment epitheliumchoroid and anterior uveal tract extracts and in vitreous as well as purified pigment epithelium-choroid renin was inhibited by $97 \%, 83 \%, 83 \%, 93 \%$, $70 \%$ and $83 \%$, respectively, by the antiserum against bovine pituitary renin (Table 1). No inhibition was observed when samples were incubated with preimmune rabbit serum. Cathepsin $\mathrm{D}$ was not inhibited by the antiserum at $\mathrm{pH}$ 5.5, whereas purified pigment epithelium-choroid renin was. This demonstrates that the inhibitory activity of the antiserum was retained at $\mathrm{pH}$ 5.5 and that the antiserum was specific for bovine renin.

For the sake of clarity only the inhibition curves for kidney renin, anterior uveal tract extract and cathepsin D for each of the two renin inhibitors at $\mathrm{pH}$ 5.5 are depicted in Fig. 3. Samples of the other ocular tissues and vitreous showed identical curves. The $\mathrm{IC}_{50}$ of Ro 42,5892 for bovine renin was approximately $8.3 \times 10^{-9} \mathrm{M}$, whereas for bovine cathepsin $\mathrm{D}$ the $\mathrm{IC}_{50}$ appeared to be well over $10^{-5} \mathrm{M}$. There was no difference in inhibitory activity of Ro 42,5892 on human kidney renin at $\mathrm{pH} 5.5$ nor at $\mathrm{pH} 7.4$, proving that in this range $\mathrm{pH}$ did not influence the inhibitory activity of Ro 42,5892. CGP 29,287 was clearly less potent than Ro 42,5892 , with an $\mathrm{IC}_{50}$ of $2.6 \times 10^{-7} \mathrm{M}$, which is still much lower than the $\mathrm{IC}_{50}$ for bovine cathepsin $\mathrm{D}\left(4 \times 10^{-5} \mathrm{M}\right)$. Apparently, CGP 29,287 is more species-specific than Ro 42,5892.

\section{Activation of prorenin}

Acidification followed by rapid neutralization and subsequent plasmin treatment resulted in the highest renin activity in the ocular tissues and in vitreous (Table 2). Not so, however, in plasma, in which treatment with trypsin-Sepharose was the more effective to activate prorenin. Activation with trypsin-Sepharose at $\mathrm{pH} 7.4$ (without prior acid treatment) and activation with plasmin at pH 7.4 (after acid-treatment) reached a plateau after $48 \mathrm{~h}$ at $4{ }^{\circ} \mathrm{C}$ in all samples tested (results not shown). Hence for quantification of total renin, i.e. renin plus prorenin, in the various compartments of the eye, we chose the acidification-plasmin method for the eye tissue extracts and for plasma we used the trypsin-Sepharose method. From these maximal activation values a 
percentage of prorenin can be calculated. In vitreous prorenin comprised $99 \%$ of total renin, in retina $81 \%$, whereas in pigment epithelium-choroid and anterior uveal tract less than $50 \%$ of total renin was prorenin.

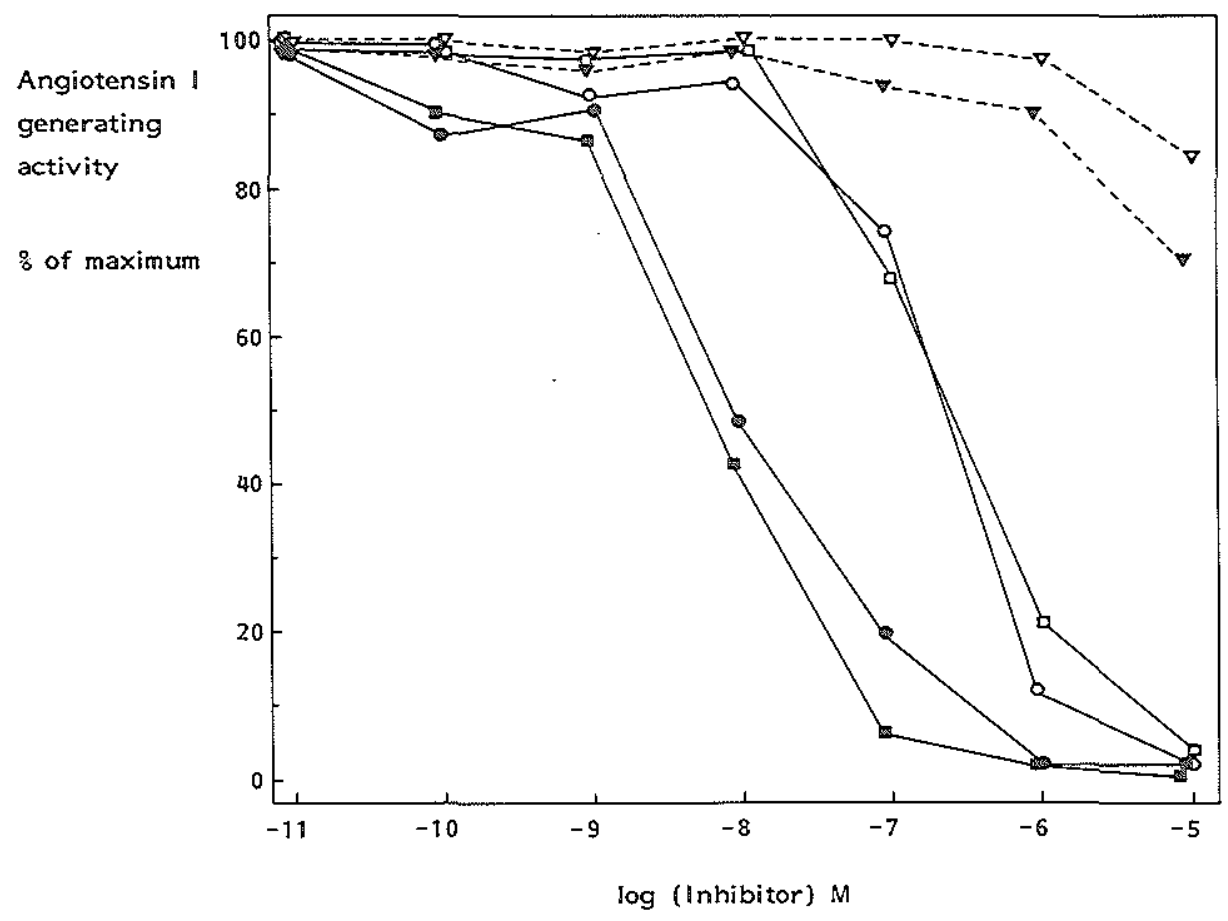

Figure 3. Inhibition of angiotensin I-generating activity of extract of bovine anterior uveal tract ( - and $\square$ ), bovine kidney extract ( $\bullet$ and 0 ) and bovine cathepsin $D(\nabla$ and $\nabla$ ) by the renin inhibitors Ro 42,5892 (closed symbols) and CGP 29,287 (open symbols).

Renin and prorenin levels in different parts of the eye

Table 3 shows the total renin (renin plus prorenin) levels of plasma, aqueous humor, vitreous, retina, pigment epithelium-choroid and anterior uveal tract of eight cows. In none of the eye samples tested, renin could be accounted for by trapped plasma or by simple diffusion from plasma, since the renin/albumin ratio was much higher in the eye compartments than in plasma. In pigment epithelium-choroid $10 \%$ of renin could be explained by contamination with plasma. In retina and anterior uveal this was only $1 \%$ and $4 \%$ respectively. 
Total renin levels, expressed as enzymatic activity per $\mathrm{mL}$ of fluid, were approximately equal in vitreous and plasma. In pigment epithelium-choroid and anterior uvea the total renin concentration per gram tissue surpassed even that in plasma.

From Fig. 4 it can be seen that a concentration gradient exists for prorenin in the vitreous, with levels being highest in the posterior vitreous. There was a large difference in prorenin between anterior vitreous and aqueous, which was not apparent for total protein.

Table 3. Total renin (renin plus prorenin) and serum albumin in bovine plasma and different parts of the bovine eye.

\begin{tabular}{lccc}
\hline Sample & $\begin{array}{c}\text { Total renin } \\
\text { (ng ANG I/g tissue } \cdot h \text { ) }\end{array}$ & $\begin{array}{c}\text { Total renin per albumin } \\
\text { (ng ANG I/mg albumin } \cdot h \text { ) }\end{array}$ & $\begin{array}{c}\text { Total renin } \\
\text { attributable to plasma } \\
(\%)\end{array}$ \\
\hline Plasma & $6.3 \pm 0.5$ & $0.21 \pm 0.02$ & 100 \\
Aqueous & $0.3 \pm 0.04$ & $2.36 \pm 0.39$ & $11 \pm 2$ \\
Vitreous & $5.7 \pm 0.4$ & $26.8 \pm 3.6$ & $1+0.2$ \\
Retina & $5.1 \pm 0.7$ & $16.3 \pm 2.0$ & $1 \pm 0.2$ \\
Pigment epithelium-choroid & $14.5 \pm 0.8$ & $2.26 \pm 0.19$ & $10 \pm 1$ \\
Anterior uveal tract & $10.1 \pm 0.7$ & $6.18 \pm 0.50$ & $4 \pm 0.3$ \\
\hline
\end{tabular}

The percentage of total renin attributable to contamination with or diffusion from plasma was calculated as follows: (alb tissue $\left./ \mathrm{alb}_{\text {plasma }}\right) \times\left(\right.$ renin $_{\text {plasma }} /$ renin $\left._{\text {tissue }}\right) \times 100 \%$. Results were obtained from 8 cows and are means \pm SEM.

\subsection{Discussion}

A critical problem in studying renin in tissue extracts is the distinction between renin and other aspartyl proteases that are present in the tissues. These pepsinlike acid proteases act optimally at a $\mathrm{pH}$ lower than the $\mathrm{pH}$ optimum of true renin. Nevertheless, they can influence the renin assay in which renin-like activity is detected by angiotensin I generation from renin substrate. The presence of acid proteases other than renin can cause an overestimation of renin content, even when the reaction is performed at $\mathrm{pH} 7.4$ (22). That the renin-like activity we detected at $\mathrm{pH} 7.4$ in ocular tissues was due to true renin is demonstrated by the following findings. We separated ocular tissue renin from acid protease by $\alpha$-casein-Sepharose affinity chromatography. The peak that contained renin activity but not acid protease activity, showed a $\mathrm{pH}$ optimum of 6.5-7, which was similar to that of activated prorenin from vitreous and also similar to the $\mathrm{pH}$ optimum of kidney or plasma renin and very different from the $\mathrm{pH}$ optimum of purified cathepsin $\mathrm{D}$, which is the most 
important of the angiotensin I-generating acid aspartyl proteases in tissues. This almost neutral pH optimum already indicates that we are dealing here with true renin, since renin is the sole angiotensin I-generating aspartyl protease known to have a near-neutral $\mathrm{pH}$ optimum. Definitive proof that the renin-like activity in the eye extracts is true renin, was obtained by inhibition of enzymatic activity with a specific antiserum and with two experimental renin inhibitors, Ro 42,5892 and CGP 29,287, whereas purified bovine cathepsin D was inhibited by neither antiserum nor the renin inhibitors.
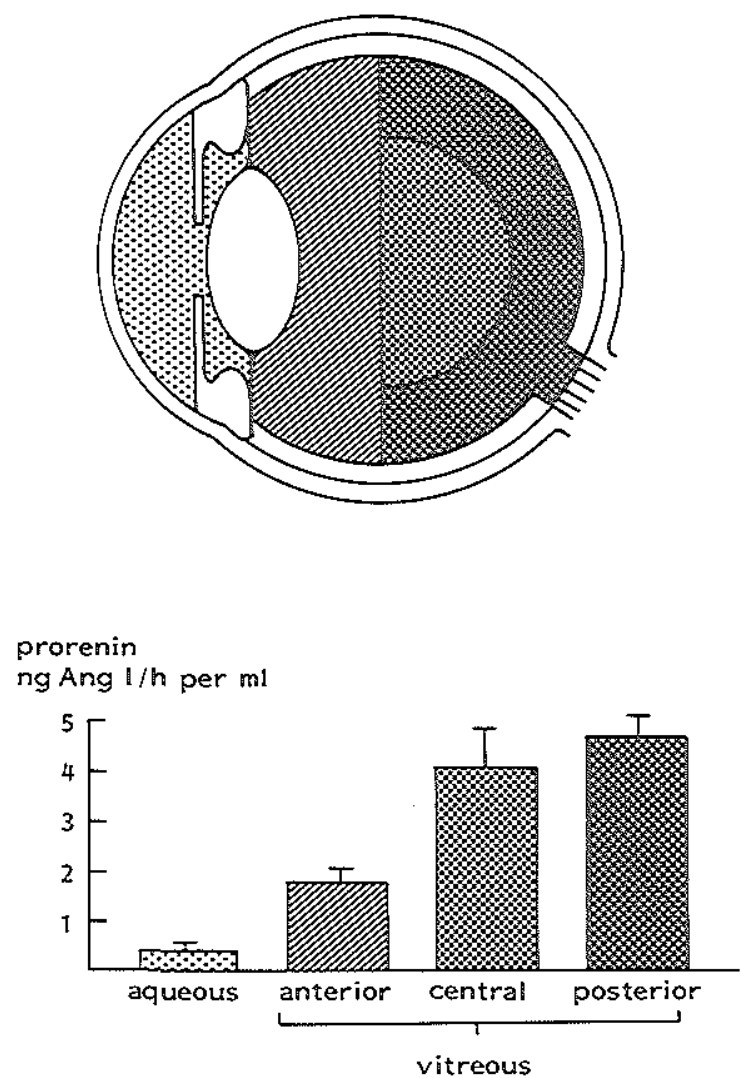

Figure 4. Prorenin in aqueous and in anterior, central and posterior vitreous of the bovine eye. 
Another problem in the present study is that the eye is a highly vascularized organ, so that ocular tissue extracts are heavily contaminated with plasma. Renin-like activity in tissue extracts may, therefore, be due to kidney-derived renin present in plasma. Obviously, we could not perform nephrectomy to eliminate this source of renin, so we had to correct for plasma renin in the tissues. We did not wash the tissues for quantification studies so as not to lose any tissue renin. Determination of albumin content of the ocular speciments and of simultaneously taken plasma showed that plasma renin was of no or minor importance, since the renin/albumin ratio in eye structures was much higher than in plasma. In the experiments aimed at the identification of renin in the ocular tissues we first washed the tissues gently in buffer, and in this way we were able to remove some $80 \%$ of the plasma, as estimated by measurement the albumin concentration. Consequently some $80 \%$ of plasma renin was removed. The remainder of plasma renin in the resulting extracts was negligible relative to tissue renin, i.e. extravascular renin, since in the extracts that had not been washed, tissue renin already exceeded plasma renin by far.

Little is known about activation of bovine prorenin. Activation is possible with trypsin (23) but in tissues this has never been proven to be the optimal method. Moreover, we were dealing with two kinds of specimens, namely plasma and tissue extracts, which were very different in composition and may require different procedures for activating prorenin. We examined different methods in order to establish optimal activation conditions. Together they cover the activation mechanisms that are known for human prorenin. From our results it appears that in bovine materials endogenous activators play a less important role in in vitro activation of prorenin than in human plasma. In bovine plasma it was not possible to activate prorenin maximally by acidification followed by a neutral phase. In human plasma this occurs via the factor XI/kallikrein pathway (24). In tissue extracts acidification is supposed to activate acid proteases that, in turn, will activate prorenin (18). However in the bovine ocular tissue extracts acidification alone did not yield optimal results. These were obtained when plasmin was added during the neutral phase after the acidification step. Plasmin is known to be an effective activator also of human prorenin. Acid-pretreatment was a prerequisite for the activation of prorenin by plasmin; plasmin alone did not give activation in the ocular tissue extracts. In vitreous, however, acidification was not necessary (results not shown), probably because of the low content of plasmin inhibitors.

Some remarks can be made on the observed renin/prorenin ratio's. Little activation of prorenin seems to occur during the preparation of the ocular tissue extracts; the addition of inhibitors acting on different groups of proteases during preparation of these extracts had no effect on the renin/prorenin ratio. Our finding of bovine vitreous containing almost exclusively prorenin is consistent with our measurements in human vitreous, in that also human vitreous contains much more prorenin than renin (13). Furthermore the 
renin/prorenin ratio in the various parts of the eye differs from that in plasma. This difference suggests that a separate regulation mechanism exists for renin in plasma and in the eye and, possibly, that renin in the eye is produced locally. A striking analogy exists with the situation in the bovine ovary (23). In follicular fluid the prorenin/renin ratio is greater than 30 , as in vitreous, whereas in the surrounding theca cells this ratio is approximately 1 , as compared to $0.7-4.0$ in retina and uveal tract.

From our results it cannot be said whether renin in the eye is located intraor extracellularly, nor is it possible to conclude whether renin is synthesized locally in the eye or sequestered from plasma. Sequestration is not very likely, since that would imply a specific uptake process. Until now cell receptors for plasma renin or prorenin have not been described. The distribution of renin and prorenin at various sites in the eye suggests local synthesis. Vitreous, being the large extracellular space in the eye, has a high percentage of prorenin, which is in agreement with findings of others that extrarenal renin synthesis is accompanied by secretion of exclusively prorenin into the extracellular fluid $(6,7,8,15)$. The higher concentration of prorenin in the posterior segment of the vitreous suggests that the origin of vitreous prorenin is located either in the posterior retina or in the posterior uveal tract. A comment must be made on this observation. It has been shown that rapidly freezing and thawing of a balloon filled with a homogenous solution of albumin can cause uneven displacement of solute (25). The concentration differences amounted to no more than $15 \%$, with the outer onionskin-like fractions having the highest concentration. If a similar displacement of prorenin had occurred in our experiment, then the concentration in the anterior vitreous would be expected to be equal to that in the posterior, which clearly was not the case. Although our results, thus, may have been influenced to some extent by the freezing procedure, we think that our finding of a prorenin gradient is real and that indeed prorenin originates from the posterior pole of the eye.

One problem with the uveal tract as a source of vitreous prorenin is that, in order to explain the high levels in vitreous, prorenin has to be transferred across the retinal pigment epithelium, which, by virtue of its tight junctions, is part of the blood-retinal barrier. This barrier is not very permeable to proteins. Still, the high renin concentrations in the anterior and posterior uvea make this tissue a candidate for production of renin. Production in the retina is also conceivable. In the brain the same cell types that are present in the retina, both neuronal and glial cells, have been shown to synthesize renin (26). Since vitreous can be considered the sink of products originating from the retina (27), its high level of prorenin might well be explained by production in and secretion from the retina. The renin/prorenin ratio is quite different in uveal tissues, on the one hand, and in retina and vitreous, on the other hand, suggesting a third option that two distinct renin-producing systems exist in uvea and in retina separated by the blood-retinal barrier.

Reports have been published on components of the renin-angiotensin system 
in the eye. Angiotensin converting enzyme has been found in bovine retina, in both vascular and neural fractions (28). Binding sites of angiotensin II are present in eye-vessels (29), apparently also on the abluminal side, not in reach of systemic angiotensin II, since intravitreal administration of this peptide causes vasoconstriction (30). Recently prorenin has been found by immunohistochemistry in human ciliary body (31). This raises the possibilty that prorenin produced in the ciliary body is secreted into the aqueous. From there it may diffuse into the vitreous. However, we found prorenin in aqueous to be much lower than in the vitreous, and it is difficult to conceive how prorenin could be transported from a lower concentration in aqueous to a higher concentration in vitreous.

The function of a renin-angiotensin system in the eye is not yet clear. The higher concentration of renin in the uveal tract suggests that its major function is exerted there. Since the uveal tract is extremely vascular, and angiotensin II is a vasoactive peptide, it may serve a role in local blood supply. Topical administration of an angiotensin converting enzyme inhibitor to the eye lowers intraocular pressure (32). The renin-angiotensin system may, therefore, play a role in the control of intraocular pressure, possibly, in view of the presence of prorenin in the ciliary body (31), through an effect on the production of aqueous humor. Angiotensin II has trophic and mitogenic actions on vascular smooth muscle and other cells (33). We found prorenin to be increased in human vitreous from patients with proliferative diabetic retinopathy (13). In view of possible angiogenic effects of angiotensin II $(12,34)$ the reninangiotensin system may be a causative factor in proliferative retinopathy. In the ovary such a role of renin-angiotensin II has been proposed for the rapid vascularization of the developing corpus luteum which occurs after ovulation (35). Finally, inhibition of angiotensin converting enzyme in the isolated perfused feline eye causes changes in the electrophysiological response of the retina to light (36), suggesting that angiotensin II may have some neuromodulatory role in the retina.

\subsection{References}

1. Sealey $\mathrm{JE}$, Moon $\mathrm{C}$, Laragh $\mathrm{JH}$, Atlas SA. Plasma prorenin in normal, hypertensive and anephric subjects and its effect on renin measurements. Circ Res 40 (suppl l): 41-45, 1977.

2. Naruse $\mathbb{K}$, Murakoshi $M$, Osamura RY, Naruse $M$, Toma $H$, Watanabe $\mathbb{K}$, Demura $H$, Inagami $\mathbb{T}$, Shizume $\mathbb{K}$. Immunohistochemical evidence for renin in human endocrine issues. J Clin Endocrinol Metab 61: 172-177, 1985.

3. DeSchepper CF, Mellon SH, Cumin F, Baxter JD, Ganong WF. Analysis by immunohostochemistry and in situ hybridization of renin and its mRNA in kidney, testis, adrenal and pituitary of the rat. Proc Natl Acad Sci USA 83: 7552-7557, 1986.

4. Ganten D, Printz M, Phillips MI, Schölkens BA.The renin-angiotensin system in the brain. Exp Brain Res 48 (suppl 4): 3-293, 1982. 
5. Derkx FHM, Alberda AT, de Jong FH, Zeilmaker GH, Makovitz JW, Schalekamp MADH. Source of plasma prorenin early and late in pregnancy. Observations in a patient with primary ovarian failure. $\int$ Clin Endocrinol Metab 65: 349-354, 1987.

6. Do YS, Sherrod A, Lobo RA, Paulson RJ, Shinagawa T, Chen S, Kjos S, Hsueh WA. Human ovarian theca cells are a source of renin. Proc Natl Acad Sci USA 85: 1957-1961, 1988.

7. Glorioso N, Atlas SA, Laragh JH, Jewelewicz R, Sealey JE. Prorenin in high concentrations in human ovarian follicular fluid. Science 233: 1422-1424, 1986.

8. Corvol P, Pinet F, Galen FX, Plouin PF, Chatellier G, Pagny JY, Corvol MT, Menard J. Seven lessons from seven renin-secreting tumors. Kidney Int 34 (suppl 25): S38-S44, 1988.

9. Ohashi H, Matsunaga M, Kuwahara T, Pak CH, Kawai C. Production and release of inactive renin by human vascular smooth rauscle cells. Clin Exp Hypertension Theory Pract A7: 1395-1407, 1985.

10. Pinet F, Corvol MT, Bourguignon J, Corvol P. Isolation and characterization of renin-producing human chorionic cells in culture. J Clin Endocrinol Metab 67: 1211-1220, 1988.

11. Fernandez LA, OIsen TG, Barwick KW, Sanders M, Kaliszewski C, Inagami T. Renin in angiolymphoid hyperplasia with eosinophilia. Its possible effect on vascular proliferation. Arch Pathol Lab Med 110: 1131-1135, 1986.

12. Fernandez LA, Twickler J, Mead A. Neovascularization produced by angiotensin II. $J$ Lab Clin Med 105: 141-145, 1985.

13. Danser AHJ, van den Dorpel MA, Deinum J, Derkx FHM, Franken AAM, Peperkamp E, de Jong PTVM, Schalekamp MADH. Renin, prorenin and immunoreactive renin in vitreous fluid from eyes with and without diabetic retinopathy. $J$ Clin Endocrinol Metab 68: 160-167, 1989.

14. Hirose $S$, Ohsawa $T$, Inagami $T$, Murakami $K$. Brain renin from bovine anterior pituitary. J Biol Chem 257: 6316-6321, 1982.

15. Howard RB, Pucell AG, Bumpus FM, Husain A. Rat ovarian renin: Characterization and changes during the estrous cycle. Endocrinology 123: 2331-2340, 1988.

16. Hirose $S$, Yokosawa $H$, Inagami $T$. Immunochemical identification of renin in rat brain and distinction from acid proteases. Nature 274: 392-393, 1978.

17. Wood JM, Gulati N, Forgiarini P, Fuhrer W, Hofbauer KG. Effects of a specific and long-acting renin inhibitor in the marmoset Hypertension 7: 797-803, 1985.

18. Derkx FHM, Schalekamp MPA, Schalekamp MADH. Prorenin-renin conversion. Isolation of an intermediary form of activated prorenin. J Biol Chem 262: 2472-2477, 1987.

19. Derkx FHM, Tan-Tjiong HL, Wenting GJ, Boomsma F, Man in 't Veld AJ, Schalekamp MADH. Asynchronous changes in prorenin and renin secretion after captopril in patients with renal artery stenosis. Hypertension 5: 244-256, 1983.

20. Mancini $G$, Carbonara AO, Heremans JF. Immunochemical quantification of antigens by single radial immunodiffusion. Immunochemistry 2: 235-254, 1965.

21. Anson ML. The estimation of cathepsin with hemoglobin and the partial purification of cathepsin. $J$ Gen Physiol 20: 565-574, 1934.

22. Hackenthal $\mathbb{E}$, Hackenthal $\mathbb{R}$, Hilgenfeldt $U$. Isorenin, pseudorenin, cathepsin $D$ and renin. A comparative enzymatic study of angiotensin-forming enzymes. Biochim Biophys Acta 522: 574-588, 1978.

23. Schultze D, Brunswig B, Mukhopadhyay AK. Renin and prorenin-like activities in bovine ovarian follicles. Endocrinology 124: 1389-1398, 1989.

24. Derkx FHM, Bouma BN, Schalekamp MPA, Schalekamp MADH. An intrinsic factor XII-prekallikrein-dependent pathway activates the human renin-angiotensin system. Nature 280: 315-316, 1979.

25. Hermann K, Raizada MK, Sumners C, Phillips MI. Presence of renin in primary neuronal and glial cells from rat brain. Brain Res 437: 205-213, 1987. 
26 Swann DA, Constable IJ. Vitreous structure I. Distribution of hyaluronate and protein. Invest Ophthalmol 11: 159-163, 1972.

27. Wurster U, Hoffmann K. Glaskörper. In: Biochemie des Auges, edited by Hockwin O. Enke-Verlag, Stuttgart 1985, pp. 114, 119 and 121.

28. Ferrari-Dileo G, Ryan JW, Rockwood EJ, Davis EB, Anderson DR. Angiotensin-converting enzyme in bovine, feline and human ocular tissues. Invest Ophthalmol Vis Sci 29: 876-881, 1988.

29. Ferrari-Dileo G, Davis EB, Anderson DR. Angiotensin binding sites in bovine and human retinal blood vessels. Invest Ophthalmol Vis Sci 28: 1747-1751, 1987.

30. Rockwood EJ, Fantes F, Davis EB, Anderson DR. The response of retinal vasculature to angiotensin. Invest Ophthalmol Vis Sci 28: 676-682, 1987.

31. Sramek SJ, Wallow IHL, Day RP, Ehrlich EN. Ocular renin-angiotensin: Immunohistochemical evidence for the presence of prorenin in eye tissue. Invest Ophthalmol Vis Sci 29: 1749-1752, 1988.

32. Constad WH, Fiore P, Samson C, Cinotti AA. Use of an angiotensin converting enzyme inhibitor in ocular hypertension and primary open-angle glaucoma. Am J Ophthalmol 105: 674-677, 1988.

33. Lever AF. Slow pressor mechanisms in hypertension: A role for hypertrophy of resistance vessels? J Hypertension 4: 515-524, 1986.

34. Ariza A, Fernandez LA, Inagami T, Kim JH, Manuelidis EE. Renin in glioblastoma multiforme and its role in neovascularization. Am J Clin Pathol 90:437-441, 1988.

35. Palumbo A, Jones C, Lightman A, Carcangiu ML, DeCherney AH, Naftolin F. Immunohistochemical localization of renin and angiotensin II in human ovaries. $A m J$ Obstet Gynecol 160: 8-14, 1989.

36. Dahlheim P, Schneider T, Reiter W, Zrenner E. Das Angiotensin-I-Converting Enzyme (ACE): Aktivitätsverteilung im Auge und neurophysiologische Wirkingen auf die Netzhautfunktion. Fortschr Ophthalmol 85: 709-715, 1988. 


\section{ANGIOTENSIN LEVELS IN THE $\mathbb{E} \mathbb{Y}$}

\subsection{Summary}

Prorenin, the inactive precursor of renin, has been found in human vitreous fluid in concentrations that were too high to be explained by contamination with plasma. Moreover, its levels were twofold higher in vitreous fluid from eyes affected by proliferative diabetic retinopathy than in vitreous fluid from eyes without neovascularization, suggesting a role for the renin-angiotensin system in the development of retinopathy. Angiotensin (ANG) II has been reported to play a role in neovascularization. In the present study we measured angiotensin levels in ocular fluids obtained from diabetic and non-diabetic subjects, and in ocular tissues obtained from pigs. ANG I and ANG II were present in aqueous, vitreous and subretinal fluid of eyes from subjects with and without diabetic retinopathy. Large differences (by a factor of 10) in angiotensin concentrations were found between the various ocular fluid types, but after correction for leakage from plasma by expressing the angiotensin concentrations relative to ocular fluid albumin concentrations, all angiotensin concentrations became equal, indicating that ANG I and ANG II in human ocular fluid samples are largely plasma-derived. No differences were found between diabetic and non-diabetic subjects in either plasma or ocular fluid. angiotensin concentrations. During a 2 -hour i.v. infusion of ${ }^{125}$ I-ANG I in the rabbit, less than $1 \%$ of plasma ${ }^{125}$ I-ANG I reached the vitreous fluid compartment, showing that, under normal conditions, angiotensins pass the blood-retinal barrier (BRB) only in very limited amounts. The relatively high angiotensin levels in human ocular fluid obtained during eye surgery are therefore probably the result of a partial breakdown of the $B R B$, leading to increased diffusion from plasma. Metabolism of ANG I in human ocular fluid occurred at a very low rate and was mainly due to conversion by $\mathrm{ACE}$. Measurement of angiotensins in porcine ocular tissues showed that both ANG I and ANG II were present in retina, pigment epithelium-choroid and anterior uveal tract in concentrations much too high to be explained by contamination with plasma only. Low to undetectable angiotensin levels were found in porcine vitreous fluid. The ANG IIANG I ratio was 3-5 fold higher in the ocular tissues than in plasma or vitreous fluid. These data strongly support the presence of a local renin-angiotensin system in the eye. In contrast with prorenin, little or no intraocularly synthesized ANG I and ANG II seems to be released into the ocular fluids, suggesting an autocrine or paracrine function of the intraocular renin-angiotensin system. 


\subsection{Introduction}

According to the classical concept, angiotensin I (ANG I) and angiotensin II (ANG II) are generated within the circulation by sequential cleavage of liverderived renin substrate. Renin, synthesized in the kidney, cleaves this substrate, forming ANG I, after which angiotensin converting enzyme (ACE) converts ANG I to ANG II, a potent vasoconstrictor and stimulant of the release of aldosterone from the adrenal. Recent evidence suggests that besides this circulating renin-angiotensin system, there also exist tissue or local reninangiotensin systems in different organ sites, for instance in the adrenal, kidney, brain, testis and ovary (1-7). Local angiotensin production may therefore occur independent of circulating renin and circulating renin substrate.

Recently, we reported that high levels of prorenin, the inactive precursor of renin, are present in ocular fluids obtained from both diabetic and non-diabetic subjects during eye surgery (8). The prorenin concentrations were up to 100 times higher than expected based upon the plasma protein content of these samples. In vitreous fluid from eyes affected by proliferative diabetic retinopathy the prorenin concentrations were on average 2 times higher than in vitreous fluid from eyes of non-diabetic subjects, also when allowance was made for the differences in plasma protein content. The renin levels in most ocular fluid samples were close to the detection limit of the assay. These findings suggested that intraocular production of prorenin (and possibly renin) may occur, and that this production is increased in the presence of diabetic retinopathy.

Further studies in bovine eyes (9) showed indeed that both renin and prorenin were present in virtually all segments of the eye in concentrations much too high to be explained by the plasma content of the various ocular tissues only. The presence of ACE in the eye has been shown as well, not only in the retina, choroid and ciliary body (10), but also in aqueous fluid (11). Taken together, these findings suggest that the eye has its own renin-angiotensin system (RAS).

The function of an ocular RAS is not yet known. Its activation in the eyes of diabetic subjects with proliferative retinopathy may suggest that ANG II is involved in the development of neovascularization, as has been shown by others $(12,13)$. As ANG II receptors have been detected in retinal blood vessels (14), a role for the RAS in the regulation of retinal vascular tone is also conceivable (15). Finally, the fact that both renin inhibitors (16) and ACE inhibitors (17) lower intraocular pressure would suggest that an intraocular RAS may play a role in the regulation of aqueous humor dynamics.

To our knowledge, no measurements of angiotensins in the eye have been reported so far. In this study, we present data on angiotensin levels in ocular fluid samples from diabetic and non-diabetic subjects. We also investigated the presence of ACE in human ocular fluid by measuring the amount of ${ }^{125}$ I-ANG II formed in subretinal or vitreous fluid after the addition of ${ }^{125 I-A N G ~ I ~ t o ~}$ 
these fluids. In order to study whether plasma ANG I reaches the vitreous or aqueous fluid compartments, constant infusions of 125 I-ANG I were given to rabbits. The presence of radiolabeled angiotensins in the eye was studied at various time intervals during these infusions. Finally, an attempt was made to measure angiotensin levels in tissue extracts from porcine eyes.

\subsection{Subjects and methods}

\section{Chemicals}

[Me5]-ANG-(1-10) decapeptide (ANG I), [Me5]-ANG-(1-8) octapeptide (ANG II), and [Mle5]-ANG-(2-8) heptapeptide (ANG III) were obtained from Bachem, Bubendorf, Switzerland. [Ile5]-ANG-(2-10) nonapeptide (ANG-(2-10)) was from Senn Chemicals, Dielsdorf, Switzerland. [Ile5]-ANG-(3-8) hexapeptide (ANG-(3-8)), [Ile5]-(4-8) pentapeptide (ANG-(4-8)), and [Ile5]-ANG-(1-7) heptapeptide (ANG-(1-7)) were from Peninsula Laboratories, Belmont, CA, USA. Methanol, ethanol, ortho-phosphoric acid (all analytical grade), trisodium citrate and 1,10-phenantroline were from Merck, Darmstadt, Germany. Bovine serum albumin (BSA) was from Sigma, St. Louis, MO, USA. Disodium EDTA was from Riedel de Haën, Scelze, Germany. Water for high performance liquid chromatography (HPLC) was prepared with a Milli-Q system from Waters, Millford, MA, USA. The renin inhibitor CGP 29,287 was a gift of Dr. K. Hofbauer (Ciba-Geigy, Basel, Switzerland). The renin inhibitor Ro 42,5892 was a gift of Dr. P. van Brummelen (Hoffmann-La Roche, Basel, Switzerland).

\section{Preparation of radiolabeled angiotensins}

Mono-iodinated 125I-ANG I was prepared with the chloramine-T method and purified as described previously (19). ${ }^{125}$ I-labeled preparations of ANG $\mathbb{I I}$, ANG II, ANG-(3-8), ANG-(4-8), ANG-(2-10), ANG-(1-7) and tyrosine were also made.

Separation of angiotensins by HPLC

Angiotensins and their metabolites were extracted from plasma, ocular fluid or tissue homogenates by reversible adsorption to octadecylsilyl silica (SepPak C18, Waters, Millford, MA, USA) and separated by reversed phase HPLC, according to the method of Nussberger et al (20) with some modifications (19). The SepPak cartridges were conditioned with $4 \mathrm{~mL}$ methanol and equilibrated with 2 times $4 \mathrm{~mL}$ of cold water. Samples were passed trough the cartridge followed by a wash with 2 times $4 \mathrm{~mL}$ of cold water. Adsorbed angiotensins were eluted with $3 \mathrm{~mL}$ methanol into polypropylene tubes and the 
methanol was evaporated under vacuum rotation, using a Savant Speed Vac concentrator (Savant Instruments, Farmingdale, NY, USA). Separations were performed on a reversed phase Nucleosil C18 steel column of $250 \times 4.6 \mathrm{~mm}$ and $10 \mu \mathrm{m}$ particle size. Mobile phase A was $0.085 \%$ ortho-phosphoric acid containing $0.02 \%$ sodium azide. Mobile phase B was methanol. The flow was $1.5 \mathrm{~mL} / \mathrm{min}$ and the working temperature was $45^{\circ} \mathrm{C}$. SepPak methanol extracts were dissolved in $100 \mu \mathrm{L}$ of HPLC solvent and injected. Elution was performed as follows: $65 \% \mathrm{~A} / 35 \% \mathrm{~B}$ from 0 to $9 \mathrm{~min}$ followed by a linear gradient to $45 \% \mathrm{~A} / 55 \% \mathrm{~B}$ until $18 \mathrm{~min}$. The eluate was collected in 20 -sec fractions into polystyrene tubes coated with BSA. The concentrations of 125IANG I and its metabolites in the HPLC fractions were measured in the gamma counter. The fractions containing unlabeled ANG I and ANG II were neutralized with $0.5 \mathrm{M}$ sodium hydroxide and vacuum dried at $4{ }^{\circ} \mathrm{C}$. The concentrations of unlabeled ANG I and ANG II were measured by radioimmunoassay (19).

\section{Assay of angiotensins}

ANG I and ANG II concentrations were measured by radioimmunoassay after SepPak extraction and HPLC separation. The ANG I antiserum crossreacted with ANG-(2-10) (100\%) but not (less than 0.1\%) with ANG II, ANG III, ANG-(3-8), ANG-(4-8) and ANG-(1-7). The ANG II antiserum crossreacted with ANG III (55 \%), ANG-(3-8) (73\%) and ANG-(4-8) (100\%), but not (less than $0.2 \%$ ) with ANG I, ANG-(2-10) or ANG-(1-7). The lower limit of detection was $0.5 \mathrm{fmol} /$ fraction for the ANG II assay, and $1.0 \mathrm{fmol} /$ fraction for the ANG I assay.

\section{Measurement of albumin and renin substrate}

Human albumin was measured by single radial immunodiffusion (LC and NOR-Partigen plates, Behringwerke, Marburg, Germany) according to the method of Mancini et al (21). The concentration of renin substrate was determined as the maximum quantity of ANG I that was generated during incubation at $37^{\circ} \mathrm{C}$ and $\mathrm{pH} 7.5$ with an excess of active purified human kidney renin in the presence of inhibitors of angiotensinases and ACE (22). The lower limit of detection was $1 \mathrm{nmol} / \mathrm{L}$.

\section{Human studies}

Non-diabetic subjects. Aqueous fluid was collected at the time of cataract extraction from 26 subjects ( 20 women, 6 men; mean age 71 yr, range 38-92 yr). Nine subjects were receiving a diuretic and 3 a $ß$-adrenergic antagonist.

Vitreous fluid aspirates were obtained from 18 subjects (11 women, 7 men; mean age $57 \mathrm{yr}$, range $10-80 \mathrm{yr}$ ). The samples were collected at the time of 
pars plana vitrectomy, which was performed because of recurrent retinal detachment due to proliferative vitreoretinopathy $(n=12)$, macula pucker $(n=3)$ or vitreous hemorrhage $(n=3)$. Three subjects were receiving a diuretic and 1 a $B$-adrenergic antagonist.

Subretinal fluid was obtained from 21 subjects (11 women, 10 men; mean age $55 \mathrm{yr}$, range $13-79 \mathrm{yr})$, with a rhegmatogenous $(n=20)$ or traumatic $(n=1)$ retinal detachment. Three subjects were receiving a diuretic.

Diabetic subjects. Vitreous fluid was obtained from 24 diabetic subjects (6 women, $18 \mathrm{men}$; mean age $51 \mathrm{yr}$, range 21-75 yr). The duration of diabetes ranged from 1 to 55 years. The eyes were affected by proliferative diabetic retinopathy and vitrectomy was performed because of traction retinal detachment $(n=15)$ or vitreous hemorrhage $(n=9)$. Seventeen subjects were taking insulin, 6 were receiving a diuretic, in 4 of them combined with a Badrenergic antagonist. No subretinal nor aqueous fluid was collected from diabetic subjects.

Collection of plasma and ocular fluid samples. Approximately $0.1 \mathrm{~mL}$ aqueous fluid was collected with a tuberculin syringe and a 27 gauge needle. The needle was introduced at the limbus of the comea through the groove of the cataract incision. Vitreous fluid was aspirated before substitution fluid was infused into the vitreous. Subretinal fluid was aspirated transsclerally, after local diathermic coagulation of the choroid.

The ocular fluid samples were free of macroscopically visible blood and were collected, after informed consent was obtained, in prechilled plastic tubes containing $25 \mu \mathrm{L}$ of inhibitor solution (containing $2 \mu \mathrm{M}$ CGP $29,287,125 \mathrm{mM}$ disodium EDTA and $25 \mathrm{mM}$ 1,10-phenantroline) in order to block renin, ACE and angiotensinases. The samples were frozen immediately after collection at $70{ }^{\circ} \mathrm{C}$. Some ocular fluid was frozen separately without inhibitor solution for studies on the metabolism of $125 \mathrm{I}-\mathrm{ANG}$ I and for the measurement of renin substrate and albumin.

A peripheral venous blood sample was drawn simultaneously with the collection of ocular fluid in all patients. Blood for angiotensin measurements $(10 \mathrm{~mL})$ was collected in prechilled tubes containing $0.5 \mathrm{~mL}$ of the above inhibitor solution and centrifuged at $3000 \mathrm{~g}$ for 10 minutes at $4{ }^{\circ} \mathrm{C}$. Plasma was stored at $-70{ }^{\circ} \mathrm{C}$ and assayed within two weeks. Blood for the measurement of renin substrate and albumin and for studies on the metabolism of ${ }^{125}$ I-ANG I $(10 \mathrm{~mL})$ was collected in tubes containing 0.1 vol $0.13 \mathrm{M}$ trisodium citrate. The blood was immediately centrifuged at $3000 \mathrm{~g}$ for $10 \mathrm{~min}$ at room temperature and plasma was stored at $-70^{\circ} \mathrm{C}$.

Because of the relatively low angiotensin levels and the small size of most ocular fluid samples (less than $0.5 \mathrm{~mL}$ ), angiotensin measurements in ocular fluid were only performed in pools consisting of several $\mathrm{mL}$ of ocular fluid. The recovery of angiotensins added to subretinal and vitreous fluid pools was 
96 and $85 \%$ respectively ( $n=2$ for each). Plasma levels of ANG I and ANG II were measured in individual patients. Renin substrate and albumin were measured in all individual samples.

Metabolism of ${ }^{25 I}$-ANG I in human ocular fluid and plasma. The metabolism of $125 \mathrm{I}-\mathrm{ANG}$ I was studied in pools $(2 \mathrm{~mL})$ of subretinal fluid, vitreous fluid and plasma. After the ocular fluid and plasma pools had been brought to a temperature of $37^{\circ} \mathrm{C}$ in a waterbath, the experiment was started by adding at $t=050.000$ counts per minute (cpm) of ${ }^{125 I-A N G ~ I ~(i n ~} 50 \mu \mathrm{L}$ of TRIS buffer). Experiments were done in the presence or absence of the ACE inhibitor captopril (final concentration in the sample $0.4 \mathrm{mM}$ ). Samples of $400 \mu \mathrm{L}$ were taken at various times (at $0,1,2$ and $5 \mathrm{~min}$ for plasma, at $0,5,10$ and $20 \mathrm{~min}$ for subretinal fluid and at 0,30 and $60 \mathrm{~min}$ for vitreous fluid) and immediately mixed with $50 \mu \mathrm{L}$ inhibitor solution. The samples were kept on ice and SepPak extraction was performed within one hour. The SepPak extracts were applied to the HPLC column and ${ }^{125} \mathrm{I}-\mathrm{ANG} \mathrm{I}$ and ${ }^{125 \mathrm{I}-\mathrm{ANG}} \mathrm{II}$ were measured by gamma counting as described before. Results are expressed as a percentage of total cpm recovered after SepPak extraction.

\section{${ }_{125}$ I-ANG I infusions in rabbits}

All procedures were in accord with the ARVO Resolution on the Use of Animals in Research. Three rabbits, weighing $2.9-3.3 \mathrm{~kg}$, were anesthetized using intramuscular xylazine (Bayer, Leverkusen, Germany; $2 \mathrm{mg} / \mathrm{kg}$ ) and ketamine $\mathrm{HCl}$ (Aesculaap BV, Boxtel, The Netherlands; $20 \mathrm{mg} / \mathrm{kg}$ ). Additionally, they received topical oxybuprocaine $\mathrm{HCI}$ (M.S.D., Haarlem, The Netherlands) for local anesthesia. The ACE inhibitor ramipril was injected intraperitoneally $(1 \mathrm{mg} / \mathrm{kg}$ ) shortly before the experiment. This was performed in order to slow down the fast breakdown of infused 125I-ANG I. 125I-ANG I (mean concentration $3.4 \times 10^{6} \mathrm{cpm} / \mathrm{mL}$ ) was infused at a rate of $0.1 \mathrm{~mL}$ per minute in the ear lobe vein during two hours. Arterial samples (1-2 mL) were taken from the carotid artery at $15,30,45,60,90$ and 120 min after the start of the infusion. The blood was collected in prechilled tubes containing $0.1 \mathrm{~mL}$ of the above inhibitor solution and centrifuged at $3000 \mathrm{~g}$ for 10 minutes at 4 ${ }^{\circ} \mathrm{C}$. One $\mathrm{mL}$ of plasma was counted in a gamma counter for measuring total radioactivity. After 1 hour, an aqueous and a vitreous sample were removed from one eye with an injection needle with a 25 and a 19 gauge respectively, and total radioactivity was counted in both samples. At the end of the infusion period the animals were killed and immediately aqueous and vitreous samples were taken from the second eye and counted in the gamma counter.

After the experiment, the ocular fluid and plasma samples were passed through SepPak columns and applied to the HPLC, as described before. Radiolabeled angiotensins were measured by gamma counting. 
Eyes were taken from 20 anesthetized pigs (weight $25-50 \mathrm{~kg}$, crossbred Yorkshire x Landrace, H.V.C., Hedel, The Netherlands). The pigs had been used for various pharmacological studies not involving the eye. An adequate depth of anesthesia had been maintained by the administration of $160 \mathrm{mg} / \mathrm{kg} \alpha$ chloralose (Merck, Darmstadt, Germany) in the superior caval vein, followed by continuous i.v. infusion of low dose sodium pentobarbitone $(5 \mathrm{mg} / \mathrm{kg} \mathrm{per} \mathrm{h})$. The eyes were dissected immediately following enucleation. Each eye was cut equatorially at the ora serrata, and the anterior segment was lifted off. The vitreous body was isolated by gently shaking it out of the eye cup. The neural retina was cautiously removed from the pigment epithelium with a thin glass rod and isolated by cutting it at the optic nerve. The choroid with adhering retinal pigment epithelium layer was isolated by dissecting it from the sclera with a pair of fine scissors. The anterior uveal tract, consisting of iris and ciliary body, was isolated by removing the lens from the anterior eye cup, then gently pulling the anterior uveal tract loose from the sclera and blotting it on dry paper to remove any adhering vitreous. Cornea, lens and sclera were discarded, whereas retina, pigment epithelium-choroid, anterior uveal tract and vitreous were snap frozen on dry ice and stored at $-70^{\circ} \mathrm{C}$. The whole procedure took 2-3 $\mathrm{min}$.

Simultaneously with the removal of the eyes a peripheral blood sample was taken, after which the animals were killed. The blood $(10 \mathrm{~mL})$ was collected in a chilled polystyrene tube containing. $0.5 \mathrm{~mL}$ inhibitor solution (containing 0.2 $\mathrm{mM}$ Ro 42,5892, $125 \mathrm{mM}$ disodium EDTA and $25 \mathrm{mM} \mathrm{1,10-phenantroline).}$ The blood was centrifuged at $3000 \mathrm{~g}$ for $10 \mathrm{~min}$ at $4{ }^{\circ} \mathrm{C}$. Plasma was stored at $70^{\circ} \mathrm{C}$ and assayed as described above within 2 weeks.

Pools of tissues obtained from 10 pigs (20 eyes) were homogenized with a Polytron PT10/35 (Kinematica, Luzern, Switzerland) in an iced solution of 0.1 $\mathrm{M} \mathrm{HCl} / 80 \%$ ethanol according to the method of Chappell et al (23) with some modifications. In short, homogenates were centrifuged at $4{ }^{\circ} \mathrm{C}$ for $20 \mathrm{~min}$ at $20.000 \mathrm{~g}$ and the supernatant was stored for $12 \mathrm{hrs}$ at $-20{ }^{\circ} \mathrm{C}$. The supernatant obtained after a second centrifugation $\operatorname{step}\left(4^{\circ} \mathrm{C}, 20.000 \mathrm{~g}, 20 \mathrm{~min}\right)$ was diluted 1:1 (v:v) with $1 \%$ ortho-phosphoric acid, stored for $4-6 \mathrm{hrs}$ at $4{ }^{\circ} \mathrm{C}$, and again centrifuged at $20.000 \mathrm{~g}$. The final supernatant was further diluted $1: 1$ with 0.2 $\%$ ortho-phosphoric acid and concentrated on a SepPak column. Vitreous was concentrated on SepPak columns without further additions. SepPak extracts were applied to the HPLC as described above and angiotensins were measured by RIA.

Metabolism of angiotensins during storage at $-70^{\circ} \mathrm{C}$ was studied by adding ${ }^{125} \mathrm{I}$-ANG I to frozen tissues one week before homogenization. The efficiency of the extraction was determined by the addition of 200.000 CPM 125I-ANG I immediately before homogenization. Overall recovery was $59 \pm 9 \%$ (mean and $\mathrm{SD}, \mathrm{n}=6$ ). 


\section{Statistical evaluation}

Angiotensin levels in ocular fluid and plasma are expressed as mean and range. Because of non-linear distribution, albumin and renin substrate in ocular fluid and plasma are expressed as geometric mean and range. Unpaired t-tests were performed to analyze differences between diabetic and non-diabetic subjects. Values were considered significant if $p<0.05$.

\subsection{Results}

ANG I, ANG II, renin substrate and albumin levels in human ocular fluid and plasma

Plasma angiotensin levels were similar in diabetic and non-diabetic subjects (Table 1). In non-diabetic subjects, the highest ocular angiotensin levels were found in subretinal fluid and the lowest (close to the detection limit of the assay) in aqueous fluid. ANG I and ANG II levels in vitreous fluid of diabetic subjects were similar to those in vitreous of non-diabetic subjects, although relative to ANG I, ANG II tended to be slightly higher $(p>0.05)$ in vitreous from diabetic subjects than in vitreous from non-diabetic subjects. The ANG I and ANG II concentrations in subretinal, vitreous and aqueous fluid were approximately 100,50 and $10 \%$ of those in plasma.

No differences in plasma or vitreous fluid albumin and renin substrate levels were found between diabetic and non-diabetic subjects (Table 2). As for ANG I and ANG II, the highest concentrations of albumin and renin substrate were found in subretinal fluid and the lowest in aqueous fluid. The concentrations of albumin and renin substrate in subretinal, vitreous and aqueous fluid were approximately 10,5 and 1 percent of those in plasma.

The ocular fluid/plasma concentration ratio of renin substrate equalled that of albumin and both ratios were strongly correlated ( $\mathrm{r}=0.99, \mathrm{p}<0.001$ ), suggesting that both proteins enter the ocular fluid to the same degree, presumably by diffusion from plasma. This confirms earlier findings (8). Expressing the angiotensin levels relative to albumin (Figure 1) results in similar angiotensin levels in all ocular fluids. Apparently, the differences in angiotensin levels found between subretinal, vitreous and aqueous fluid parallel the differences in albumin (and renin substrate) levels, and therefore angiotensins in ocular fluid are most likely plasma-derived. 
Table 1. Levels of ANG I and ANG II in individual plasma samples and ocular fluid pools of diabetic and non-diabetic subjects.

\begin{tabular}{llllll}
\hline & $\mathrm{n}$ & \multicolumn{2}{c}{$\begin{array}{c}\text { ANG I } \\
(\mathrm{pM})\end{array}$} & \multicolumn{2}{c}{$\begin{array}{c}\text { ANG II } \\
(\mathrm{pM})\end{array}$} \\
\hline $\begin{array}{l}\text { Non-diabetic subjects } \\
\text { plasma }\end{array}$ & 39 & 27.0 & $(1.9-86.6)$ & 8.0 & $(0.7-20.7)$ \\
$\begin{array}{l}\text { subretinal fluid } \\
\text { vitreous fluid }\end{array}$ & 3 & 24.5 & $(14.5-37.8)$ & 5.4 & $(5.2-5.8)$ \\
aqueous fluid & 3 & 12.7 & $(7.0-17.2)$ & 2.3 & $(1.3-3.0)$ \\
$\begin{array}{l}\text { Diabetic subjects } \\
\text { plasma }\end{array}$ & 2 & 2.0 & $(1.7-2.2)$ & 0.5 & $(0.5-0.6)$ \\
vitreous fluid & 16 & 23.6 & $(3.9-94.7)$ & 6.7 & $(0.9-24.9)$ \\
\hline
\end{tabular}

Values are given as mean and range.

Table 2. Levels of albumin and renin substrate in ocular fluid and plasma of diabetic and non-diabetic subjects.

\begin{tabular}{lccccl}
\hline & $\mathrm{n}$ & $\begin{array}{c}\text { Albumin } \\
(\mathrm{g} / \mathrm{L})\end{array}$ & $\begin{array}{c}\text { Renin Substrate } \\
(\mathrm{nM})\end{array}$ \\
\hline $\begin{array}{l}\text { Non-diabetic subjects } \\
\text { plasma }\end{array}$ & 39 & 32.5 & $(24.1-40.9)$ & 1038 & $(572-1667)$ \\
$\begin{array}{l}\text { subretinal fluid } \\
\text { vitreous fluid }\end{array}$ & 21 & 3.05 & $(0.35-29.6)$ & 99 & $(21-963)$ \\
aqueous fluid & 18 & 1.25 & $(0.12-20.3)$ & 42 & $(5-643)$ \\
Diabetic subjects & 26 & 0.24 & $(0.06-0.45)$ & 6 & $(2-15)$ \\
$\begin{array}{l}\text { plasma } \\
\text { vitreous fluid }\end{array}$ & 16 & 31.1 & $(22.9-38.4)$ & 937 & $(557-1280)$ \\
& 24 & 1.87 & $(0.84-14.6)$ & 58 & $(24-635)$ \\
\hline
\end{tabular}

Values are given as geometric mean and range. 

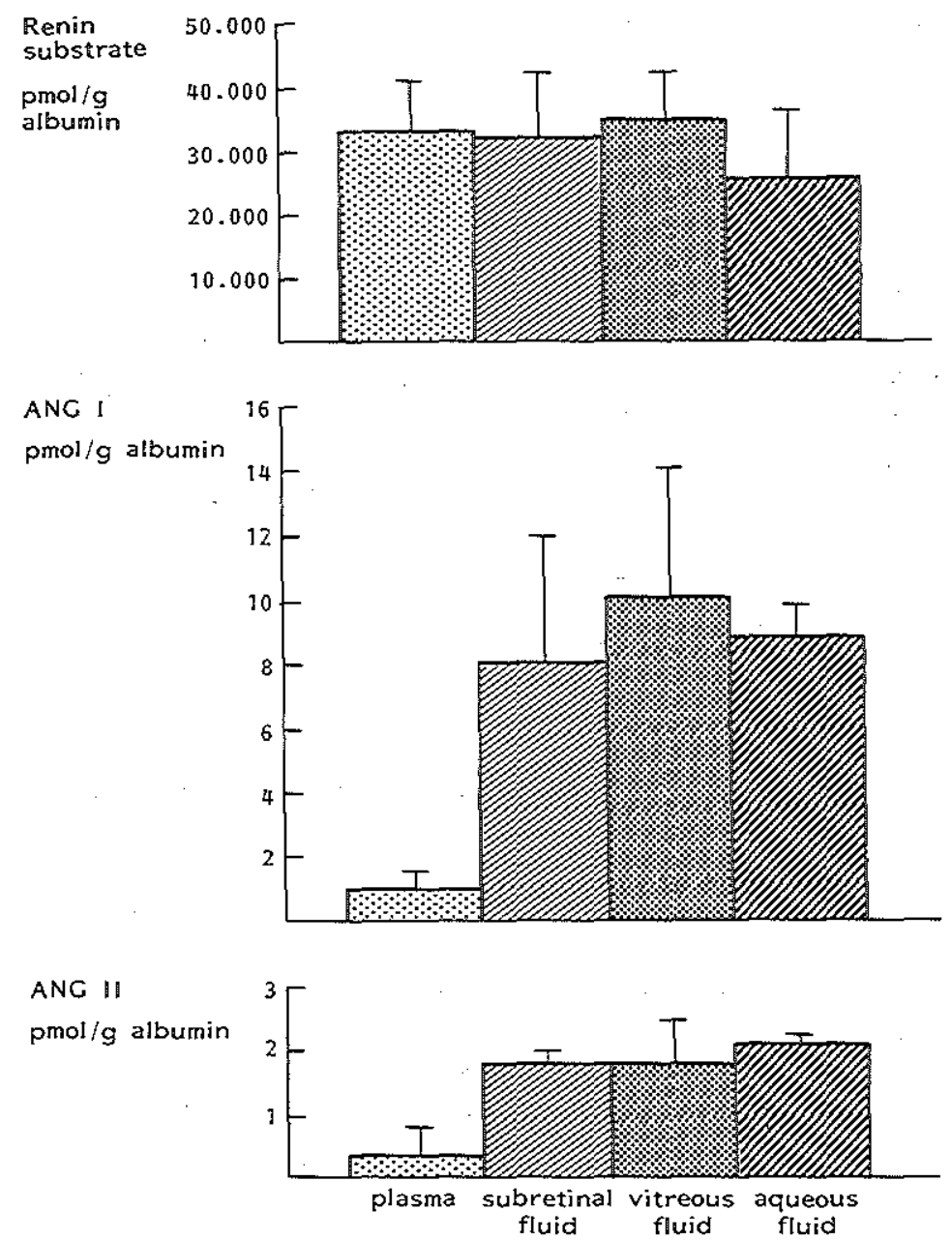

Figure 1. Levels (mean and SD) of renin substrate, ANG I and ANG II relative to those of albumin in plasma, subretinal fluid, vitreous fluid and aqueous fluid of non-diabetic subjects. 
NO CAPTOPRIL

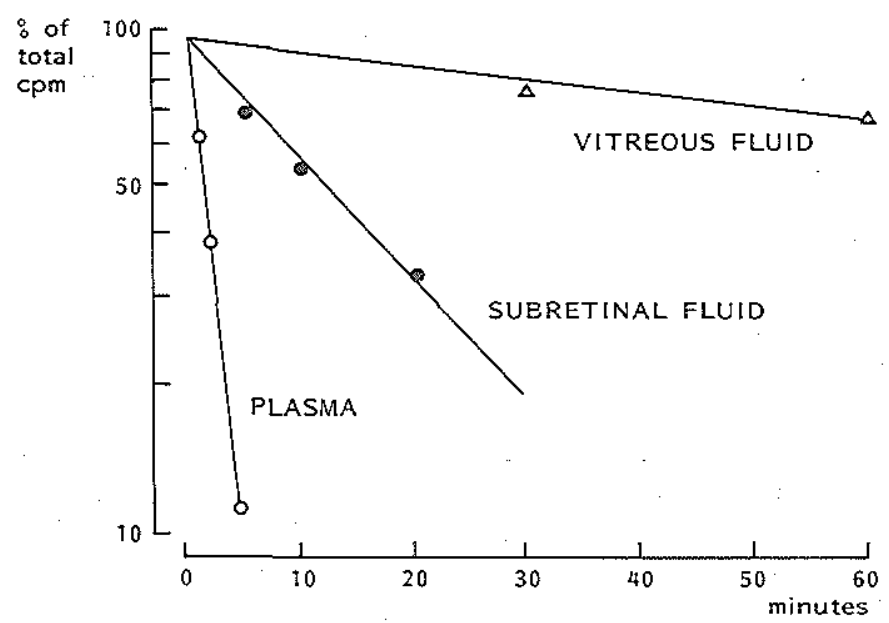

CAPTOPRIL

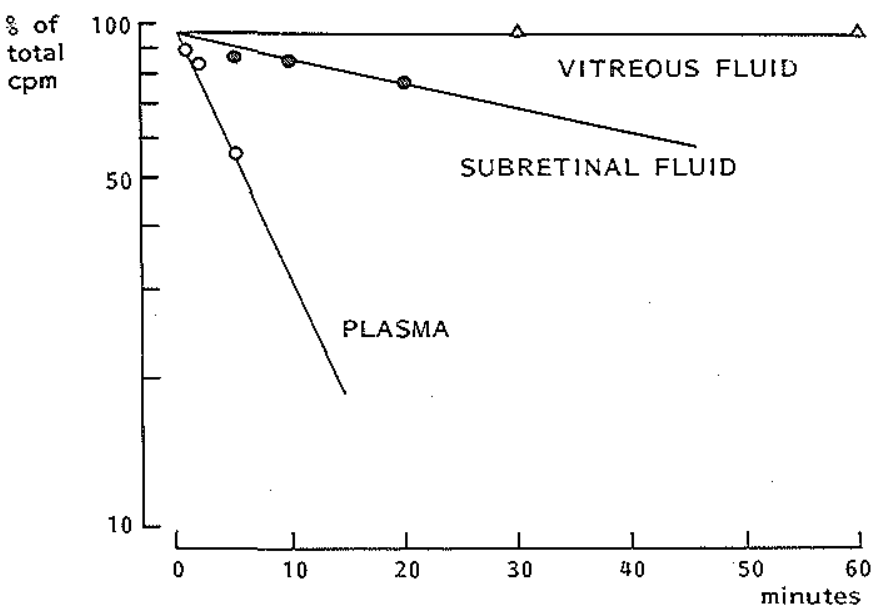

Figure 2. Metabolism of ${ }^{125}$ I-ANG I in plasma, subretinal fluid and vitreous fluid during incubation at $37^{\circ} \mathrm{C}$ in the absence (top panel) or presence (bottom panel) of captopril. Data are means of 2 experiments each. 
Incubating pools of plasma, pools of subretinal fluid and pools of vitreous fluid with 125 I-ANG I at $37{ }^{\circ} \mathrm{C}$ resulted in the prompt breakdown of the peptide (Figure 2). The half lives of 125I-ANG I in plasma, subretinal fluid and vitreous fluid were $1.5,14$ and 134 minutes respectively (mean of 2 experiments each). HPLC separation of the various metabolites clearly showed that formation of ${ }^{125}$ I-ANG II occurred (Figure 3). In vitreous only ${ }^{125}$ I-ANG II and no other metabolites were formed.

In the presence of the ACE inhibitor captopril the breakdown of ${ }^{125}$ I-ANG I was markedly reduced in subretinal fluid (half life $87 \mathrm{~min}, \mathrm{n}=2$ ) and plasma (half life $5.4 \mathrm{~min}, \mathrm{n}=2$ ) and completely inhibited in vitreous fluid $(\mathrm{n}=2)$ (Figure 2). ${ }^{125}$ I-ANG II was no longer present among the metabolites, indicating that it is indeed $\mathrm{ACE}$ that is responsible for the formation of ${ }^{125} \mathrm{I}$ ANG II in both ocular fluid and plasma. Based on the difference in half life with and without captopril, it could be calculated that $70-80 \%$ of ANG I metabolism in plasma and subretinal fluid, and $100 \%$ of ANG I metabolism in vitreous fluid is due to ANG I-M conversion by $\mathrm{ACE}$.

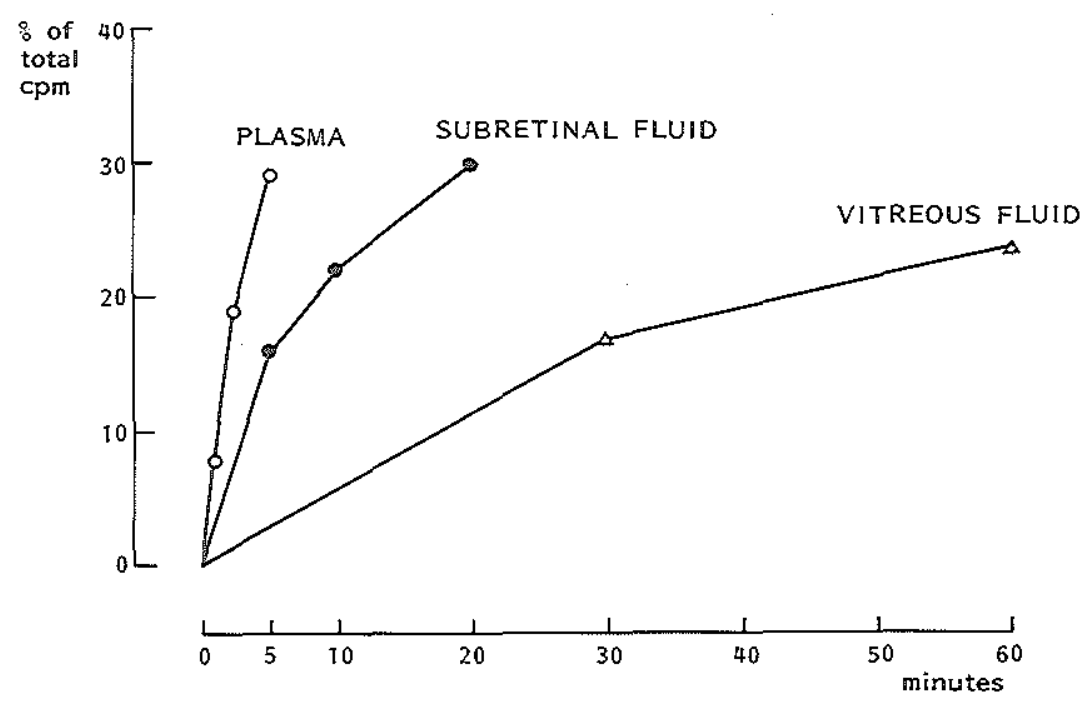

Figure 3. Formation of ${ }^{125}$ I-ANG II during incubation of ${ }^{125}$-ANG I at $37^{\circ} \mathrm{C}$ in plasma, subretinal fluid and vitreous fluid. Data are means of 2 experiments each. 
Total radioactivity in plasma increased with time, but the ${ }^{125 I-A N G ~ I ~ l e v e l s ~}$ reached a plateau within 15 minutes which did not change during the infusion. The mean plateau concentration in the carotid artery $(n=3)$ was 550 (range 165-1060) $\mathrm{cpm}$ 125I-ANG I/mL plasma. Expressed as a percentage of total plasma radioactivity, the total radioactivity in aqueous and vitreous fluid did not differ between samples from the first $(t=1 \mathrm{~h})$ and the second $(t=2 \mathrm{~h})$ eye. The radioactivity levels were in aqueous fluid 25.8 (range $22.9-27.3$ ) $\%$ and in vitreous fluid 2.4 (range $1.6-3.5$ ) \% of concomitant plasma values. HPLC separation of the radioactive components in ocular fluid revealed that virtually all radioactivity concentrated in the first few HPLC fractions. These fractions are known to contain small radiolabeled metabolites (predominantly $125 \mathrm{I}$ tyrosine). Only very limited amounts of ${ }^{125} \mathrm{I}$-ANG I were found in aqueous and vitreous fluid: $21 \pm 24 \mathrm{cpm} / \mathrm{mL}$ and $6 \pm 2 \mathrm{cpm} / \mathrm{mL}$, respectively. The aqueous, but not the vitreous fluid $125 \mathrm{I}-\mathrm{ANG}$ I concentrations correlated significantly $(r=0.98 ; p<0.001)$ with the plasmalevels of ${ }^{125}$ I-ANG I.

These findings demonstrate that, in normal healthy rabbits with presumably intact blood-retinal barriers, only approximately $1 \%$ of plasma ANG I reaches the vitreous compartment and $4 \%$ the aqueous compartment.

\section{Angiotensin levels in porcine eyes}

The levels of ANG I and ANG II in porcine plasma, vitreous and ocular tissues are given in Table 3. Figure 4 shows the results in a pigment epitheliumchoroid extract. Not only ANG I and ANG II were detected, but small amounts of ANG III were present as well (Fig. 4). in absolute terms (expressed per g tissue, plasma or vitreous fluid) the levels of ANG I at all ocular sites were lower than those in plasma. The ANG II levels in the retina and anterior uveal tract were similar to or slightly higher than those in plasma, whereas in the pigment epithelium-choroid ANG II was threefold higher than in plasma. The relatively high tissue levels of ANG II were not the result of in vitro conversion of ANG I, nor was ANG I metabolized by other degrading enzymes during storage or purification, since adding ${ }^{125}$ I-ANG I during storage or immediately before homogenization did not result in the formation of any angiotensin metabolite other than ${ }^{125} \mathrm{I}-\mathrm{ANG} \mathrm{I}$. Previous studies have documented that ${ }^{125}$ I-labeled angiotensins have similar recoveries to unlabeled

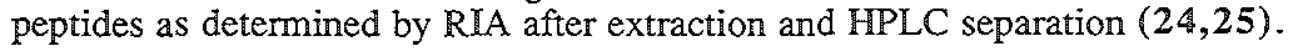
In vitreous fluid ANG I and ANG II were frequently close to or below the detection limit of the assay. Vitreous angiotensin levels were less than 10 percent of concomitant plasma angiotensin levels. The vitreous ANG II/ANG I ratio was similar to that in plasma, suggesting that ANG I and ANG II in vitreous fluid are probably largely plasma-derived. The ANG II/ANG I ratios in ocular tissues were 3-5 fold higher than the plasma ANG II/ANG I ratio. 
Table 3. Levels of ANG I and ANG II in porcine plasma, vitreous and ocular tissues.

\begin{tabular}{lccc}
\hline & $\begin{array}{l}\text { ANG I } \\
\text { (fmol/g) }\end{array}$ & $\begin{array}{c}\text { ANG I } \\
\text { (fmol/g) }\end{array}$ & $\begin{array}{c}\text { ANG II/ANG I } \\
\text { ratio }\end{array}$ \\
\hline plasma & 9.7 & 7.5 & 0.8 \\
vitreous fluid & $<1.1$ & $<0.9$ & 0.8 \\
retina & 3.1 & 11.2 & 3.6 \\
pigment epithelium-choroid & 8.0 & 23.2 & 2.9 \\
anterior uveal tract & 3.1 & 12.4 & 4.1 \\
\hline
\end{tabular}

Values are means of individual samples (plasma and vitreous fluid) or means of 2 measurements in tissue pools (taken from 20 eyes each).

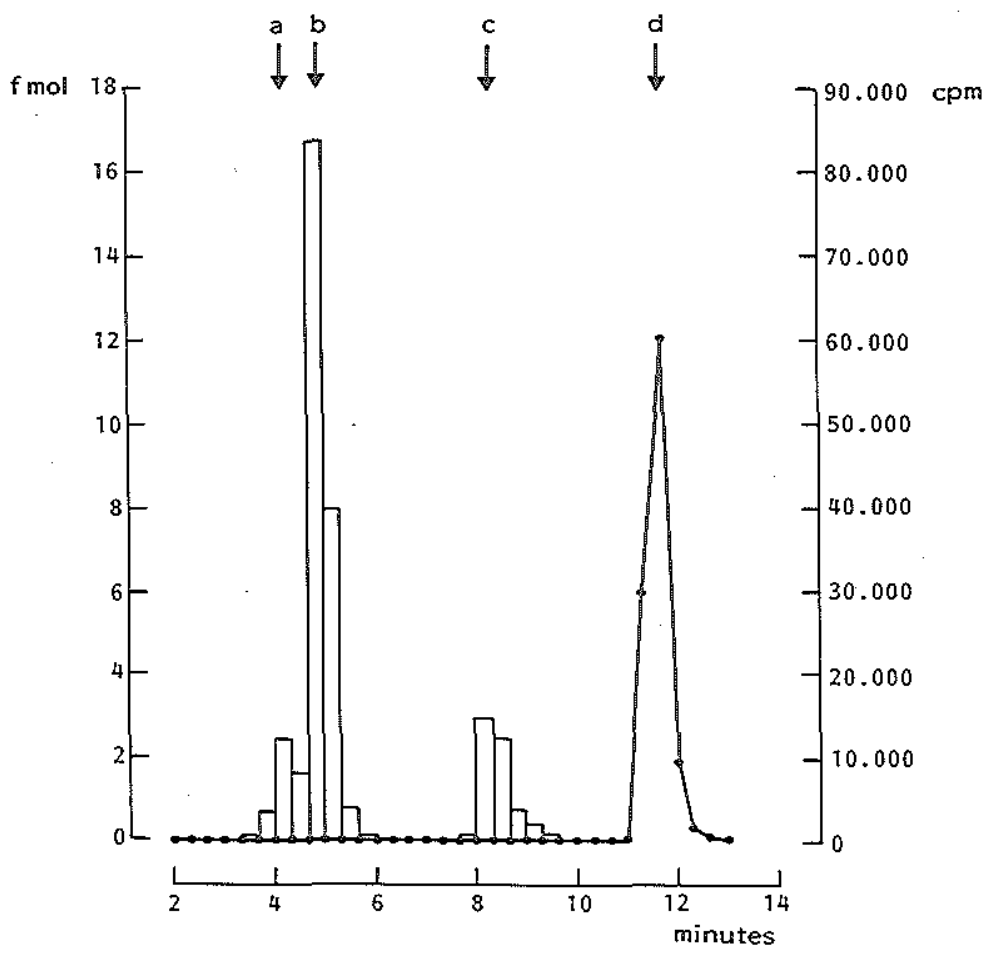

Figure 4. HPLC elution profile of endogenous angiotensins (bars) in a porcine pigment epithelium-choroid tissue extract. ${ }^{125}$ I-ANG I (closed circles) was added to study metabolism during storage and purification (see Subjects and methods for details). The retention times of standard angiotensins are given as a (ANG IM), b (ANG II), c (ANG I) and d (125I-ANG I). 


\subsection{Discussion}

ANG I and ANG II are present in ocular fluid samples taken from patients undergoing eye surgery. No differences in plasma or vitreous fluid angiotensin content were found between diabetic and non-diabetic subjects. In non-diabetic subjects, the highest angiotensin levels were present in subretinal fluid (equalling those in plasma) and the lowest (close to the detection limit of the assay) in aqueous fluid. Similar findings were done for albumin and renin substrate, confirming earlier data (8). Relative to concomitant plasma levels, the concentrations of albumin and renin substrate were approximately 10-fold lower than those of ANG I and ANG II. The ocular fluid/plasma concentration ratio of renin substrate equalled that of albumin in each individual sample, suggesting that both proteins enter the ocular fluid to the same degree, presumably by diffusion from plasma. The vitreous concentration of plasma proteins in normal, healthy eyes has been described to be only $1-2 \%$ of concomitant plasma concentrations $(26,27)$. The higher levels (5\% of plasma levels) we found in vitreous fluid for both albumin and renin substrate are probably due to partial breakdown of the blood-retinal barrier (BRB), leading to increased diffusion. Since no differences were found in the albumin and renin substrate content of vitreous fluid taken from diabetic and non-diabetic subjects, the degree of breakdown of the BRB must have been comparable in both groups of subjects.

As shown by our experiments in the rabbit, approximately $1 \%$ of arterially present ${ }^{125}$ I-ANG I enters the vitreous fluid compartment of healthy eyes during a 2-hour infusion. The levels reached in aqueous fluid were in a similar low range ( $4 \%$ of arterial plasma levels), and correlated significantly with the arterial 125I-ANG I levels. Apparently, the plasma ANG I levels determine the aqueous levels of ANG I. That no correlation was found with the concentrations in vitreous fluid is probably. due to their extremely low levels. Following intravenous infusion, fluorescein (which has a molecular weight 4-5 fold lower than that of angiotensins) has also been reported to reach very low levels in vitreous and aqueous fluid (28-30). Fluorescein levels in vitreous were usually below $1 \%$ of concomitant plasma levels. Others have shown $(31,32)$ that ANG I nor ANG II is able to pass the blood-brain barrier, which is very comparable, if not equal to the BRB (33). Microperoxidase, which has a molecular weight in the same range as ANG I and ANG II, does not pass the $B R B$ in normal rats (34). Thus, we may assume that in normal, healthy eyes with an intact BRB plasma ANG I (and ANG M) cross the BRB, if at all, only in very limited amounts. Partial breakdown of the BRB however, may lead to increased diffusion of angiotensins from the blood into the eye. Leakage of fluorescein into the eye for example is known to be increased 2-3 times in diabetic rats as compared with normal rats (35), and a direct correlation has been described between fluorescein leakage and breakdown of the BRB (36). ANG I and ANG II in ocular fluid may therefore, like albumin and renin 
substrate, also be derived from plasma. Local generation of ANG I in ocular fluid seems unlikely because of the low levels of renin substrate and renin (8) reported in the various ocular fluids. The present study shows that ACE is present in subretinal and vitreous fluid, but the low rate at which ANG I-II conversion in these fluids occurs as compared with ANG I-II conversion in plasma, suggests that ANG II formation in ocular fluid is also of minor importance. An alternative for leakage from plasma or generation in ocular fluid would be that angiotensins are released from an intraocular angiotensin producing source, for instance the retina or the ciliary body. One would then expect a concentration gradient for ANG I and ANG $M$ to exist independent of the plasma protein content of the samples. We have shown this for prorenin $(8,9)$. However, after correction for leakage from plasma by expressing the angiotensin levels relative to those of albumin no more concentration differences were found between the various ocular fluids. This suggests that ANG I and ANG II in ocular fluid are indeed largely plasma-derived. The angiotensin ocular fluid/plasma concentration ratio being higher than the albumin and renin substrate ocular fluid/plasma concentration ratio is probably due to the much smaller size of ANG I (mol wt, $1.3 \mathrm{~K}$ ) and ANG II (mol wt, $1.0 \mathrm{~K}$ ) as compared with albumin (mol wt, $69 \mathrm{~K}$ ) and renin substrate (mol wt, $65 \mathrm{~K})$, leading them to diffuse far more easier from the circulation into the various ocular fluids. This is in accordance with our earlier observation (8) that the concentration of IgG (mol wt, $150 \mathrm{~K}$ ) in vitreous fluid, relative to that of albumin, was somewhat lower than that in plasma due to its larger molecular size.

The high levels of prorenin, renin and $\mathrm{ACE}$ found by us and others in retina, choroid and ciliary body $(9,10,37)$ favour the possibility that ANG $I$ and ANG II are produced within ocular tissue(s) rather than in ocular fluid. The present study shows that both renin substrate and angiotensins in ocular fluid are largely plasma-derived, suggesting that if angiotensins are produced intraocularly they remain in the tissues where they are produced rather than that they enter the vitreous or aqueous fluid compartment. Possibly the rate at which angiotensins are metabolized in ocular tissues is too high to allow overflow into ocular fluids. Alternatively, angiotensin production may occur in compartment which does not equilibrate with the vitreous or aqueous fluid. Prorenin seems to be the only component of the intraocular RAS that does leak into ocular fluid. Both human and bovine vitreous contained virtually only prorenin and no renin $(8,9)$. Cultured bovine theca cells $(38)$ and rat adrenal glomerulosa cells (39) have also been reported to release only prorenin and no renin into the medium. In these cells, both protenin and renin were found, suggesting that angiotensin production occurs presumably intracellularly only.

To test our hypothesis that angiotensins are produced locally within the eye, we measured angiotensin levels in plasma, vitreous and various ocular tissues of the pig. Pigs that had been used for various pharmacological studies were enucleated shortly before they were killed. In this way it was possible to 
remove the eyes under standardized conditions, reducing the time between enucleation and freezing of the various tissues to a minimum of $2-3 \mathrm{~min}$, a situation which proved to be impossible in the local slaughterhouse. Angiotensin levels in porcine vitreous fluid were extremely low, close to or below the detection limit of the assay. Plasma angiotensin levels were at least 10 times higher, confirming our finding in the rabbit that virtually no plasma ANG I nor plasma ANG II reaches the vitreous fluid compartment in normal eyes. In contrast, the angiotensin levels in the retina, pigment epitheliumchoroid and anterior uveal tract (iris + ciliary body) were too high to be explained by contamination with plasma only. Expressed per $g$ of tissue weight ocular ANG II levels were similar to or higher than plasma ANG II levels, whereas ocular ANG I levels were $30-80 \%$ of plasma ANG I levels. Previous studies in bovine eyes (9) have shown that the plasma content of the retina, anterior uveal tract and pigment epithelium-choroid is only 1,5 and $20 \%$ of total tissue weight respectively, and one may assume that this is similar in porcine eyes. Thus, the high angiotensin levels in ocular tissues can only be explained by assuming either that angiotensins are taken up selectively from the circulation, or that they are synthesized locally. In disagreement with the former explanation is the fact that the tissue ANG M/ANG I ratio was 3-5 fold higher than the plasma ANG I/ANG I ratio. In vitro formation or metabolism of angiotensins is unlikely to be the explanation of this finding, for it was shown that no angiotensin metabolism occurred during either storage or purification of the samples. No metabolites of ${ }^{125 I-A N G ~ I ~ w e r e ~ f o u n d ~ a f t e r ~}$ purification and HPLC separation, no matter whether 125I-ANG I was added shortly before the homogenization or already during storage at $-70^{\circ} \mathrm{C}$. Our findings therefore suggest that ANG I and ANG II in ocular tissues are synthesized locally rather than taken up from plasma.

In conclusion, we have shown that angiotensins are present in human ocular fluid samples as well as in porcine ocular tissues. Angiotensins in human ocular fluids do not seem to be generated within these fluids because of the low levels of renin, renin substrate and ACE found in these fluids, nor are they the result of angiotensin release from intraocular tissue sites. Comparison with ocular albumin levels suggests that angiotensins in human ocular fluid are probably largely plasma-derived. Prorenin, the inactive precursor of renin, is the only component of the intraocular RAS that is released into ocular fluid. The relatively high levels of ANG I and ANG II in porcine retina, pigment epithelium-choroid and anterior uveal tract, which cannot be explained based upon the presence of plasma in these tissues only, strongly support the idea of intraocular angiotensin generation. The virtual absence of angiotensins in porcine vitreous fluid and our finding that angiotensins in human ocular fluid samples are mainly plasma-derived suggest that the rate at which angiotensins are metabolized in ocular tissues is too high to allow overflow into ocular fluids, or that angiotensin production occurs in compartment which does not equilibrate with ocular fluids. Most likely, ANG II generated in ocular tissues 
exerts a autocrine or paracrine function. An intraocular RAS may play a role in the development of diabetic retinopathy, in the regulation of retinal vascular tone or in the regulation of aqueous humor dynamics.

\subsection{References}

1. Naruse $\mathrm{K}$, Murakoshi $\mathrm{M}$, Osamura RY, Naruse $\mathrm{M}$, Toma $\mathrm{H}$, Watanabe $\mathrm{K}$, Demura $\mathrm{H}$, Inagami $\mathrm{T}$, Shizume $\mathrm{K}$. Immunohistochemical evidence for renin in human endocrine tissue. J Clin Endocrinol Metab 61: 172-177, 1985.

2. DeSchepper CF, Mellon SH, Cumin F, Baxter JD, Ganong WF. Analysis by immunohistochemistry and in situ hybridization of renin and its mRNA in kidney, testis, adrenal and pituitary of the rat. Proc Natl Acad Sci USA 83: 7552-7556, 1986.

3. Mizuno $K$, Imada $T$, Higashimori $K$, Inagami $T$. Direct release of angiotensin $I$ and angiotensin II from isolated rat kidney perfused with angiotensinogen-free medium. Biochem Biophys Res Commun 149: 475-481, 1987.

4. Ganten $D$, Speck $G$. The brain renin-angiotensin system: a model for the synthesis of peptides in the brain. Biochem Pharmacol 27: 2379-2389, 1978.

5. Glorioso N, Atlas SA, Laragh JH, Jewelewicz $\mathbb{R}$, Sealey JE. Prorenin in high concentrations in human ovarian follicular fluid. Science 233: 1422-1424, 1986.

6. Derkx FHM, Alberda AT, de Jong FH, Zeilmaker GH, Makovitz NW, Schalekanap MADH. Source of plasma prorenin early and late in pregnancy. Observations in a patient with primary ovarian failure. J Clin Endocrinol Metab 65: 349-354, 1987.

7. Do YS, Sherrod A, Lobo RA, PauIson RJ, Shinagawa T, Chen S, Kjos S, Hsueh WA. Human ovarian theca cells are a source of renin. Proc Natl Acad Sci USA 85: 1957-1961, 1988.

8. Danser AHU, van den Dorpel MA, Deinum J, Derkx FHM, Franken AAM, Peperkamp P, de Jong PTVM, Schalekamp MADH. Renin, prorenin, and immunoreactive renin in vitreous fluid from eyes with and without diabetic retinopathy. $J$ Clin Endocrinol Metab 68: 160-167, 1989.

9. Deinum J; Derkx FHM, Danser AHJ, Schalekamp MADH. Identification and quantification of renin and prorenin in the bovine eye. Endocrinology 126: 1673-1682, 1990.

10. Ferrari-Dileo G, Ryan JW, Rockwood EJ, Davis EB, Anderson DR. Angiotensin-converting enzyme in bovine, feline and human ocular tissues. Invest Ophthalmol Vis Sci 29:876-881, 1988.

11. Weinreb RN, Sandman R, Ryder MI, Friberg TR. Angiotensin-converting enzyme activity in human aqueous humor. Arch Ophthalmol 103: 34-36, 1985.

12. Fernandez LA, Twickler J, Mead A. Neovascularization produced by angiotensin II. $J$ Lab Clin Med 105: 141-145, 1985.

13. Ariza A, Fernandez LA, Inagami T, Kim JH, Manuelidis EE. Renin in glioblastoma multiforme and its role in neovascularization. Am J Clin Pathol 90: 437-441, 1988.

14. Ferrari-Dileo G, Davis EB, Anderson DR. Angiotensin binding sites in bovine and human retinal blood vessels. Invest Ophthalmol Vis Sci 28: 1747-1751, 1987.

15. Rockwood EJ, Fantes F, Davis EB, Anderson DR. The response of retinal vasculature to angiotensin. Invest Ophthalmol Vis Sci 28: 676-682, 1987.

16. Giardina WJ, Kleinert HD, Ebert DM, Wismer CT, Chekal MA, Stein HH. Intraocular pressure lowering effects of the renin inhibitor ABBOTT-64662 diacetate in animals. $J O C$ Pharmacol 6: 75-84, 1990.

17. Constad WH, Fiore P, Samson C, Cinotti AA. Use of an angiotensin-converting enzyme inhibitor in ocular hypertenision and primary open-angle glaucoma. AmJ Ophthalmol 105: 674-677, 1988. 
18. Greenwood FC, Hunter WM, Glover JS. The preparation of ${ }^{131} \mathrm{I}$-labeled human growth hormone of high specific radioactivity. Biochem J 89:114-123, 1963.

19. Admiraal PJ, Derkx FHM, Danser AHJ, Pieterman H, Schalekamp MADH. Metabolism and production of angiotensin I in different vascular beds in subjects with hypertension. Hypertension 15: 44-55, 1990.

20. Nussberger J, Brunner DB, Waeber B, Brunner HR. Specific measurement of angiotensin metabolites and in vitro degradation of angiotensin $\mathrm{X}$ in plasma. Hypertension 8: $476-482,1986$.

21. Mancini $G$, Carbonara $A O$, Heremans JF. Immunochemical quantitation of antigens by single radial immunodiffusion. Immunochemistry 2: 235-254, 1965.

22. Derkx FHM, Stuenkel C, Schalekamp MPA, Visser W, Huisveld IH, Schalekamp MADH. Immunoreactive renin, prorenin, and enzymatically active renin in plasma during pregnancy and in women taking oral contraceptives. $J$ Clin Endocrinol Metab 63: 1008-1015, 1986.

23. Chappell MC, Bosnihan KB, Diz DI, Ferrario CM. Identification of angiotensin-(1-7) in rat brain. J Biol Chem 264: 16518-16523, 1989.

24. Hermann $K$, Lang RE, Unger $T$, Bayer C, Ganten $D$. Combined high-performance liquid chromatography-radioimmunoassay for the characterization and quantitative measurement of neuropeptides. I Chromatogr 312: 273-284, 1984.

25. De Silva PE, Husain A, Smeby RR, Khairallah PA. Measurement of immunoreactive angiotensin peptides in rat tissues: some piffalls in angiotensin II analysis. Anal Biochem 174: 80-87, 1988 .

26. Wurster U, Rise K, Hoffman K. Enzyme activities and protein concentration in the intraocular fluids of ten mammals. Acta Ophthalmol (Copenh) 60: 729-741, 1982.

27. Wurster U, Hoffman K. Glaskörper. In: Biochemie des Auges, edited by Hockwin O. Enke-Verlag, Stuttgart 1985, pp. 110-121.

28. Krogsaa B, Lund-Andersen H, Mehlsen J, Sestoft L. The blood-retinal barrier permeability to fluorescein in normal subjects and in juvenile diabetics without retinopathy. Acta Ophthalmol (Copenh) 64: 173-179, 1986.

29. Cunha-Vaz J, Faria de Abreu JR, Campos AJ, Figo GM. Early breakdown of the blood-retinal barrier in diabetes. Brit J Ophthal 59: 649-656, 1975.

30. Zeimer RC, Blair NP, Cunha-Vaz J. Pharmacokinetic interpretation of vitreous fluorophotometry. Invest Ophthalmol Vis Sci 24: 1374-1381, 1983.

31. Schelling $P$, Ganten $U$, Sponer $G$, Unger $T$, Ganten $D$. Components of the renin-angiotensin system in cerebrospinal fluid of rats and dogs with special consideration of the origin and fate of angiotensin II. Neuroendocrinology 31: 297-308, 1980.

32. Castellion AW, Fulton RW. Preclinical pharmacology of saralasin. Kidney Int 15: S11-S19, 1979.

33. Cunha-Vaz J. The blood-ocular barriers. Surv Ophthalmol 23: 279-296, 1979.

34. Lightman S, Rechthand E, Latker C, Palestine A, Rapoport S. Assessment of the permeability of the blood-retinal barrier in hypertensive rats. Hypertension 10: 390-395, 1987.

35. Waltman S, Krupin T, Hanish S, Oestrich C, Becker B. Alteration of the blood-retinal barrier in experimental diabetes. Arch Ophthalmol 96: 878-879, 1978.

36. Cunha-Vaz J, Maurice DM. The active transport of fluorescein by the retinal vessels and the retina. J Physiol 191: 467-486, 1967.

37. Sramek SJ, Wallow IHL, Day RP, Ehrlich EN. Ocular renin-angiotensin: immunohistochemical evidence for the presence of prorenin in eye tissues. Invest Ophthalmol Vis Sci 29: 1749-1752, 1988.

38. Brunswig-Spickenheimer B, Mukhopadhyay AK. Inhibitory effects of a tumor-promoting phorbol ester on luteinizing hormone-stimulated renin and prorenin production by cultured bovine theca cells. Endocrinology 127: 2157-2165, 1990. 
39. Yamaguchi T, Naito Z, Stoner GD, Franco-Saenz R, Mulrow PJ. Role of the adrenal renin-angiotensin system on adrenocorticotropic hormone- and potassium-stimulated aldosterone production by rat adrenal glomerulosa cells in monolayer culture. Hypertension 16: 635-641, 1990. 


\section{DEMONSTRATION OF RENIN-, ANGIOTENSINOGEN- AND ANGIOTENSIN CONVERTING $\mathbb{E N Z Y M E - m R N A ~} \mathbb{E X P R E S S I O N ~ I N ~}$ HUMAN EYES BY THE POL YMERASE CHAIN REACTION}

\subsection{Introduction}

The presence of all components of the renin-angiotensin system has been demonstrated in the eye, not only in ocular fluids obtained from human eyes $(1,2)$ during eye surgery, but also in ocular tissues from bovine and porcine eyes $(2,3)$. The levels were too high to be explained by contamination with plasma. The levels of prorenin were higher in vitreous fluid from eyes with proliferative diabetic retinopathy than in vitreous fluid from eyes of nondiabetic subjects (1). This suggests that an intra-ocular renin-angiotensin system may be involved in the pathogenesis of diabetic proliferative retinopathy. Angiotensin II has been implicated in the development of neovascularization (4).

However, definite proof of intra-ocular production of renin, angiotensinogen and angiotensin converting enzyme (ACE) in human eyes, as opposed to specific uptake from plasma, can only be obtained by demonstrating ocular renin-, angiotensinogen- and ACE-mRNA expression. In the present study we employed the RNAse protection assay to detect renin-mRNA expression in fresh human ocular tissues. Since the ocular total mRNA content was at the limit of detection of the RNAse protection assay, we also also applied the polymerase chain reaction (PCR) to improve sensitivity. For synthesis of double-stranded cDNA, ocular mRNA was reversely transcribed and subsequently renin-cDNA was amplified by PCR using two primers flanking 376 basepairs (bp) of human renin-cDNA and spanning the second and third exon. Angiotensinogen- and ACE-mRNA were determined by primers spanning a $240 \mathrm{bp}$ or $380 \mathrm{bp}$ fragment, respectively. The amplified cDNAs were processed by Southem blotting and hybridization with the corresponding randomly labeled probes. 


\subsection{Subjects and methods}

Subjects. Ocular tissues were removed from enucleated eyes within 1-2 min after enucleation and frozen in liquid nitrogen. The eyes were obtained from 18 subjects ( 12 men and 6 women; mean age $54 \mathrm{yr}$, range 26-78 yr). The indications for enucleation were: choroidal melanoma $(n=11)$, ciliary body melanoma $(n=1)$, phtisis bulbi $(n=2)$, neovascular glaucoma $(n=2)$, bullous keratopathy in a blind eye $(n=1)$ and an inflamed blind eye after trauma $(n=1)$. Depending on what part of the eye had to be sent to the pathology department, retina, retinal pigment epithelium-choroid, anterior uveal tract and sclera were isolated as described before $(2,3)$. Sometimes it was not possible to separate retina and pigment epithelium-choroid from each other. The ocular tissues were stored at $-70^{\circ} \mathrm{C}$.

RNAse protection assay for renin. ${ }^{32} \mathrm{P}-\mathrm{labeled} \mathrm{RNA}$-transcripts were prepared by transcription of a 291 nucleotide antisense RNA from a Saci/EcoRV fragment of the human renin cDNA subcloned into pGEM4 vector using T7 RNA polymerase. This transcript comprised 225 nucleotides of human renin antisense RNA and 66 nucleotides of vector encoded sequence.

Total RNA was isolated from combined human ocular tissues by lithium chloride precipitation (5). RNAse protection assays were performed according to Goedert et al (6). Samples of dried RNA were dissolved in $30 \mu \mathrm{L} 80 \%$ formamide, containing $40 \mathrm{mM}$ PIPES ( $\mathrm{pH} 6.8$ ), $400 \mathrm{mM} \mathrm{NaCl}, 1 \mathrm{mM}$ EDTA and $200.000 \mathrm{cpm}$ of the gel-purified transcript. After denaturation at $95^{\circ} \mathrm{C}$ for $60 \mathrm{sec}$ and incubation at $50{ }^{\circ} \mathrm{C}$ for $20 \mathrm{~h}$, RNAse digestion was performed in $300 \mu \mathrm{L}$ buffer containing $40 \mu \mathrm{g} / \mathrm{mL}$ RNAse A (Sigma, St. Louis, MI, USA) and $2 \mu \mathrm{g} / \mathrm{mL}$ RNAse T1 (Calbiochem, USA) for $45 \mathrm{~min}$ at $37^{\circ} \mathrm{C}$. After digestion with proteinase $\mathrm{K}$, samples were electrophoresed on denaturing $5 \%$ polyacrylamide gels.

Polymerase chain reaction. Total RNA was isolated from individual human ocular tissue samples by a modification of the lithium chloride method (5). After isolation, total RNA samples were checked by gel electrophoresis in an 1 $\%$ agarose gel stained with ethidium-bromide after denaturation with $6 \mathrm{M}$ glyoxal, $0.25 \mathrm{M} \mathrm{DMSO}$ and $0.1 \mathrm{M} \mathrm{NaH}_{2} \mathrm{PO}_{4}\left(\mathrm{pH} 7.0\right.$ ) at $50^{\circ} \mathrm{C}$ for $60 \mathrm{~min}$.

For use in the polymerase chain reaction, total RNA was reversely transcribed to cDNA according to Wang et al (7). $1 \mu \mathrm{g}$ of total RNA was dissolved in $20 \mu \mathrm{L}$ of a reaction mixture containing $1 \mathrm{mM}$ of dATP, dCTP, dTTP and dGTP, 1 U of RNAsin (Boehringer Mannheim, Germany), $100 \mathrm{pmol}$ random hexamers (Boehringer Mannheim), $50 \mathrm{mM} \mathrm{KCl}, 20 \mathrm{mM}$ Tris- $\mathrm{HCl}(\mathrm{pH}$ 8.4), $2.5 \mathrm{mM} \mathrm{MgCl}_{2}, 10 \mu \mathrm{g} / \mu \mathrm{L}$ nuclease-free bovine serum albumin and $200 \mathrm{U}$ of Murine leukemia virus reverse transcriptase (MULV-RT, Gibco BRL, Germany). After incubation for $45 \mathrm{~min}$ at $42^{\circ} \mathrm{C}$, temperature was raised to 95 
${ }^{\circ} \mathrm{C}$ and then quickly lowered on ice. For amplification of the resulting CDNA, the sample volume was increased to $100 \mu \mathrm{L}$ by a solution containing $50 \mathrm{mM}$ $\mathrm{KCl}, 20 \mathrm{mM}$ Tris- $\mathrm{HCl}(\mathrm{pH} 8.4)$ and $2.5 \mathrm{mM} \mathrm{MgCl}$ and $25 \mathrm{pmol}$ of up- and downstream primers as well as $3 \mathrm{U}$ of Taq polymerase (Perkin-Elmer, Cetus, USA). The thermal profile used on a Perkin Elmer/Cetus thermal cycler consisted of denaturation at $95^{\circ} \mathrm{C}$ for $1 \mathrm{~min}$, annealing at $60^{\circ} \mathrm{C}$ for renin and at $55^{\circ} \mathrm{C}$ for angiotensinogen and angiotensin converting enzyme, respectively, for $1 \mathrm{~min}$, and an extension temperature of $72{ }^{\circ} \mathrm{C}$ for $1 \mathrm{~min}$ for 26 cycles. After PCR, $10 \mu \mathrm{L}$ loading buffer (50\% glycerol, $10 \mathrm{mM}$ Tris- $\mathrm{HCl}$ (pH 8.0) and $0.25 \%$ bromphenol blue and xylene cyanol) were added to each sample and the amplification products were checked for the predicted sizes by agarose gel electrophoresis and then submitted to Southern blot analysis. Primers were selected with the computer program developed by Lowe et al (8), which was licensed to M. Paul. Human renin-cDNA was amplified by $21-$ mer oligonucleotides with the following sequences: AAATGAAGGGGGTGTCTGTGG as sense primer (bases 851-872) and AAGCCAATGCGGTTGTTACGC (bases 1206-1227) as antisense primer. This yielded an amplification product of $376 \mathrm{bp}$ in length spanning the second and third exon of renin-cDNA. The sense primer for the detection of ACE-CDNA spanned oligonucleotide bases 492-512 (GCCTCCCCAACAAGACTGCCA), and the antisense primer spanned base 860-880 (CCACATGTCTCCAGCCAGATG) of the human ACE-cDNA. Human angiotensinogen primers were situated over the fourth and fifth exon with the sense primer (bases 1209-1231) CTGCAAGGATCTTATGACCTGC and the antisense primer (bases 1404-1426) TACACAGCAAACAGGAATGGGC.

Southern blotting was performed as described (9). The amplified cDNA sequences were transferred from $1.3 \%$ agarose gels to nylon membrane (Pall, Great Britain) in a LKB-vacuum blot chamber using $0.25 \mathrm{~N} \mathrm{HCl}$ for precipitation for $30 \mathrm{~min}$ and subsequent neutralization on $0.5 \mathrm{~N} \mathrm{NaOH}$ and 1.5 $\mathrm{M} \mathrm{NaCl}$. Blotting was terminated after $2 \mathrm{~h}$ on $20 \times$ SSC $(1 \times$ SSC: $0.15 \mathrm{M}$ $\mathrm{NaCl}, 0.015 \mathrm{M}$ sodium citrate). cDNA was crosslinked to the nylon membrane in a UV-linker (Stratagene 1800). Membranes were prehybridized with $0.5 \%$ deionized formamide, Denhard's solution, $25 \mu \mathrm{m} / \mathrm{mL}$ herring sperm DNA for $4 \mathrm{~h}$. Hybridization was done in the same buffer overnight at $60^{\circ} \mathrm{C}$ adding the corresponding probes, which were randomly labeled using ${ }^{32} \mathrm{P}-\mathrm{dCTP}$. Labeled probes were purified on a Sephadex G-50 column. Renin-cDNA was hybridized to a $1.3 \mathrm{~kb}$ long BamHI/HindIII rat renin-cDNA fragment obtained from the complete rat renin-cDNA cloned into a pGEM4 vector. The restriction fragment was separated from the vector on an agarose gel and isolated by Qiaex (Quiagen, Germany). A plasmid vector (Bluescript KS, pB 35-19) containing 3334 bp of human ACE-CDNA was cut with EcoRI and Bgl II to yield 1.7 and $1.6 \mathrm{~kb}$ inserts of ACE-CDNA, which were isolated from the $3.0 \mathrm{~kb}$ as probes. A $1 \mathrm{~kb}$ Stul fragment of a pGEM5 vector containing the 
human angiotensinogen-cDNA allowed detection of angiotensinogen-cDNA. Nylon membranes were washed after hybridization at room temperature in 0.2 $x$ SSC and $0.1 \%$ sodiumdodecylsulphate for $30 \mathrm{~min}$ and 3 times at $56^{\circ} \mathrm{C}$ for $30 \mathrm{~min}$. Blots were exposed for $18-36 \mathrm{hrs}$ at $-80{ }^{\circ} \mathrm{C}$ to XAR $\mathrm{X}$-ray films (Kodak).

\subsection{Results}

Using the RNAse protection assay it was possible to demonstrate renin-mRNA expression in human pigment epithelium-choroid/retina, but not in retina alone or in sclera (Figure 1). These results were obtained by pooling tissues from several eyes, since the amount of total RNA recovered from individual eye samples was below the detection limit of the assay. Compared to the kidney, where $20 \mu \mathrm{g}$ of RNA was used, the ocular renin mRNA levels seemed to be low, since $45 \mu \mathrm{g}$ of RNA from pigment epithelium-choroid/retina did, but 25 $\mu \mathrm{g}$ of retinal RNA and $35 \mu \mathrm{g}$ of scleral RNA did not reveal any renin-mRNA expression by this method.

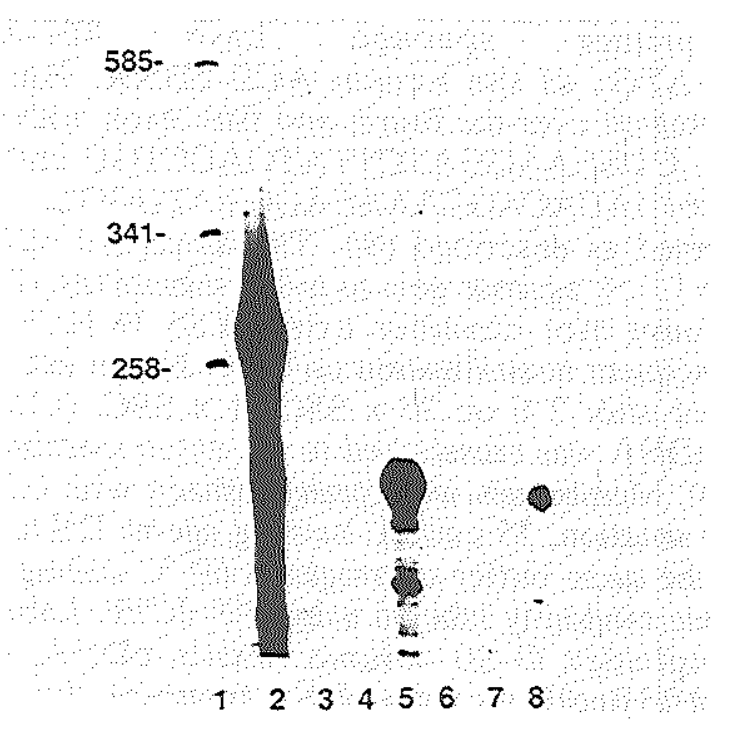

Figure 1. Detection of renin mRNA by RNAse protection assay. Autoradiograph of 5 $\%$ polyacrylamide gel. Results in human ocular samples were obtained by pooling tissues from several patients. 1. pUC/Sau3a (length marker); 2. human renin probe (positive control); 3. IRNA (negative control); 4. rat kidney; 5. human kidney $(20 \mu \mathrm{g}) ; 6$. sclera (35 $\mu \mathrm{g}) ; 7$. retina $(25 \mu \mathrm{g}) ; 8$. pigment epitheliumchoroid/retina $(45 \mu \mathrm{g})$. 


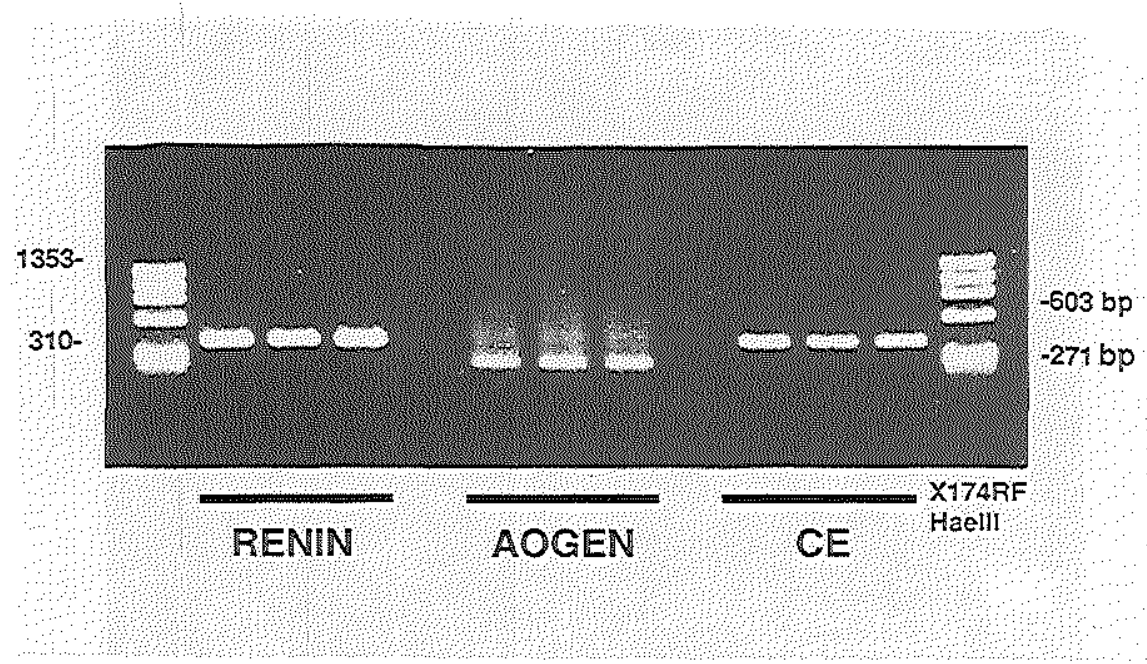

Figure 2. Detection of renin-, angiotensinogen- and ACE-mRNA expression by the polymerase chain reaction. Amplification products of renin (376 bp), angiotensinogen (217 bp) and ACE (388 bp) as obtained from renal total RNA (3 samples each). Ethidium-bromide stained $1.3 \%$ agarose gel. X174RF vector HaeII-fragments are used as length markers.

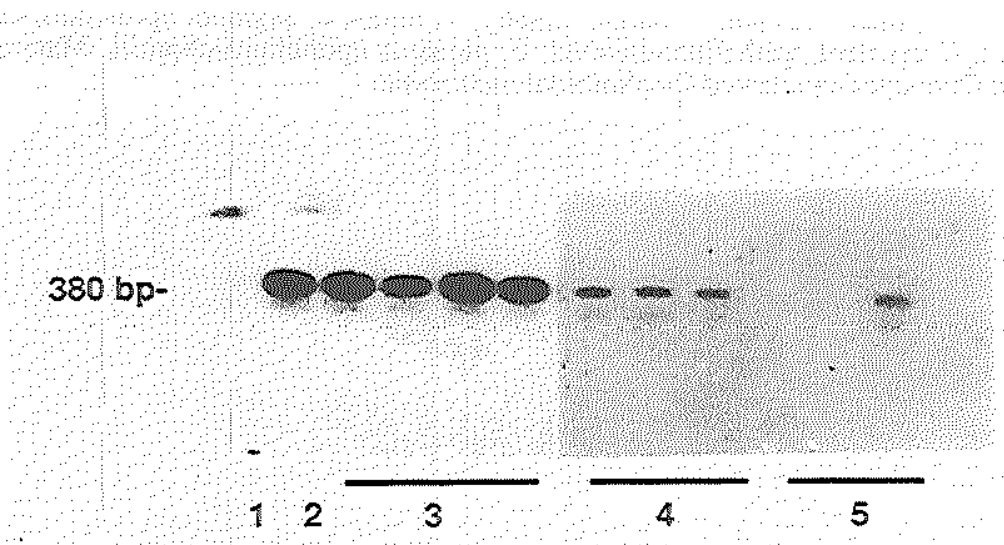

Figure 3. Demonstration of renin-mRNA expression in human eyes by the polymerase chain reaction. Southern blot of amplification products. 1 . negative control; 2 . human kidney; 3. pigment epithelium-choroid; 4. retina; 5. sclera (3-5: 3 samples each). Material was obtained from eyes enucleated for choroidal melanoma. 


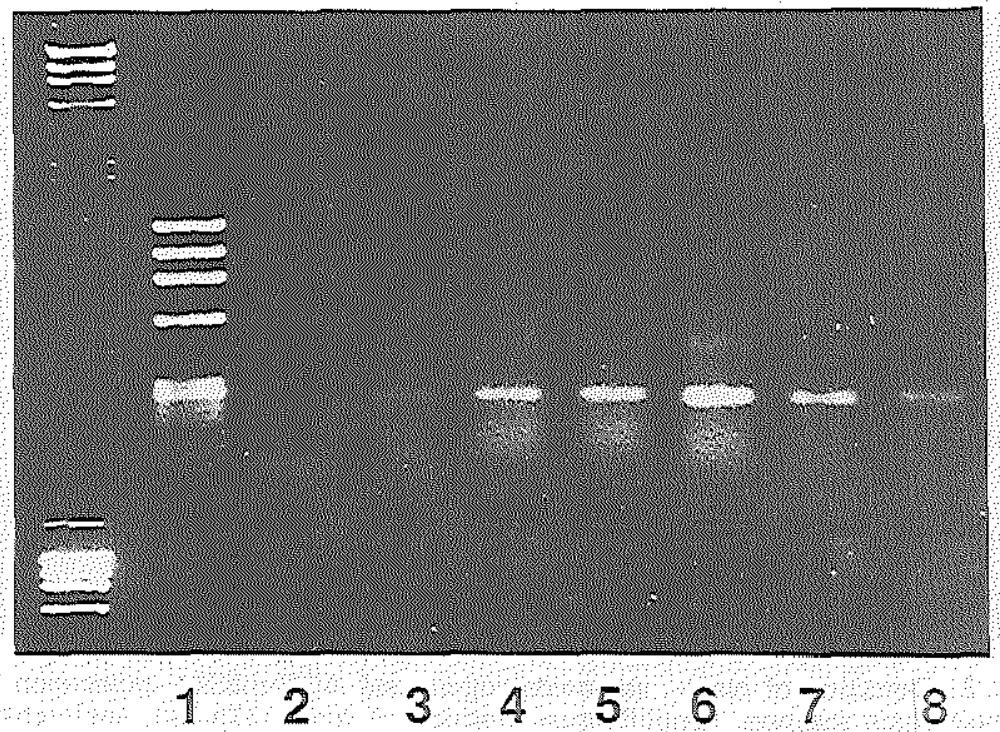

Figure 4. Demonstration of angiotensinogen-mRNA in human eyes by the polymerase chain reaction. Ethidium-bromide stained 1.3\% agarose gel. 1. X174RF HaellI (length marker); 2. negative control; 3. human kidney; 4. retina; 5. pigment epithelium-choroid; 6. retina; 7. pigment epithelium-choroid; 8. pigment epithelium-choroid. Material was obtained from eyes enucleated for choroidal melanoma.

\section{$\begin{array}{lllllllll}1 & 2 & 3 & 4 & 5 & 6 & 7\end{array}$}

Figure 5. Demonstration of angiotensinogen-mRNA in human eyes by the polymerase chain reaction. Southern blot of amplification products. 1. negative control; 2 . human kidney; 3. retina; 4. pigment epithelium-choroid; 5. retina; 6. pigment epithelium-choroid; 7. pigment epithelium-choroid. Material was obtained from eyes enucleated for choroidal melanorma. 
Sensitivity could be improved by using the polymerase.chain reaction. Using this method we were able to confirm that all components of the reninangiotensin system are expressed in the kidney (Figure 2). Human kidney could therefore be used as a positive control in each assay. After amplification of cDNA by PCR all components of the renin-angiotensin system could be detected by Southern blotting in both retina and pigment epithelium-choroid (Figures 3,5 and 6). The amplification products were checked for the predicted size by agarose gel electrophoresis (Figure 4). The retinal reninmRNA levels were low but detectable (Figure 3), whereas in scleral tissue no positive signal for renin-mRNA could be found. The latter finding confirms the results from the RNAse protection assay. In anterior uveal tract no amplification products could be detected. This may have been due to the fact that the mRNA in these samples was largely degraded, as observed when checking total RNA by gel electrophoresis.

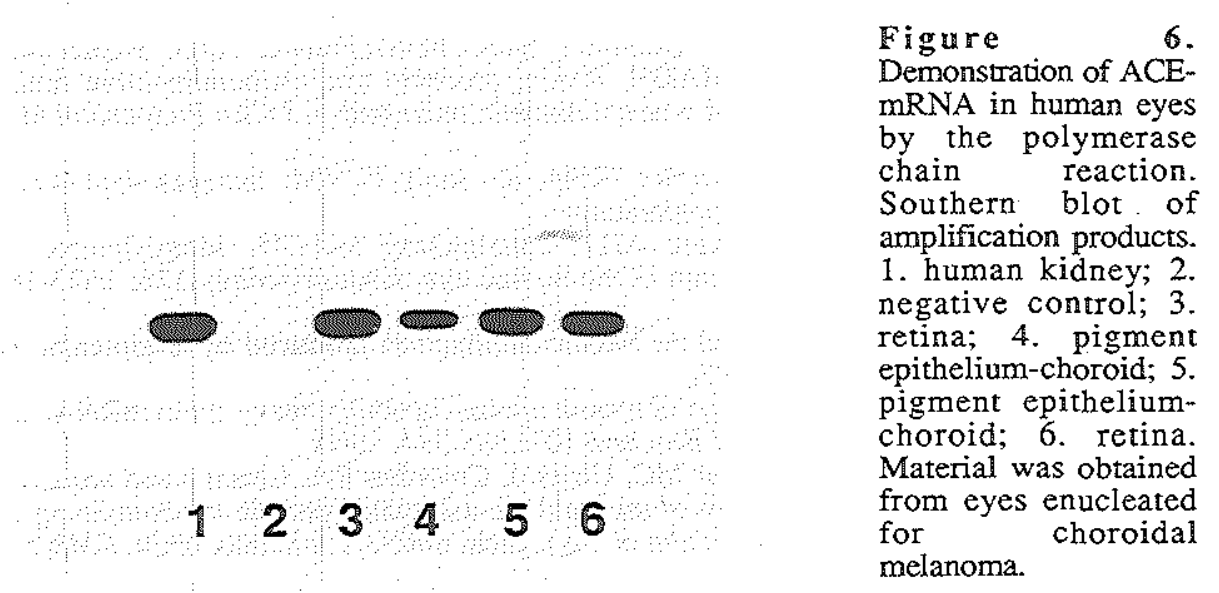

\subsection{Discussion}

The polymerase chain reaction is a powerful tool to amplify small amounts of DNA or mRNA for various molecular analyses (10). Using PCR we were able to demonstrate renin-, angiotensinogen- and ACE-mRNA expression in both retina and pigment epithelium-choroid, but not in sclera, of human eyes. 
Renin mRNA could also be detected by the RNAse protection assay. The pigment epithelium-choroid was found to contain the highest concentration of renin mRNA. Pooled samples of retinal RNA alone remained below the detection limits of this method.

These results strongly support the existence of an intra-ocular reninangiotensin system. As gene-expression is highest in ocular parts, which are highly vascularized, the renin-angiotensin system may influence local blood supply and play a role in the process of neovascularization in such diseases as diabetic retinopathy. However, further work is needed to study whether changes in renin-mRNA expression do indeed occur in eyes with neovascularization.

From our results it can not be said in which cells the mRNA of the various components of the renin-angiotensin system is situated. In situ hybridization studies may provide an answer as to where exactly in the eye renin, angiotensinogen and $\mathrm{ACE}$ are synthesized.

\subsection{References}

1. Danser AHJ, van den Dorpel MA, Deinum J, Derkx FHM, Franken AAM, Peperkamp P, de Jong PTVM, Schalekamp MADH. Renin, prorenin and immunoreactive renin in vitreous fluid from eyes with and without diabetic retinopathy. $J$ Clin Endocrinol Metab 68: 160-167, 1989.

2. Danser AHJ, Admiraal PJJ, Derkx FHM, de Jong PTVM, Schalekamp MADH. Angiotensin levels in the eye (in preparation).

3. Deinum J, Derkx FHM, Danser AHJ, Schalekamp MADH. Identification and quantification of renin and prorenin in the bovine eye. Endocrinology 126: 1673-1682, 1990.

4. Fermandez LA, Twickler J, Mead A. Neovascularization produced by angiotensin II. $J$ Lab Clin Med 105: 141-145, 1985.

5. Auffray C, Rougeon F. Purification of mouse immunoglobulin heavy chain mRNAs from total myeloma tumor RNA. Eur J Biochem 107: 303-314, 1980.

6. Goedert M, Spillantini MG, Potier MC, Ulrich J, Crowther RA. Cloning and sequencing of the cDNA encoding an isoform of microtubule-associated protein tau containing four tandem repeats: differential expression of tau protein mRNAs in human brain. EMBO J 8: 393-399, 1989.

7. Wang AM, Doyle MV, Mark DF. Quantification of mRNA by the polymerase chain reaction. Proc Natl Acad Sci USA 86: 9717-9721, 1989.

8. Lowe $T$, Sharefkin $J$, Yang SQ, Dieffenbach CW. A computer program for selection of oligonucleotide primers for polymerase chain reaction. Nucl Acid Res 18: 253-257, 1990.

9. Hirsch AT, Talsness CE, Schunkert H, Paul M, Dzau VJ. Tissue-specific activation of cardiac angiotensin converting enzyme in experimental heart failure. Circ Res 69: 475-482, 1991.

10. Mullis KB, Faloona FA. Specific synthesis of DNA in vitro via a polymerase-catalyzed chain reaction. Methods in Enzymology 155 (part F): 335-350, 1987. 


\section{SUMMARY AND CONCLUSIONS}

\subsection{Aim of the thesis Chapter 1}

The renin-angiotensin system (RAS) is considered to be a major component in the maintenance of cardiovascular homeostasis in both the normal and the diseased state. Traditionally, the RAS has been viewed as an endocrine system. Circulating renin, released from the kidney, cleaves circulating liver-derived angiotensinogen (also known as renin substrate) to form angiotensin I (ANG D). ANG $I$ is converted by endothelial-bound angiotensin converting enzyme (ACE) to angiotensin II (ANG II), a highly potent vasoconstrictor and aldosterone-releasing hormone. Initially, it was thought that blockers of the formation of ANG II (e.g. the ACE inhibitors, which were developed in the 1970s) would be effective for treating high renin-dependent forms of hypertension only. It was therefore an unexpected finding that $\mathrm{ACE}$ inhibitors were also effective in hypertensive patients with low or normal renin levels. Long-term treatment with ACE inhibitors does not seem to completely suppress the circulating RAS, as plasma ANG II and aldosterone tend to return to pretreatment levels. These findings have led to many speculations on the presence of so-called 'tissue' or 'Iocal' renin-angiotensin systems, as opposed to the circulating RAS, and their role in the maintenance of high blood pressure. ACE inhibitors would then primarily exert their effect through blockade of these local systems.

Indeed, molecular biologic techniques have now convincingly shown that both renin and angiotensinogen genes are expressed in multiple tissues, including the heart, adrenal, brain, vessel wall, ovary and testis. An emerging concept is therefore that angiotensin may be produced locally in many tissues, independent of the circulating system, and that locally generated angiotensin plays an important role in influencing the function of these target organs. Locally generated angiotensin may even reach the circulating blood and thus contribute to the angiotensin levels found in plasma. To what extent generation of ANG I outside the blood stream and conversion of this locally generated ANG I to ANG II contribute to the circulating levels of ANG I and ANG II has not been investigated so far.

It was the first aim of the thesis to quantify the metabolism and production of ANG I and ANG II in various vascular beds in both humans and pigs. This was done by administrating constant infusions of 125 I-ANG I. Under steady state conditions the levels of 125 I-labeled and endogenous ANG I and ANG II were measured at both arterial and venous sampling sites. In addition, the plasma renin activity (PRA), the rate of ANG I formation in vitro, was 
measured at each sampling site. The regional metabolism (including ANG I-II conversion) of ANG I and ANG II could be estimated from the arterial and venous levels of the radiolabeled peptides. The regional production could be calculated by comparing the regional extraction of the radiolabeled peptides with the actual levels of the endogenous ANG I and ANG II in arterial and venous plasma. In order to estimate the generation of ANG I outside the circulating blood, the contribution of PRA to the total regional ANG I production was calculated. The contribution of conversion of arterially delivered ANG I to the total regional ANG $M$ production was also calculated.

The second aim of the thesis was to investigate the existence of a local RAS in the eye. Previously, a close correlation was found between the high plasma levels of prorenin, the inactive precursor of renin, and the presence of retinopathy, especially the proliferative type, in diabetic subjects. Prorenin may be involved in the local generation of angiotensin, whereas ANG II has been reported to have growth-promoting effects. The levels of the various components of the RAS were measured in human ocular fluids (both from eyes affected by proliferative diabetic retinopathy and from eyes of non-diabetic subjects) and in bovine and porcine ocular tissues. An attempt was also made to demonstrate the presence of renin-, angiotensinogen- and ACE-mRNA expression in human ocular tissues by the polymerase chain reaction.

\subsection{Local metabolism and production of ANG I and ANG II in humans and pigs \\ Chapters 2, 3 and 4}

During constant infusion of ${ }^{125}$ I-ANG I extensive metabolism of the radiolabeled peptide occurred in all vascular beds that were studied, both in man and in the pig. In captopril-treated human subjects with essential hypertension, the regional extraction ratio of 125 I-ANG I was $47 \pm 4 \%$ (mean \pm SEM) across the forearm, $59 \pm 3 \%$ across the leg, $81 \pm 1 \%$ across the kidneys, and $96 \pm 1 \%$ across the hepatomesenteric vascular bed. These results were not different from those obtained for simultaneously infused unlabeled ANG I. Despite the rapid removal of arterially delivered ANG I, no difference was found between the venous and arterial levels of endogenous ANG I across the various vascular beds, with the exception of the liver where ANG I in the vein was $50 \%$ lower than in the aorta. Thus, $50-90 \%$ of endogenous ANG I in the veins appeared to be derived from regional de novo production. The blood transit time is 0.1-0.2 min in the limbs and in the kidneys and 0.3-0.5 min in the hepatomesenteric vascular bed. This is too short for PRA to account for the measured de novo ANG I production. Less than 20-30\% in the limbs and kidneys and approximately $60 \%$ in the hepatomesenteric region of de novo produced venous ANG I could be accounted for by PRA.

These findings in humans could be confirmed in captopril-treated pigs and 
were extended to untreated and furosemide-treated pigs. A kinetic model was introduced to estimate regional degradation and conversion of ANG I in the 3 groups of pigs. It was found that the metabolic degradation rate in the various vascular beds that were studied was the same for ${ }^{125}$ I-ANG I and ANG I, but that the conversion rate was 2 times higher for 125I-ANG I than for ANG I. ANG I appeared to be distributed over a compartment with a size corresponding to that of the extracellular fluid compartment $(25 \%$ of total body weight). After ACE inhibitor treatment, fractional ANG I metabolism (the fraction of arterially delivered ANG I that was metabolized during a single passage of blood) was $10 \%$ in the lungs (conversion $4 \%$ ), as compared to $56 \%$ in the combined systemic vascular beds (conversion $1 \%$ ). Fractional ANG I metabolism during ACE inhibition was $93 \%$ in the kidney, $50-70 \%$ in myocardium, skeletal muscle, head and skin, and $21 \%$ in the left and $14 \%$ in the right cardiac cavity. Without ACE inhibition, fractional ANG I metabolism was $29 \%$ in the lungs (conversion $25 \%$ ), $49 \%$ in the combined systemic vascular beds (conversion $10 \%$ ), $38 \%$ in the left cardiac cavity (conversion 11 $\%$ ) and $14 \%$ in the right cardiac cavity (conversion $0 \%$ ). These data show that in the systemic vascular beds, but not in the lungs or cardiac cavities, decreased conversion is accompanied by increased degradation.

Total regional ANG I and ANG II production rates in the various porcine systemic vascular beds were calculated on the basis of the so-called 'venous equilibrium' model. De novo ANG I production in the combined systemic vascular beds was increased during treatment with captopril or the diuretic furosemide, as compared to untreated animals. ANG II production in the combined systemic vascular beds was greater than in the lungs, demonstrating the importance of extrapulmonary ANG I-II conversion. ACE inhibition did not alter the ANG II production in the lungs or the combined systemic vascular beds. Apparently, reduced ANG I-II conversion was compensated for by increased ANG I production. Furosemide increased the ANG II production in all vascular beds that were studied.

In the lungs, ANG I production could fully be accounted for by circulating PRA, and ANG II production could be attributed to the intrapulmonary conversion of circulating ANG $I$. In contrast, in the other vascular beds we studied a substantial fraction of. ANG I production could not be accounted for by circulating PRA, assuming a transit time of $10 \mathrm{sec}$ (myocardium $>25 \%$, head, skin and skeletal muscle $>80 \%$, kidney $>95 \%$ ). The local ANG I production in all vascular beds correlated with the level of PRA. Part of the local ANG II production in these regions could not be attributed to regional conversion of circulating ANG I (myocardium $>30 \%$, head, skin and skeletal muscle $>50 \%$, kidney $>80 \%$ ). These results indicate that indeed production of ANG I at tissue sites contributes to its circulating level, and that some circulating ANG II may not be derived from circulating ANG I. 


\subsection{The ocular renin-angiotensin system Chapters 5, 6, 7 and 8}

Renin, prorenin, angiotensinogen, ANG I and ANG II were present in aqueous, vitreous and subretinal fluid obtained from human eyes during eye surgery. In many samples the renin levels were close to the detection limit of the assay. Large differences (up to factor of 10) in angiotensinogen, ANG I and ANG II concentrations were found between the various ocular fluid types, but these were reflected by similarly large differences in ocular fluid albumin concentrations, indicating that angiotensinogen, ANG I and ANG II in human ocular fluid samples are most likely plasma-derived. In contrast, the prorenin levels in human ocular fluid were up to 100 times higher than expected on the basis of the plasma protein content of these fluids. Moreover, there was little difference in prorenin concentrations between samples with a low and high plasma protein content. Relative to albumin, prorenin was higher in vitreous fluid from eyes with proliferative diabetic retinopathy complicated by traction retinal detachment than in vitreous fluid from eyes of non-diabetic subjects with spontaneous retinal detachment. These findings suggest that an intraocular RAS does exist and that it may play a role in the development of retinal neovascularization in diabetes mellitus.

To further substantiate the evidence for an intraocular RAS, the ANG Igenerating activity was measured in bovine aqueous and vitreous fluid and in extracts of bovine retina, pigment epithelium-chorioid and anterior uveal tract before and after subjecting these ocular fluids and extracts to procedures known to convert prorenin to renin. Renin in the ocular samples could be separated from nonrenin acid protease by $\alpha$-casein-Sepharose affinity column chromatography at $\mathrm{pH} 3.5$; renin did not bind to the column, whereas acid protease did. Renin was further identified by its relatively high $\mathrm{pH}$ optimum (6.5-7.0) for ANG I generation, its complete inhibition with specific renin antiserum, and its high affinity for specific renin inhibitors. More than $75 \%$ of ANG I-generating activity of the bovine ocular samples consisted of renin. Approximately $90 \%$ or more of total renin (renin + prorenin) in aqueous humor, vitreous fluid, and ocular tissue could not be explained by trapped plasma. In vitreous fluid, prorenin comprised $99 \%$ of the total renin, in retina $81 \%$, and in pigment epithelium-choroid and anterior uveal tract less than 50 $\%$. Prorenin in ocular fluid showed a concentration gradient, posterior vitreous $>$ anterior vitreous $>$ aqueous humor, suggesting that the main source of prorenin in ocular fluid was in the posterior eye.

During a 2-hour intravenous infusion of ${ }^{125}$ I-ANG $I$ in the rabbit less than 1 $\%$ of intact plasma ${ }^{125}$ I-ANG I reached the vitreous fluid compartment, showing that, under normal conditions, plasma angiotensins pass the bloodretinal-barrier only in very limited amounts. Measurements of angiotensins in porcine ocular tissues showed that both ANG I and ANG II were present in retina, pigment epithelium-choroid and anterior uveal tract in concentrations 
much too high to be explained by contamination with plasma only. Low to undetectable angiotensin levels were found in porcine vitreous fluid. The ANG II/ANG I ratio was 3-5 fold higher in the ocular tissues than in plasma or vitreous fluid. Finally, using the polymerase chain reaction it was possible to demonstrate the expression of renin-, angiotensinogen- and ACE-mRNA in human eyes. The highest expression was found in the pigment epitheliumchoroid and retina.

\subsection{General conclusions}

In all systemic vascular beds that were studied, both in man and in the pig, venous ANG I could not be accounted for by arterial delivery of ANG I, by the action of circulating renin on circulating angiotensinogen ('PRA') or by the sum of these two. A high percentage of plasma ANG I must therefore have been produced locally, i.e. not in circulating plasma. Our calculations of the local production rates of ANG I show indeed that in myocardium, head, skin, skeletal muscle and kidneys, but not in lungs, the contribution of PRA (assuming a transit time of $10 \mathrm{sec}$ in the various systemic vascular beds and 3 sec in the lungs) to total ANG I production is considerably less than $100 \%$. For instance, in the kidneys only $2 \%$ of the total ANG I production could be attributed to PRA. These calculations were based on the local extraction of ANG I and the arterial and venous ANG I levels; the venous ANG I levels were considered to be representative for the tissue levels of ANG I. In fact, the tissue levels may be higher than the ANG I levels in the venous effluent. Probably, the capillaries are the main site where ANG I is removed from the circulation by diffusion into the interstitium and peptidase attack. This is also the site where ANG I from the interstitium equilibrates with circulating ANG I. The blood transit time in the capillary beds is $1-3 \mathrm{sec}$. Thus, our estimated transit time of $10 \mathrm{sec}$ in most systemic vascular beds is probably too high. Therefore our results may have underestimated the tissue ANG I production and at the same time they may have overestimated the contribution of PRA. However, this only strengthens our conclusion that ANG I is produced locally at tissue sites. The ANG I production rates in the various tissues correlated with PRA, suggesting that most of the renin responsible for local ANG I production is kidney-derived. Indeed, the plasma ANG I levels in nephrectomized subjects are known to be low and, in addition, the release of ANG I by isolated tissues perfused with non-renin containg perfusion fluids is also low or even undetectable.

Following captopril, the regional conversion of ANG I was markedly decreased. In the systemic vascular beds, but not in the lungs or the cardiac cavities, this decrease in conversion was accompanied by an increase in degradation. These findings suggest that there may be some degree of compartmentalization of the processes of conversion and degradation in the 
sense that it is mainly the blood-borne ANG I that is subject to conversion whereas interstitial ANG I is mainly subject to degradation. The lungs are known to contain relatively little interstitial fluid. The size of the distribution volume of ANG I equalled the size of the extracellular fluid volume, suggesting that circulating ANG I is limited to the circulation and the interstitial fluid only. In other words: plasma ANG I may equilibrate with interstitial ANG I. This does not exclude ANG I production at tissue sites not equilibrating with circulating plasma, for instance intracellular ANG I production sites. Possibly, kidney-derived renin is limited to the extracellular fluid and cleaves angiotensinogen in plasma or interstitial fluid only, whereas locally synthesized (pro)renin cleaves (locally synthesized) angiotensinogen intracellularly.

Not only ANG I, but also ANG II appeared to be produced locally. Regional conversion of arterially delivered ANG I was not sufficient to account for the total regional production of ANG II. ANG II may originate from ANG I produced at tissue sites, although alternative pathways for ANG II generation (e.g. direct cleavage from angiotensinogen) have also been described.

The above assumptions concerning tissue ANG I and ANG II production could be tested by examining an as yet unexplored RAS, in the eye. The ocular tissue (pro)renin and angiotensin levels were found to be far too high to be explained by trapped plasma only. This confirms that plasma renin is not the only contributor to tissue angiotensin production, at least in the eye. In contrast, the levels of angiotensinogen, ANG I and ANG II in the various ocular fluids that could be obtained (both from humans and from animals) largely correlated with the albumin levels in these fluids. Angiotensinogen, ANG I and ANG II in ocular fluid are therefore most likely derived from plasma. This was not the case with prorenin. Our finding that prorenin was higher in vitreous from eyes affected by proliferative diabetic retinopathy than in vitreous from eyes of non-diabetic patients suggests a role for the ocular RAS in the development of retinal neovascularization. This would be compatible with our measurements of renin-, angiotensinogen- and ACEmRNA in human ocular tissues, demonstrating the highest expression in the most vascularized parts of the eye. It seems therefore that both ANG I and ANG II are synthesized in ocular tissues, but that, in contrast with prorenin, little or no intraocularly synthesized ANG I and ANG II is released into the ocular fluids. This suggests an autocrine or paracrine function for the intraocular RAS. It cannot be concluded from our data if there is any diffusion of ocular angiotensins or prorenin into the plasma compartment. However, other organs known to contain a local RAS (such as ovary and testis) have been reported to secrete prorenin into the circulation.

Based upon differences in vitreous prorenin levels found between eyes with and without proliferative retinopathy long-term clinical studies should be performed to examine whether ACE inhibitor treatment has a favourable effect on the development and progression of retinal neovascularization in diabetic subjects. 


\section{SAMENVATTING EN CONCLUSIES}

\subsection{Doel van het onderzoek Hoofdstuk 1}

Het renine-angiotensine systeem (RAS) speelt een belangrijke rol bij de handhaving van de cardiovasculaire homeostasis. Traditioneel werd het RAS altijd gezien als een endocrien systeem. Circulerend renine, aan het bloed afgegeven door de nieren, reageert met angiotensinogeen (ook wel aangeduid als renine substraat) uit de Iever, waarbij angiotensine I (ANG I) gevormd wordt. ANG I wordt door endotheel-gebonden angiotensin converting enzyme (ACE) omgezet in angiotensine II (ANG II), een zeer potente vasoconstrictor die tevens de vrijzetting van aldosteron stimuleert. Op grond hiervan leek het logisch om aan te nemen dat remmers van de vorming van ANG II (zoals bijvoorbeeld de $A C E$ remmers, die ontwikkeld werden in de zeventiger jaren) vooral werkzaam zouden zijn bij die vormen van hypertensie waarbij hoge plasma renine spiegels de oorzaak zijn van de hoge bloeddruk. Onverwacht bleken ACE remmers echter ook bij hypertensieve patienten met een lage of normale renine spiegel de bloeddruk te verlagen. Recent is zelfs gebleken dat langdurige behandeling met ACE remmers het circulerende RAS niet volledig onderdrukt, aangezien de plasma ANG II en aldosteron spiegels weer terugkomen op hun uitgangswaarden (terwijl de bloeddruk verlaagd blijft). Deze bevindingen hebben geleid tot talloze speculaties over de aanwezigheid van zgn. 'weefsel' of 'lokale' renine-angiotensine systemen, in tegenstelling dus tot het circulerende RAS, welke een rol zouden spelen bij de handhaving van de hoge bloeddruk. ACE remmers zouden dan met name hun effect bewerkstelligen via blokkade van deze lokale systemen. Gebruik makend van moleculair-biologische technieken kon men inderdaad aantonen dat renine- en angiotensinogeen-mRNA aanwezig zijn in een groot aantal weefsels en organen, $0 . \mathrm{m}$. het hart, de bijnier, de hersenen, de vaatwand, het ovarium en de testis. Men begint daarom meer en meer aan te nemen dat angiotensine lokaal geproduceerd wordt op vele plaatsen in het lichaam, onafhankelijk van het circulerende systeem, en dat dit lokaal geproduceerde angiotensine ook lokaal een functie heeft. Wellicht zou zelfs lokaal geproduceerd angiotensine de circulatie kunnen bereiken en zo bijdragen aan de in plasma gevonden angiotensine spiegels. Of produktie van ANG I buiten de circulatie en omzetting van dit lokaal gevormde ANG I in ANG II daadwerkelijk een rol spelen bij de handhaving van de plasma spiegels van ANG I en ANG II is nooit uitgezocht. 
Het eerste doel van het onderzoek was om in diverse vaatbedden, zowel bij mensen als bij varkens, kwantitatief het metabolisme en de produktie van ANG I en ANG II vast te stellen. Hiertoe werd gebruik gemaakt van constante infusen van ${ }^{125}$ I-ANG I. Na het bereiken van een steady state werden de spiegels van 125I-gelabeld en endogeen ANG I en ANG II gemeten in diverse arteriële en veneuze monsters. Tevens werd de plasma renine activiteit (PRA), een maat voor de vorming van ANG I in vitro, op elke bloedafnameplaats gemeten. Het regionale metabolisme (inclusief ANG I-II conversie) van ANG I en ANG II kon worden afgeleid uit de arteriële en veneuze spiegels van de gelabelde peptiden. De regionale produktie kon worden berekend door de regionale extractie van de gelabelde peptiden te vergelijken met de daadwerkelijk gemeten endogene spiegels van ANG I en ANG II in arterieel en veneus plasma. Om een schatting te kunnen maken van de ANG I generatie buiten het circulerende plasma werd de bijdrage van de PRA aan de totale ANG I produktie uitgerekend. Tevens werd de bijdrage van conversie van arterieel aangeleverd ANG I aan de totale ANG II produktie berekend.

Het tweede doel van het onderzoek was om het bestaan van een lokaal RAS in het oog aannemelijk te maken. Eerder werd namelijk een sterke samenhang gevonden tussen de hoge plasma spiegels van prorenine, de inactieve precursor van renine, en de aanwezigheid van retinopathie, met name het proliferatieve type, bij patiënten met diabetes mellitus. Prorenine zou een rol kunnen spelen bij de lokale angiotensine vorming, terwijl van ANG II wordt verondersteld dat het ook groei-stimulerend zou kunnen werken. De spiegels van de diverse componenten van het RAS werden gemeten in humane oogvloeistoffen (zowel van ogen van patiënten met proliferatieve diabetische retinopathie als van ogen van niet-diabetische patiënten) en in oogweefsels van koeien en varkens. Tevens werd, met behulp van de polymerase ketting reaktie, getracht de aanwezigheid van renine-, angiotensinogeen- en ACE-mRNA in humaan oogweefsel aan te tonen.

\subsection{Lokaal metabolisme en lokale produktie van ANG I en ANG II bij de mens en bij het varken Hoofdstukken 2, 3 en 4}

Tijdens constante infusie van ${ }^{125}$ I-ANG I bleek het gelabelde peptide in alle vaatbedden die werden bestudeerd, zowel bij de mens als bij het varken, voor een belangrijk deel te worden afgebroken. In patiënten met essentiële hypertensie die met captopril behandeld werden, bedroeg de regionale extractie ratio van ${ }^{125}$ I-ANG I $47 \pm 4 \%$ (gemiddelde \pm SEM) in de onderarm, $59 \pm 3 \%$ in het been, $81 \pm 1 \%$ in de nieren, en $96 \pm 1 \%$ in het hepatomesenteriale vaatbed. De resultaten waren niet verschillend van die voor gelijktijdig geïnfuseerd ongelabeld ANG I. Ondanks de hoge mate van extractie van arterieel aangevoerd ANG I, waren er geen verschillen tussen de veneuze en arteriële spiegels van endogeen ANG I in de onderzochte vaatbedden, met 
uitzondering van de lever, waar veneus ANG I $50 \%$ lager was dan arterieel ANG I. Kennelijk is 50-90\% van veneus endogeen ANG I afkomstig van regionale de novo produktie. De bloed doorstromingstijd is 0.1-0.2 min in arm, been en nieren en 0.3-0.5 min in het hepatomesenteriale vaatbed. Deze tijd is veel te kort om de volledige de novo produktie van ANG I aan de PRA toe te kunnen schrijven. Minder dan 20-30\% in de ledematen en nieren en rond de $60 \%$ in het hepatomesenteriale vaatbed van de novo geproduceerd veneus ANG I kon worden toegeschreven aan de PRA.

Deze bevindingen bij de mens konden worden bevestigd in captoprilbehandelde varkens, en werden uitgebreid met metingen in onbehandelde en furosemide-behandelde varkens. Een farmacokinetisch model werd geïntroduceerd om de regionale degradatie en conversie van ANG I in de 3 groepen varkens te schatten. De degradatie van 125I-ANG I en ANG I bleek niet te verschillen, maar de conversie van ${ }^{125 I-A N G ~ I ~ v e r l i e p ~ o n g e v e e r ~} 2$ keer zo snel als die van ANG I. ANG I verdeelde zich over een volume dat wat grootte betreft overeen kwam met het extracellulaire vloeistof compartiment ( $25 \%$ van het totale lichaamsgewicht). Na voorbehandeling met captopril, bedroeg het fractionele metabolisme van ANG I (de fractie van arterieel aangevoerd ANG I die tijdens de passage van een vaatbed afgebroken wordt) $10 \%$ in de longen (waarvan $4 \%$ door conversie) en $56 \%$ in de gecombineerde systemische vaatbedden ( $1 \%$ door conversie). Gedurende ACE remming was het fractionele metabolisme van ANG I $93 \%$ in de nier, 50-70\% in myocard, skeletspierweefsel, hoofd en huid, en $21 \%$ in de linkerhartholte en $14 \%$ in de rechter hartholte. Zonder ACE remming bedroeg het fractionele metabolisme van ANG I $29 \%$ in de longen ( $25 \%$ door conversie), $49 \%$ in de gecombineerde systemische vaatbedden ( $10 \%$ door conversie), $38 \%$ in de linker hartholte (11\% door conversie) en $14 \%$ in de rechter hartholte $(0 \%$ door conversie). Deze getallen tonen aan dat in de systemische vaatbedden, maar niet in de longen of hartholtes, afgenomen conversie gepaard gaat met toegenomen degradatie.

De totale regionale ANG I en ANG II produktie in diverse systemische vaatbedden bij het varken werd berekend op grond van het zogenaamde 'veneuze equilibrium' model. De novo ANG I produktie in de gecombineerde systemische vaatbedden was toegenomen tijdens behandeling met de ACE remmer captopril en het diureticum furosemide, in vergelijk met de onbehandelde varkens. De ANG II produktie was groter in de gecombineerde systemische vaatbedden dan in de longen, hetgeen wijst op het belang van ANG I-II conversie buiten de longen. De ANG II produktie in de longen en de gecombineerde systemische vaatbedden veranderde niet significant na $\mathrm{ACE}$ remming. Kennelijk werd de afgenomen ANG I-II conversie gecompenseerd door toegenomen ANG I produktie. Onder furosemide nam de ANG II produktie in alle bestudeerde vaatbedden toe.

In de longen kon de ANG I produktie volledig worden toegeschreven aan de PRA in het circulerende plasma. Tevens bleek de ANG II produktie in de 
longen volledig verklaard te kunnen worden uit intrapulmonale conversie van arterieel aangevoerd ANG I. In alle andere vaatbedden die werden bestudeerd was dit niet het geval: een belangrijk deel van de ANG I produktie kon daar niet worden verklaard door aan te nemen dat alleen de PRA in het circulerende plasma (uitgaande van een doorstromingstijd van $10 \mathrm{sec}$ ) verantwoordelijk is voor de lokale ANG I produktie (hart $>25 \%$, hoofd, huid en skeletspierweefsel $>80 \%$, nier $>95 \%$ ). Wel correleerde de lokale ANG I produktie in alle bestudeerde vaatbedden met de gemeten PRA. Een deel van de ANG II produktie in deze vaatbedden kon tevens niet worden verklaard uit de lokale conversie van circulerend ANG I (hart $>30 \%$, hoofd, huid en skeletspierweefsel $>50 \%$, nier $>80 \%$ ). Deze resultaten tonen aan dat lokale produktie van ANG I inderdaad bijdraagt aan de spiegels van circulerend ANG I, en dat een deel van het circulerende ANG II niet van circulerend ANG I afkomstig is.

\subsection{Het renine-angiotemsine systeem in het oog Hoofdstukken 5, 6, 7 en 8}

Renine, prorenine, angiotensinogeen, ANG I en ANG II waren aanwezig in kamerwater, glasvocht en subretinaalvocht verkregen uit menselijke ogen tijdens oogoperaties. In veel monsters lagen de renine spiegels dicht bij de detectie limiet van de meetmethode. Grote verschillen (soms wel 10-voudig) in de angiotensinogeen, ANG I en ANG II concentraties werden gevonden tussen de verschillende types oogvloeistof, maar deze gingen vergezeld van even grote verschillen in de albumine concentraties in deze oogvloeistoffen, hetgeen er op wijst dat angiotensinogeen, ANG I en ANG II in kamerwater, glasvocht en subretinaal vocht waarschijnlijk afkomstig zijn uit plasma. In tegenstelling hiermee, bleken de prorenine spiegels in humane oogvloeistoffen soms wel 100 keer hoger te liggen dan je zou verwachten op grond van de plasma eiwit concentraties in deze vloeistoffen. Bovendien verschilden de prorenine concentraties nauwelijks tussen monsters met een hoog gehalte aan plasma eiwitten en monsters met een laag gehalte aan plasma eiwitten. Uitgedrukt per $\mathrm{g}$ albumine was de prorenine concentratie in glasvocht afkomstig van ogen van patiënten met proliferatieve diabetische retinopathie en een tractie retinaloslating hoger dan in glasvocht van ogen van niet-diabetische patiënten met een spontane retinaloslating. Deze bevindingen suggereren dat er inderdaad sprake is van een intraoculair RAS, dat wellicht een rol speelt bij de ontwikkeling van retinale vaatnieuwvorming in patiënten met diabetes mellitus.

Om het bestaan van een intraoculair RAS verder te substantiëren, werd de ANG I-vormende activiteit in kamerwater en glasvocht en in extracten van retina, pigment epithelium-choroidea en iris-corpus ciliare van runderen gemeten, zowel voor als na blootstelling van deze oogvochten en extracten aan procedures die kunnen leiden tot de omzetting van prorenine in renine. Renine in do oogmonsters kon worden gescheiden van zure proteasen door gebruik te 
maken van $\alpha$-caseine-Sepharose affiniteitskolomchromatografie bij $\mathrm{pH} 3.5$; renine werd niet door deze kolom gebonden, maar zure proteasen wel. Renine kon verder worden geïdentificeerd door het relatief hoge $\mathrm{pH}$ optimum (6.57.0) voor de ANG I vorming, en het feit dat de ANG I-vormende activiteit volledig kon worden geremd door gebruik te maken van hetzij een specifiek renine antilichaam, hetzij specifieke renine remmers. Meer dan $75 \%$ van de ANG I-vormende activiteit van de runderoogmonsters was te wijten aan renine. Ongeveer $90 \%$ van de totale hoeveelheid renine (renine + prorenine) in kamerwater, glasvocht en oogweefsels kon niet worden verklaard door het hierin aanwezige plasma. In glasvocht bestond $99 \%$ van de totale hoeveelheid renine uit prorenine, in de retina $81 \%$, en in pigment epithelium-choroidea en iris-corpus ciliare minder dan $50 \%$. Er was een concentratiegradiënt voor prorenine aanwezig in de onderzochte oogvloeistoffen: glasvocht ${ }_{\text {achterin oog }}>$ glasvocht $_{\text {voorin oog }}>$ kamerwater. Dit lijkt erop te wijzen dat de belangrijkste bron van prorenine in oogvochten zich achterin het oog bevindt.

Gedurende een 2-uur durend infuus van ${ }^{125}$ I-ANG I bij het konijn, bereikte minder dan $1 \%$ van intact plasma ${ }^{125}$ I-ANG I het glasvocht, suggererend dat er, onder normale condities, nauwelijks lekkage van plasma angiotensines door de bloed-retina-barrière plaatsvindt. Metingen van angiotensines in oogweefsels van varkens toonden aan dat zowel ANG I als ANG II aanwezig waren in retina, pigment epithelium-choroidea en iris-corpus ciliare in concentraties die veel te hoog waren om verklaard te kunnen worden uit contaminatie met plasma. Lage tot onmeetbare angiotensine concentraties werden gevonden in varkensglasvocht. De ANG II/ANG I ratio was 3-5 keer zo hoog in de oogweefsels als in plasma of glasvocht. Tenslotte bleek het, gebruik makend van de polymerase ketting reaktie, mogelijk om de expressie van renine-, angiotensinogeen- en ACE-mRNA in humaan oogweefsel aan te tonen. De hoogste mate van expressie werd aangetroffen in pigment epithelium-choroidea en retina.

\subsection{Conclusies}

In alle systemische vaatbedden die werden onderzocht, zowel bij mensen als bij varkens, kon een zeer groot deel van veneus ANG I niet worden verklaard door hetzij arteriële aanvoer van ANG I, hetzij de reactie van circulerend renine met circulerend angiotensinogeen ('PRA'), noch door de combinatie van deze twee bronnen. Een groot gedeelte van plasma ANG I wordt dus waarschijnlijk lokaal (d.w.z. niet in circulerend plasma) geproduceerd. Inderdaad bleek uit berekeningen van de lokale produktie van ANG I dat in hart, hoofd, huid, skeletspierweefsel en nieren, maar niet in longen, de bijdrage van de PRA (gebaseerd op een doorstromingstijd van $10 \mathrm{sec}$ in de verschillende systemische vaatbedden en $3 \mathrm{sec}$ in de longen) aan de totale produktie van ANG I beduidend minder is dan $100 \%$. In de nieren kon 
bijvoorbeeld maar $2 \%$ van de totale ANG I produktie geweten worden aan de PRA. Bovenstaande berekeningen zijn gebaseerd op de lokale extractie van ANG I en de arteriële en veneuze ANG I spiegels; aangenomen werd dat de veneuze ANG I spiegels een afspiegeling zijn van de spiegels op weefselniveau. In werkelijkheid zijn de weefsel ANG I spiegels misschien hoger dan de ANG I spiegels in het veneuze effluent. Waarschijnlijk zijn het met name de capillairen waar ANG I door diffusie naar het interstitium en door afbraak door peptidases uit de circulatie verwijderd wordt. Hier ook staat ANG I uit het interstitium in evenwicht met plasma ANG I. De doorstromingstijd van de capillaire vaatbedden is slechts 1-3 sec. Daarom leidt het gebruik van een doorstromingstijd van $10 \mathrm{sec}$ voor de berekening van de bijdrage van de PRA in de meeste systemische vaatbedden waarschijnlijk tot een te hoge bijdrage van de PRA. Onze resultaten zullen dus tegelijkertijd de weefsel ANG I produktie iets onderschatten en het aandeel van de PRA iets overschatten. Zodoende wordt echter onze conclusie dat ANG I lokaal geproduceerd des te meer ondersteund. De lokale ANG I produktie correleerde met de PRA, wat er op zou kunnen wijzen dat het renine dat verantwoordelijk is voor deze lokale produktie afkomstig is uit de nier. Deze theorie wordt ondersteund door recente bevindingen dat a) de ANG I plasma spiegels in genefrectomeerde patiënten zeer laag zijn en b) de vrijzetting van ANG I uit geïsoleerde weefsels die geperfuseerd worden met een vloeistof die geen renine bevat ook zeer laag (vaak zelfs niet aantoonbaar) is.

$\mathrm{Na}$ voorbehandeling met captopril nam de lokale conversie van ANG I significant af. In de systemische vaatbedden, maar niet in de longen of hartholtes, ging deze afname in conversie gepaard met een toename in degradatie. Deze bevindingen suggereren dat er een zekere mate van compartimentalisatie bestaat voor conversie en degradatie: ANG I uit de circulatie staat vooral bloot aan conversie, terwijl ANG I in het interstitium met name door degraderende enzymen wordt afgebroken. De longen bevatten relatief weinig interstitieel vocht. De grootte van het verdelingsvolume van ANG I kwam overeen met de grootte van het extracellulaire vloeistof volume. Kennelijk is circulerend ANG I beperkt tot de bloedbaan en het interstitium. Met andere woorden: plasma ANG I equilibreert met interstitieel ANG I. Dit sluit niet uit dat er ook nog elders ANG I produktie plaatsvindt, in een compartiment dat niet uitwisselt met het circulerende plasma (bijvoorbeeld een intracellulair compartiment). Mogelijk beperkt renaal renine zich tot extracellulair vocht en reageert het alleen met angiotensinogeen in plasma of in het interstitium, terwijl lokaal gesynthetiseerd (pro)renine slechts intracellulair ANG I vormt uit (lokaal gesynthetiseerd) angiotensinogeen.

Niet alleen ANG I, maar ook ANG II bleek lokaal geproduceerd te worden. De regionale conversie van arterieel aangevoerd ANG I was niet voldoende om de totale regionale produktie van ANG II te verklaren. ANG II kan afkomstig zijn van in de weefsels geproduceerd ANG I, maar er zijn ook andere manieren waarop ANG II gevormd kan worden (bijvoorbeeld directe 
afsplitsing van angiotensinogeen).

Bovenstaande aannames betreffende lokale ANG I en ANG II produktie konden worden onderzocht op hun juistheid tijdens een onderzoek naar een tot dusverre onbekend lokaal RAS, in het oog. De spiegels van (pro)renine en angiotensine in oogweefsels waren veel te hoog om verklaard te worden uit hierin aanwezig plasma. Dit bevestigt dat plasma renine niet als enige bijdraagt aan de lokale produktie van angiotensines, althans in het oog. In tegenstelling hiermee, bleek dat de spiegels van angiotensinogeen, ANG I en ANG II in diverse oogvochten (subretinaal vocht, glasvocht, kamerwater) grotendeels correleerden met de albumine spiegels in deze oogvochten. Angiotensinogeen, ANG I en ANG II in oogvocht zijn dus waarschijnlijk afkomstig uit plasma. Dit gold echter niet voor prorenine. Onze bevinding dat prorenine hoger was in glasvocht uit ogen van diabetische patiënten met proliferatieve retinopathie dan in glasvocht uit ogen van niet-diabetische patiënten suggereert dat het oculaire RAS een rol speelt bij de ontwikkeling van retinale neovascularisatie. De metingen van renine-, angiotensinogeen, en ACE-mRNA in humane oogweefsels ondersteunden deze theorie, aangezien de hoogste expressie gevonden werd in die delen van het oog die het meest doorbloed zijn. Kennelijk worden ANG I en ANG II wel gesynthetiseerd in oogweefsel, maar lekt er hiervan weinig naar glasvocht en/of kamerwater. Onze bevindingen suggereren daarom een autocriene of paracriene functie voor het RAS in het oog. Of er angiotensines of prorenine vanuit het oog diffunderen naar plasma kan uit onze gegevens niet worden vastgesteld. Prorenine lijkt in ieder geval wél naar oogvocht weg te lekken. Ook in het ovarium is gebleken dat lokaal geproduceerd prorenine niet alleen terechtkomt in (onder meer) follikelvocht, maar ook wordt afgegeven aan de bloedbaan.

Gebaseerd op de verschillen in prorenine concentratie in glasvocht tussen ogen met en zonder proliferatieve retinopathie zou het aanbeveling verdienen om de effecten van ACE remmers op het ontstaan respectievelijk de progressie van retinale neovascularisatie bij patiënten met diabetes mellitus nader te onderzoeken. 



\section{PUBLICATIONS}

1. Danser AHI, van den Ende R, Flavahan NA, Lorenz RR, Vanhoutte PM. Prejunctional $\mathrm{B}_{1}$-adrenoreceptors inhibit cholinergic transmission in canine bronchi. $J$ Appl Physiol 62: $785-790,1987$.

2. Danser AHI, van den Dorpel MA, Deinum J, Derkx FHM, Peperkamp E, de Jong PTVM, Schalekamp MADH. Prorenin in vitreous and subretinal fluid of the human eye. Clin Exp Hypertension Theor Pract A10: 1297-1299, 1988.

3. Danser AFI, van den Dorpel MA, Deinum J, Derkx FHM, Franken AAM, Peperkamp E, de Jong PTVM, Schalekamp MADH. Renin, prorenin, and immunoreactive renin in vitreous fluid from eyes with and without diabetic retinopathy. $J$ Clin Endocrinol Metab 68: 160-167, 1989.

4. Danser AHJ, Deinum J, Derkx FHM, Schalekamp MADH, de Jong PTVM. Components of the renin-angiotensin system in vitreous fluid from eyes with and without diabetic retinopathy. Current Advances in ACE Inhibition (Proceedings of the First International Symposium on ACE Inhibition), edited by G.A. MacGregor and P.S. Sever, Churchill Livingstone, p. 195-197, 1989.

5. Deinum J, Derkx FHM, Danser AHJ, Schalekamp MADH. Renin in the bovine eye. $J$ Hypertension 7 (suppl 6): S216-\$217, 1989.

6. Admiraal PJJ, Derkx FHM, Danser AHJ, Schalekamp MADH. In vivo production of plasma angiotensin I: is plasma renin sufficient? J Hypertension 7 (suppl 6): S222-S223, 1989.

7. Deinum J, Derkx FHM, Danser AHJ, Schalekamp MADH. Identification and quantification of renin and prorenin in the bovine eye. Endocrinology 126: 1673-1682, 1990.

8. Admiraal PJJ, Derkx FHIM, Danser AHY, Pieterman H, Schalekamp MADH. Metabolism and production of angiotensin I in different vascular beds in subjects with hypertension. Hypertension 15: 44-55, 1990.

9. Admiraal PJJ, Derkx FHM, Danser AHJ, Pieterman H, Schalekamp MADH. De novo production of angiotensin I by the affected and unaffected kidney in subjects with renal artery stenosis; role of circulating and non-circulating renin. Hypertension 16: 555-563, 1990.

10. Danser AHJ, Sassen LMA, Admiraal PJI, Derkx FHM, Verdouw PD, Schalekamp $\mathrm{MADH}$. Regional production of angiotensin I. Contribution of vascular kidney-derived renin. Current Advances in ACE Inhibition (Proceedings of the Second International Symposium on ACE Inhibition), edited by G.A. MacGregor and P.S. Sever, Churchill Livingstone, 1991 (in press).

11. Danser AHJ, Sassen LMA, Admiraal PJ, Derkx FHM, Verdouw PD, Schalekamp MADH. Regional production of angiotensins $I$ and II. Contribution of vascular kidney-derived renin. J Hypertens 9 (supp! 6): S234-\$235, 1991.

12. Admiraal PJJ, Danser AHJ, Derkx FHM, Schalekamp MADH. Angiotensin II production in different vascular beds in hypertensive subjects. J Hypertens 9 (suppl 6): \$208-\$209, 1991.

13. Danser AHJ, Koning MMG, Admiraal PJJ, Derkx FHM, Verdouw PD, Schalekamp MADH. Metabolism of angiotensin I by different tissues in the intact animal. Provisionally accepted AmJ Physiol.

14. Danser AHJ, Koning MMG, Admiraal PJJ, Sassen LMA, Derkx FHM, Verdouw PD, Schalekamp MADH. Production of angiotensins I and II at tissue sites in the intact pig. Provisionally accepted AmJ Physiol.

15. van der Giessen WJ, Danser AHJ, van Beusekom HMM, Derkx FHM, Verdouw PD, Lamers MMJ, Serruys PW. Local angiotensin $I I$ production in porcine coronary arteries: 
reduction of release during neointimal hyperplasia induced by stent implantation. Submitted.

16. Admiraal PJJ, Danser AHJ, Jong S, Pieterman H, Derkx FHM, Schalekamp MADH. Renal and extrarenal angiotensin II production in subjects with essential hypertension and renal artery stenosis. Submitted.

17. Danser AHJ, Derkx FHM, Admiraal PJJ, Deinum J, de Jong PTVM, Schalekamp MADH. Angiotensin levels in the eye. In preparation.

18. Wagner J, Danser AHJ, Paul M, Derkx FHM, de Jong PTVM, Schalekamp MADH, Ganten D. Demonstration of renin-, angiotensinogen- and angiotensin converting enzyme-mRNA expression in human eyes by the polymerase chain reaction. In preparation.

\section{ABSTRACTS}

1. Flavahan NA, Danser AHJ, Vanhoutte PM. Arachidonic acid and calcium ionophore cause epithelium-dependent relaxation of canine bronchial smooth muscle. Proceedings of the International Union of Physiological Sciences XVI: 148, 1986.

2. Lorenz RR, Danser AHJ, van den Ende R, Flavahan NA, Vanhoutte PM. Endogenous norepinephrine activates inhibitory prejunctional $B_{1}$-adrenoceptors on cholinergic nerves in canine bronchi. Proceedings of the International Union of Physiological Sciences XVI: $148,1986$.

3. Admiraal PJJ, Derkx FHM, Danser AHJ, Schalekamp MADH. Local production of angiotensin I in hypertensive subjects. Pharm Weekbl Sci Ed 11 (suppl H): 3, 1989.

4. Danser AHJ, Koning MMG, Admiraal PJJ, Verdouw PD, Schalekamp MADH. Contribution of circulating plasma renin to whole-body production of angiotensin $I$ (AI). $J$ Hypertension 8 (suppI 3): S31, 1990.

5. Schalekamp MADH, Admiraal PJJ, Danser AHJ, Derkx FHM. The site of angiotensin I formation. J Hypertension 8 (suppl 3): S36, 1990.

6. Admiraal PJJ, Derkx FHM, Danser AHJ, Schalekamp MADH. Production of angiotensin I by the kidneys in renal artery stenosis and essential hypertension. Role of circulating and non-circulating renin. J Hypertension 8 (suppl 3): S39, 1990.

7. Danser AHJ, Koning MMG, Derkx FHM, Admiraal PJJ, Verdouw PD, Schalekamp MADH. Release of angiotensin I from tissue sites into the systemic and cardiopulmonary circulations. Eur J Pharmacol 183: 1312-1313, 1990.

8. Danser AHJ, Sassen LMA, Admiraal PJ, Derkx FHM, Verdouw PD, Schalekamp MADH. Regional production of angiotensins I and II. Contribution of vascular kidney-derived renin. Acta Clinica Belgica 46: 258, 1991.

9. van der Giessen WJ, Danser AHJ, van Beusekom HMM, Derkx FHM, Verdouw PD, Jongkind JF, Lamers JMJ, Serruys PW. Local angiotensin II production in porcine coronary arteries: reduction of release during neointimal hyperplasia after stenting. Circulation 84 (suppl II): 297, 1991.

10. Danser AHJ, Admiraal PJJ, Sassen LMA, Verdouw PD, Schalekamp MADH. Metabolism and production of angiotensin $I(A I)$ and angiotensin $I I(A I I)$ in the porcine heart. Circulation 84 (suppl II): 625, 1991.

11. Admiraal PJJ, Derkx FHM, Danser AHJ, Schalekamp MADH. Angiotensin II production in different vascular beds in hypertensive patients. Pharm Weekbl Sci Ed 13 (suppI E): 3, 1991

12. Admiraal PJJ, Derkx FHM, Danser AHJ, Schalekamp MADH. Extrapulmonary angiotensin I-II conversion in hypertensive subjects. Kidney International (in press). 


\section{DANKWOORD}

Dit proefschrift is bij uitstek het gevolg van samenwerking, niet alleen binnen de afdeling Inwendige Geneeskunde I, maar ook binnen de Erasmus Universiteit en het Academisch Ziekenhuis Rotterdam Dijkzigt (afdelingen Experimentele Cardiologie en Oogheelkunde), en zelfs binnen Europa (Universiteit van Heidelberg).

Mijn dank en bewondering gaan in eerste instantie uit naar mijn promotor, professor dr. M.A.D.H. Schalekamp. Dank, Maarten, voor de zeer intensieve begeleiding niet alleen wat betreft het plannen en uitvoeren van experimenten, maar ook en vooral wat betreft het (leren) schrijven van artikelen. Bewondering voor je enorme enthousiasme, je onmiddellijke inzicht in de wetenschappelijke waarde(loosheid) van een bevinding, hoe klein ook, en de wijze waarop je ideeën en theorieën ontwikkelt.

Niet minder wil ik professor dr. P.D. Verdouw en professor dr. P.T.V.M. de Jong bedanken. Piet, ik hoefde bij jou maar langs te komen met een voorstel voor een varkensexperiment, of je wilde dezelfde middag al beginnen. Ik hoop dat we onze samenwerking nog lang zullen voortzetten. Professor de Jong, ook bij $U$ was een (voorlopig) protocol al voldoende om de verzameling van alle mogelijke soorten oogvochten en oogweefsels bij een haast onuitputtelijke reeks patiënten op gang te brengen. Naar verwachting zullen wij ook hier straks nog mee doorgaan.

Professor dr. P.A. van Zwieten, dankzij Uw wereldwijde contacten was ik in staat om een bijvakonderzoek op de Mayo Clinic in de Verenigde Staten (bij professor dr. P.M. Vanhoutte) uit te voeren, de plaats waar mijn belangstelling voor wetenschappelijk onderzoek ontstond. U en professor dr. P.R. Saxena bedank ik voor de bereidheid het proefschrift te beoordelen op zijn wetenschappelijke waarde.

Peter Admiraal, jou dank ik voor je onmisbare hulp bij het opzetten en in stand houden van de angiotensine bepaling, je kritische beoordeling van diverse door mij geschreven stukken en de vele discussies die wij gehad hebben over de interpretatie van de resultaten. Jaap Deinum, veel dank ben ik jou verschuldigd voor je hulp bij de uitvoering van talloze 'ogen-experimenten'. We hebben zo'n beetje alle proefdieren de revue laten passeren, van koeien, varkens, konijnen en ratten tot mensen. Eénmaal stonden we zelfs op een zaterdagochtend TippEx en inkt in Groningse runderogen te injecteren...

Monique Koning, Loes Sassen, Dirk-Jan Duncker, Rob van Breemen, Ed McFalls en Loe Kie Soei: jullie dank ik voor de soepele en vlekkeloze uitvoering van alle varkensexperimenten. Welk bloedmonster of stukje weefsel ik ook wilde hebben, alles behoorde tot de mogelijkheden.

De oogartsen van het Oogziekenhuis Rotterdam bedank ik voor hun hulp bij 
het verzamelen van humane oogvochten.

Professor dr. D. Ganten, at the ISH Meeting in Kyoto in 1988 you offered us the possibility to measure renin-mRNA in human eyes with the help of your laboratory in Heidelberg. This resulted in a fruitful cooperation between our 2 departments, for which I am most grateful. I would like to thank dr. J.J. Mullins and dr. J. Wagner for doing the mRNA measurements, and I hope that we will continue working together.

René de Bruin, Jeanette van Gool, Josita Limborgh, Paula Brouwer-Brand, Angelique van Houwen, Usha Bhaggoe, Carolien van Gelderen en Nelleke BosSonneveld: altijd boden jullie mij de gelegenheid om op het laatste moment monsters in assays mee te laten lopen, tussendoor kool te draaien, en langdurig de gamma counter en de HPLC te bezetten. Hiervoor mijn hartelijke dank? Carla Swaab wil ik bedanken voor het maken van de omslag van dit proefschrift en voor het vervaardigen van alle illustraties, posters en dia's in de afgelopen jaren. Binnen de afdeling Inwendige Geneeskunde I dank ik verder Frans Derkx, Frans Boomsma, Arie Man in 't Veld, René van den Dorpel, Joop Janssen, Annette de Wind, Bob Zietse, Ton van den Meiracker, Gerrit Jan Wenting, René Brouwer, Anton Franken, René Idema, Ellen Melse-Hoogeveen, Gooitzen Alberts, Loes van Eijk, Hilma van Asperen, Alice Hammer en Edith Visschers voor hun steun en samenwerking. Tevens dank ik Bart de Bruyn voor alle hulp bij het uitvoeren van studies bij anefrici in Enschede.

Hoffmann-La Roche, Ciba-Geigy, Bristol-Myers Squibb, ICI-Farma en de Nier Stichting Nederland dank ik voor de financiële ondersteuning, het beschikbaar stellen van diverse farmaca en monoclonale antilichamen, en het bieden van de mogelijkheid om onderzoeksresultaten op buitenlandse congressen te presenteren.

Tot slot wil ik mijn ouders bedanken voor hun liefde, zorg en enthousiaste stimulering, zonder welke dit alles niet mogelijk zou zijn geweest.

Romana, mijn echtgenote, jouw liefde, voortdurende steun en begrip vormen de redenen waarom ik dit proefschrift aan jou opdraag. 


\section{CURRICULUM VITAE}

naam:

Alexander Hessel Jan Danser

geboortedatum: 9 juni 1962

burgerlijke staat: gehuwd met Romana van den Ende

1974-1980 Vossius Gymnasium te Amsterdam

1980 aanvang studie Farmacie aan de Universiteit van Amsterdam

1983

kandidaatsexamen Farmacie (cum laude)

1984

3 maanden stage in Zuid-Afrika in het kader van een 'student-exchange' (gewerkt bij Pharma Natura in Johannesburg en H.J. Williamson Drug Company in Pinetown)

1985

bijvakonderzoek op de Mayo Clinic te Rochester, Minnesota, USA (Department of Physiology and Biophysics), onder leiding van professor P.M. Vanhoutte en dr. N.A. Flavahan

doctoraalscriptie onder leiding van professor P.A. van Zwieten "De medische chemie van de angiotensin converting enzyme remmers: structuur-activiteit-relaties"

doctoraalexamen Farmacie

apothekersexamen

1987-1991

assistent-in-opleiding op de Erasmus Universiteit te Rotterdam (Afdeling Inwendige Geneeskunde I), onder leiding van professor M.A.D.H. Schalekamp

1992universitair docent op het vakgebied Cardiovasculaire Farmacologie aan de Erasmus Universiteit te Rotterdam (Afdeling Farmacologie, hoofd professor P.R. Saxena) 
